Universidad deValladolid

PROGRAMA DE DOCTORADO EN QUÍMICA: QUÍMICA DE SÍNTESIS, CATÁLISIS Y MATERIALES AVANZADOS

TESIS DOCTORAL:

\title{
ACCESSING NEW BIOMEDICAL \\ APPLICATIONS BY COMBINING \\ GENETIC DESIGN AND CHEMICAL \\ MODIFICATION OF ELASTIN-LIKE \\ RECOMBINAMERS
}

Presentada por Leander Aaron Adrian Siddartha Poócza para optar al grado de Doctor por la Universidad de Valladolid

Dirigida por:

José Carlos Rodríguez Cabello 

Für Jalah

Für Lian 

AGRADECIMIENTOS ACKNOWLEDGEMENTS 



\section{Agradecimientos - Acknowledgements}

En las siguientes páginas me gustaría conmemorar a las personas que me han acompañado y siempre me han apoyado en esta fase emocionante e intensiva de mi vida para obtener el grado de doctorado. Este capítulo de mi vida no solo me ha educado científicamente, sino que también me ha desarrollado personalmente. Si mi vida fuera una novela, esta última etapa llenaría las paginas de más de más de un capítulo, pudiendo rellenar una pagina con cada uno de vosotros. A veces unas palabras son capaces de trasmitir un mensaje más grande, como el amor, el respeto o la amistad, que me conectan con todos de usted.

En primer lugar, quisiera dar las gracias a mi director Carlos. Gracias por acogerme en el grupo, por guiarme y por darme todos los medios para poder llevar a cabo este trabajo y por tu tiempo y tus consejos indispensables. Quiero mostrar igualmente mi gratitud a Matilde y lsrael, que siempre han dedicado su tiempo y su predisposición cuando lo necesitaria.

Gracias a los seniors de grupo, Javi, Merche, Alessandra y Luis, por vuestra amabilidad y por vuestras ganas de ayudar.

Muchas gracias a mis compañeros de despacho BIOGEL, Soraya y Filippo vosotros habéis llenado el espacio con alegría, y me habéis dado ganas de volver a trabajar no solo en momentos buenos, pero también en temporadas criticas . Tanto a mis "compañeros de doctorado y sobre mesa" (Doriana, Tatjana, Sofia, Ito, Sergio, Arturo, Juan), como a las nuevas incorporaciones Miguel, Marcos, Fernando. Me habéis apoyado muchísimo para llegar a Valladolid y habéis apoyado aprender las técnicas del grupo. Muchísimos gracias. 
Rocío, muchas gracias por enseñarme los secretos de la purificación y por tu paciencia. Gracias Irene y Alicia por proporcionarme cientos de veces vuestro ánimo.

Todos vosotros impregnáis esta tesis. Solo espero haber sido capaz en este tiempo de devolveros, aunque solo sea una pequeña parte de todo el afecto que me habéis dado durante estos años.

This work as being part of an incredible international project was further supported by a phenomenal group of people. I am very proud that I can consider you as my friends and that we have shared such an incredible time together at so many interesting and wonderful places and that you have shared your research with me. This interdisciplinary input really leveraged my knowledge.

First, I have to name Laura, Professor Möller and Elisabeth, who did an incredible job in managing and realizing this wonderful project. Further, I like to thank Alan and Paul for their input on the mechanical characterization, especially during my stay in the university of Nijmegen (the Netherlands) and the support of my project colleagues Paula and Max (Kai-zengh Li-u) it was so inspiring to work on your side. My journey also brought me to Aachen were I want to thank my resident colleagues Arturo, Luis, Marcel and Sitara and their co-workers Christopher and Yashoda for their help in the lab and for their inspiring thoughts.

To complete the Biogel group, a special thanks goes to those who I unfortunately could not work with for a longer period, but not least we had an incredible time in countless meetings and I think we managed to get to know each other pretty well. Thank you Melanie, Daria, Jenny, Dominik, and Nestor, and of course Delphine who was a short member, but remains part of our group 
Abschließend möchte ich noch meiner Familie Danken ohne deren Unterstüzung ich diese Aufgabe in der Form nicht hätte realisieren können. Als erstes Danke Ich meiner Ehefrau Jalah für Ihre Unterstüzung und Ihre Stärke in einer Phase in der Ich gerne mehr für Sie getan hätte als es mir durch die räumliche Trennung möglich war. Ich Danke Dir, vielen Dank das du so wundervoll bist und unserem Sohn eine so tolle Mutter bist, auch wenn ich nicht immer da sein konnte. Weiterhin gilt ein Dank meinem Bruder Nico und meiner Mutter Andrea und meiner Großmutter Eva, für Ihre immer währende Unterstüzung. Ein Dank auch an meinen Vater Piet und seine Frau Anke, ich bin froh das ich in dieser prägenden Phase auf euch zählen konnte. 
ACCESSING NEW BIOMEDICAL APPLICATIONS BY COMBINING GENETIC DESIGN AND CHEMICAL MODIFICATION OF ELASTIN-LIKE RECOMBINAMERS 
ABSTRACT 



\section{Abstract}

The diversity of nature including biopolymers, organisms, or active molecules and the fact that these natural systems can be transformed to be used for other purposes, enables a myriad of promising starting points for new developments. Here, Elastin-like recombinamers (ELRs) as a class of intrinsically disordered recombinant proteins that exhibit features like a lower critical solution temperature (LCST), thermosensitive hydrophobicity, self-assembly, together with the possibility to introduce other peptide-based functionalities, stand out.

The present work coveres the steps of the value chain of ELRs from nucleotide fragments, over DNA transfection, protein production, purification, chemical modification and application of the final protein. Including the utilization of related methods ranging from genetic engineering, microbiology, physico-chemical characterization and modification to in-vitro cell culture and manipulation.

One part of the tesis is focused on the generation of new proteolytically cleavable ELRs modified with methacrylamide groups as a substrate for a new zymographic technique enabling the detection of proteases. The present method uses the advantage of the spatial design of the ELR for the detection of proteases in a zymography-like manner. As a prerequisite, the ELR should consist of at least three domains, a degradable group (peptidase target), a mechanism of detection, and a stable cross-link to the acrylamide matrix. For better integrity with the matrix an additional block, which is not a target to most of the peptidases was implemented, as a spacer, to augment the molecular weight and to minimize sterical hindrance between cross-links and degradable groups. The presented method has the potential as a protease screening, which gains significance directly proportional to the 
number of protease targets (ELRs) used. The presented in-well zymography (IWZ) method has a high throughput potential, therefore, further substrates are currently developed to generate a library of substrates that allow discovering new cleavage patterns of proteases, and might have relevance to detect abnormalities in clinical samples.

In the following, the low complexity of these polypeptides is used as a model for the investigation of hydrophobic contributions to self-assembly. In this work, an upper critical solution temperature (UCST)-type phase separation was obtained upon adding hydrophobic cholesteryl side-chains, which leads to the formation of stable hydrogels. Circular dichroism, dynamic light scattering, and viscosity measurements indicate reversible UCST gelation of a pseudo-zwitterionic species, with retention of the ELR secondary structure. Furthermore, the gelation process could be associated with micelle-derived nanofiber formation to yield a porous or laminar structure in a process that is either time- or concentration-dependent. Herein we present a model system that sheds light on the diversity of effects resulting from the incorporation of cholesteryl side-chains into proteins by relating structural changes to macroscopic observations.

In addition, a cellular coating based on hydrophobic interactions of an elastin-like recombinamer (ELR) with the cell membrane is presented. It is well documented that biophysical properties such as net charge, hydrophobicity, and protein-driven cell-ligand (integrin binding) interactions influence the interaction of polymers, proteins or peptides with model membranes and biological cells. Most studies to enhance membranesubstrate interactions have focused on the introduction of positively charged 
groups to foster electrostatic interactions with the negatively charged membrane. Herein we present an antagonistic approach based on ELRs with varying amounts of hydrophobic cholesteryl groups (ELR $\left.{ }^{C T A} s\right)$. The ability of membranes to stabilize cholesteryl groups is hypothesized to assist the coordination of hydrophobic ELRs with the membrane. The main objective was to generate a defined cellular coating of a recombinant protein that allows for total sequence control and less host, or batch-to-batch, variation as a substitute for existing coatings like alginate, polyelectrolytes, collagens and fibronectin. We used an in vitro cell-binding assay to quantify cellmembrane interactions, with the substrates showing enhanced cellular recognition and matrix distribution with an increasing number of cholesteryl groups incorporated. These novel materials and the versatile nature of their protein sequence have great potential as cellular markers, drug carriers, or hydrophobic cell-binding domains. 

RESUMEN 



\section{Resumen/Summary}

\section{Introducción}

La adquisición de un conocimiento profundo de biomateriales requiere comprender su papel en diversas aplicaciones, tanto en ingeniería de tejidos como en nanotecnología. Dentro de las distintas estrategias destinadas al desarrollo de aplicaciones biomédicas, cabe destacar el uso de materiales que mimetizan las propiedades y características propias que se encuentran en materiales naturales'. En primer lugar, los materiales empleados para aplicaciones médicas deben de cumplir una serie de requisitos como la biocompatibilidad, pero además deben aportar funciones específicas para su uso, como estabilidad mecánica, o la posibilidad de ajustar la degradación del propio material.

Los primeros materiales empleados en biomedicina fueron distintos metales o cerámicas, ya conocido por las antiguas civilizaciones ${ }^{2}$. Tras esto, con el avance de la química macromolecular aparecieron los polímeros sintéticos como el ácido poli(láctico-co-glicólico) (PLGA) o el ácido poliláctico (PLLA). En las últimas décadas el desarrollo de la ingeniería genética y de la tecnología del $A D N$ recombinante ha permitido generar nuevos materiales proteicos, los cuales representan un gran paso en la fabricación de materiales biomiméticos ${ }^{3,4}$.

De este modo, se abría un extenso abanico de posibilidades para el uso del biomaterial más abundante, y probablemente más complejo que podemos encontrar en la naturaleza, las proteínas. En los últimos años, la ciencia ha hecho un gran avance en la elucidación estructural de proteínas, y sigue avanzando en el estudio de las relaciones entre estructura y función ${ }^{3,4}$. Este 
conocimiento permite no sólo modificar la secuencia de un material tan complejo como las proteínas, e incluso mejorarlas.

Dentro de esta clase de biomateriales recombinantes, encontramos la familia de proteínas inspirada en la secuencia de aminoácidos de la tropoelastina natural, que es el monómero soluble de la elastina ${ }^{5-11}$. De forma simplificada nos referimos a esta familia de proteínas es como recombinámeros tipo elastina ("elastin-like recombinamers", ELRs, en inglés). Las ventajas en el uso de la tropoelastina como "proteína madre", son las funcionalidades ésta como biocompatibilidad, elasticidad y comportamiento termo-sensible que conduce a procesos de autoensamblado $^{12}$. Además, la secuencia subyacente de amino ácidos a estas propiedades es bastante simple desde el punto de vista de la complejidad de las proteínas. Dicha secuencia está basada en la repetición del pentapéptido L-Valina-L-Prolina-Glicina-X-Glicina (VPGXG), en el que $X$ (denominado aminoácido invitado) puede ser cualquier aminoácido, excepto L-Prolina ${ }^{7,13-}$ 17. Dependiendo del número de repeticiones y de la composición del amino acido invitado, $X$, se pueden crear una gran variedad de ELRs. Debido a su carácter recombinante, es posible fusionar secuencias de $A D N$ que codifican distintos péptidos y proteínas. Así se puede combinar bloques de pentapéptidos con distintos aminoácidos invitados, en el lugar $\mathrm{X}$, en la misma molécula del ELR. Además, es posible añadir secuencias peptídicas como secuencias biodegradables ${ }^{18,19}$, o con dominio de adhesión celular ${ }^{20,21}$ para generar materiales 'a la carta' de la aplicación deseada.

\section{Objetivos}

El objetivo de esta tesis es demostrar que la versatilidad de estos recombinámeros se puede aumentar meidante modificación química y 
genética para la configurar la degradación, el autoensamblado y la interacción con células de los ELRs. El trabajo desarrollado en esta tesis aborda todo el proceso de diseño, producción, purificación, caracterización y aplicación directa de los nuevos ELRs. Para ello, se han utilizado una amplia variedad técnicas de ingeniería genética, microbiología, física, química junto con los correspondientes cultivos celulares.

A. La tecnología del ADN recombinante permite un control total sobre el diseño de ELR, y de este modo la inserción de distintas secuencias biofuncionales, como secuencias sensibles a proteasas. Mediante el control de la disposición espacial de este tipo de secuencias proteolíticas queremos demostrar la biodegradación especifica de ELRs. Además, la capacidad de biodegradación selectiva será aplicada para la biofabricación de sustratos para detección zimográfica.

B. Debido a la degradabbilidad controlable de los ELRs, su uso será estudiado como sustrato selectivo para la identificación de enzimas proteolíticas. Por lo tanto, siguiendo el estudio de la aplicación de ELRs para técnicas zimográficas diseñaremos un nuevo método de detección de proteasas con potencial para sistemas de inspección avanzados de alto rendimiento.

C. Se ha demostrado que los biomateriales modificados con colesterol exhiben fuertes interacciones intermoleculares. Así, aplicaremos estas interacciones en un sistema de ELRs para generar fuerzas intermoleculares que desencadenen el autoensamblado de los ELR.

D. Además, gracias a la capacidad de interacción de los grupos colesterol con membranas lipídicas, estudiaremos la capacidad de ELRs ricos en colesterol para mejorar la interacción de los éstos con ciertos tipos 
celulares implicados en la captación de lípidos, para aumentar el recubrimiento de células vivas con proteínas ELR.

Metodología del Diseño de ELRs con grupos proteolíticos (A y B)

Con el objetivo de utilizar ELRs como sustrato de zimografía de geles (IGZ) más específicas, se pueden fusionar secuencias de degradación enzimática, por ejemplo la secuencia que contiene el hexapéptido L-Valina-Glicina-LValina-L-Alanina-L-Prolina-Glicina (VGVAPG), y cuya L-Alanina con especificad a la enzima elastasa, aumentando la biodegradabilidad de los ELRs, que es de gran importancia en el remodelado del tejido ${ }^{22}$. Además concentraciones altas en proteasas también son típicamente efectos secundarios de cáncer promovando la infiltración de tejido ${ }^{23}$. Pese a que la degradación enzimática es más estudiada en el campo de la regeneración tisular, la degradación de sustratos basados en proteínas también puede ser utilizada para desarrollar técnicas de detección de proteasas, enzimas capaces de degradar proteínas. Una de las técnicas más conocido es la zimografía de gelatina ${ }^{24}$. El método funciona como una electroforesis de poliacrilamida en que la gelatina se añade al gel, si la muestra electroforética en ese gel contiene una enzima con actividad proteolítica, la gelatina será degradada en el lugar que corresponde al peso molecular de esta proteasa. En el caso de la gelatina este método está bien establecida por los metalloproteasas de la matriz MMP2 y MMP925.

Sin embargo, aparte de gelatina, otras proteínas naturales pueden utilizarse como substrato de la zimografía, y de este modo aumentar la variedad de secuencias degradables presentadas a las enzimas. Por otro, lado esa variedad en su secuencia depende de muchos factores, como el organismo 
de origen o el proceso de purificación. Así, aunque de la gelatina se conocen muchos elementos estructurales, se desconoce su secuencia completa. Por lo que, los resultados pueden ser confusos, e inclusos erróneos debido a que no se conozca la secuencia proteolítica que está siendo degradada por la enzima. En esta tesis utilizamos ELRs como substrato para zimografia que presenten únicamente un grupo proteolítico, y que tengan una secuencia conocida, para investigar la degradación con una selección de MMPs I a 20. Esto facilita el uso de dicho ELRs en un nuevo método de zimografia dentro de una placa (in-well zymography (IWZ).

\section{Resultados (A y B)}

Los resultados mostraron que las diferencias en las concentraciones de peptidasas se pueden medir con zimografía utilizando ELRs como sustrato. Además, el uso de ELRs permitió la detección de proteasas de degradación inespecífica tipo serina, las cuales son indetectables en sustratos clásicos como la gelatina.

Más concretamente, los resultados revelaron que, a diferencia de métodos zimográficos clásicos, la ELR-IGZ permite la detección de las enzimas metaloproteasas MMP2 y MMP9. La sensibilidad hacia MMP9 fue casi diez veces mayor con ELR ${ }^{E l a}+F N$ que en gelatina, mientras que el control negativo ELR sin ninguna región proteolítica no fue degradado. El cambio a IWZ reduce la complejidad en comparación con IGZ mediante la eliminación de la separación electroforética y la desnaturalización de la muestra. La sensibilidad se limitó a un $10 \%$ respecto al control no degradado. Se pudo detectar patrones distintos de degradación de cada MMP y se redujo la cantidad necesaria para la cuantificación de 50-500 ng (en IGZ) a 10 ng por muestra. 
Los resultados permitieron clasificar las enzimas proteasas en cuatro grupos diferentes respecto a los sustratos empleados: I) sin degradación (MMP 2, 3, I0, 14, I6, 19 y 20); 2) mediada por FN (MMPI, I3, 16); 3) mediada por ELA (MMP7); 4) no específica (MMP 8,9, 12, 17).

\section{Conclusiones ( $\mathrm{A}$ y $\mathrm{B}$ )}

Se demostró que la producción de sustratos para IGZ basados en ELRs y secuencias proteolíticas. Los cuales permiten la incrustación en matrices de gel, y la detección con CBB. Empleando dos grupos de degradación diferente, se revelaron diferencias en la especifidad frente proteasas tipo serina y distintas MMPs. Cabe mencionar que el sustrato ELR-Control, al carecer de secuencias específicas de degradación, no fue digerido por ninguna de las MMPs seleccionadas, pero sí se detectó su ligera degradación en presencia de tripsina. La degradación del control pudo deberse a la presencia de lisinas que son son un punto de corte preferente para las proteasas tipo serina, además las lisinas, debido a su cadena lateral catiónica, son sensibles a la tinción con CBB.

Por otro lado, presentamos un nuevo método de detección de proteasas mediante la adaptación de la IGZ en una zimografía de placa de pocillo (IWZ), lo que permite una lectura rápida y cuantitativa. Este nuevo método proporciona una técnica de detección capaz de determinar diferencias en patrones de degradación de metaloproteasas (MMPI-20) con sólo dos secuencias de degradación. El control positivo y negativo sirvió como un circuito de retroalimentación adicional en términos del patrón derivado. Complementariamente, este método de cuantificación permitiría seguir la cinética de degradación de cada una de las enzimas sobre los sustratos específicos. La especificidad de los sustratos basados en ELRs aporta varios 
avances a las técnicas zimográficas basadas en gel, por ejemplo gracias al control de los motivos de degradación se pueden elaborar dispositivos de reconocimiento de enzimas proteolíticas basado en un sistema binario.

\section{Metodología de la Modificación de ELRs con grupos hidrofóbicos (C)}

El interés por los biomateriales autoensamblados ha aumentado considerablemente en las últimas décadas debido a su compleja disposición espacial y a que puedan controlar la exposición de distintas funcionalidades. Las implicaciones directas de la estructura en el autoensamblaje en polímeros de bloque anfifílicos y proteínas, junto a la posibilidad de generar interacciones hidrofóbicas ${ }^{26,27}$ e hidrofílicas ${ }^{28,29}$, ha permitido cierto grado de control sobre estructuras jerárquicas, como micelas esféricas o cilíndricas, vesículas, membranas bimoleculares e hidrogeles ${ }^{30-33}$. Además, propiedades tales como la respuesta frente a estímulos como cambios de temperatura ${ }^{27,34}$ o $\mathrm{pH}^{35}$, han dado como resultado la aplicabilidad de estos materiales en la ingeniería de $\operatorname{tejidos}^{36}$, sistemas para la administración de fármacos ${ }^{35-38}$, dispersantes de polímeros ${ }^{39}$, agentes gelificantes físicos ${ }^{40}$ o biosensores ${ }^{41-43}$. La capacidad de respuesta térmica es la característica más investigada y mejor controlada para los copolímeros de bloque ${ }^{27,34}$ y, como tal, ha ganado un mayor interés en el diseño de proteínas recombinantes de vanguardia, especialmente a la luz de los hallazgos de Urry con respecto a la LCST de péptidos miméticos de elastina ${ }^{44-47}$. Además, debido a que los ELRs permiten distintos diseños modulares combinando bloque análogos con dominios de diferente hidrofilicidad, se han estudiado como modelos para comprender el plegamiento, el autoensamblaje y la función de otras proteínas naturales más complejas ${ }^{48-50}$. 
Aunque se espera que el comportamiento de separación de fases del tipo de temperatura de solución crítica superior (UCST) en el agua ${ }^{51-54}$ contribuya a la creación de materiales poliméricos intrínsecamente ordenados $^{55-59}$, también se han observado ejemplos de proteínas intrínsecamente desordenados que exhiben separación de fases de tipo UCST $^{55-59}$. Como la abductina y la resilina, que exhiben una UCST y $\mathrm{LCST}^{60,61}$, sin embargo, hasta la fecha no se ha observado una UCST tras la modificación química de las proteínas recombinantes, especialmente las ELRs. En este sentido, hemos aumentado la interacción hidrófoba de las proteínas mediante la adición de cadenas laterales de colesterol, que se sabe que fomenta las interacciones intermoleculares en los polímeros, aumentando el orden en la proteína y hemos investigado cómo se ve afectada la estructura secundaria de la proteína. Para una mejor comprensión de los determinantes de la gelificación inducida hidrofóbicamente, los ELR resultantes de la modificación con grupos colesterol (CTA) se caracterizaron en detalle; concentración crítica de micelas, ángulo de contacto, dispersión dinámica de la luz, dicroísmo circular, imágenes SEM y TEM. Se descubrió que los CTA resultantes (CTAx $(x=$ número de grupos de colesterol)) constituyen un grupo de materiales novedoso y peculiar, los cuales presentan dos $T_{t} s$ y gelificación fría a temperaturas inferiores a UCST.

\section{Resultados (C)}

Debido a la naturaleza intrínsicamente desordenada de los ELRs, la formación de estructuras cristalinas para su análisis mediante espectroscopía de rayos $X$ no es posible. Además su alto peso molecular dificulta enormemente su evaluación mediante espectroscopía de RMN, de este modo, se estudió mediante CD la estructura secundaria de los distintos 
ELRs modificados con grupos colesterol. La similitudes estructurales observadas entre los estados del CTA5 por encima de la LCST y por debajo de la UCST confirmaron la hipótesis de que el colesterol contribuye al autoensamblado de los ELRs por debajo de la temperatura de transición.

De este modo, demostramos por primera vez que el comportamiento UCST puede ser inducido por modificaciones de la cadena lateral en ELRs. Para la caracterización de la gelificación fría (característica del los ELR ${ }^{C T A x}$ ), se investigaron soluciones de mayor concentración utilizando técnicas de reología oscilatoria y de flujo. En general, no se observó gelificación en ausencia de grupos laterales colerterol. Comparando el módulo de almacenamiento, se observó que éste aumentó en función del número de grupos colesterol (3I Pa para ELR ${ }^{\text {CTAl }}$ y 60 Pa ELR $^{\text {CTA5 }}$ ). De los resultados obtenidos se puede derivar el comportamiento de fase de ELR ${ }^{\mathrm{CTA}}$ con dos transiciones alrededor de 10 y $20{ }^{\circ} \mathrm{C}$ con una región intermedia de solubilidad, caracterizada por la ausencia de estructuras secundarias paralela y antiparalela (relajada).

\section{Metodologia Interacción celular de colesteryl ELRs (D)}

La bicapa de membrana es una barrera física que define la frontera de las células y divide el interior en distintos compartimentos con funciones especializadas. La naturaleza anfifílica de la membrana conduce a una superficie externa cargada negativamente y a un núcleo hidrófobo dentro de la membrana, que sirve como anclaje para proteínas de membrana y transmembrana ${ }^{62}$. En consecuencia, las células tienen la capacidad de unirse a sustratos mediante la unión de integrinas, interacciones electrostáticas, enlaces de hidrógeno o interacciones hidrofóbicas ${ }^{63}$. Además, la membrana contiene una variedad de compuestos y proteínas que son cruciales para la 
función celular. Una de las moléculas más abundantes en la membrana es el colesterol, que se encuentra dentro de la membrana debido a su hidrofobicidad. El colesterol representa hasta el $20 \%$ de la masa de la membrana $^{63}$ y es responsable de la integridad de membrana además de participar en procesos de señalización celular. El colesterol, entre los muchos componentes lípidos de las membranas celulares de los mamíferos, es un regulador clave de la fluidez de la membrana y contribuye a la formación de caveolas y al mantenimiento del microdominio de las caveolas $^{64,65}$. Las caveolas son dominios especializados de la membrana plasmática que se encuentran en la mayoría de los tipos de células ${ }^{66}$. Sin embargo, son más abundantes en células como adipocitos, células endoteliales, fibroblastos y células musculares ${ }^{67}$. Además de la influencia de la fluidez de la membrana, el colesterol es importante para la estructura y la función celular, es esencial en la locomoción y sirve como precursor metabólico para varias moléculas de señalización, incluidos los oxiesteroles $^{68}$, los esteroides ${ }^{68}$ y los ácidos biliares ${ }^{65,69,70}$. La mayoría de los sustratos o hidrogeles se centran en motivos de unión a integrinas, en particular el motivo de RGD, para generar unión celular o la infiltración. Sin embargo, los materiales sintéticos con residuos de RGD unidos covalentemente luchan por cumplir con los resultados de los materiales de proteínas ECM nativas ${ }^{71}$. Otra investigación para la fabricación de construcciones de tejido $3 \mathrm{D}$ se ha centrado en la ingeniería de la lámina celular ${ }^{62}$, los liposomas magnéticos ${ }^{72}$, las perlas celulares ${ }^{73}$ y las células que contienen capas de gel ${ }^{74-76}$. En particular, la creación de nanodominios y microdominios específicos para distintos tipos celulares o específicos de tejido utilizando interacciones biológicas, como avidina-biotina ${ }^{77-80}$, anticuerpo-antígeno ${ }^{81,82}$, lectina-polisacáridos ${ }^{83,84}$ o proteínas ECM como fibronectina, colágeno y / o gelatina ${ }^{74,75,85-89}$, ha sido prometedora y permite la "manipulación jerárquica de células" in vitro ${ }^{85,88,90,9 !}$. 
Seleccionamos grupos colesterol como anclajes hidrófobicos debido que simulan la situación intramembranosa y facilitan la movilidad y distribución de las proteínas en la membrana. Para una mejor interacción del material de colesterol con la membrana, se estudió en tipos celulares ricos en caveolina como son las células derivadas del endotelio de la vena umbilical humana (HUVEC) y las células del músculo liso aórtico humano (HASMC), que están involucradas en la absorción de lípidos del fluido sanguíneo y en procesos tales como estenosis. Para ello, se modificaron varios ELRs con grupos colesterol y se estudió el potencial de estos grupos hidrófobos como anclajes intramembranosos para recubrimientos celulares. En este sentido, hemos desarrollado un recubrimiento celular basado en interacciones hidrófobas con la membrana celular. Para eludir las variaciones de proteínas naturales como variaciones específicas al organismos de origen, se utiliza un recombinante similar a la elastina análogo de ECM como proteína modelo para el recubrimiento inductivo de tejido. El objetivo principal es la creación de un recubrimiento proteico para células basado en una monocapa bien distribuida.

\section{Resultados (D)}

Los diferentes sustratos se probaron para determinar su efecto sobre la proliferación celular durante 7 días usando el ensayo AlamarBlue $\AA$ a concentraciones de 375 y 750 nM. Los HUVEC no mostraron diferencias significativas en la proliferación en todas las condiciones, mientras que para los HASMC, el tratamiento con una alta concentración de los ELRs ELR CTA0 y ELR ${ }^{\text {CTAI }}$ condujo a la disminución de la proliferación con el tiempo.

Se observó que el número de eventos de células fluorescentes aumentó de ELR $^{\text {CTA0 }}$ a ELR ${ }^{\text {CTA5 }}$, del $10 \%$ al $80 \%$ (HUVEC), o del 20\% al 85\% (HASMC), 
respectivamente. Las células HASMC interactúaron en mayor medida con ELR $^{\text {CTA0 }}$ a ELR ${ }^{\text {CTA3 }}$, aumentando de un $20 \%$ a $60 \%$ respectivamente, mientras que la eficiencia de recubrimiento de estos ELRs permaneció por debajo del $30 \%$ para las células HUVEC. Además, las imágenes confocales de células tripsinizadas después de la incubación revelaron un cambio en la distribución de los ELRs en la membrana celular en función del contenido en colesterol, variando desde partículas de tamaño micrométrico aglomeradas (sin colesterol) hasta puntos submicrométricos altamente dispersados (con colesterol).

\section{Conclusiones (C y D)}

Hemos demostrado que las propiedades novedosas, como el autoensamblaje y la gelación termorreversible, se pueden controlar mediante la modificación selectiva de IDPs poliméricas, lo que resulta en materiales altamente innovadores que pueden exhibir un comportamiento UCST y LCST, donde el plegamiento y la formación de estructuras secundarias ordenadas se ve favorecida tanto por encima de la LCST como por debajo de la UCST. En base a nuestros resultados, los grupos de colesterol parecen actuar como mediadores estructurales, en este caso como estabilizadores de micelas en condiciones impulsadas por la entropía por encima de la LCST o como conectores de micelas expuestas en condiciones impulsadas por la entalpía por debajo de la UCST. En ambos casos, los grupos de colesterol aceleran la organización estructural de los ELR con el tiempo. El hecho de que se obtengan estructuras secundarias similares con grupos de colesterol orientados hacia adentro o hacia afuera (por debajo o por encima de la UCST y LCST, respectivamente) podría deberse al esqueleto del ELR subyacente, que gobierna los motivos estructurales a los que se puede acceder. 
Hasta donde sabemos, los restos hidrofóbicos que funcionan como anclajes de membrana celular para proteínas aún no se han investigado. Dado que no se observó ningún efecto citotóxico en los tipos celulares seleccionados a concentraciones bajas, con un resultado $>60 \%$ de células marcadas, el presente sistema puede conducir a una mejor comprensión de las interacciones hidrofóbicas membrana-sustrato y al desarrollo de nuevos recubrimientos celulares impulsados por la hidrofobicidad, proporcionando una alternativa a los recubrimientos actuales. Además, estos nuevos materiales y su versatilidad en términos de secuencia tienen un alto potencial como marcadores celulares, portadores de fármacos o dominios de unión celular hidrófobos. 

INDEX 



\section{Table of Content}

Agradecimientos - Acknowledgements ............................................................................... III

Abstract..............................................................................................................................

Resumen/Summary ......................................................................................................... XV

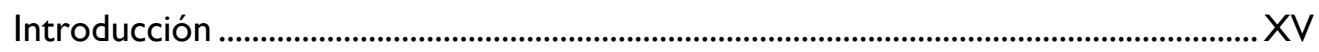

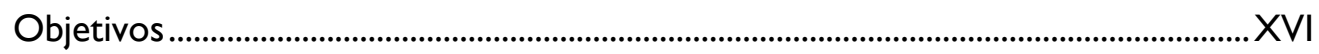

Metodología del Diseño de ELRs con grupos proteolíticos (A y B) ........................ XVIII

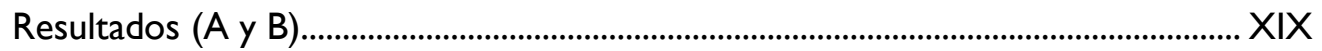

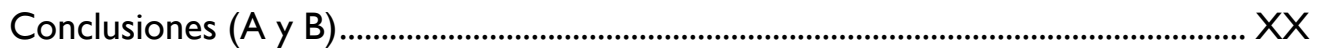

Metodología de la Modificación de ELRs con grupos hidrofóbicos (C) .................... XXI

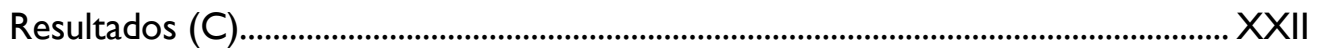

Metodologia Interacción celular de colesteryl ELRs (D) ..........................................XXIII

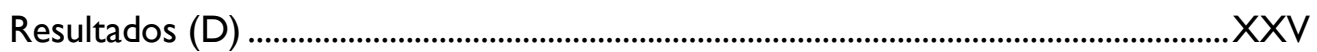

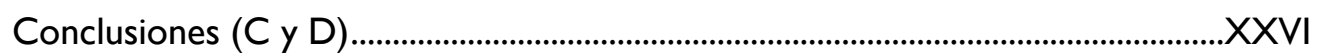

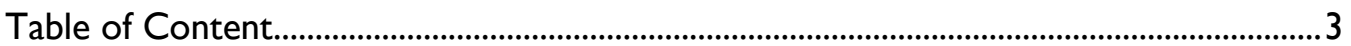

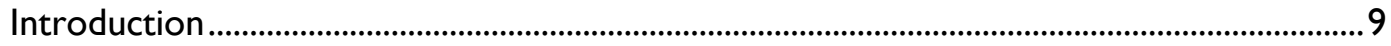

I Introduction ................................................................................................................... I I

I.I Biomimetic Materials ....................................................................................... I

I.I.I. Natural Elastin................................................................................................... 12

I.I.2. Elastin bio-inspired polypeptides (Elastin-like Recombinamers) ................. 14

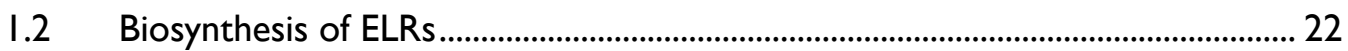

I.2.I Design of the codifying gene ............................................................................... 23

I.2.2 Construction of the multi block .......................................................................... 24

I.2.3 Gene expression and recombinant production ................................................... 28

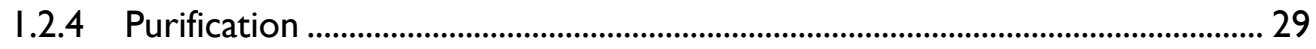

1.3 Protein - interactions .......................................................................................... 3 |

I.3.I Physical ELR interactions ..................................................................................... 32

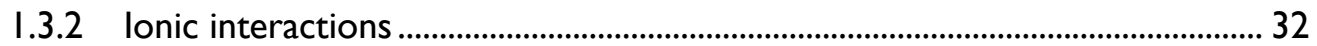

1.3.3 Hydrophobic interaction of amphiphilic blocks and graft copolymers.......... 33

I.3.4 Intermolecular interaction of protein secondary structures ............................ 33

I.4 Chemical Modifications of ELRs .................................................................................. 36

I.4.I Functionalization of ELRs and Covalent Cross-linked ELR Hydrogels .......... 36

I.5 ELR structures and applications.............................................................................. 38

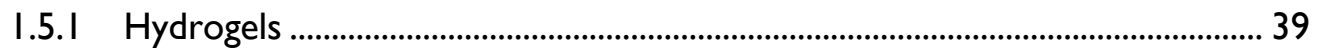

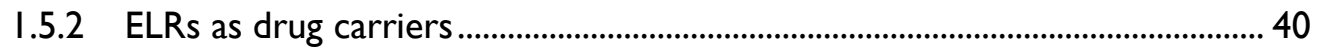


I.6.I Cholesterols role in cell membranes................................................................ I

I.6.2 Cholesterol modified materials...................................................................................4

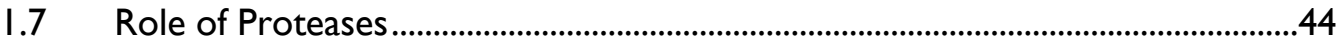

I.7.I Peptidase Classification ......................................................................................

1.7.2 Role of Proteases in Matrix Remodeling and Related diseases.............................46

I.7.2 Serine Proteases .........................................................................................................49

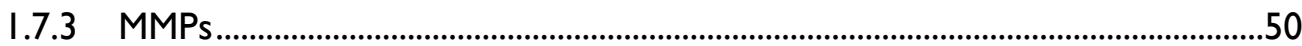

I.7.4 Cleavable peptide bonds....................................................................................52

I.7.5 Involvement of Peptidase in tissue regeneration ..................................................54

1.7.6 Disease related to peptidases....................................................................................58

I.7.7 Zymographic Methods of Protease Detection..................................................60

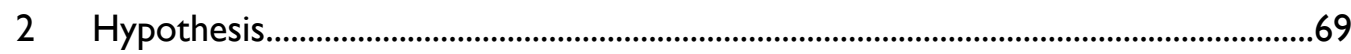

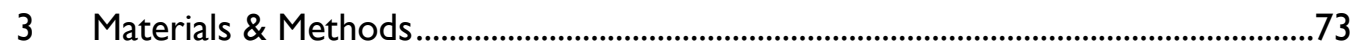

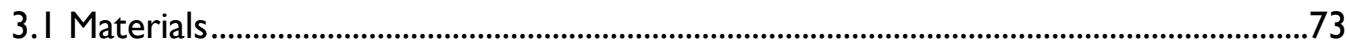

3.I.I Chemical Reagents....................................................................................................73

3.I.2 Glass ware \& other materials.....................................................................................74

3.1.3 Molecular biology materials. .................................................................................74

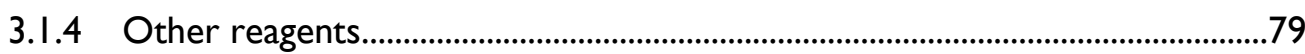

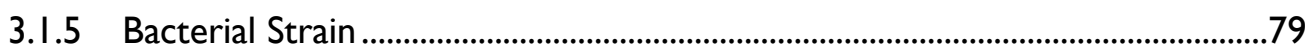

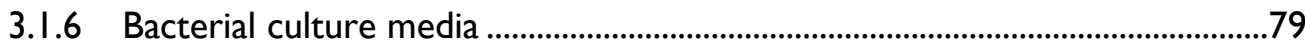

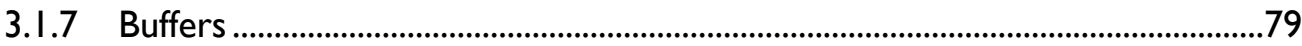

3.1.8 Elastin-like recombinamers ................................................................................

3.1.9 Cell lines and culture conditions .........................................................................82

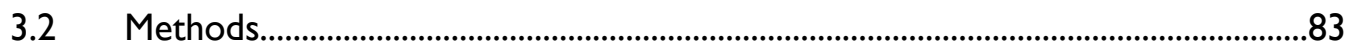

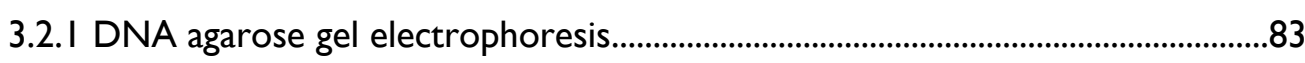

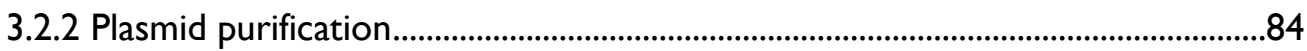

3.2.3 DNA digestion with restriction enzymes .....................................................84

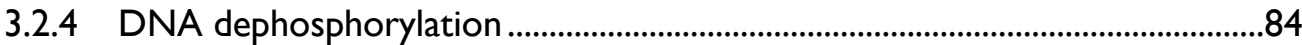

3.2.5 DNA separation and extraction from agarose gel ...............................................84

3.2.6 Ligation of genes ......................................................................................................... 85

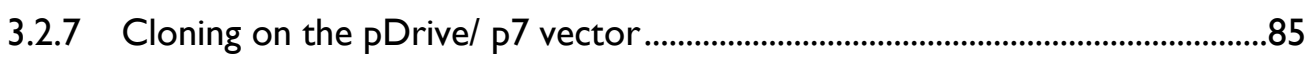

3.2.8 Transformation of competent cells....................................................................85

3.2.9 Glycerol stock preparation .......................................................................................8

3.2.10 Biopolymers expression and purification .........................................................87

3.2.1I SDS Polyacrylamide gel electrophoresis .............................................................89

3.2.12 Modification of ELRs ....................................................................................... I 


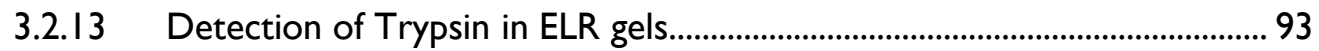

3.2.15 Optimization of screening parameters ........................................................... 95

3.2.16 Screening of MMPs ........................................................................................... 95

3.2.17 Critical Micelle Concentration ......................................................................... 96

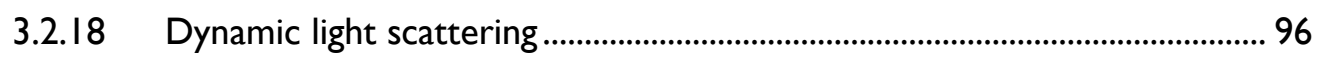

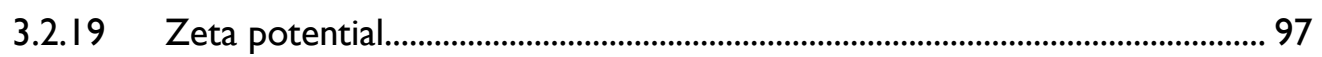

3.2.20 Circular Dichroism ................................................................................... 97

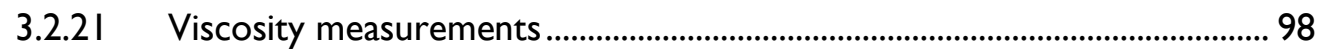

3.2.22 Rheological determination of low-temperature gelation ............................. 98

3.2.23 Contact Angle........................................................................................................ 99

3.2.24 Transmission electron microscopy TEM........................................................... 99

3.2.25 Scanning electron microscopy SEM ............................................................. 100

3.2.26 Spectrophotometric cloud point determination ........................................ 100

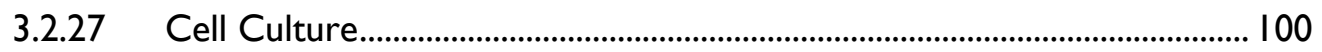

3.2.28 FACS and Confocal Microscopy ................................................................. 10

4 Results and Discussion .......................................................................................... 107

4.I CHAPTER I: Development of a novel screening method for proteases based on proteolytically degradable ELR-acrylamide hydrogels..................................................... 107

4.I.I ELR IK-HEX gene Synthesis.............................................................................. I I I

ELRs expression and purification............................................................................. 115

4.I.2 Methacrylation of ELRs ........................................................................................ 117

4.I.3 WORKING PRINCIPLE OF THE METHOD ................................................. 120

4.I.4 ELR in gel zymography ......................................................................................... 122

4.I.5 ELR in-well zymography (IWZ) ………………......................................... 126

4.2 CHAPTER 2: Chemical Modification of ELRs with Cholesterol and Structural Mechanistics of Cholesteryl Group Mediated UCST Gelation........................................ I 35

4.2.I Chemical Modification of ELRs ........................................................................ 139

4.2.2 Characterization in solution .......................................................................... 142

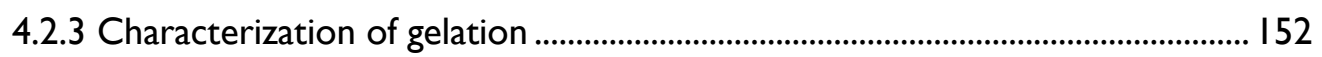

4.2.4 Evolution of macrostructures below the UCST .............................................. 158

4.3 CHAPTER 3: ELR - Cell interaction triggered by hydrophobic modification....... 169

4.3.I ELR Modification ................................................................................................... 173

4.3.2 Characterization in solution .............................................................................. 177

4.3.3 Cytotoxicity of ELR particles ................................................................................. 179

4.3.4 ELR - cell Interactions .......................................................................................... I 18 I

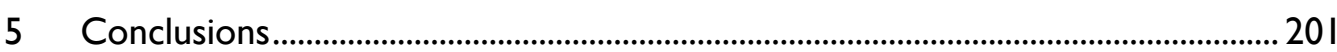


5.I ELR Zymography 201

5.2 Structural deductions of cholesterol modified ELRs ................................................... 202

5.3 Cellular interactions with Cholesteryl-ELRs .............................................................2 204

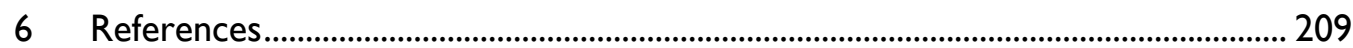

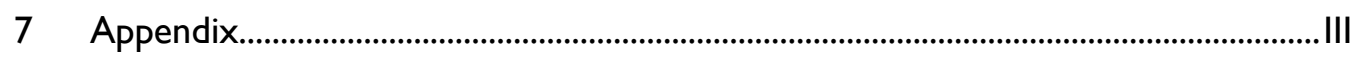

7.I Supporting Information ........................................................................................... III

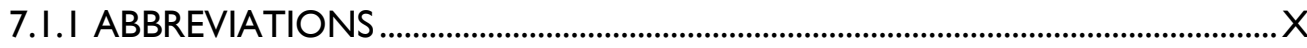

7.I.2 TABLE OF STANDARD AMINO ACID ABBREVIATIONS............................ XIII

7.I.3 List of Tables ................................................................................................... XIV

7.I.4 List of Figures ................................................................................................. XV

7.I.3 LIST OF ARTICLES AND PATENTS ORIGINATED FROM THE WORK OF THIS PhD THESIS ..................................................................................................................... XXII 

INTRODUCTION 



\section{Introduction}

\subsection{Biomimetic Materials}

Building on the discoveries and experiences of our ancestors is one key driver of mankind's progression and technical evolution, saving us from reinventing the wheel over and over again. Biomimicking pursues the same target to build on the results of several millions of years of evolution, which have forged nature close to perfection generating a diversity of biological systems with extraordinary properties ${ }^{92}$. The goal is not just to copy natural systems, but rather to deduce synergetic potential with known technologies to improve certain applications. The diversity of nature including biopolymers, organisms, or active molecules and the fact that these natural systems can be transformed to be used for other purposes, enables a myriad of promising starting points for new developments'.

Taking a closer look at biomimetic materials, one class of biopolymers stands out in terms of diversity, taylorability and applicability. These are protein based materials, where the properties are based on the arrangement of the amino acid residues ${ }^{3,4}$. Natural proteins consist of up to 20 different amino acids and an unspecified number of amino acids ( $n$ ) which opens possible $20^{n}$ arrangements for a distinct number of amino acids $n$. Since this number becomes rather big with protein size, a fundamental understanding of the biophysical properties imparted by certain peptide structures is crucial. The resulting structural complexity and limited computing power made it inevitable to deduce structural relations by manipulating single amino acids in known structural resolved natural amino acid sequences. The number of natural protein sources and their diversity already facilitated their use in 
novel materials and applications. The advancements in exogenous protein expression, in the past decades enabled the creation of de novo proteins with new or enhanced properties, which were a priori designed to comprise specific functionalities 3,4 . The primary goal of protein polymer science is to alter protein sequences to obtain unique properties in a single molecule either in terms of structure or functionality which satisfies a need in biomedicine, or nanotechnology amongst others.

When considering the effect on structure of protein sequences alteration, covalent and noncovalent interactions, such as peptide and disulfide bonds, interactions or van der Waals forces, have to be taken into account ${ }^{12}$. Moreover, spatial arrangements can foster intermolecular interaction which can lead to aggregation or self-assembly events. In general, many structure function relation known in polymers can be translated to protein based materials, such as alternating- or block-copolymers by using as monomers, amino acids of differing hydrophilicities, which in turn result in comparable structural observations like micelles, vesicles, micro phase separation, or even macroscopic hydrogels ${ }^{93}$. furthermore, current advances in biotechnology and recombinant protein expression facilitate the generation of desired protein motifs in a defined and accurate way towards an increasing understanding of protein structure and function relationship.

\subsubsection{Natural Elastin}

The prerequisite for materials to be used in biomedicine is biocompatibility and bioactivity, when desired and controlled, which make proteins a suitable candidate. Especially, in tissue engineering, extra cellular matrix (ECM) components are in focus of current research ${ }^{94}$. Here, elastin has to be 
highlighted. Elastin is a fibrous and insoluble protein that constitutes one of the most important structural and functional components of the ECM, allowing for high deformations without damage ${ }^{95}$. It is abundant in the lungs (3-7 \%), skin (2-3\%), blood vessels (28-32\%) and elastic ligaments $(50 \%)^{96}$, where elastic properties are required. Elastin whose main function is to provide elasticity to organs and tissues, is an excellent example of how all the properties displayed by biological materials and systems are determined exclusively by the physicochemical properties of the monomers and their sequence ${ }^{97,98}$. Elastin possesses several extraordinary characteristics, such as an ability to undergo high deformation without breaking and subsequent recovery of the original conformation once the stress disappears ${ }^{99,100}$. This energy-conserving process allows for billions of relaxation-stretching cycles of the elastic fibers ${ }^{101}$. Several peptide sequences like VPGVG, VPGG, VGVAPG in elastin's soluble precursor tropoelastin have been found to be responsible for the elastic behavior ${ }^{102}$, which have been used to circumvent the insolubility of native elastin. In the beginning elastin mimetic proteins/peptides, derived from chemical solid phase synthesis have been used, and since the late $90 \mathrm{~s}$ are produced by genetic engineering strategies ${ }^{103-107}$. Investigation of short peptide sequences originating from tropoelastin by D. Urry further deduced a sub-structure of elastin, the socalled $\alpha$-elastin, to be responsible for the thermal behavior of elastin. In aqueous solution, $\alpha$-elastin is able to transition from a disordered state to an ordered state where the molecules are capable of aggregating, resulting in a sticky and dense separated phase as a result of a temperature increment ${ }^{7,13-17}$. 


\subsubsection{Elastin bio-inspired polypeptides (Elastin-like Recombinamers)}

The translation of this properties into novel proteins by conservation of a reduced sequence, a repetitive pentapeptide, which has been shown to be responsible for the elastic behavior in elastin, led to a new class of recombinant proteins called elastin-like proteins (ELPs) or recombinamers $(E L R s)^{5-11}$. The term ELR will be used throughout this work to avoid confusion. The most used sequence is a pentapeptide, which is responsible for the beta helical shape, based on the discoveries by Urry et al.. Interestingly, the fourth position of the pentapeptide can be altered with any amino acid besides proline, without loss of beta helical secondary structure $^{7,13-17}$. This led to the class of pentapeptide of the structure VPGXaaG (namely poly(Val-Pro-Gly-Val-Gly), where Xaa is any natural amino acid except proline).

In natural elastin, lysine residues act as intermolecular crosslinking nods by desomsin formation, which are in part responsible for mechanical stability and poor solubility ${ }^{108}$ and more efficient recombinant genetic engineering methodologies ${ }^{103,104,106,107}$. The spatial incorporation of lysine in the four positions of the elastin mimetic pentapeptides (VPGXG VPGKG VPGXG)n, permits spatially controlled chemical or enzymatic crosslinking $106,109,110$. Moreover, genetic engineering based strategies facilitate the alteration of peptide chain length, consensus repeat sequence, as well as the introduction of additional functional groups or oligopeptide units that modulate the biological, thermodynamic, and mechanical properties of the peptide polymer. The synthetic design adapted from the native sequence, and its repetition enhances the bioproducibility of the resulting protein. The genetic 
engineering further allows for the incorporation of other biological relevant moieties into the elastin-mimetic peptide. The appropriate choice of peptide sequence has led to the development of recombinant proteins that have been processed into elastomeric hydrogels, thin films ${ }^{104}$, thermoreversible gels ${ }^{\prime \prime \prime}$, lyotropic, or smectic mesophases ${ }^{12,113}$, and lamellar crystallites ${ }^{114}$. Moreover, the sequences of the obtained proteins are uniform and completely controlled. In summary, the approaches that have been described to date have provided important insights into the physiochemical behavior of bioelastic systems under a variety of environmental conditions and have led to novel processing strategies for creating elastomeric hydrogels for drug delivery and other applications. Whereas little work has been done on the use of elastin mimetic proteins for detection or sensing applications.

\subsubsection{Properties and Characteristics}

All functional ELRs present reversible lower critical solution temperature (LCST) in aqueous solution with sharp responsiveness ${ }^{115}$, according to Urry's model the polymer chains undergo a hydrophobic folding and conformational transition that leads to phase separation ${ }^{108,116}$. The underlying mechanism is the water ELR interaction which in Urry's definition is characterized by highly ordered, hydrogen-bonded shells of water molecules, which surround nonpolar residues of the polymer in a clathratelike organization, which enables the "hydrophobic hydration" (Figure Ib). With increasing temperature, the mobility of water molecules is increased, which at the transition temperature $\left(T_{t}\right)$ results in a disruption of the "hydrophobic hydration", initiating folding of the polypeptide by hydrophobic forces. The molecular structure of ELR pentapeptides leads to 
the formation of $\beta$-turns (Figure IC) which in the polypeptide result in $\beta$ spirals formed by consecutive $\beta$-turns ${ }^{117}$. As a consequence, the hydrophobic groups are exposed to the solvent phase leading to phase separation. Due to the hydrophilicity of the ELRs the segregated phase might still retain more than $60 \%$ of water by weight and has viscoelastic properties $^{118}$.

a)

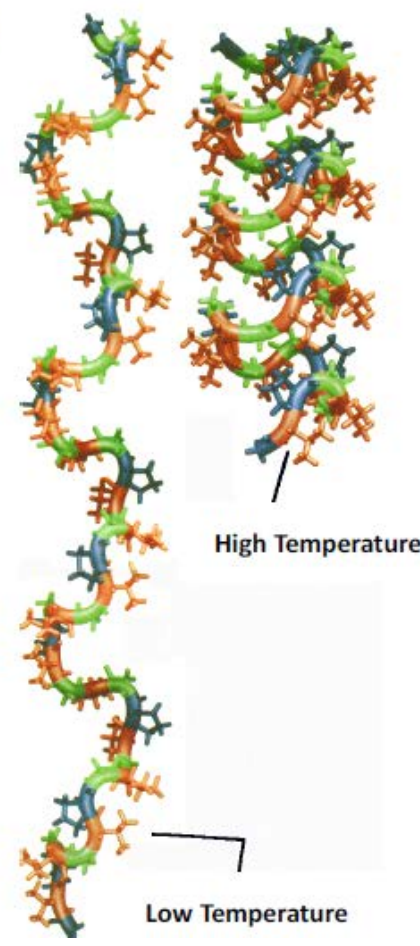

b)

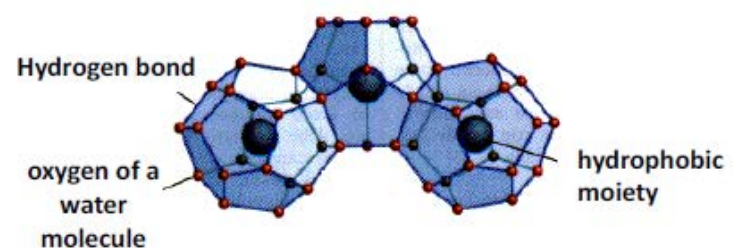

c)

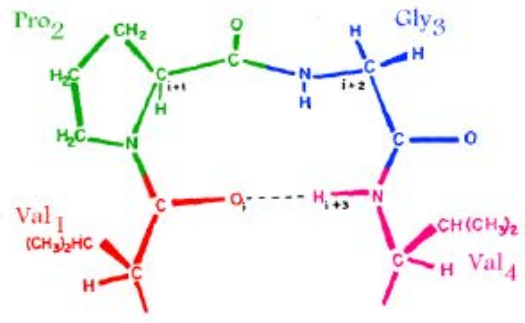

Figure I: a) Structural changes of VPGVG oligopeptide below and above their LCST. b) Water in the clathrate-type structured state. c) Type II $\beta$-turn in the VPGVG pentapeptides ${ }^{119}$.

In most proteins an increase in temperature causes loss of order (unfolding - denaturation), remarkably ELRs behave in a distinct way. Nonetheless, taking enthalpic and entropic events into account, this abnormality does not contradict the second law of thermodynamics.

The loss of clathrate interactions, is compensated by approximately just one third with Van der Waals forces of the hydrophobic aggregation of the 
polypeptides $^{119}$, therefore the folding is not driven by enthalpy. With respect to entropy, the order in the polypeptide is increased with folding, which as well is unfavorable. But considering the whole system, the rupture of water clathrate structures does increase the entropy of the whole system by the release of water molecules into a disordered "free" state. This process of folding and unfolding water is completely reversible in water.

\subsubsection{Factors to influence ELR properties}

It has been proven that the amino acid sequence has a great influence on the LCST of ELRs ${ }^{120}$. Substitutions of the amino acid at the fourth position (Xaa) of the pentamer modify the LCST, to an extent that depends on the polarity of the amino acid side chain.

The transition temperature of an ELR sequence based on (VPGXG) $)_{n}$ can be controlled and adjusted to the desired applications by the selection of $X$ (hydrophobic AA decrease, hydrophilic AA increase $\left.T_{t}\right)^{120}$, the segment length $n$ (longer ELR sequences have lower $\left.T_{t}\right)^{121,122}$, concentration (higher concentrations of ELR decrease $\left.T_{t}\right)^{121}$, and by extrinsic factors like $\mathrm{pH}^{48}$, salt concentration, or solvents ${ }^{123-125}$.

Intrinsic Factors

Manipulation of the $X$ position and the chain length have the biggest potential to tailor the $T_{t}^{121,122}$. The substitution of the $X$ position affects the $T_{t}$ with respect to the hydrophobicity of the inserted AA (Figure 2$)^{126}$.

Trp $>$ Tyr $>$ Phe $>$ Leu $\sim$ lle $\sim$ Met $>$ Val $>$ Ala $>$ Gly 


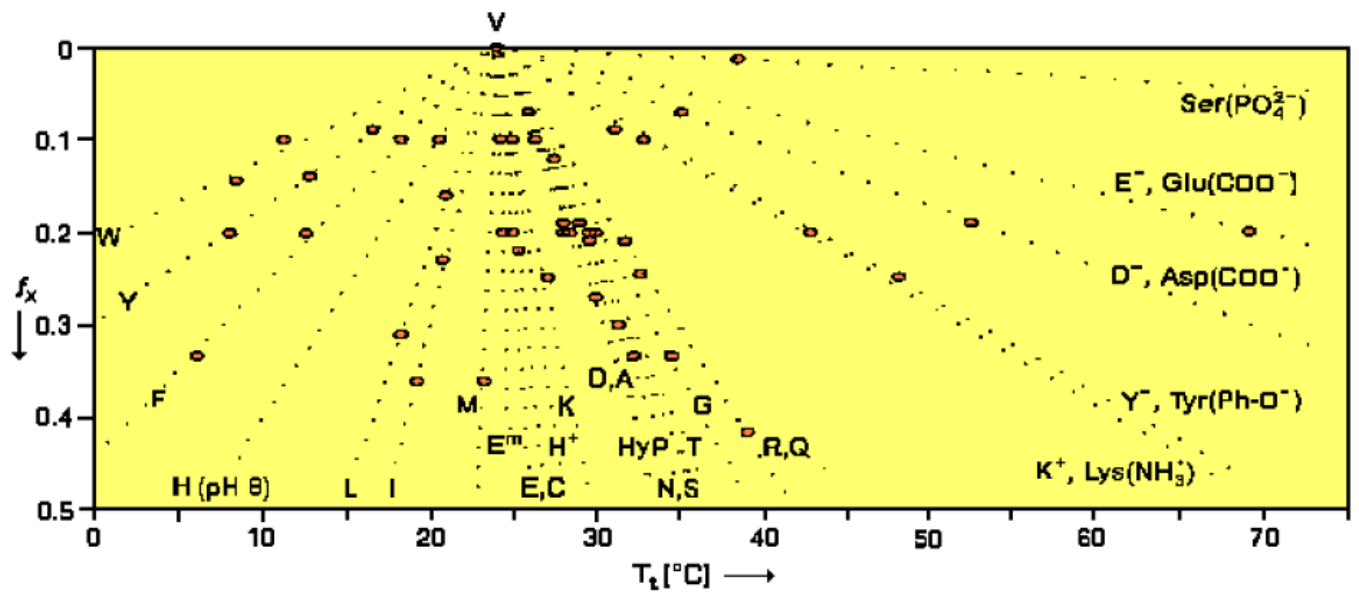

Figure 2: Dependence of Tt on the guest residue in poly penta-peptide of the structure poly[fv (VPGVG), $f x(V P G X G)] . f v$ and $f x$ represent the mole fractions of the respective co-monomers $(f v+f x=I)^{127}$.

As a rule of thumb an increase in the polarity, causes an increase in $T_{t}$ and a decrease in $\Delta \mathrm{H}_{\mathrm{T}}$.

Incorporation of an acid or a basic amino-acid (acid: Glu, Asp; basic: Lys, Arg, Asn or Gln) are also $\mathrm{pH}$ sensitive, and the ionization degree of those amino-acids will have an important effect on the $T_{t}$ as can be seen in Figure 2. In this sense, above its characteristic $\mathrm{pK}_{\mathrm{a}}$ (for acidic $\mathrm{AA}$ ), or below its characteristic $\mathrm{pk}_{\mathrm{b}}($ for basic $\mathrm{AA})$, , the residue is charged, resulting in an increasing of the mean polarity, which leads to an increase in the $T_{t}{ }^{127}$.

The effect of chain length is of interest for very short oligopeptides, where the $T_{t}$ decreases with increasing chain length, but can be neglected for polypeptides composed by more than 100 pentapeptides according to Meyer et al. ${ }^{128}$. 


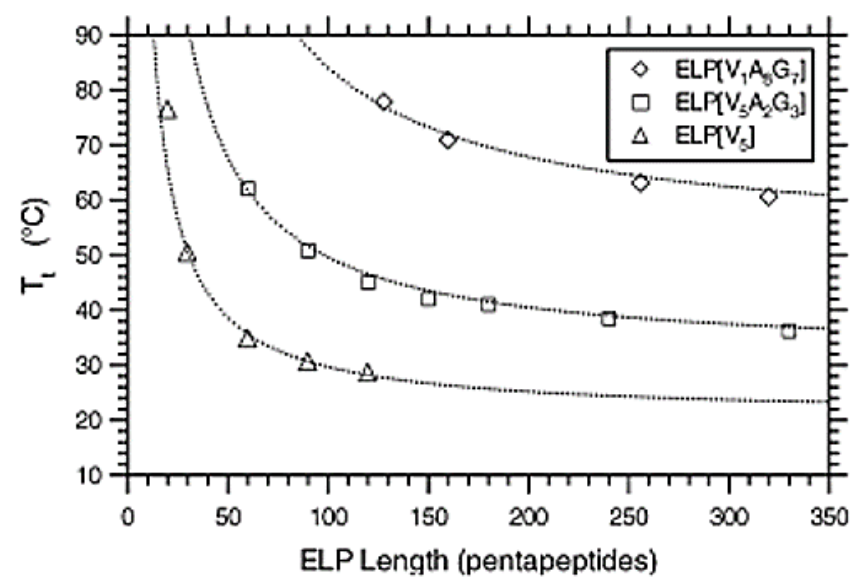

Figure 3: $T_{t}$ as a function of the number of pentapeptides for three different types of ELRs at $25 \mu \mathrm{M}$ in PBS. Reproduced from Meyer et. al. ${ }^{128}$.

It is worth to mention, that none of the three intrinsic factors, (concentration, guest residue and chain length) should be considered independently in order to alter $T_{t}$, since the conjunction of the three together will determine the final $T_{t}$.

Extrinsic Factors

The effect of different salt anions and their concentration on the $T_{t}$ of ELRs has been extensively studied by Cho et al. ${ }^{49}$ as depicted in Figure 4 . The effect of salt concentration on ELRs can be best explained with the Hofmeister series ${ }^{129,130}$, anions to the left of $\mathrm{Cl}^{-}$(kosmotropes) have a strong tendency to salt out polymers/ proteins from solution, as well as cations to the right of $\mathrm{Na}^{+}$. "Salting in" ions (chaotropes) provoke opposite effects. 


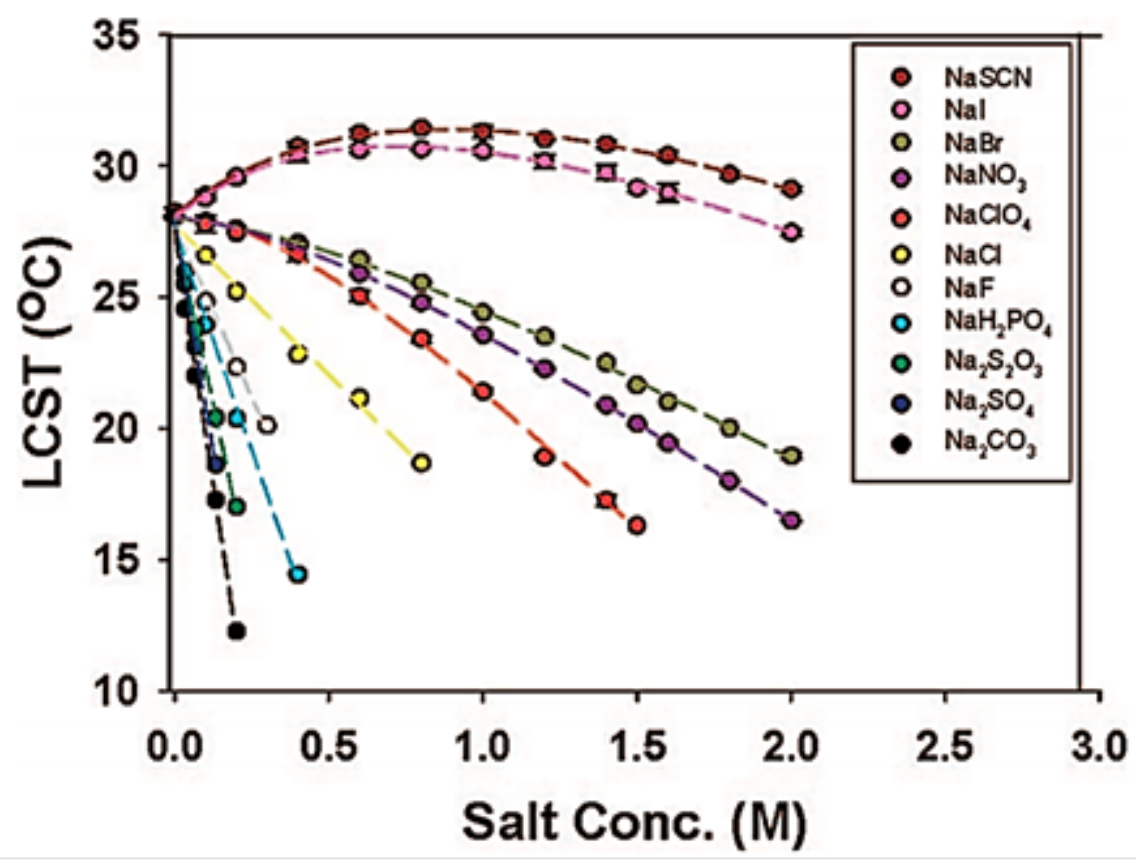

Figure 4: Effect of Hofmeister anions on the transition temperature of ELRs. Figure adopted from

$\mathrm{CO}_{3}{ }^{2}->\mathrm{SO}_{4}{ }^{2}->\mathrm{S}_{3} \mathrm{O}_{3}{ }^{2}->\mathrm{H}_{2} \mathrm{PO}_{4}^{-}>\mathrm{F}^{-}>\mathrm{Cl}^{-}>\mathrm{Br}^{-}>\mathrm{NO}_{3}^{-}>\mathrm{I}^{-}>\mathrm{SCN}^{-}$

$\mathrm{NH}_{4}{ }^{+}>\mathrm{Cs}^{+}>\mathrm{Rb}^{+}>\mathrm{K}^{+}>\mathrm{Na}^{+}>\mathrm{Li}^{+}>\mathrm{Ca}^{2+}>\mathrm{Mg}^{2+}$

It is believed, that kosmotropic anions polarize the water molecules which are involved in hydrogen bonding to the amide group of the ELR employed. The direct interaction between the anions and the water molecules, weakens ELR-water interaction, causing a decrease in $T_{t}$ and solubility. Whereas, chaotropic anions directly interact with amide moieties by ion binding, causing a salting-in effect ${ }^{129,130}$.

The most commonly used salt is $\mathrm{NaCl}$ which has been found to cause a significant concentration-dependent decrease in $T_{t}$ and an increase in the transition enthalpy in ELR-water systems ${ }^{119}$. The effect on the thermal behavior of the ELR can be compared to an increase in the hydrophobicity 
of the recombinamer chain, fostering a better organization of the recombinamer in the folded state.

Besides salt changes, $\mathrm{pH}$ changes can result in changes in the degree of ionization of the ELR, which is more pronounced when polar guest amino acids are present ${ }^{48}$.

Biotechnology provides us with a powerful set of tools that can be used to successfully control the physicochemical features of the amino acid side chains and their association ${ }^{131,132}$, or to include any protein based functionality like protease active sides, which become important when degradation of the scaffold has to be adjusted, e.g. to the growth rate of new tissue $^{133}$. 


\subsection{Biosynthesis of ELRs}

Biosynthesis of proteins uses the natural route of protein production by inserting a DNA fragment specific for the protein of interest into the protein expression chain of an organism. The very susceptible process of protein expression requires very close control of DNA manipulation, which is obtained by recombinant DNA techniques ${ }^{2}$. The manipulation of DNA, insertion into an expression vehicle (vector), the insertion into a producing organism and the purification of the final protein is a time and resource intense process, nonetheless it is without alternative for the generation of larger amino acid sequences, where synthetic peptide production reaches its limit.

Despite the time and effort required for the synthesis of genetically encoded polypeptides and the restriction to natural amino acids, the use of genetic engineering to obtain recombinant proteins has several advantages over their synthetic counterparts. Bioproduction provides a facile route for the design of novel protein polymers composed of repetitive amino acid sequences or peptide blocks whose structural complexity imparts distinct mechanical, chemical or biological properties ${ }^{2}$. The accentuate reduction on the production costs, the time reduction in large scale bio-production, the greater control over product sequence, size and uniformity, higher yields and the possibility of achieving structural complexity into an assortment of bio-inspired materials with distinct mechanical, chemical or biological properties, summarize some of them.

Related to the establishment of this recombinant technology for the creation of protein-based materials, a new term, namely recombinamer ${ }^{134}$, has been implemented to evoke the oligomeric and recombinant nature of protein polymers produced by genetic engineering techniques. Following this new 
terminology, from now onwards, recombinant protein polymers will be referred to as recombinamers in the present work. The biosynthesis of a recombinamer can be drafted in four main steps, namely I) design of the codifying gene for the protein, 2) obtaining the monomeric gene and construction of the multi-block, 3) transformation of a bacterial strain for expression with the selected positive plasmid and 4) bio-production of the recombinant polypeptide and subsequent purification ${ }^{135}$.

\subsubsection{Design of the codifying gene}

At the gene design stage it proved necessary to try to overcome the contradiction that exists between the use of the most common and appropriate codons that identify highly repeated amino acids and the need not to overload or even impoverish the cell translation system to the point of collapse ${ }^{136,137}$. If heterologous prokaryotic systems are used, the problem arising from their limited use of the genetic code, which varies with species, must be taken into account. The problem arising from the creation of a gene formed by a long sequence that codes for multiple and/or small artificial fragments have also to be taken into account. Finally, the high recombination frequency commonly found when the exogenous DNA contains repeats of highly similar domains also has to be overcome ${ }^{138,139}$.

This stage involves the use of automated DNA synthesizers together with recombinant DNA techniques. The production of polymers with multiple repeats necessarily involves the production of a gene that codes for them which, depending on the length of the sequence, may require the prior synthesis of a polynucleotide-based monomer that can be connected linearly in the correct direction ${ }^{135}$. 
The production of sufficient amounts of the monomeric gene containing the correct sequence for producing the repeat nucleotide sequences that code for the various polypeptides required a culture of the appropriate clones and digestion of their plasmids. This allows for high yields of monomer required for the controlled ligation, concatenation or concatenamerisation reaction to obtain oligomerized genes in a simple manner ${ }^{|40,14|}$.

Although this approach may appear to be wasteful in terms of time, in vivo synthesis guarantees the production of the correct sequence in large amounts and also offers additional advantages, such as control of the monomeric gene prior to oligomerisation and the ability to subsequently modify the sequence by either directed mutagenesis or by the creation of copolymers prior to oligomerisation.

\subsubsection{Construction of the multi block}

Polymerisation of the monomeric nucleotide sequences may be undertaken by, but is not limited to, concatenation, in other words random ligation of the monomeric blocks; the iterative/recursive method, a step-by-step technique for preparing oligomers from monomers; or by the Seamless cloning method, a definition that refers to the possibility to select a specific sequence that is translated into the desired amino acid at the cut-off point $^{|40,14|}$. 


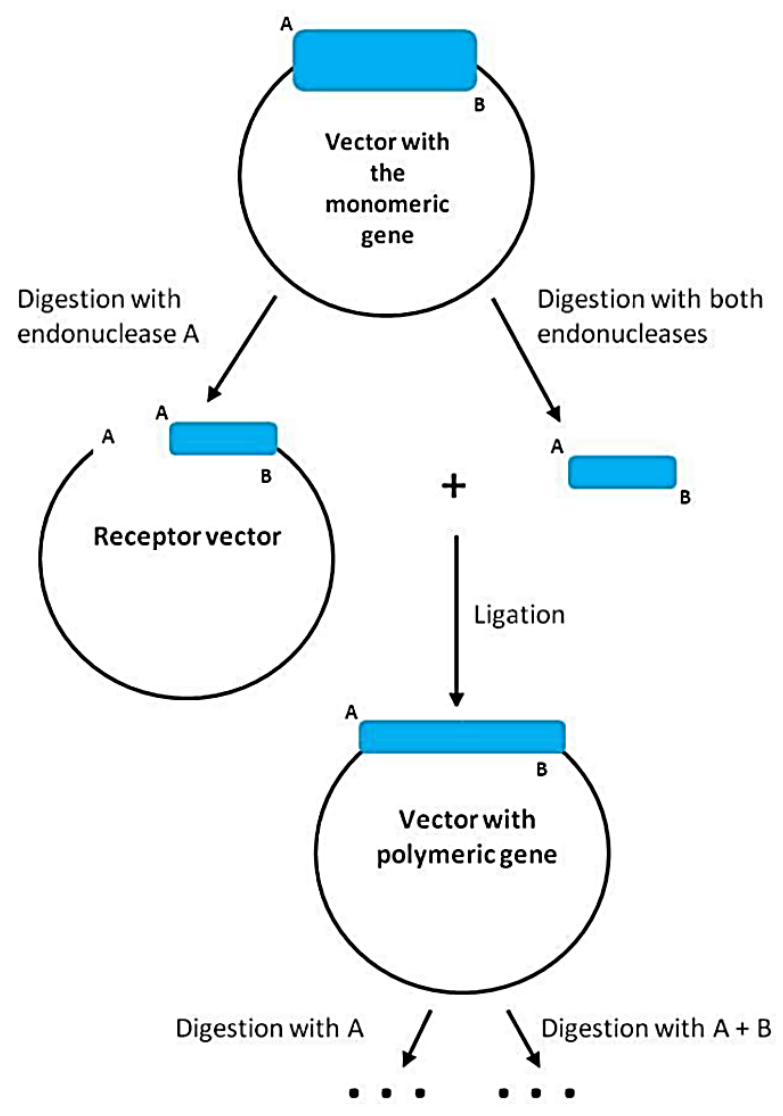

Figure 5: Condensed summary of recombinant gene oligomerization in a vector with 2 restriction enzymes. Adapted from ${ }^{142}$.

Concatenation allows the synthesis of polymers from oligomers by the unidirectional, linear head-to-tail attachment of the DNA segments that make up the monomer, although such attachment is only possible if the ends of the segments are single-stranded, protuberant and cohesive amongst themselves but not with themselves. Thus, the single stranded head end of the monomer will be complementary to, and will only hybridise with, the tail end of another identical monomer. These ends cannot therefore be palindromic, as currently occurs when they are generated by the restriction endonucleases routinely used in genetic engineering, where the recognition and cleavage sites occur sequentially, but must be different ${ }^{143}$. 
Various modifications of the concatenation technique have been developed considering the specific requirements. Monomers with cohesive, singlestranded ends were obtained by the hybridisation of oligomers, by the joining of short oligonucleotides (linkers) and also by digestion with specific endonucleases

The iterative/recursive method is a step-by-step technique used to prepare oligomers from monomers that allow both, the addition sequence and the number of blocks to be joined during each growth stage to be controlled, thereby allowing ad hoc polymer production. This method requires the creation of sequences at the ends of the segment that code for the proteinbased monomer, which are recognised by two different endonucleases and whose cleavage produces complementary, but not palindromic, ends ${ }^{144}$. By this approach DNA monomers are oligomerized exclusively "head-to-tail" by enzymatic ligation, which ensures the translation of the sense strand into the polypeptide of interest and allows to fully control the polypeptide length (compare Figure 5). This monomeric sequence is cloned in a plasmid that serves as a gene amplification vector and provides both the following cloning vector when digested with a single enzyme and the clone insert when cleaved by two enzymes ${ }^{145}$.

The Seamless cloning method removes the relationship between the design of the sequence for the insert that codes for the monomer and the sequences recognised by the endonucleases that generate it. This strategy is possible due to the existence of a limited number of type II restriction enzymes that recognise a specific, non-palindromic sequence that does not coincide with the cleavage site. This unique characteristic eliminates the drawbacks resulting from the need to include unusual sequences into the polymer in order to allow the generation of cohesive ends that allow 
concatenation and also means that fragments that join in a unidirectional manner can be achieved in single digestion.

Type IIS endonucleases Sapl and Earl

SapI and Earl are two type IIS endonucleases that recognize similar nonpalindromic sequences only varying by the fact that the Sap I sequence is extended by one nucleotide (Figure 6).

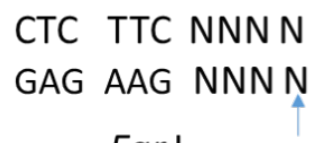

Ear I

\author{
G CTC TTC NNN N \\ C GAG AAG NNN N \\ Sap I
}

Figure 6: Illustration of the recognition sequences of Ear I and Sap I type IIS endonucleases.

The fact that the Ear I recognition sequence is fully presented in the Sap I recognition site, implies that Earl is capable of digesting the Sap I region, whereas Sapl does not cut the Ear I region when the preceding nucleotide differs from guanine. Additionally, the resulting asymetric ends with three nucleotides ( $\mathrm{N}$ in Figure 6) generated with Sap I or Ear I digestion have the same size and orientation.

The existence of a constant displacement between the recognized sequence and the exact cleavage place, which is characteristic for type IIS restriction endonucleases, allows for the insertion of nucleotides of any order ${ }^{143}$. This makes this pair of restriction enzymes an ideal candidate for the seamless cloning technique, since the additional base of the restriction site ("seam") are not part of the extracted final gene (Figure 7$)^{145}$. 
(a)

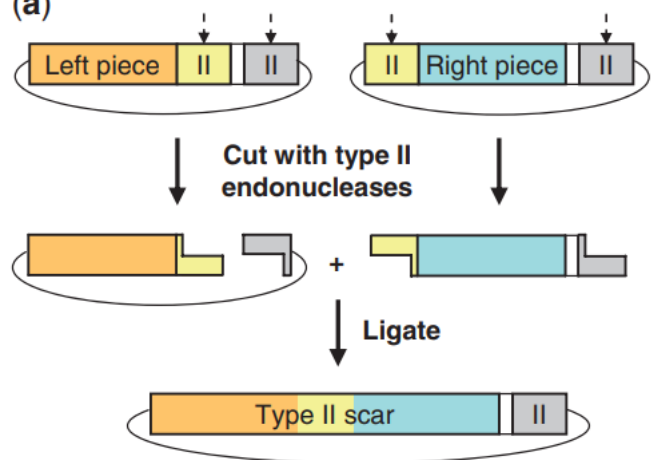

(b)

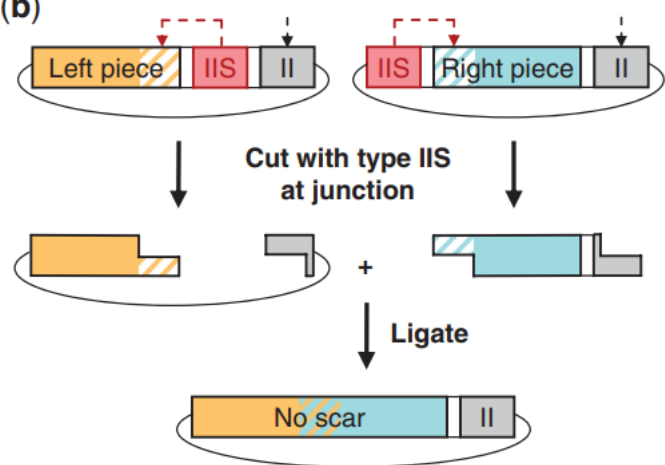

Figure 7: Ligation-based DNA assembly using restriction endonucleases. a) DNA assembly using conventional type II endonucleases requires a type II recognition site at the junction between the two starting pieces of DNA. The junction remains in the product, precluding the construction of arbitrary DNA sequences. b) DNA assembly using type IIS endonucleases, which allow the generation of overhangs of any arbitrary sequence, and thus sequence-independent construction. Reproduced from ${ }^{130}$.

In summary, two prerequisites are necessary for the successful application of the iterative recursive method using Sap I and Earl:

I. A singel Sapl restriction site within the vector to perform vector linearization and to create protruding ends at the end of the gene for the addition of subsequent genes.

2. Two Earl sites flanking the gene in the vector allowing for the extraction of the gene segment and even the oligomerized genes after applying oligomerization.

For these reasons, the iterative nature of the gene design results in fully controlled gene constructs

\subsubsection{Gene expression and recombinant production}

Once the final gene construction is achieved, it is cloned into an expression vector for the transformation of suitable bacterial strains for expression. 
The biosynthesis of an ELR ends with the bioproduction of the recombinant protein followed by its purification.

Due to availability, fast reproduction rates, and its well-known constraints, Escherichia coli (E.coli) has become one of the most popular organisms for heterologous overexpression of polypeptides ${ }^{146}$. In this regard, expression vectors tailored to the conditions found in E.coli have to be used to obtain good yields.

One of the most widely used promoters is the T7lac promoter which is suitable for the concomitant recombinant gene construction. The T7 promoter is a target to the RNA polymerase T7 and the lac operator indicates the regulation by lac repressor $(\mathrm{lacl})^{143}$. For optimal performance the encoding sequence of the repressor has to be present in both the vector and the chromosome of the organism (native form lacUV5). The repressor avoids the basal expression of the recombinant protein by acting over T7lac and lacUV5 promoters in the response of glucose and lactose levels of the media. So that only when glucose is absent, and lactose is present, the expression of T7 RNA polymerase is induced.

Once the gene of interested is inserted in the expression vector in the above mentioned process, the vector has to be transfected into a bacterial strain containing a chromosomal copy of the gene of the T7 RNA polymerase.

\subsubsection{Purification}

After protein/recombinamer expression it has to be purified and separated from endogenous bacterial proteins. Here, caution has to be paid to the released peptidases from the bacteria, which potentially could degrade the protein of interest, especially when protease sensitive sites are 
incorporated, therefore the addition of protease inhibitors is crucial. For the separation of proteins chromatography, especially affinity chromatography is the standard method. A drawback of affinity chromatography is, that the protein of interest needs to be marked with a recognizable region (e.g. a his-tag) and that the yield is limited to the efficiency and capacity of the purification column ${ }^{147}$.

The physico-chemical properties of ELRs with their inverse temperature transition (ITT) behavior has enabled a new route of purification by repeated precipitation of the ELR and resolubilization followed by dialysis, a process that was named inverse temperature cycling (ITC) ${ }^{148,149}$. ITC is able to generate much higher yields without the need for further special equipment and has paved the way to the novel approach of recombinant purification, where even other proteins of interest can be linked to an ELR domain solely for purification purposes ${ }^{150}$. Furthermore, ITC protocols are compatible with state of the art endotoxin removal methods ${ }^{146}$. 


\subsection{Protein - interactions}

The predominant matrices for tissue regeneration, which were also the first applied in humans ${ }^{151}$ are hydrogels. Due to the high water content, the resemblance of natural tissues, biocompatibility and stimuli-responsiveness, they have gained raising interest in the last 40 years ${ }^{152,153}$. Traditional methods of hydrogel synthesis are lacking an exact control of cross-linking points, chain length and sequence. Thus, the three dimensional structure reveals deficiencies that might impair the mechanical properties of the material ${ }^{154}$. These problems have been addressed by the development of novel polypeptide-based responsive hydrogels, including blockcopolypeptides ${ }^{155}$, or recombinant copolypeptides flanked by two coiled-coil blocks ${ }^{11,156}$ and recombinant segments of elastin, silk and collagen ${ }^{157-159}$.

A prerequisite to formation of ECM analogous matrices from ELRs is to integrate crosslinking motifs that lead to a stable hydrogel. This cross-link can be either of physical or covalent nature, whereas the feasible crosslinking mechanisms are as versatile as the ELRs themselves. They reach from ionic and hydrophobic interaction and the reaction of complementary groups to bioinspired protein crosslinks ${ }^{160,161}$.

ELRs have the potential to create a material that is not just biocompatible and has certain mechanical properties, but also one that interacts with the organism to improve the nativeness of regenerated tissue. The repetitive ELR pentapeptide (VPGXG) itself does not facilitate adhesion but the extraordinary design allows for the integration of adhesive (like RGD) ${ }^{20,21}$ and degradable sequences ${ }^{18,19}$, as well as for the integration of temperature or biological triggers. ${ }^{162-164}$ All these strategies can provide very close control over the length and the molecular weight of the proteins by the 
selection of the cross-link sites, which usually correspond to the lysine groups $^{106,165}$.

\subsubsection{Physical ELR interactions}

Several strategies can be applied to foster physical ELR interaction. Among those the following have been described.

\subsubsection{Ionic interactions}

The ionic cross-linking motifs are based on ELR segments of opposite charge, or by introducing chelating capacities for multivalent cations into the ELR backbone that can be further controlled by salt concentrations.

Peptide sequences of alternating charge and with complementary ionic sides have been shown to perform well to physically crosslink. They are classified in different moduli, depending on the size of the equally charged ionic blocks ( $\mathrm{I}-4$ aminoacids). Modulus $\mathrm{I},-+-+++-+$; modulus $\mathrm{II},--++--++$; modulus III ---+++ ; and modulus IV ----++++ . A modulus I sequence reported by Holmes et al. ${ }^{166}$ showed a salt induced in-situ gelation $^{167}$. The complexation of ions is obtained by including glutamic and aspartic acid residues into the ELR sequence accompanied by the addition of $\mathrm{Ca}^{2+}$ ions, such hydrogels can be stabilized at room temperature and at physiological $\mathrm{pH}^{168}$ and react sensibly towards chelating agents which reduce the number of accessible $\mathrm{Ca}^{2+}$. Another approach by Yeo et al. ${ }^{169}$ was to add monosaccharides to the side chains of the ELRs which are capable to form stable complexes with potassium. Furthermore, blends of ELR/Chitosan have shown to form stable films in the presence of sodium ions ${ }^{170}$. 


\subsubsection{Hydrophobic interaction of amphiphilic blocks and graft copolymers}

Self-assembly of amphiphilic blocks and graft copolymers. Hydrogels can be obtained through aggregation among hydrophobic segments of multi- block copolymers of ELRs. The hydrophobic functionalities are provided by alkylrich amino acids like alanine (Ala), leucine (Leu), isoleucine (lle), valine (Val), phenylalanine (Phe), tryptophan (Thp), tyrosine (Tyr) or methionine (Met). These ELR based amphiphilic blocks have been shown to be stable in vivo $^{159,171,172}$. Furthermore, it is common to find protein polymers characterized by alternating blocks of essentially hydrophilic and essentially hydrophobic amino acids. The presence of chemically distinct segments within the same protein chain causes a mutual repulsion between the different blocks, which tend to segregate. Nevertheless, such segregation is constrained by the "forced cohabitation" of these blocks within the same molecule. As a result, they just separate into different domains, and as a consequence, periodic nanostructures are formed ${ }^{173}$.

\subsubsection{Intermolecular interaction of protein secondary structures}

The structure design offers the possibility to include almost any sequences into the ELR backbone that are able to form intramolecular interacting secondary structures, limiting factors here are, to retain the ELR temperature transition, and to take into account that complex folding might not be realized by a recombinant approach. 
One bioinspired approach was to include natural silk sequences that are known to form intramolecular betasheets that self-assemble into crystalline regions and have unique mechanical properties ${ }^{174-178}$. These silk-based materials can be used to form a variety of structures like hydrogels, films, $3 \mathrm{D}$ porous matrices and submicron to macroscale fibers ${ }^{179}$. Furthermore, silk scaffolds have been proven to be biocompatible and performed well invivo $^{180-182}$. In terms of the silkworm (Bombyx mori) a repetitive hydrophobic sequence of GAGAGS has been identified to be responsible for the strength of silk fibers $^{183}$. These blocks are stabilized by hydrophilic compartments in the protein and a complex mixture of stabilizing proteins ${ }^{184}$. FernandézColino et al. have shown that the GAGAGS sequence can be successfully integrated into an ELR, facilitating in-situ gelation of the material and its uses as an injectable system ${ }^{159}$.

A more complex crosslinking has been realized by the use of coiled-coil induced oligomerization through leucine-zipper motifs, which include sequences that are known to develop well defined secondary structures ${ }^{185-}$ 187. Leucine zippers are characterized by heptad repeating peptide-units that form a distorted $\alpha$-helix designated as "abcdefg", where the "a" and " $d$ " positions are occupied by hydrophobic residues such as leucine, whereas "b”, “c”, “e”, “f”, “g” usually displays a hydrophilic nature ${ }^{188}$. The oligomerization of different $\alpha$-helices is primarily driven by the hydrophobic interactions $^{189-192}$, and partly by electrostatic interactions ${ }^{193-195}$ and the number of heptad repeats ${ }^{190,196,197}$.

The potential extrapolation of these domains to the creation of bioinspired domains has been explored in a much lower extension than it is the case for elastin or silk domains, which involves also a lower number of studies available regarding their biocompatibility. However, its human origin as well as the conserved nature of the sequence of these domains alleviate any 
concerns regarding its biocompatibility. To further support this notion, in vivo implantation of the leucine zipper based scaffolds in a mouse model has been recently reported, and no foreign body reaction to the scaffold was detected ${ }^{198}$.

Protein based physical cross-links in nature are ubiquitous and it can be assumed that was has been reported to date is merely just the tip of the iceberg. 


\subsection{Chemical Modifications of ELRs}

\subsubsection{Functionalization of ELRs and Covalent Cross-linked ELR Hydrogels}

Posttranslational modification in ELRs is obtained by the reaction of the functional groups in the protein backbone. Which in ELRs can be included by active amino acids into the $X$ position of the (VPGXG) sequence, thus maintaining the $\mathrm{pH}$ and temperature sensitivity of the ELRs ${ }^{199,200}$. These active amino acids facilitate on the one hand for cross-linking reactions, and on the other for chemical modifications. Concentration, molecular weight and lysine content of ELRs are key parameters for hydrogel formation. Below a critical concentration ${ }^{201}$, the hydrogel network is not formed due to the lack of inter-molecular contacts. ELRs with high molecular weight are more prone to establish an elevated number of inter-molecular contacts that promote network formation. ELRs with a high content in lysine are the most used to prepare hydrogel networks, because of the suitability of the amino group of lysine to form covalent bonds between ELRs chains. Furthermore, relevant features of the hydrogel, such as gelation time, network pore size, stiffness and degradability, can be narrowly controlled through the nature and the concentration of the cross-linker agent. Labile chemical linkages can also be formed in order to be broken under physiological conditions, either enzymatically or chemically ${ }^{202}$. As a drawback, chemical cross-linking usually requires organic solvents and reagents that have to be exhaustively removed for biomedical applications, after synthesis of the network.

Chemical cross linking can be obtained through the following mechanisms: I) radical polymerization (acrylates), 2) coupling of complementary groups 
(click, reaction, Michael-addition ${ }^{203}$, condensation ${ }^{204}$ ), 3) high energy irradiation $^{205}$, or 4) enzymatical cross-linking (transglutaminase) ${ }^{206-208}$. Typical functionalization motifs are fluorescent probes or bioactive sequences which include adhesion sites, inhibitors, antibodies and anchor, or signaling molecules.

Permanent or chemical hydrogels are covalently cross-linked networks and may contain clusters spread within regions of the low cross-linking density and high water swelling. The free chain ends also cause defects in the gel and do not contribute to the elasticity of the networks. Both aqueous and organic media can be used to form ELRs networks; the cross-linking in an organic solvent rendering hydrogels with a more uniform structure due to the absence of transitions. Conversely, in water the behavior of the ELRs molecules is governed by the LCST ${ }^{105}$. Some organic solvents, such as trissuccinimidyl aminotriacetate, can react with the lysine residues of different ELRs chains to form a network. The cross-linking confers the hydrogel with structural stability, being insoluble in water even upon cooling. Also intermolecular crosslinks between proteins can be obtained by genipin, as it was shown for an ELR/fibronectin hybrid ${ }^{209}$. The chemical cross-linking strategy has some important advantages, for instance the covalent bonds avoid hydrogel network dilution and prevent components diffusing out from the place where the hydrogel is implanted. Click-chemistry has been of growing interest in the past 5 years to form ELRs networks avoiding the use of organic solvents ${ }^{210,211}$. It can be used to fuse ELRs with different bioactivity together ${ }^{212}$, or even form hybrid systems of the ELRs in an in-situ gelating manner. This method has further been used for the creation of nonthrombogenic stents ${ }^{213}$. 


\subsection{ELR structures and applications}

Based on the design of ELRs and that nods of interactions incorporated, ELRs can form a variety of structures from nanoparticle to hydrogels (Figure 8), which allow for a variety of structure related applications.

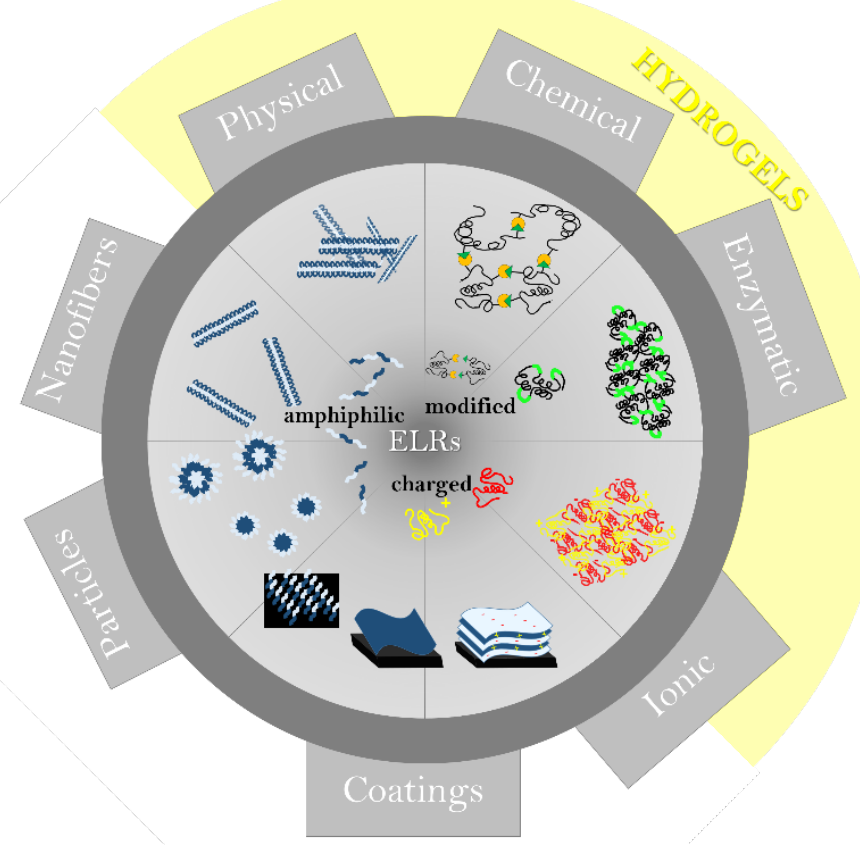

Figure 8: The diversity of ELR structures and their sequential origin.

Amphiphilic ELRs consist of blocks of different polarity, which have the ability to form micelles in solution, here the hydrophobic block is embedded in the core and the hydrophilic block(s) form the corona. The formation of stable nanoparticles requires a relatively high molecular weight of 48 pentapeptides, and the particle size and molecular weight for a comparable ELR are directly related to ${ }^{214}$. The ITT of the ELRs depending on the characteristics of the micelles, can either lead to coalescence of micelles into lyotrophic gels ${ }^{112}$, to polydisperse microparticles ${ }^{215}$, or swelling and deswelling of the micelles, accompanied by size changes. Typical sizes of ELR 
nanoparticles reported are usually in the range of 10 to $100^{124,216-220}$, but due to the temperature sensitivity and related agglomeration, also micro sized particles have been reported ${ }^{215,221}$. The approaches to influence ELR micelles are similar to those affecting the $T_{t}$ of ELRs, like changing concentration ${ }^{1 / 2}$, the addition of surfactants ${ }^{222}$, salt concentrations ${ }^{124,218,220}$ and $\mathrm{pH}^{218}$.

In general the shape of micelles is round, but with specific designed ELRs consisting of different amphiphilic blocks, micelles with a cylindrical shape have been obtained ${ }^{223}$. The rearrangement typically occurs over the critical micelle temperature (CMT) and is driven by a change in the secondary structure of the hydrophobic core, the cylindrical shape change further seems to enhance the cellular uptake of the particles ${ }^{214}$. Micelle solutions further have been used to generate thin coatings with nano topographic, or anti-fouling properties ${ }^{224}$.

\subsubsection{Hydrogels}

Due to the ELRs origin, inspired by the extracellular matrix (ECM) protein elastin, most research is focused on the generation of matrices. In tissue engineering, where the predominant matrices in the past 40 years were hydrogels which already made it to application in the human body ${ }^{151}$, their high water content, the resulting mechanical properties, and stimuliresponsiveness are a good model for natural tissue ${ }^{152,153}$. To resemble the ECM physical properties (elasticity, stiffnes), the nano-topography and the presence of signaling molecules, protease active and adhesion sites. For the generation of hydrogels from linear ELRs, cross-linking points must be considered. They can be either of covalent or physical nature and their position along the ELR backbone can be fully controlled. Polypeptide-based block-copolypeptides for example manage to self-assemble into stable 
hydrogels ${ }^{155}$, which can be further stabilized when flanked by protein segments with coiled-coil secondary structure ${ }^{111,156}$, another approach is the incorporation of recombinant segments of elastin, silk or collagen ${ }^{157-159}$.

\subsubsection{ELRs as drug carriers}

ELRs have several advantages over other macromolecules as drug delivery carriers. They can be utilized in an active (by hyperthermia induced phase transition), or passive (by controlling the molecular weight) approach. Moreover, the recombinant nature of ELRs allows for the insertion of specific sequences that enhance tumor targeting.

It was shown that an anticancer drug that has been conjugated to an ELR is administered, and focal hyperthermia applied, the thermoresponsive properties and enhanced permeability and retention effects of the ELP facilitate drug aggregation within tumor tissues ${ }^{225}$. Further supported by studies by by Chilkoti et al. using ELRs for targeting solid tumors by applications of hyperthermia to the tumor region, demonstrating a two-fold increase in ELR accumulation within a tumor upon application of hyperthermia, as compared to treated with the ELR construct alone ${ }^{226,227}$.

This adjustable ELR accumulation rates may be exploited to reduce drug cargo doses without impairing anti-cancer efficacy. It should be noted that besides the control over accumulation rates, ELRs are eliminated more quickly and with fewer side effects from the untreated regions that have not been subjected to hyperthermia. 


\subsection{Cholesterol}

\subsubsection{Cholesterols role in cell membranes}

One of the most abundant molecules in the membrane is cholesterol, which due to the hydrophobicity lays inside the membrane. Cholesterol is responsible for membrane integrity and cellular signaling and makes up to $20 \%$ of the membrane's mass ${ }^{63}$. Cholesterol, among the many lipid constituents of mammalian cell membranes, is a key regulator of membrane fluidity and contributes to the formation of caveolae, and in maintaining caveolae microdomain ${ }^{64,65}$. Caveolae are specialized domains of the plasma membrane that are found in most cell types ${ }^{66}$. Nevertheless, they are more abundant in cells like adipocytes, endothelial cells, fibroblasts, and muscle cells ${ }^{67}$. Besides the influence of membrane fluidity, cholesterol is important for cellular structure and function, it is essential in locomotion and serves as a metabolic precursor for several signaling molecules, including oxysterols $^{68}$, steroids ${ }^{228}$ and bile acids ${ }^{65,69,70}$. The intrisc property of cholesterol to form liquid crystal like domains (lipid rafts) in the cell membrane makes cholesterol an interesting group for the interaction cholesterol modified materials with cells.

\subsubsection{Cholesterol modified materials}

A new class of materials, has been obtained by the hydrophobic modification of hydrophilic polymers with cholesteryl groups, generating polymer amphiphiles that self-assemble into nanoparticles in aqueous solutions. The underlying mechanism was described in cholesterol modified pullulan as a 
poly-core model (Figure 9), where the cholesterol groups serve as physical crosslinks leading to multiple cores stabilizing the nanoparticle ${ }^{229}$.

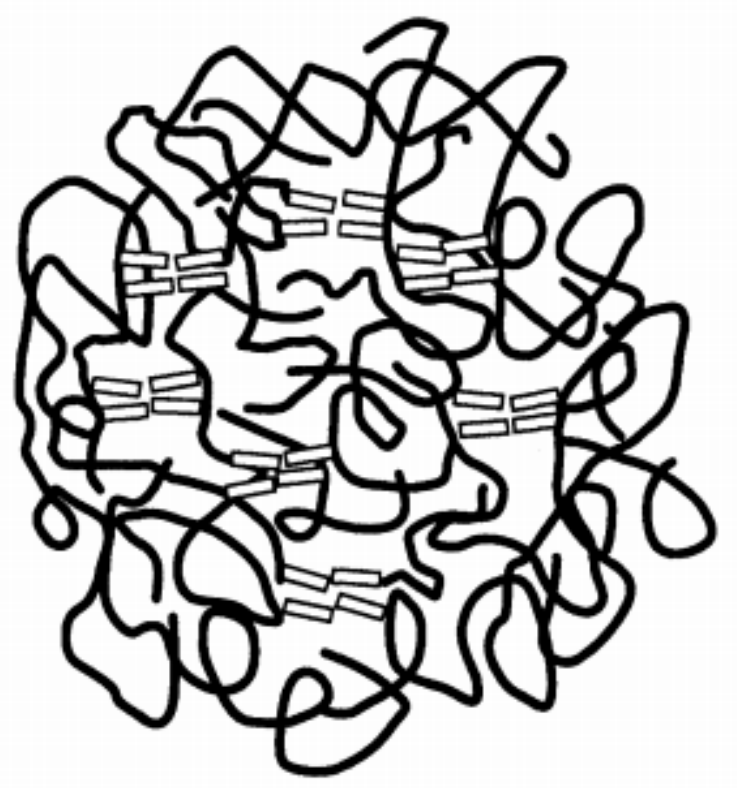

Figure 9: Schematic illustration of the poly core model for cholesteryl stabilized particles. Reproduced from ${ }^{230}$.

Other cholesterol-bearing materials that exhibit nano-aggregation into hydrogels, like pullulan 229,231 , anti-microbial peptides, or deoxycholic acid modified heparin ${ }^{232}$ and chitosan ${ }^{233}$, were described by the poly-core model $^{229}$ as self-aggregated nanoparticle forming non-covalently cross-linked supramolecular hydrogel structures mediated by hydrophobic association of cholesterol moieties. Furthermore, for temperature sensitive polymers, the characteristic temperature to cause a structural change decreased with the degree of cholesteryl substituions ${ }^{229}$. It is noteworthy, that based on the findings of Morishima et al. this effect of self-association is more probable to occur in bulky hydrophobic groups such as cholesterol or deoxycholic acid, than in long alkyl hydrocarbon chain 229,234 . 
Furthermore, cholesterol modified materials recently have been investigated as potential cell targeting and drug-delivery systems, using the affinity of cholesterol groups to cell membranes. Here the studies are ranging from cholesterol assisted DNA transfection ${ }^{235}$, the treatment of type II diabetes $^{236}$, or the targeting of cancer cells ${ }^{237}$. 


\subsection{Role of Proteases}

To understand the process of enzymatic degradation and related demands on the ELR constructs, the diversity of proteases and their role in regulation and disease will be explained in the following.

\subsubsection{Peptidase Classification}

\subsubsection{Classification}

The numerous types of proteolytic enzymes demand a system of nomenclature to facilitate better scientific communication that accelerates scientific progress. Alone the presence of a system of classification underlines the importance of a field of investigation. In the case of proteolytic enzymes, the need to distinguish between different types of proteases emerged already in the early $20^{\text {th }}$ century and since than the field is rapidly expanding due to an increase in research as well as through novel techniques that help to discover new proteases, new catalytic domains, or to discover new ways of action. In mammalian cells multiple proteolytic systems are present that serve distinct functions. These include the endosomal lysosomal system (e.g., cathepsin B, D, H, L, and other hydrolases), mitochondrial proteases and the ubiquitin-proteasome pathway. The development of a classification system that is continuously updated, helps to draw a better picture of the interactions and connections of what has already been discovered, and not least importantly to give it a name. In the following, the terminology of proteases will be briefly described ${ }^{238}$. 


\subsubsection{Terminology}

One of the first approaches to differentiate proteolytic enzymes from other enzymes was the introduction of the term proteases in the late $19^{\text {th }}$ century in Germany. Grassman and Dyckenhoff differentiated between peptidase (proteolysis of oligopeptides) and proteinases (proteolysis of bigger proteins) $)^{238}$. The term peptidase was than further specified by the finding, that the preference to hydrolyze small peptides was not driven by the size of the peptide, but by the accessibility of the $\mathrm{N}$ - or C-termini, where on the other hand some peptidase did not even require a free-termini. This led to the introduction of the prefixes endo- and exo- peptidases, where exo relates to the preferences for regions close to the protein terminus. Additionally, the term peptidase became a more general synonym for the class of proteolytic enzymes ${ }^{239}$, to account for the peptide size dependency other terms like oligopeptidases have also been suggested ${ }^{238}$. The further classification was done by moving away from the substrate as a mean for classification to the enzyme structure ${ }^{240}$. Here, the active sites of peptidases served as a mean to differentiate between peptidase classes. The active sites are commonly located in a surface groove of the enzyme, adjoined by structural domains that increase specificity, and can consist of different key amino acids, or even metal ions. Thus, the nature of the catalytic site let to peptidase specific classifications into five classes of peptidases, serine, aspartic, cysteine, threonine and metallo peptidases ${ }^{238}$. 


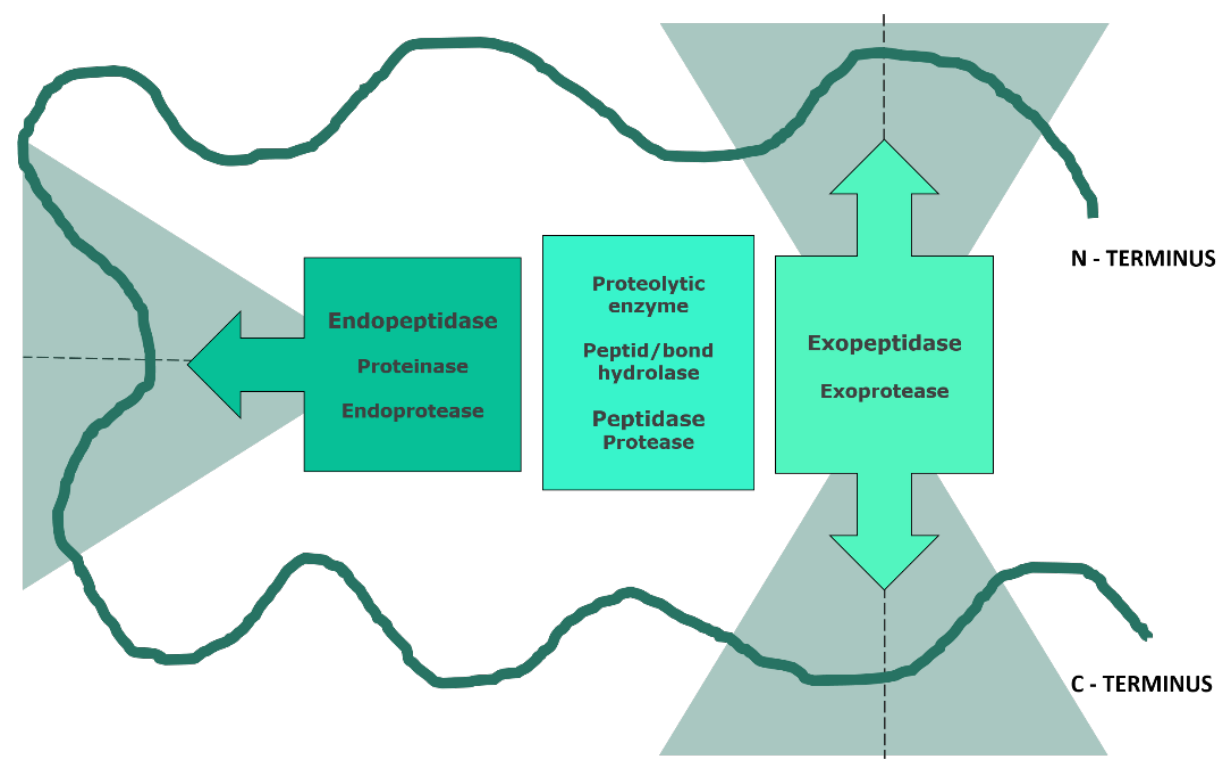

Figure 10: Synonyms of peptidases and the differences in endo- and exopeptidases. The names in the box are commonly used terms for proteolytic enzymes. The differences in endo- and exopeptidases are, that endopeptidases preferentially act away from protein termini and exopeptidases act close to the $\mathrm{C}$ - or $\mathrm{N}$-terminus (as indicated by the triangular shades) ${ }^{238}$.

Due to the numerous discoveries of new peptidases, and to avoid confusion, a systematic classification of peptidase was needed to distinguish, or group the peptidases. Thus, the enzymes were classified according to the structure of their active site in a list better known as the EC-list of peptidases ${ }^{238}$.

\subsubsection{Role of Proteases in Matrix Remodeling and Related diseases}

The dynamic equilibrium of the ECM under physiological conditions is a consequence of the balance between the regulation of synthesis and degradation of ECM components. Proteolytic enzymes are ubiquitous, being distributed in all biological fluids and tissues ${ }^{241,242}$. Peptidases are involved in a variety of processes, where tissue proteins need to be removed or remodeled. In general, peptidases accomplish two major functions, 
regulation of enzyme (including other peptidases) activation, or inactivation of specific proteins, besides their general proteolytic function. The degradative mechanisms remove denatured proteins and native proteins no longer needed by the body or cell. Both types of proteolysis are highly regulated and usually occur in response to specific extracellular signals, such as differentiation, injury, and tissue development ${ }^{22}$. An example of the tight interdependence and regulation of peptidases is the normal wound healing cascade. It begins with hemostasis and fibrin deposition, which leads to an inflammatory cell cascade, characterized by recruitment of neutrophils, macrophages and lymphocytes into the inflammatory area. At this point, proteolytic substances are secreted followed by attraction and proliferation of fibroblasts and collagen deposition, and finally remodeling by collagen cross-linking and scar maturation ${ }^{243}$. The removal of old or denaturated proteins like cellular debris, fibrous tissue, blood clots, or ECM proteins that have to be rearranged in the regeneration process is mainly done by peptidases. The peptidases involved in tissue regeneration can be subdivided into four classes: aspartic peptidases, serine peptidases, cysteine peptidases and matrix metallopeptidases (MMPs). Generally, the peptidases are secreted in a non-active form, which is activated by peptidase mediated cleavage. A scheme for the interdependence of peptidases is given in Figure II. 


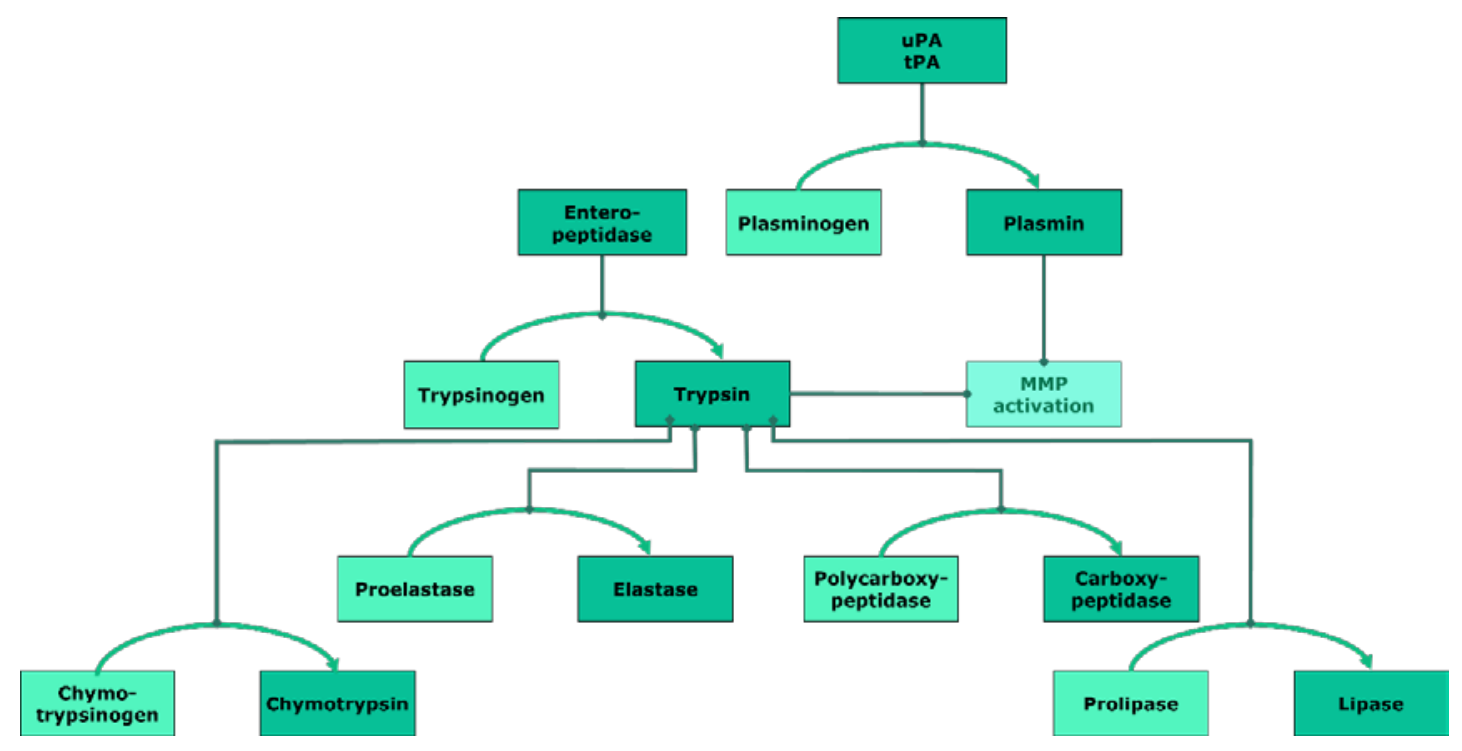

Figure I I: Cascade of peptidase pro-form activations by peptidase mediated cleavage ${ }^{244}$.

The inactive precursor of a peptidase that is activated by proteolytic cleavage, is called zymogen, or proenzyme. In contrast to phosphorylation phenomena, no energy source is needed, and activation can also occur extracellularly, it is noteworthy, that this form of activation is irreversible, the enzyme might be deactivated by other mechanisms, but cannot return to its initial uncleaved form ${ }^{244}$. Besides the secretion in a non-active form, there are several other regulatory functions in tissue, to avoid the false activity of peptidases. The coordinated control of ECM degradation on the cell surface involves three crucial elements: secreted proteases and their inhibitors, surface protease receptors and integral membrane proteases ${ }^{245}$. The very prominent role in regulation play inhibitors of peptidases, which are derived from plasma, or cells in the tissues. About $10 \%$ of the proteins in plasma are peptidase inhibitors, which are in general class specific, besides $\alpha 2$ macroglobulin, an inhibitor capable to act across the peptidase classes. The balance between peptidase and their inhibitors depends on several factors, including production rates of proteinases and inhibitors, and their 
secretion. Production levels of the proteinases and inhibitors within the cells are controlled mainly by their gene expression.

Activation processes of proMMPs and membrane anchoring of their activities have been established by extensive experimental work. The presence of plasminogen activator (PA) inhibitors in the ECM is supposed to influence the extent of local PA and plasmin-mediated proteolysis. It was found, that the PA inhibitor is homogeneously distributed under fibroblast and fibrosarcoma cells ${ }^{246,247}$ and closely associated with the pericellular space of endothelial cells ${ }^{248-250}$, controlling the remodeling of the membrane locally.

\subsubsection{Serine Proteases}

Serine peptidases induce hydrolysis of peptides via a serine group; they include the largest number of peptidases. The main ECM degrading proteases include neutrophil derived elastase, cathepsin G, proteinase 3, plasma derived plasminogen, kallikrein, and the plasmin and plasminogen activators like tissue-type plasmin activator (tPA) and urokinase-type plasminogen activator (UPA). The role of these proteases is best studied in endothelial cells, fibroblasts, chondrocytes or tumor cells ${ }^{243}$. Plasmin activators are secreted immediately after synthesis, thus the enzymes are found to be extracellular ${ }^{251}$. The synthesize occurs in the liver and is secreted to the plasma, due to the binding capacity to cells, proximity related to local control of cellular response can be exerted ${ }^{252,253}$. tPA and uPA play a key role in the activation of plasminogens for fibrinolysis and tPA in particular induce clearance fibrin from the blood and blood clots ${ }^{254}$. Serine proteases are crucial for a cascade of zymogen conversions, in which the activated form of one clotting factor catalyzes the activation of the next 
precursor (compare Figure II proenzymes). One of the most studied zymogens is fibrinogen and its role in blood clotting. Fibrinogen is a highly soluble molecule in the plasma, and is converted into the insoluble fibrin by the hydrolysis of several arginine bonds causing its precipitation in the final step of blood clotting, a process which is induced by the serine proteases thrombin. As well as being responsible for the clotting of blood, serine proteases are also involved in the lysis of the blood clots and the remodeling, mediated by uPA and tPA plasminogen activation. Although zymogen activation is irreversible, specific inhibitors like anti-thrombin III function as modulators of peptidase activity ${ }^{244}$. Plasmin can degrade most of the matrix components laminin, fibronectin, and possibly type $\vee$ collagen $)^{255,256}$, but not types I, II, and III collagens. Thus, serine proteases are partly complementary to collagenases (MMPI, 8, I3). Elastase and cathepsin $\mathrm{G}$ are capable of elastin cleavage and cleave the telopeptide region of fibrillar collagen (types I, II, III, IV, VI, VIII, IX, X, and XI). Moreover, they can degrade ECM components such as fibronectin, laminin, and aggrecan. It was further reported, that serine proteases play a role in the activation of latent collagenases and other MMPs and thereby participate in the complete degradation of ECM ${ }^{257-260}$, as well as in the inactivation of peptidase inhibitors like $\alpha 2$ antiplasmin, $\alpha$ I antichymotrypsin, and tissue inhibitors of metalloproteinases (TIMPs) ${ }^{261,262}$.

\subsubsection{MMPs}

The second largest group of peptidases involved in tissue remodeling are MMPs; MMPs degrade most of the components of the ECM, like collagen, gelatin, aggrecan, tenascin, fibrinogen, elastin, laminin, osteonectin, or fibrin. MMPs possess several common characteristics: they are secreted in a latent form and require activation for proteolytic activity, they contain a heavy 
metal ion, and require $\mathrm{Ca}^{2+}$ for proteolytic activity, they degrade ECM components, and are a target to TIMPs ${ }^{262,263}$. Most secreted-type MMPs, including collagenases, gelatinases, and stromelysins, are composed of three basic domains; a propeptide, a catalytic domain, and a hemopexin-like domain, with a prepended hydrophobic signal domain. The propeptide domain includes a free cysteine that occupies a coordination spot on the zinc atom, hampering the catalytic hydrolysis of peptides. The propetide region is a target to other peptidases, by hydrolysis/activation of the propetide, the active site is released from the cysteine and fully functional. The catalytic domain includes the metal ion (mainly zinc) complexed by a histidine containing sequence. C-terminal hemopexin-like domain, interacts with ECM components via a proline-rich hinge region, and determines the MMPs substrate specifity. In the process of collagen remodeling, peptidases like collagenases (MMPI, 8, 13) are crucial for the degradation of the collagen. Collagenases are enzymes that are secreted by fibroblasts, neutrophils, or macrophages ${ }^{264,265}$, and that clip the collagen molecule at a specific site. The activated collagenases specifically degrade the native triple helix of type I, II or III collagen, by making a single, sequence-specific ${ }^{266}$. The action of the collagenase on collagen further results in "unwinding" of the helical structure to produce a molecule that is now susceptible to proteolytic cleavage by other proteinases and gelatinases ${ }^{243,267}$. ECM molecules like Proteoglycans, laminin and fibronectin are more susceptible to stromelysin (MMP3; MMPI0) degradation ${ }^{268}$, but stromelysins are less capable of degrading type IV collagen and elastin. Moreover, MMPs are involved in the regulation of actin microfilament system ${ }^{269}$ and in lung remodeling (MMP9) ${ }^{270}$. Some MMPs are anchored to the membrane of cells, allowing for cell-directed cleavage of ECM. These MMPs located in the cell membrane differ in their c-terminal anchorage region, and can be classified into three groups: glycophosphatidylinositol (GPI) - linked MMPs; 
transmembrane-type I; and type 2 MMPs. Type I transmembrane-type MMPs (MTx-MMPs) include MMP-14-16 $6^{271,272}$ and MMP-24 ${ }^{273}$, capable of degrading collagens, gelatins, aggrecans, FN, Ln, fibrin, tenascin, nidogens, and proteoglycans ${ }^{274-277}$. GPI linked MMPs include MMP-I7 and MMP-25, involved in the degradation of gelatin and fibrin/fibrinogen ${ }^{278,279}$. So far just one type-2 transmembrane type MMP has been discovered, MMP23, which is expressed in reproducible organs of males and females, but the exact function remains to be discovered ${ }^{280,281}$.

\subsubsection{Cleavable peptide bonds}

Current research in tissue engineering materials is challenged by a paucity of renewable sources, which include functional and immunologically compatible cells; appropriate biomaterials with desired mechanical, chemical and biological properties; and the inability to generate, vascularized tissues $^{282}$. In the past ten years, the field has advanced tremendously catalyzed by the achievments in the related fields of biology, material science, chemistry and engineering. The lack of immunologically compatible cells might be covered by the discovery of induced pluripotent stem cells (iPSCs), paving the way for more sophisticated applications in personalized medicine ${ }^{283,284}$.

Research has begun in detecting the proteolytic sequences in natural proteins, especially in ECM proteins. These groups were the first candidates for tissue engineering construct, by using short specific peptides as crosslinkers of natural or synthetic hydrogels. More recently, peptide libraries were designed to discover new proteolytic groups that were not or not yet found in natural proteins. The specificity of cleavage is mainly focused on the detection and or the targeted delivery of drugs in cancer, 
but can also be used for the targeted degradation and more specific regeneration of tissue engineering constructs. The number of proteolytic groups is steadily increasing, thus is their use for degradable hydrogels.

A simple one component synthetic polymers might be the material of choice in terms of mechanical stability, and emerging techniques such as spatial patterning ${ }^{285,286}$, two-photon polymerization ${ }^{287}, 3 \mathrm{D}$ printing ${ }^{288-295}$, programmed self-assembly ${ }^{296,297}$ overcome the lack of defined sub micro structures in synthetic polymers. These techniques allow the generation of complex biological structures with integrated vasculature and multiple cells or extracellular matrix (ECM) types at high spatial resolution. The material stiffness in TE targets several key functions, such as stem cell differentiation, enabling new ways of controlling cell phenotypes using physical cues ${ }^{298-300}$. The limitations of synthetic polymers are mainly related to the lack of biochemical cues like growth factors and cytokines to be presented with improved bioavailability and bioactivity ${ }^{301,302}$.

The mimicking of the extracellular matrix, with all its mechanical and biological complexities, also demands proteolytically cleavable segments ${ }^{303,304}$. To be effective mimics of extracellular matrix molecules like fibrin and collagen, an artificial extracellular matrix analogue would have to be proteolytically degradable, just like the natural extracellular matrix ${ }^{305,306}$. Here the kinetics of degradation depends on the application, e.g. the release of small and large molecules in targeted treatments demands a degradation rate that fosters the controlled release and diffusion of the molecules, whereas encapsulation for immunoisolation of cells ideally does not degrade. In tissue regeneration application the rate of degradation should match the neo tissue formation rate ${ }^{307}$.

Further challenges involving the design of future hydrogels are related to the understanding of the foreign bodies and the body's immune surveillance 
system $^{282,308,309}$. By now biomaterials are designed to be invisible for the immune system or to induce a weak inflammatory response to initiate the regeneration cascades. A better understanding of the body's immune system might enable further cues triggering the immune system for more controlled regeneration.

\subsubsection{Involvement of Peptidase in tissue regeneration}

The general role of peptidases in protein degradation, is crucial for tissue regeneration. Peptidases are especially involved in vascularization, osteogenesis, neurogenesis and wound healing.

\subsubsection{Vascularization}

Vascularization is crucial for all types of tissues and blood vessels are needed for the supply with nutrients. Peptidases might not be the key player in vascularization, but they complete the complex event cascades new blood vessel generation. Growth factors (GFs) like aFGF, bFGF, VEGF, TGFs are important for the cellular signaling related to vascularization, but there is also a need for proteases, that degrade and penetrate the ECM, for the invasion of blood vessels into the tissue. It has been shown, that the presence of growth factors affects the peptidase expression of endothelial cells in vitro, raising the issue of their importancs in vascularization. The cells responded to bFGF with an increased synthesis of uPA and collagenases ${ }^{310}$ 312. Further, it was shown, that endothelial cells invade ECM proteins like fibrin and type I collagen in the presence of tPA, resulting in blood vessellike tubes ${ }^{313,314}$, accompanied by increased collagenases (type I and IV), PA, 
and stromelysin activity ${ }^{310,311,315,316}$. Even though the MMPs are secreted in their latent form, their activity is regulated by the plasmin activation, which itself has been activated by the coordinately secreted serine proteases like UPA and tPA. The interdependency of peptidases-mediated vasculatization in the signaling cascade is highly controlled and further self-regulated by the presence of several peptidase inhibitors. The main inhibitiors synthesized by endothelial cells are plasminogen activator inhibitor-I (PAI-I) ${ }^{310,317}$, and tissue inhibitors of metalloproteinases TIMPs ${ }^{315}$, which directly target plasminogen activators (uPA, tPA), and MMPs (collagenases and stromelysin). The mechanisms of peptidase activation and inhibition are most likely controlled by the localization of peptidases and inhibitors. Peptidases are frequently cell surface associated, whereas TIMP is secreted to interstitial fluids and PAI-I is secreted to the ECM.

It has been proposed that the localization of proteases to cell surfaces may provide several advantages for more invasive neovascularization, including concentrations of proenzyme and activator enzymes. It is supposed, that the rate of enzyme activation is enhanced, by the protection from inactivation by secreted or ECM-associated inhibitors, giving regional specifity to enzymatic activity, directing proteolysis and angiogenesis ${ }^{310}$.

\subsubsection{Osteogenesis}

The regulation of matrix (re)modeling and degradation, by growth factors and peptidases is essential in bone development. Intramembranous and endochondral bone formed during embryogenesis, is subsequently remodeled in response to use, stress, or injury. Similar to vascularization events, a cascade of complex processes is involved, which include matrix deposition and resorption, cell recruitment and differentiation and related 
expression of signaling molecules and proteases. Growth factors of the TGFb family play a pivotal role in the regulation of bone matrix synthesis and degradation, as well as bone morphogenic proteins (BMPs), crucial for the formation of new, and the remodeling of the existing bone. The complexity of the process is troublesome. The identification of cell types and their function is complicated by differentiation events, and the interpretation of obtained in vivo results, aggravated by simultaneously occurring processes like angiogenesis and hematopoiesis ${ }^{267}$.

The peptidases for bone remodeling are mediated by osteoblasts, which are the major source of bone collagenase, as has been shown by biochemical and immunohistochemical studies. Osteotrophic hormones such as parathyroid hormone (PTH) stimulate osteoblasts to produce procollagenase, PA, and TIMP and TGF-b ${ }^{318}$. TGF-b might stimulate the osteoblasts to produce type I collagen and fibronectin, and the parallel secretion of TIMP may prevent the collagenase mediatated degradation of newly synthesized matrix components ${ }^{267}$. PTH, which also stimulates PA accumulation in cultured osteoblasts ${ }^{319}$, may provide the means of activating collagenase in the resorption of bone. TGF-b and PA, may therefore also mediate the release of procollagenase from mineralized bone matrix and its conversion to an active form. Some of the TGF-b may remain latent and subsequently be released or incorporated in the remodeling process. The remodeling is induced by osteoclasts, they locally acidify the environment and secrete enzymes, TGF-b and PA. Thus, osteoblasts might be potentially stimulated by TGF-b released either from osteoclasts, or from the degraded bone matrix, and consequently release collagenases. The released collagenases can be activated by osteoclast derived PA, as a consequence bone resorption and synthesis a coupled in a feedback loop. 


\subsubsection{Neurogenesis}

In neurogenesis, neurite protrusion happens in a back-and-forth motion, making temporal contacts with ECM components. A similar process is observed in tumor cell invasion, where peptidases are involved, suggesting, that peptidases are most likely of general importance for the neurite outgrowth as well. This is corroborated by the fact, that approximately $50 \%$ of the neurons in the dorsal root ganglion secrete PA, with increased concentration at the growth cones ${ }^{320}$. The peptidase activity in the growth cone has been shown to be mediated by calcium ions ${ }^{321}$. Furthermore, the plasmin activated by PAs induces peptidase (MMPs, serinepeptidases) mediated degradation of the growth cone surrounding tissues. The dependence of neurite growth to ECM adhesion is supposed to be dependent on serine protease-like inhibitors, that are secreated by glial cells. The so called glia-derived nexin inactivates PA and thrombin ${ }^{322,323}$, which could stabilize the interaction of the growth cone with the ECM, resulting in an increasing neurite length.

\subsubsection{Muscle injury}

In muscle injury, neutrophils and their secreted proteases are involved in the degradation, of debris and peptides. Their key function is phagocytosis and degradation of proteins, debris and foreign organisms, such as bacteria. This happens through the activation of peptidases and other antibiotic molecules, as well as the generation of toxic oxygen radicals. The neutrophil invasion is related to muscle usage ${ }^{324,325}$, the neutrophils are supposed to be phagocytic ${ }^{326}$, helping to degrade cellular debris, and other muscle damage related proteins ${ }^{327}$. Besides excessive use and injury, inflammation or 
immune response in tissues can also be caused by phagocytosis-associated events. Phagocytosis results in a respiratory burst, and release of oxygen metabolites, accompanied by the secretion of peptidases and cationic proteins ${ }^{327328}$. The liberated hydrogen peroxides are transformed into hypoclorous acid by myeloperoxidase (MPO) which reduces the hydroxyl radical concentration ${ }^{329}$, MPO activity is elevated by muscle usage ${ }^{324}$. Oxidant production and proteasemediation are equally crucial, proven by an increased susceptibility to infection in NADPH oxidase or elastase and cathepsin $G$ deficient mice. It is believed that superoxide production in phagocytosis indirectly promotes protease function due to $\mathrm{pH}$ increase and liberation of cationic proteases from anionic proteoglycan matrix to degrade bacteria $^{330,331}$. It was also found, that pulmonary tissue reacts to hypoxia by an increased collagen remodeling induced by an increased collangenolytic activity $^{332}$.

\subsubsection{Disease related to peptidases}

Peptidases are involved in a variety of processes crucial for body function. Thus, their misregulation is associated with numerous diseases, making them attractive targets for inhibition. Peptidase overexpression and dysfunction are related to pathological conditions, such as cardiovascular and neurodegenerative diseases, arthritic diseases, and infection. Slight changes in expression level can cause alteration of a highly ordered and orchestrated event, such as wound healing, to a pathologic condition that leads to fibrosis or chronic ulcers ${ }^{243}$. Moreover, matrix degrading proteases like MMPs are not only crucial for the remodeling of the ECM, but also, owing to their capacity of ECM degradation, are associated with different types of tumor invasion, facilitating tumor invasion and growth ${ }^{23}$. The similiarity of the 
process of tumor invasion to that, which occurs during well-understood signaling cascade in vascularization, suggests that the proteolytic activities of endothelial cells may be related to the surrounding cells ${ }^{310}$. In fact $\mathrm{uPA}^{311}$, plasminogen, and plasmin ${ }^{333}$ have the capacity to bind to endothelial cells. Proteolytic MMP activity was found to be altered in the subventricular zone after focal stroke, and the related neurogenic migration was found to be dependent on MMPs, and MMP inhibition. It is supposed, that MMPs mediate neurovascular remodeling, and make MMP inhibitors a potential therapeutically target for the treatment of acute and chronic divergence of peptidase profiles, as well as in the post stroke treatment ${ }^{334}$. The imbalance of peptiases can also be induced by intake of the substance, as it has been shown corticosteroids that significantly increase MMP-3 activity, causing cellular apoptosis ${ }^{335}$. MMP-2 and MMP-9 are increasingly expressed in the acute lung injury and acute respiratory distress syndrome, as a consequence of the fibrotic lesions with collagen deposition that are formed ${ }^{336}$. A similar increase in peptidase activity is related to idiopathic pulmonary fibrosis, when the fibroblast activation protein activity is increasing ${ }^{337}$. Lysosomal enzyme (e.g cysteine peptidases) release and cell surface acidification are regulated events, therefore cystein peptidase dysregulation of stimulated macrophages is a cause that may contribute to injuries observed in cigarette smokers, lacking alpha-I-protease inhibitor-type emphysema ${ }^{338}$. In rheumatoid arthritis and osteoarthritis, lysosomal proteases as cathepsin $\mathrm{K}$ are believed to play a key role in bone resorption. The inactivation or deletion of the cathepsin $\mathrm{K}$, which is highly expressed by human osteoclasts $^{339}$, results in osteopetrotic phenotypes, underlying its importance in the process of bone resorption, and may also be responsible for the cartilage destruction that accompanies arthritis ${ }^{331,340}$. Also calpain type cysteine peptidases are involved in various pathologic conditions such 
as muscle dystrophy ${ }^{338}$, and membrane peptidases are involved in tumour invasion $^{245}$.

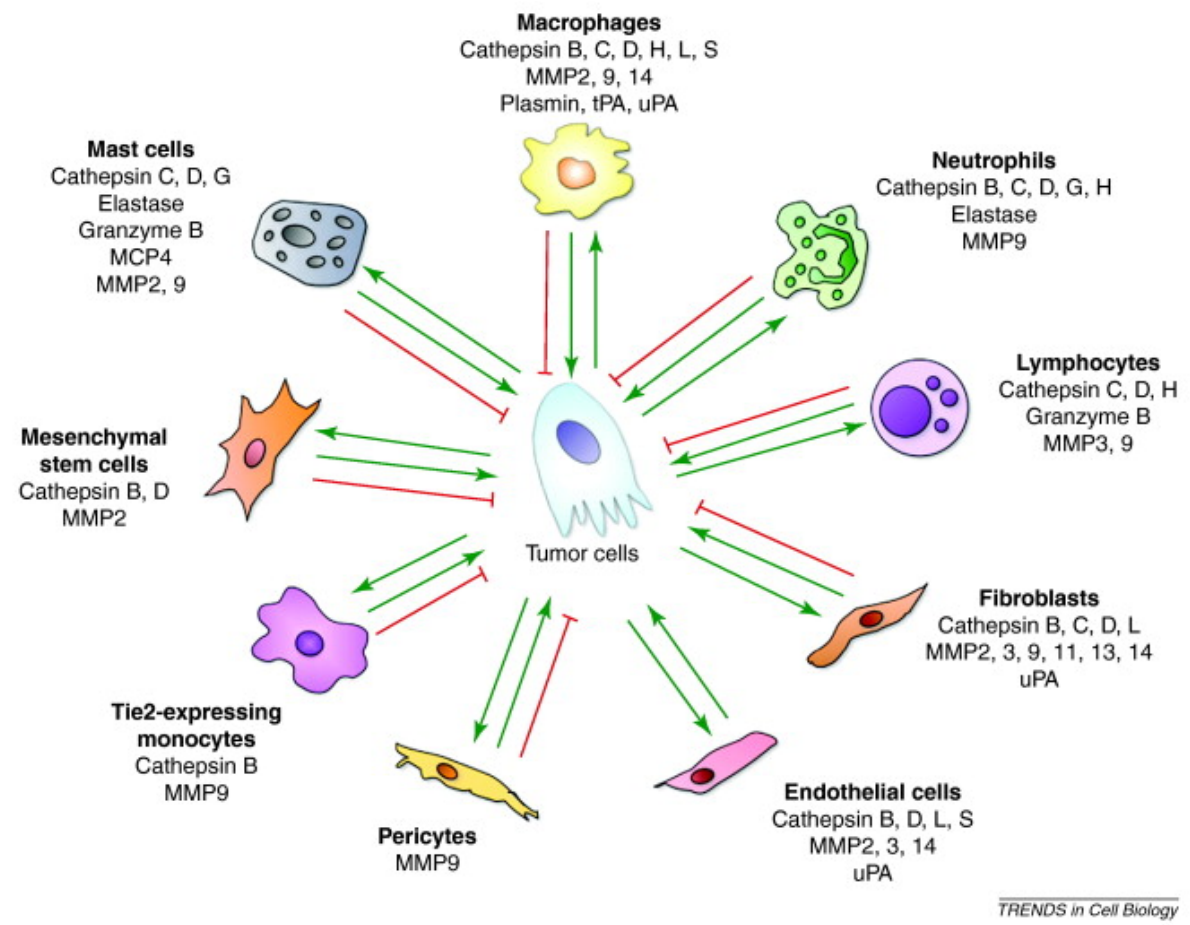

Figure 12: Peptidases expressed by cell types and their relation to tumor cells. Reproduced from ${ }^{341}$.

The numerous functions of peptidases are associated with an equal number of diseases, or dysfunctions, shifting peptidases in the scope for future therapeuctics. Especially the role of MMPs in tumor progression, growth and metastasis, raised the issue of MMP inhibitors as anti-cancer treatments

\subsubsection{Zymographic Methods of Protease Detection}

The importance of peptidase in disease like cancer, makes the a target for detection and sensing applications. Here zymographic techniques based on the detection of zymogens compose of a proteolytic target, whose 
degradation by a peptidase can be detected. The first patents regarding zymographic techniques were focused on aminopeptidase detection from serum $^{263}$, and a direct screening method evolved by the use of a hydrolytic substrate embedded in gel electrophoresis. The so called in-gel zymography (IGZ) was first introduced by Granelli-Piperno et al. in 1978 to study plasminogen activators ${ }^{24}$, and further improved by Heussen et al. by copolymerizing plasminogen and gelatin in the gel for the direct detection of plasminogen activators ${ }^{342}$. Zymography has become a standard technique for the detection of MMPs and other hydrolytic enzymes. Enzyme activities are determined based on the degradation degree of a substrate. The method requires conducting electrophoresis, and therefore it is troublesome in the procedures, and time-consuming in the detection. So far, zymographic techniques are able to detect a series of MMPs and other peptidases. Furthermore, hydrolases like: esterases ${ }^{25}$, phosphates esterases ${ }^{25,343}$, pepsin A, pepsin A/C, chymosin, thermolysin, chymotrypsin ${ }^{344}$, cysteinproteases ${ }^{345}$, sheddases $^{346,347}$, and cathepsines ${ }^{263,348}$. In the development of the method also the substrates have been varied from gelatin towards other proteolytic materials like, plasminogen, fibrin, casein, chondroitin sulfates, hyaluronan ${ }^{349-}$ ${ }^{352}$, xylans ${ }^{353}$, and zein ${ }^{354}$. Nevertheless, the majority of studies focus on gelatin as the substrate for the detection of MMP2 and or MMP9, due to the good isolation of these enzymes and their ease of detection. In in gel zymography, one drawback is the sample preparation in which tissue gets disrubted and enzymes are released, by these procedures there is a chance of colocalizing enzymes and inhibtors which would have an impact on the interpretation of the results. This drawback has been initially addressed by the immunostaining method specific to $\mathrm{MMPs}^{355}$, but these techniques lack the differentiation between the active and inactive form of the MMP, thus it is not feasible for MMP inhibitor studies. The combination of a zymographic method with tissue extracts (in-vivo zymography (IVZ)), is a zymographic 
method without electrophoretic separation, where the proteolytic activity is detected by the cleavage of substrate bound fluorescent probes (gelatin, casein, or short peptides). With IVZ real-time 3D proteolytic activity in a whole organism is quantified in small animals by the release of a fluorophor. In the early days of the technique, the substrates were not specific and could only detect broad proteolytic activities ${ }^{356-358}$. E.g. one approach used fluorescently labeled casein, gelatin or agarose as membranes, that can be applied on tissue sections, to locally access proteolytic activity. Here reproducibility issues occur, due to degradation of the substrate ${ }^{359}$. Specific FRET system, with an integrated proteolytic sequence, were used, that give fluorescent signal upon disintegration by proteolytic enzymes ${ }^{360,361}$. With an increasing number of accessible proteolytic FRET probes, more complex 3D insights are obtained, giving new insights on the role of MMPs in the development of Zebrafish, with a so called "differential IVZ"36I. It could be shown, that gelatinases are capable of degrading tumor tissues, furthermore, MMP inhibitors are able to inhibit MMP activity in human thyroid cancer ${ }^{362}$. Nevertheless, it is difficult to clinically evaluate the benefit of MMP inhibitors in cancer treatments, because the in vivo activity of MMPs is inherently controlled by endogenous inhibitors like TIMP-I and $-2^{363}$. In conventional zymography the MMP-inhibitor complex is partially dissociated during the electrophoresis, and therefore the method does not allow the exact determination of the inhibitory activity of MMP inhibitors. The method is limited by the substrate that is used, information about the presence of peptidases are lacking indications about the exact cleavage site, and the type of peptidase detected is limited to the substrate. Gelatin zymography is only detecting MMP2 and MMP9, other bands that appear in the zymogram are mainly of unkown origin, or ignored in publications. This is mainly due to the presence of a variety of possible targets in native proteins like gelatin, collagen, casein, plasminogen, fibrinogen, etc.. This leaves space for 
optimization of the existing techniques regarding sensitivity and in the numbers of potential peptidase that can be detected. When referring to the EC-list of peptidases there are more than 13 sub-groups of proteolytic enzyme classes with about 300 entries of different peptidases, all involved in the degradation of proteins ${ }^{238}$. In the scope of tissue engineering and oncology one subclass moved into the focus, which is the class of MMPs, which are known to be secreted by cancer cells or normal cells surrounding cancers. Furthermore, these class of enzymes is able to degrade extracellular matrix proteins like collagen ${ }^{282}$. Type IV collagenases (MMP2 and MMP9) have been frequently reported to be accompanied with tumor invasion, metastasis and proliferation.

Research carried out upon MMPs, increased, especially due to the relation of MMP activities in different types of cancer and diseases ${ }^{364}$, and on the other hand in tissue engineering, to introduce remodeling cues into the matrices. More recent methods and patents that involve zymographic detection are focused on the detection of certain forms of cancer (Table I). 


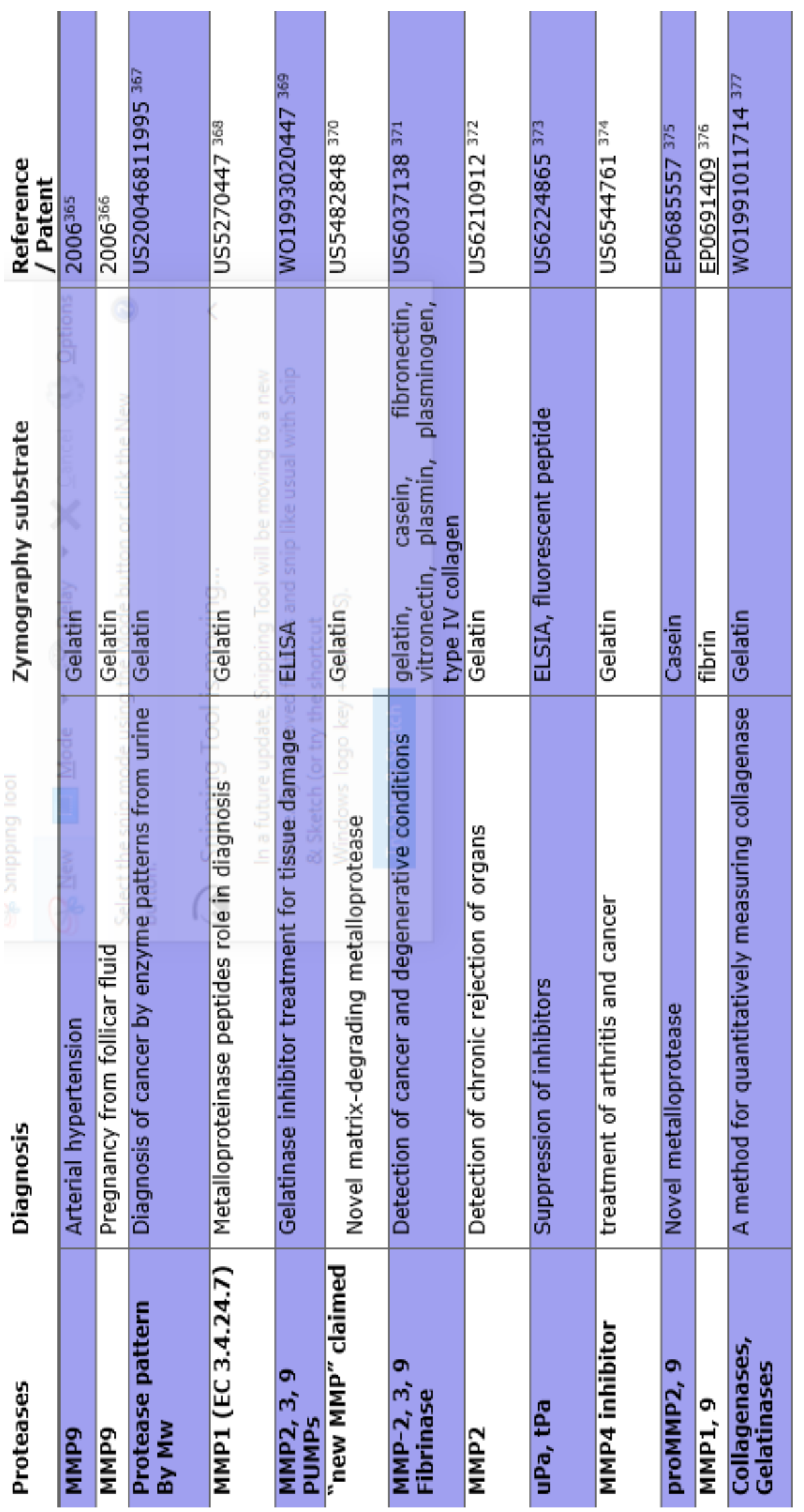




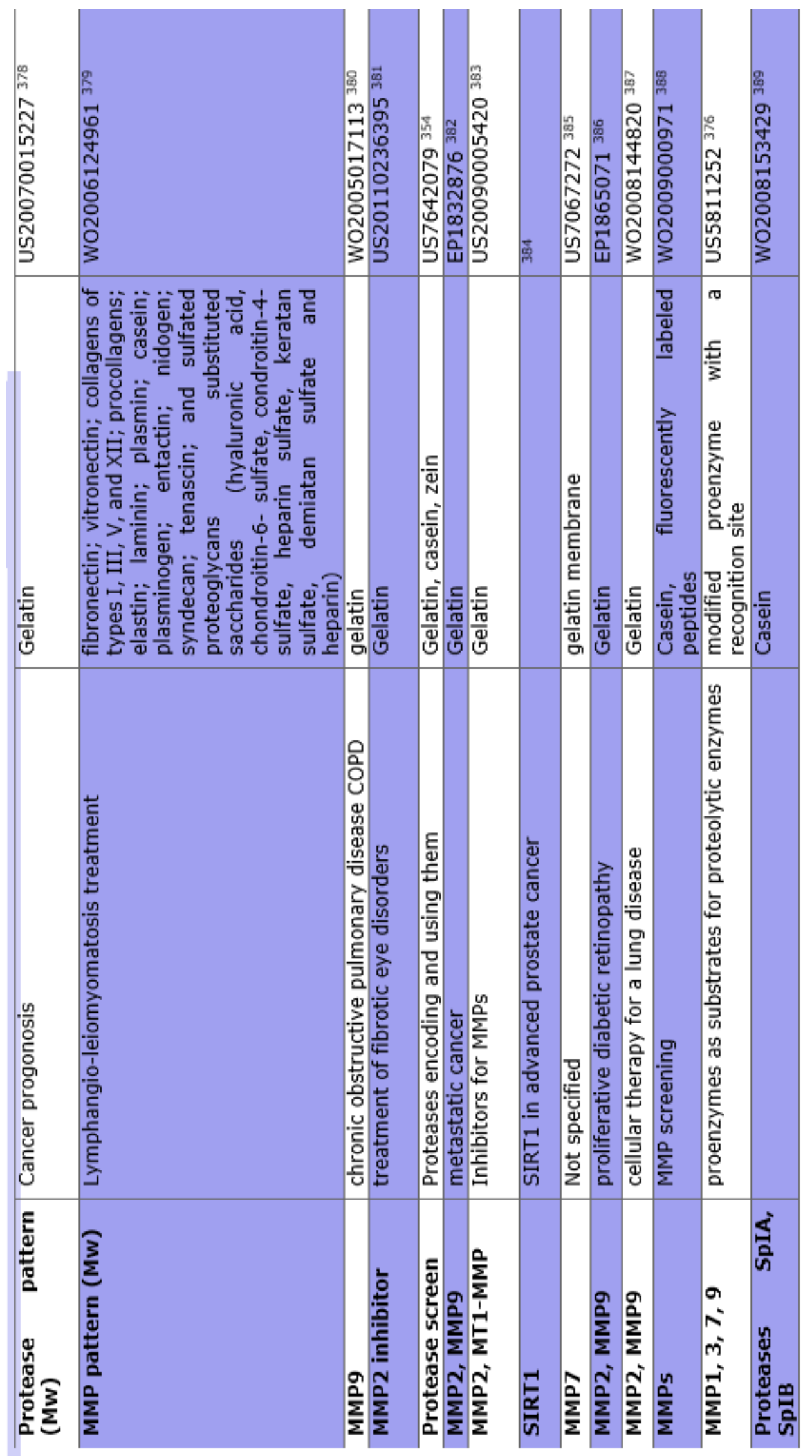



HYPOTHESIS 



\section{Hypothesis}

A. The DNA recombinant technique enables total control over the design of ELRs, further it allows for the insertion of any kind of peptidic sequence. It is hypothesized that the use of a spatial arrangement of protein sequences will allow for the enzymatic degradation of these ELRs. Additionally, it is hypothesized, that the capability of degradation is possible to be detected by a zymographic method using ELRs as a novel substrate.

B. Using ELR as a substrate for zymographic methods enables the opportunity to present only a short selective region to the enzymes. Thus it is hypothesized, that using ELRs for zymographic techniques allows for the design of a new method with potential for high throughput applications for protease detection.

C. Cholesterol modified materials have been shown to exhibit strong intermolecular interactions. It is hypothesized, that these interactions can be translated into an ELR system to generate intermolecular forces and to trigger self-assembly of ELRs.

D. Cholesterol rich ELRs are further hypothesized to enhance the interaction of ELRs with certain cell types involved in lipid uptake. This mechanism is hypothesized to assist in the coating of living cells with ELR proteins. 

MATERIAL

AND

METHODS 

3 Materials \& Methods

3.1 Materials

3.1.1 Chemical Reagents.

All reagents employed in this work are listed in Table 2.

Table 2: Reagents employed and corresponding suppliers.

\begin{tabular}{|c|c|}
\hline Reactive and Abbreviation & Supplier \\
\hline 4-Dimethylaminopyridine (DMAP) & Sigma Aldrich. \\
\hline Acetic acid & Merck. \\
\hline Acetone & Sigma Aldrich. \\
\hline Acrylamide/Bis-acrylamide & Amresco. \\
\hline Agarose seakem. & Cambrex. \\
\hline Alamar Blue & Thermofisher \\
\hline Ammonium persulphate (APS). & Sigma Aldrich. \\
\hline Ampicilin & Apollo Scientific. \\
\hline Bromophenol blue & Sigma Aldrich \\
\hline Calcium chloride $\left(\mathrm{CaCl}_{2}\right)$ & Sigma Aldrich. \\
\hline Chloridric acid & Merck. \\
\hline Coomassie Brillant-blue R-250 & Sigma Aldrich \\
\hline Diethyl ether & Scharlau. \\
\hline Dimethyl sulfoxide (DMSO) & Carlo Erba \\
\hline $\begin{array}{lll}\text { Disodium } & \text { hydrogen } \\
\left(\mathrm{Na}_{2} \mathrm{HPO}_{4}\right) & & \end{array}$ & Fluka \\
\hline Ethanol & Merck \\
\hline $\begin{array}{l}\text { Ethylenediaminetetraacetic } \\
\text { acid(EDTA) }\end{array}$ & Sigma Aldrich \\
\hline Gelatin from porcine skin & Sigma Aldrich \\
\hline Glicerol. & Merck \\
\hline Isopropanol & Invitrogen. \\
\hline Methanol. & Sigma Aldrich. \\
\hline Methacrylic anhydride & Sigma Aldrich \\
\hline $\begin{array}{l}\text { N,N'-Dicyclohexylcarbodiimide } \\
\text { (DCC) }\end{array}$ & Sigma Aldrich. \\
\hline N,N-Dimethylformamide (DMF). & Sigma Aldrich. \\
\hline
\end{tabular}




\begin{tabular}{|l|l|}
\hline $\begin{array}{l}\text { Phenylmethylsulfonyl fluoride } \\
\text { (PMSF). }\end{array}$ & Apollo. \\
\hline Phosphate buffered saline (PBS) & Gibco. \\
\hline Potassium chloride (KCI). & Sigma Aldrich. \\
\hline Sodium chloride (NaCl)- & Sigma Aldrich \\
\hline Sodium dodecyl sulfate (SDS) & Sigma Aldrich. \\
\hline Sodium hydroxide & Sigma Aldrich. \\
\hline Sodium sulfate $\left(\mathbf{N a}_{2} \mathbf{S O}_{4}\right)$ & Fluka \\
\hline $\begin{array}{l}\text { Tetramethylethylenediamine } \\
\text { (TEMED). }\end{array}$ & Sigma Aldrich. \\
\hline Triton X-100 & Merck \\
\hline $\begin{array}{l}\text { Tris(hydroxymethyl)aminomethane } \\
\text { (Tris). }\end{array}$ & Sigma Aldrich. \\
\hline Ultrapure water & Millipore \\
\hline Urea. & Fluka. \\
\hline B-Mercaptoethanol. & Merck \\
\hline
\end{tabular}

\subsubsection{Glass ware \& other materials.}

During the realization of this doctoral thesis light scattering techniques have been employed, where glass test tubes were used. Tubes were rinsed distilled water followed by a wash with a mixture of soap-water (Hellmanex ${ }^{\circledR}$ II special for optical cleaning). To remove soap traces the tubes are extensively washed with water. Finally, the tubes are dry in an oven at $60^{\circ}$ $C$ for 6 hours.

Other glass materials after washing and rinsing several times with distilled water were sterilized on an autoclave (Autester E-75). Other laboratory materials like tips, conical tubes, Eppendorf tubes, etc., are bought sterile or are sterilized when needed on an autoclave (Autotester E-75, 20 minutes $120^{\circ} \mathrm{C}$ one atmosphere).

3.1.3 Molecular biology materials. 


\subsubsection{Restriction enzymes.}

Table 3: Restriction enzymes used in this work and corresponding suppliers.

Restriction enzyme

\section{BamHI}

Dpnl

Earl

EcoRI

Sapl

Xhol

Eaml I04I (Earl)

\section{Supplier}

New England Biolabs

The restriction enzymes used in this work are listed below:

BamHI, Dpnl, Earl, EcoRI, Sapl, Xhol (New England Biolabs).

Eam I I04I (further refered to as Earl) (Fermentas).

All enzymes are used according to the manufacturer's instructions.

\subsubsection{Other enzymes}

During the realization of this work the following enzymes have been employed:

T4 DNA Ligase, Shrimp alkaline phosphatase (S.A.P.), Antartic alkaline phosphatase (New England Biolabs.), Trypsin (Corning), Trypsin (Gibco), Recombinant Human MMP-I (90I-MP-0I0), MMP-7 (907-MP-0I0), MMP8(908-MP-0I), MMP-IO (9I0-MP-0 I0), MMP-II (9I0-MP-0II), MMP-BMLSE360I 2 (9I7-MPB-020), MMP-I4 (9I8-MP-0I0), MMP-I5 (9l6-MP-0I0), MMP-I6 (I785-MP-0I0), MMP-I7 (7796-MP-0I0) (all R\&D Systems, UK); 
MMP-2 (BML-SE237), MMP-9 (BML-SE360), MMP-I 3 (BML-SE246) (all enzo lifescience, Germany), MMP-I 9 (G04MPI9C), MMP-20 (G04MP20C) (Giotti Pharmaceuticals).

\subsubsection{Cloning and expressing vectors}

The DNA fragments employed were cloned in the pDrive cloning vector (Qiagen), Figure 13. 
pDrive Cloning Vector

\section{Positions of various elements}

\begin{tabular}{lr}
\hline Vector size (bp) & 3851 \\
Multiple cloning site & $266-393$ \\
LacZ $\alpha$-peptide & $216-593$ \\
T7 RNA polymerase promoter & $239-258$ \\
T7 transcription start & 256 \\
SP6 RNA polymerase promoter & $398-417$ \\
SP6 transcription start & 400 \\
Ampicillin resistance gene & $1175-2032$ \\
Kanamycin resistance gene & $2181-2993$ \\
pUC origin & 3668 \\
Phage fl origin & $588-1043$ \\
Primer binding sites: ${ }^{*}$ & \\
M13 forward (-20) & $431-447$ \\
M13 forward (-40) & $451-467$ \\
M13 reverse & $209-224$ \\
T7 promoter primer & $239-258$ \\
SP6 promoter primer & $400-418$
\end{tabular}

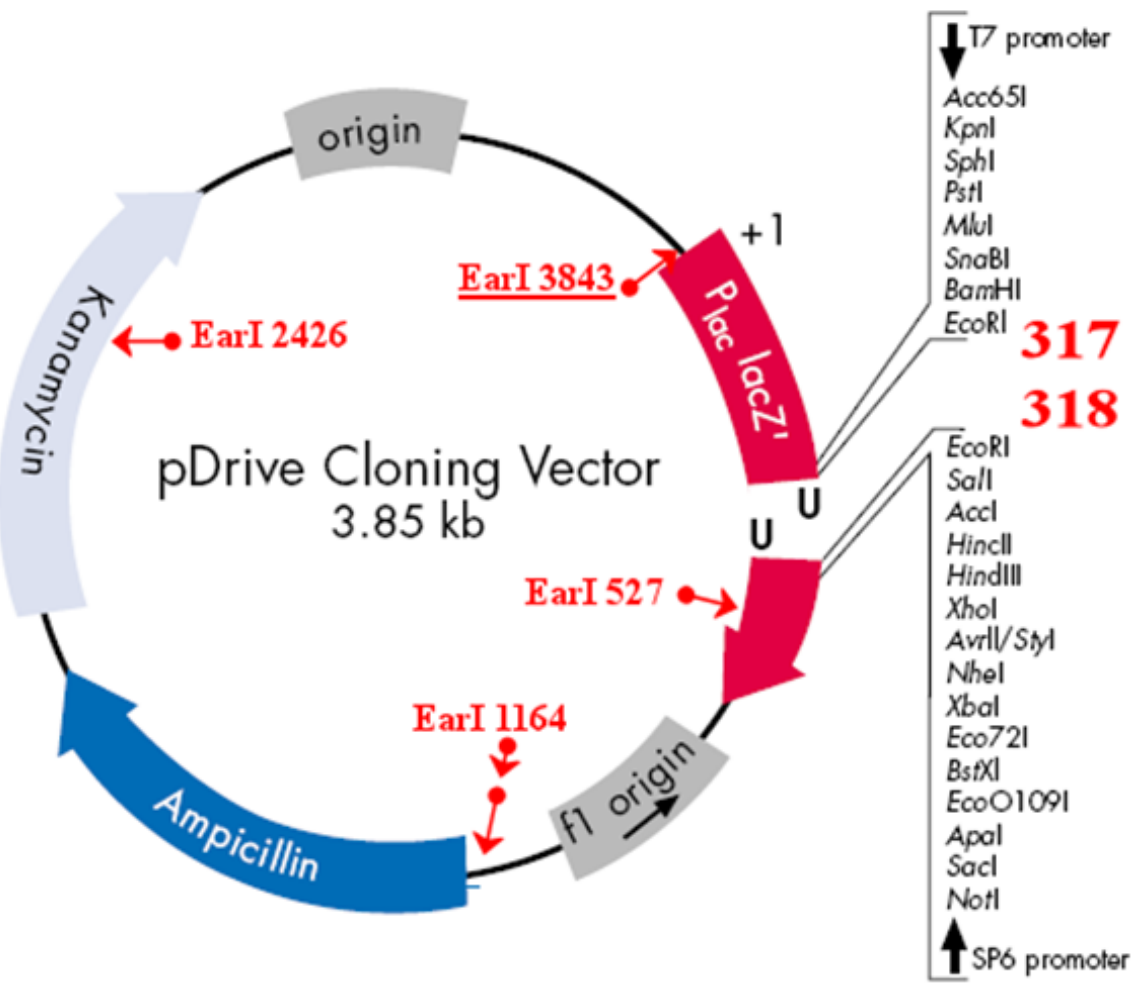

Figure 13: Scheme of the pDrive cloning vector with mapped restriction sites. 
For the expression of the different recombinant polimers a p7 expression vector has been employed (Figure 14). The p7 expression vector was constructed in our laboratory from Novagen's PET-25b (+) vector, by Dr. A. Girotti.
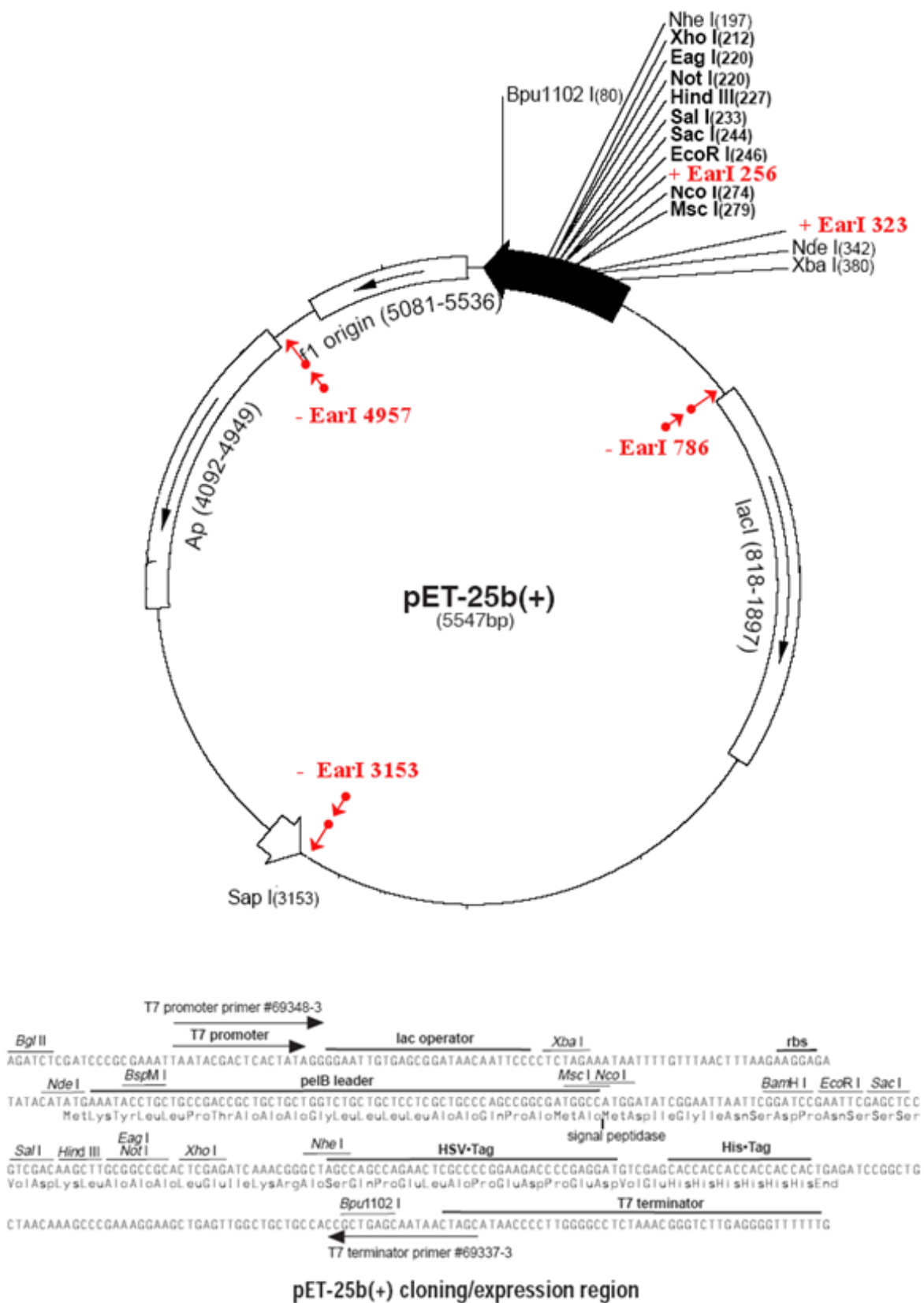

Figure 14: Scheme of p7expression vector based on Navagen's pET-25b(+) vector. 
3.1.4 Other reagents

Table 4: Other reagents used for this work.

Reagent

Supplier

Quantm Prep Plasmid Thermo Fisher

Miniprep Kit

QIAquick Gel Extraction Kit Qiagen

Protocol

3.1.5 Bacterial Strain

Table 5:Bacterial strains used for this work.

\begin{tabular}{|l|l|}
\hline E. coli strain & Supplier \\
\hline XLI-Blue & (Stratagene) \\
\hline BL2I(DE3) Star & (Invitrogen) \\
\hline BLR(DE3) & (Novagen) \\
\hline
\end{tabular}

3.1.6 Bacterial culture media

The culture media used for bacteria growth and transformation are listed below:

Luria-Broth (LB) (Pronadisa): Concentration 25g/l.

Terrific Broth (TB)(Formedium): $55.85 \mathrm{~g} / \mathrm{l}+8 \mathrm{ml} / /$ Glicerol.

LB-Agar: LB 25 g/l + I.5 \% (p/v). Agar (Fluka).

SOC I. (Sigma Aldrich)

\subsubsection{Buffers}


During the performance of the work presented on this thesis different buffers were employed:

PBS (pH=7,4): 5mM Na2HPO4 pH=7,4, NaCl $140 \mathrm{mM}$

TAE: 40 mM Tris-acetate, ImM pH=8 EDTA

TE (sonication buffer): $10 \mathrm{mM} \mathrm{pH} 8$ Tris-base, I mM pH=8 EDTA, ImM PMSF.

TBS (washing buffer) :20 mM pH 8 Tris-base, $140 \mathrm{mM} \mathrm{NaCl}$.

Running buffer: Tris-base $25 \mathrm{mM}$ pH=8,3, glicina $192 \mathrm{mM}$ y SDS 0, 1\% $(w / v)$.

DNA loading buffer: $30 \%(\mathrm{v} / \mathrm{v})$ glycerol, $0.1 \%(\mathrm{w} / \mathrm{v})$ SDS, $0.05 \%(\mathrm{w} / \mathrm{v})$ bromophenol blue (BPB), 50mM Tris $\mathrm{pH} 8,0.05 \mathrm{mM}$ EDTA

Protein loading buffer: Tris IMpH $6.5312 .5 \mathrm{mM}$, SDS 10\%(w/v), Glycerol ( v/v), $\beta$-Mercaptoethanol 25\%(v/v), bromophenol blue (BPB) $2 \%(v / v)$.

All the solutions were prepared using ultrapure ultrapure water (Millipore)

\subsubsection{Elastin-like recombinamers}

All the elastin-like recombinamers (ELRs) employed in the development of this work have been synthesized in our laboratory (Grupo Bioforge) by DNA recombinant techniques. Those recombinamers listed in bold in .

Table 6 were specifically designed and produced for the realization of this thesis. They were produced by Escherichia Coli fermentation and purified 
taking advantage of both the smart nature and the reversible thermodependent segregation showed by this kind of materials, by inverse transition cycling (ITC).

The recombinamers employed, the abbreviation, molecular weight $(\mathrm{Mw})$, and amino acid sequence are shown in .

Table 6: Composition and molecular weight of the ELbcRs and ELRs employed.

\begin{tabular}{|c|c|c|}
\hline Abbreviation & Amino-acid sequence & $M_{w}(D a)$ \\
\hline VKV & $\begin{array}{lll}\text { MESLLP } \quad\left(\left((V P G V G)_{2}\right.\right. & \text { VPGKG } \\
\left.(\mathrm{VPGVG})_{2}\right)_{24} \mathrm{~V} & \end{array}$ & \\
\hline IK (ELR-Control) & $\begin{array}{l}\text { MESLLP } \quad\left(\left((\mathrm{VPGIG})_{2} \quad \text { VPGKG }\right.\right. \\
\left.(\mathrm{VPGIG})_{2}\right)_{24} \mathrm{~V}\end{array}$ & 51969 \\
\hline $\begin{array}{l}\text { IKHEX (ELR- } \\
\text { ElaI) }\end{array}$ & $\begin{array}{l}\text { MESLLP } \quad\left((\text { VPGIG })_{2} \quad \text { VPGKG }\right. \\
\left.\left.(\text { VPGIG })_{2}\right)_{2}(\text { VGVAPG })_{3}\right)_{10} \text { V }\end{array}$ & 57856 \\
\hline PITI (ELR-Ela I+FN) & $\begin{array}{l}\text { MESLLP }\left((\text { VPGIG })_{2} \text { VPGKG (VPGIG }\right)_{2} \\
\text { EEIQIGHIPREDVDYHLYP } \quad(\text { VPGIG })_{2} \\
\left.\text { VPGKG }(\text { VPGIG })_{2}(\text { VGVAPG })_{3}\right)_{10} \mathrm{~V}\end{array}$ & 80911 \\
\hline PIT2 (ELR-FN) & $\begin{array}{l}\text { MESLLP }\left((\text { VPGIG })_{2} \text { VPGKG (VPGIG }\right)_{2} \\
\text { EEIQIGHIPREDVDYHLYP } \\
\left.\text { VPGKG }(\text { VPGIG })_{2}\right)_{10} \mathrm{~V}\end{array}$ & 66494 \\
\hline
\end{tabular}




\subsubsection{Cell lines and culture conditions}

Human umbilical vein endothelial cells (HUVECs, cc-2517) were purchased from Lonza (Lonza, Europe). Human aortic smooth muscle cells (HASMC, ref. CRL-1999) were purchased from the American Type Culture Collection (ATCC, USA).

\subsubsection{Culture Media and Buffers}

Dulbecco's Modified Eagle Medium, Medium 23I, and smooth muscle growth supplement (SGMS) were purchased from Thermo Fisher Scientific, fetal bovine serum (FBS), penicillin streptomycin solution(P/S), trypsinEDTA, DPBS, and Alamar Blue ${ }^{\circledR}$ were supplied by Invitrogen (USA), endothelial growth medium (EGM-2) was purchased from Lonza (Lonza, Europe). 


\subsection{Methods}

\subsubsection{DNA agarose gel electrophoresis}

DNA agarose gel electrophoresis is used to separate and check the appearance and size of DNA fragments form either a plasmid or from enzymatic digestion with endonucleases. Different concentrations (in Ix TAE), are applied according to the sizes of the DNA fragments and the kind of gel, analytical or preparative.

The agarose is completely dissolved in hot water $\left(70-90^{\circ} \mathrm{C}\right)$. After cooling down to $60^{\circ} \mathrm{C}$ the gel is casted in a horizontal tray with the desired comb.

0.20 volumes of $5 x$ loading buffer are added to the samples. A fixed voltage, between 2 and $7 \mathrm{~V} / \mathrm{cm}$ - according to each sample, is then applied. The electrophoresis is run having as references the color markers (Table 7). Last, the gel is stained for 10 to 30 minutes in a $1 \times$ GelRed solution, and the DNA bands are visualized by exposition to UV light in a Viber Lourmat, TFX-20M transilluminator.

Table 7: Relation of linear DNA migration with the bromophenol blue (BFB).

\begin{tabular}{|c|c|}
\hline TAE Ix -BPB & \% Agarose \\
\hline 2900 & 0.30 \\
\hline 1650 & 0.50 \\
\hline 1000 & 0.75 \\
\hline 500 & 1 \\
\hline 370 & 1.25 \\
\hline 200 & 1.75 \\
\hline 150 & 2 \\
\hline
\end{tabular}




\subsubsection{Plasmid purification}

The plasmids employed in this work were purified using "Quantum Prep Plasmid Mini, Midi o Maxiprep Kit" (Biorad) following the manufacturer's instructions. DNA was eluted with ultrapure water. For applications were higher DNA concentration is required only half of the recommended elution volume is used and the elution water is used at $65^{\circ} \mathrm{C}$.

\subsubsection{DNA digestion with restriction enzymes}

Reaction conditions (temperature, concentration, time of reaction, buffer) for the digestion are supplied by the enzyme manufacturer. The rate of digestion is followed by DNA agarose gel electrophoresis

\subsubsection{DNA dephosphorylation}

Dephosphorylation reaction conditions (temperature, time of reaction, buffer) are supplied by the phosphatase manufacturer. For the $\mathrm{p} 7$ expression vector two different consecutive phosphatases were used and the incubation time was extended to one hour.

\subsubsection{DNA separation and extraction from agarose gel}

The target DNA band is first separated and visualized in an agarose gel of an appropriated concentration and stained with RedGel, secondly, the band 
is extracted from the gel with the help of a scalpel. The minimum quantity of agarose should be cut during band extraction.

The purification of the fragment is carried out using the "QIAquick Gel Extraction Kit Protocol" (Qiagen), following the protocol indicated by the manufacturer.

\subsubsection{Ligation of genes}

The reaction ligation is carried out in a final volume of $10-12 \mu \mathrm{L}$ by mixing the insert with the vector, in a molar relation from I:I to 5:I, and T4 DNA ligase as an enzyme with its corresponding buffer following the specifications indicated by the supplier. The reaction is conducted for I hour at room temperature or for 24 hours at $4^{\circ} \mathrm{C}$.

\subsubsection{Cloning on the pDrive/ p7 vector}

The ligation reaction is interrupted by the inactivation of the T4 DNA ligase by incubation for 10 minutes at $70^{\circ} \mathrm{C}$. Once the ligation reaction is concluded, a certain quantity of it is used to transform competent cell as specified below.

3.2.8 Transformation of competent cells

3.2.8.1 Transformation of XL1 blue subcloning grade competent cells 
This bacterial strain has an efficiency of $\geq 106$ transformants per microgram of DNA. Plasmid DNA to be amplified by cloning is transformed in this bacterial strain following the protocol specified by the supplier.

\subsubsection{Transformation of XL1 blue competent cells}

This bacterial strain has an efficiency of $\geq 108$ transformants per microgram of DNA. Ligation products were transformed into this bacterial strain following the protocol specified by the supplier.

\subsubsection{Transformation of BLR (DE3) competent cells}

This bacterial strain is transformed with the expression plasmid p7 following the method TSS reagent ("Transformation and Storage Solution”)

A single colony, isolated and grown in an LB-agar plate, is used to inoculate $10 \mathrm{~mL}$ of $\mathrm{LB}$ medium and is grown at $37^{\circ} \mathrm{C}$ with shaking $(250 \mathrm{rpm})$, until reaching an $\mathrm{OD}_{600}=0.3-0.4$. At this point the metabolism and cell growth are stopped by incubation on ice for 5 minutes. The cell suspension is centrifuged at $3000 \mathrm{rpm}(1 \mathrm{I00 \textrm {Gx }})$ for 10 minutes at $4^{\circ} \mathrm{C}$. The supernatant is discarded and the pellet is re-suspended in ImL of cold $x$ ITSS solution. About $\mathrm{I}-\mathrm{IOng}$ of the plasmid in a final volume of $\mathrm{I}-\mathrm{IO} \mu \mathrm{L}$ is added to the mix. The cellular suspension plus the plasmidic DNA is kept on ice for one hour followed by a heat shock, exposition at $42^{\circ} \mathrm{C}$ for 2 minutes. The heat shock is stopped by immersion on ice for 2 minutes. $1 \mathrm{~mL}$ of warm LB is added and the suspension is incubated one hour at $37^{\circ} \mathrm{C}$ with shaking (250rpm). Finally, 
$50-200 \mu \mathrm{L}$ of the transformation mix is plated in LB-agar plus the antibiotic plates that are incubated for $16-20$ hours at $37^{\circ} \mathrm{C}$.

\subsubsection{Glycerol stock preparation}

Positive clones, which are of special interest, are stored in glycerol stocks. The selected colonies were grown at $37^{\circ} \mathrm{C}$ with shacking (250 rpm.) on LB or LB with $0.5 \%$ of glucose (for the expression strains), until reaching an $\mathrm{OD}_{600}=0.6-0.8$. At this point 0.1 volumes of $80 \%$ sterile glycerol are added and the cells are kept at $-80^{\circ} \mathrm{C}$.

\subsubsection{Biopolymers expression and purification}

Once the nucleotide sequences that encode for the whole biopolymers have been created, it must be expressed. To this end, the nucleotide sequence was transferred from the corresponding cloning vector to the specialised expression vector using conventional restriction enzymes. The expression vector $\mathrm{p} 7$ has been employed. $\mathrm{p} 7$ has been obtained in our laboratory by mutagenesis of pET25b (+) by Dr. Alessandra Girotti. The final constructions were transformed on the bacterial strain BLR (DE3) following the above mention protocol.

ELRs expression starts inoculating the desired colony in liquid LB medium plus antibiotic at $37^{\circ} \mathrm{C}$ with orbital shaking ( $250 \mathrm{rpm}$.) for approximately 6 hours. This culture is used as inoculum for a fresh TB medium (plus antibiotic), in a volume ratio of $1: 500$, not exceeding $25 \%$ of the capacity of the Erlenmeyer used. 
Expression of the recombinant polypeptides was initiated by inoculating an isolated colony containing the corresponding recombinant vector in liquid LB medium with the eventual resistance antibiotic for the strain and the acquired resistance antibiotic with the expression vector and $1 \%$ glucose.

The bacterial culture was incubated at $37^{\circ} \mathrm{C}$, with orbital shaking at $250 \mathrm{rpm}$, for approximately II hours, then this culture broth was used to inoculate a fresh medium in a I/30 ratio, preferably a 100-fold larger volume of TB medium with the same antibiotic and a concentration of $0.8 \%(\mathrm{v} / \mathrm{v})$ glycerol, $0.2 \%(\mathrm{w} / \mathrm{v})$ alpha-lactose and $0.05 \%(\mathrm{w} / \mathrm{v})$ glucose. The mean volume in the Erlenmeyers did not exceed $20-25 \%$ of their capacity in order to ensure good oxygenation of the culture, and bacterial growth was continued under the same conditions until an optical density of around 0.6 at $600 \mathrm{~nm}$ had been achieved. At that point expression of the recombinant biopolymer was induced by adding isopropyl -beta-D-I-thiogalactopyranoside (IPTG) to a final concentration of $\mathrm{I} \mathrm{mM}$, and the resulting culture was incubated at the appropriate temperature for the time required for each experiment.

Once induction was complete, further growth and metabolism of the bacteria were inhibited by cooling to $4^{\circ} \mathrm{C}$. The cells were subsequently isolated by centrifuging for $10 \mathrm{~min}$ at $5000 \mathrm{~g}$ and $4^{\circ} \mathrm{C}$, and washed twice with $100 \mathrm{~mL} / \mathrm{L}$ of culture in Tris buffered saline (TBS; Tris-base $20 \mathrm{mM}, \mathrm{NaCl} I 50$ $\mathrm{mM} \mathrm{pH} 8$ ), the bacteria resuspended by vigorous stirring and/or pipetting and the mixture centrifuged again for $10 \mathrm{~min}$ at $5000 \mathrm{~g}$ and $4{ }^{\circ} \mathrm{C}$. The supernatant was then decanted and the sediment resuspended in $25 \mathrm{~mL} / \mathrm{L}$ of culture with TE solution (Tris-base $20 \mathrm{mM}$, EDTA I $\mathrm{mM} \mathrm{pH}$ 8) by vigorous stirring and/or pipetting. The resulting mixture was maintained at $4^{\circ} \mathrm{C}$ and $10 \mathrm{Pg} / \mathrm{mL}$ of the protease inhibitor phenylmethylsulfonyl fluoride (PMSF) added. 
The bacteria were lysed by sonication in a Sonicator 3000 apparatus (Misonix, New York) for 6 cycles of 3.5 minutes, each consisting of pulses of 2 seconds every 5 seconds at a power of around $100 \mathrm{~W}$. The sample was maintained on ice throughout this process in order to prevent heat-induced denaturation and precipitation of the proteins. Finally, it was centrifuged for 60 minutes at $15,000 \mathrm{~g}$ and $4^{\circ} \mathrm{C}$, with the resulting supernatant containing the total soluble fraction and the sediment the total insoluble fraction. The total soluble fraction of the bacteria was acidified to $\mathrm{pH} 3.5$ with hydrochloric acid diluted in water, maintaining the sample on ice and stirring. The resulting precipitate (mainly acid proteins and DNA) was then removed by centrifugation for 20 minutes at $15,000 \mathrm{~g}$ and $4^{\circ} \mathrm{C}$. Depending on the polymer concerned, the saline concentration and $\mathrm{pH}$ of the supernatant were adjusted.

The biopolymers were purified by taking advantage of the smart nature of ELRs and their inverse transition. Purification of the recombinant biopolymers from the soluble fraction of $E$. coli involves successive heating/precipitation and cooling/resuspension stages. Selective precipitation was performed by heating the sample to $70^{\circ} \mathrm{C}$ for two hours. The precipitate was then separated by centrifuging for 20 minutes at $15,000 \mathrm{~g}$ and $40^{\circ} \mathrm{C}$, and solubilized in $2 \mathrm{~mL} / \mathrm{L}$ of ultrapure water at $4{ }^{\circ} \mathrm{C}$ whilst stirring for 12 hours. Each purification stage was checked by polyacrylamide electrophoresis in the presence of SDS. Once the polymer was considered sufficiently pure, it was dialysed against ultrapure water and lyophilized. After the final solubilisation, the dissolved polymer was dialysed against ultrapure water at $4{ }^{\circ} \mathrm{C}$, then lyophilised and stored at $-20^{\circ} \mathrm{C}$ until use.

\subsubsection{SDS Polyacrylamide gel electrophoresis}


The protein polyacrylamide gel electrophoresis in the presence of sodium dodecyl sulfate (SDS-PAGE) - is made following the protocol for discontinuous systems described by Laemmli ${ }^{156}$. The direct proportional relation between the protein migration velocity $(\mathrm{V})$ with the product of the effective charge ( $q$ ) and the electrical potential gradient $(E)$, and an inversely proportional relation to the friction coefficient, enables separation by mass in molecules of similar charge densities (equation).

$$
V=q \cdot E / f
$$

Similar charge densities in proteins are obtained by the use of SDS. Due to the strong interaction of SDS with the proteins, the proteins' effective charge is strongly overcompensated by SDS with approximately one negative charge per each amino acid residue. This process completely denatures the protein by disruption of non-covalent interactions. For the removal of intermolecular disulfide bonds, a reducing agent $(\beta$ mercaptoethanol) is added to the sample. For accelerated denaturation and reduction of proteins, the samples are kept at $90^{\circ} \mathrm{C}$ for $5-10$ minutes.

Samples are separated in a "MiniVE vertical electrophoresis system" from Hoefer (Amersham Pharmacia Biotech, Pittsburg, USA) electrophoretic system. The total percentage of acrylamide (\%T) in the resolving gel was adjusted according to the molecular weight of the polypeptides of interests. The optimal \%T for a determined size range is presented in Table 8.

Table 8: Optimum percentage of Acrylamide/Bisacrylamide according to protein size.

\begin{tabular}{|c|c|}
\hline Target size range (kDa) & \%T in resolving gel. \\
\hline $24-205$ & $7.5 \%$ \\
\hline $14-205$ & $7.5 \%$ \\
\hline $14-66$ & $12.5 \%$ \\
\hline I4-45 & $15 \%$ \\
\hline
\end{tabular}


The composition of a resolving and stacking for a gel $\mathrm{X} \% \mathrm{~T}$ is detail in Table 9.

Table 9: Composition of the resolving and stacking gel in a gel I5\%T

\begin{tabular}{|c|c|c|}
\hline & Resolving gel. & Stacking gel. \\
\hline Acrylamide 40\% & X \% (w/v) & $4 \%(\mathrm{w} / \mathrm{v})$ \\
\hline Tris -HCL pH 8.8 & $375 \mathrm{mM}$ & ------ \\
\hline Tris -HCL pH 6.8 & ----- & $125 \mathrm{mM}$ \\
\hline SDS 10\% & $0.1 \%(\mathrm{w} / \mathrm{v})$ & $0.1 \%(\mathrm{w} / \mathrm{v})$ \\
\hline APS I0\% & $0.05 \%(\mathrm{w} / \mathrm{v})$ & $0.05 \%(\mathrm{w} / \mathrm{v})$ \\
\hline TEMED & $0.05 \%(\mathrm{w} / \mathrm{v})$ & $0.08 \%(\mathrm{w} / \mathrm{v})$ \\
\hline
\end{tabular}

*Both gels are prepared in ultrapure water.

\subsubsection{Modification of ELRs}

\subsubsection{Methacrylation of ELRs}

ELRs were dissolved in DMF to a concentration of $10 \mathrm{mg} / \mathrm{mL}$ under nitrogen atmosphere, after complete dissolution of ELR, TEA was added (I equivalent per lysine) and the soultion was stirred for 30 minutes. Then methacrylic anhydride ( 0.5 equivalent per lysine) was added and the mixture was stirred for $16 \mathrm{~h}$ at $25^{\circ} \mathrm{C}$. The product was purified by precipitation and washing in diethylether and acetone, followed by resolvation and dialysis in MQ water. The white product was obtained after lyophilization and characterized using NMR and MALDI-TOF. 


\subsubsection{Chemical functionalization of ELR VKV [1] with BCN N- hydroxysuccinimide ester [2]}

$B C N$ moieties were introduced by amidation of the free lysines $(K)$ present in the ELR backbone I, using the NHS esters of the active compound $(I R, 8 S, 9$ S)-Bicyclo[6.I.0]non-4-yn-9-ylmethyl $\mathrm{N}$-succinimidyl carbonate

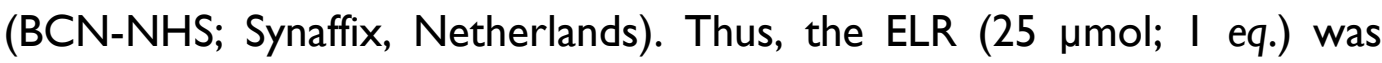
dissolved in DMF and, after complete dissolution, a solution of $2 \mathrm{~mL} \mathrm{BCN}$ NHS (250 $\mu \mathrm{mol} ; 12$ eq.) in DMF was added dropwise under a nitrogen atmosphere and the reaction mixture stirred overnight at room temperature. The pure product $\mathbf{2}$ was obtained as a white fibrous material after precipitation in diethyl ether, followed by washing with acetone, dialysis (I2,000 MwCO - Medicell Membranes Ltd, Liverpool) and freeze-drying. The degree of modification was determined by NMR spectroscopy (referencing $\mathrm{PI}$ and P2), and MALDI-TOF. ' $\mathrm{H}$ NMR $\left(400 \mathrm{MHz}, \mathrm{D}_{2} \mathrm{O}, \delta\right.$ in PPm): PI 0.6-I.0 (m, CH3), P2 2.85-2.95 (t, 2H, - $\left.\mathrm{CH}_{2}-\mathrm{NH}-(\mathrm{C}=\mathrm{O})-0-\right)$. Nuclear magnetic resonance (NMR) spectra were recorded using an Agilent $400 \mathrm{MHz}$ spectrometer operating at a resonance frequency of $399.95 \mathrm{MHz}$

for ${ }^{~} \mathrm{H}$. Spectra were recorded in $\mathrm{D}_{2} \mathrm{O}(20 \mathrm{mg} / \mathrm{mL})$ performing 500 scans. The degree of conversion was estimated by 'H NMR, quantifying the isolated $\alpha-(C(=O) N H-a l k y l)$ signals of the introduced functionalities.

\subsubsection{Covalent binding of fluorescent probe and cholesterol} moieties 
The active ELRs were treated with either triethyleneglycol-cholesterol azide (CTA; Sigma) and/or Eterneon azide (Jena Bioscience). ELRs containing 0, I, 3 or 5 cholesteryl groups were generated (CTA0-5).

First, the ELR-BCN I (20 $\mu$ mol; I equiv.) was dissolved in DMF and the azide CTA (0, I, 3, 5 equiv.) in DMF was added dropwise under nitrogen then stirred overnight at room temperature. The pure product $\mathbf{2}$ was obtained as a white fibrous tissue after precipitation in diethyl ether, followed by washing in acetone, dialysis (12,000 MwCO - Medicell Membranes Ltd., Liverpool) and freeze.drying. The degree of modification was determined by NMR (referencing PI and P3), and MALDI-TOF. 'H NMR (400 MHz, $\mathrm{D}_{2} \mathrm{O}$, $\delta$ in Ppm): P I 0.6-I.0 (m, CH3), P3 5.30-5.45 (s, IH, C-CH=C). All samples obtained were further modified for detection by insertion of a fluorophore (CTAO-5*). Thus, a solution of CTAO-5 ( $10 \mu \mathrm{mol}$; I equiv.) in DMF was treated with Eterneon azide ( $\mathrm{I} \mu \mathrm{mol}$; $0 . \mathrm{I}$ equiv.) under nitrogen in the dark for $24 \mathrm{~h}$ and purified as product I. Due to the unknown structure of the commercial compound, the insertion of the fluorophore was confirmed by fluorescence spectroscopy and by comparison of the 'H NMR spectra of the adduct and product. A newly isolated singlet at I0.I-I0.3 ppm (P4) was observed.

\subsubsection{Detection of Trypsin in ELR gels}

Preparation of substrate gels and subsequent detection of proteolytic activity were conducted as previously described according to the methods of Heussen, et al. ${ }^{342}$ by mixing the modified ELR into a $10 \%$ polyacrylamide gel. Trypsin (GIBCO) was used at concentrations of $0.3 \mathrm{nM}$ to $3 \mu \mathrm{M}$ in 10 $\mu \mathrm{L}$ of loading buffer to determine the sensitivity of ELR substrates. A comparison of trypsins (GIBCO and Corning) was performed at $0.1 \mu \mathrm{M}$. 
Samples were separated by electrophoresis on a 10\% polyacrylamide gel containing SDS. The electrophoresis was performed at $25^{\circ} \mathrm{C}$ at a constant current of $40 \mathrm{~mA}$. The gel was washed three times for 20 minutes in $2.5 \%$ Triton $X-100$, before incubation in $50 \mathrm{mM}$ Tris buffer $(\mathrm{pH} 7.5)$ containing 5 $\mathrm{mM} \mathrm{Ca}{ }^{2+}$, $150 \mathrm{mM} \mathrm{NaCl}$. After $40 \mathrm{~h}$ incubation at $37^{\circ} \mathrm{C}$., the gels were stained with $0.25 \%$ Coomassie blue in $5 \%$ acetic acid and $30 \%$ methanol for 0.5 hours and destained with 10\% acetic acid and $40 \%$ methanol. Images of destained gels were taken with GeIDoc EZ Chamber (BioRad) after I h of destaining. Proteolytic activities were detected by densitometry of clear zones using ImageJ (version I.52i).

\subsubsection{Detection of MMP2 and 9 in ELR gels}

Gels with a concentration of $\mathrm{I} \mathrm{mg} / \mathrm{ml}$, were prepared in $10 \%$ polyacrylamide gels. The gels were loaded with 50 or $500 \mathrm{ng}$ of MMP 2, or 9. After electrophoretic separation on a $10 \%$ polyacrylamide gel containing SDS, at $25^{\circ} \mathrm{C}$ with a constant current of $40 \mathrm{~mA}$, the gel was washed three times for 20 minutes in $2.5 \%$ Triton $X-100$, before incubation in $50 \mathrm{mM}$ Tris buffer $(\mathrm{pH} 7.5)$ containing $5 \mathrm{mM} \mathrm{Ca}{ }^{2+}, 150 \mathrm{mM} \mathrm{NaCl}, 10 \mathrm{uM} \mathrm{Zn}^{2+}$. After $40 \mathrm{~h}$ incubation at $37^{\circ} \mathrm{C}$, the gels were stained with $0.25 \%$ Coomassie blue in $5 \%$ acetic acid and $30 \%$ methanol for 0.5 hours and destained with $10 \%$ acetic acid and $40 \%$ methanol. Images of destained gels were taken with GeIDoc EZ Chamber (BioRad) after I h. Proteolytic activities were detected by densitometry using ImageJ (version I.52i). 


\subsubsection{Optimization of screening parameters}

Acrylamide concentration for low volume gels in a 96-well plate was optimized by varying the acrylamide concentration in a $75 \mu \mathrm{L}$ gel containing $0.1 \%$ of ELR-Ela+FN from $4-14 \%$. The other parameters were kept constant. Gels were stained with CBB-solution for 30 minutes and destained with $10 \%$ acetic acid and $40 \%$ methanol for 2 hours, the destaining solution was replaced every 20 minutes. The absorbance of gels was quantified at $590 \mathrm{~nm}$ using the GelDoc EZ Chamber (BioRad). With the optimized acrylamide concentration of $8 \%$, gels of volumes ranging from $40 \mu \mathrm{L}-200$ $\mu \mathrm{L}$ were prepared and the resulting absorbance was examined in the same way. Additionally, a screening of different absorbance wavelength (620,590, $560,530 \mathrm{~nm}$ ) was performed with gels of different volumes. In the last step, ELR concentrations varying from $0.1-7 \mathrm{mg} / \mathrm{mL}$ of gel were measured in $8 \%$ acrylamide gels with a volume of $75 \mu \mathrm{L}$. Besides quantification, gels were imaged with GelDoc EZ Chamber (BioRad) at an absorbance of $595 \mathrm{~nm}$.

\subsubsection{Screening of MMPs}

Acrylamide gels were prepared in triplicates and preincubated with $50 \mathrm{mM}$ Tris buffer ( $\mathrm{pH} 7.5$ ) containing $5 \mathrm{mM} \mathrm{Ca}^{2+}, 150 \mathrm{mM} \mathrm{NaCl}, 10 \mathrm{uM} \mathrm{Zn^{2+ }}$ for I h. $10 \mathrm{ng}$ of each MMP was dissolved in $100 \mu \mathrm{L}$ of incubation buffer and added to each well. Gels were incubated for 4 different timepoints (0.5, I.5, 4.5, 12 and $48 \mathrm{~h}$ ) at $37^{\circ} \mathrm{C}$. After each timepoint gels were washed and, stained according to the protocol mentioned above. 


\subsubsection{Critical Micelle Concentration}

The critical micelle concentration (CMC) of the different ELR solutions in Milli-Q water was determined from surface tension measurements derived from a drop shape analysis using the pendant drop technique ${ }^{390}$. The changes in the shape of the resulting drop at the air/water interface upon increasing the ELR concentration previously stabilized at $5.0,15$, or $35^{\circ} \mathrm{C}$, for $5 \mathrm{~min}$, from a blank solution of Milli-Q water to $50 \mu \mathrm{M}$ ELR, were monitored using the SCA 20 software of the Data Physics OCA20 instrument, which outlined and scaled the profile hanging from a straight precision dosing needle. Drops (4 $\mu \mathrm{L}$ at $0.5 \mu \mathrm{L} / \mathrm{sec}$ ) were infused using a $500 \mu \mathrm{L}$ Gastight ${ }^{\circledR}$ Hamilton syringe. The pendant drop image formed at the tip of the needle was captured and analyzed digitally. Five drops per condition were measured and multiple comparisons between groups were performed using a two-way ANOVA $(* * * * p<0.0001 ; * * p<0.001)$.

\subsubsection{Dynamic light scattering}

The average size distribution of the modified ELRs was determined by DLS using a Zetasizer Nano apparatus (Malvern Instruments, Worcestershire, UK), configured with a $173^{\circ}$ scattering angle and equipped with a $\mathrm{HeNe}$ laser $(633 \mathrm{~nm})$ with an output power of $10 \mathrm{~mW}$. Solutions (I5 $\mu \mathrm{M})$ of the ELRCTA modifications were dissolved in ultrapure water, and filtered $(0.45 \mu \mathrm{m}$ PVDF syringe filter) prior to analysis. Samples were incubated for 10 minutes at $5,10,15,20,25,30$ or $35^{\circ} \mathrm{C}$ prior to measurement. Each sample was measured in triplicate and multiple comparisons between groups were performed using a one-way ANOVA $(* * * * * 0.000 \mathrm{I})$ with respect to the 
high polydispersity of the samples $(0.15-0.5)$. Plotted values correspond to mean volume intensities.

\subsubsection{Zeta potential}

The particle velocity distribution (electrophoretic-mobility) was determined by Laser Doppler Velocimetry and the zeta potential (ZP) was calculated for freshly prepared and filtered samples using a Zetasizer Nano Series (Malvern, UK). Default settings on the Zetasizer were used, in other words the dielectric constant, refractive index and viscosity were assumed to be the same as for water, and the Smoluchowski approximation was used. Determinations were carried out in a temperature range from 10 to $35^{\circ} \mathrm{C}$ by performing 10 readings.

\subsubsection{Circular Dichroism}

Circular dichroism (CD) spectra were recorded using a Jasco J-I500 spectrometer in a stream of nitrogen in the range 190-250 nm. The temperature of each sample was varied from 5 to $35^{\circ} \mathrm{C}$ in steps of $5^{\circ} \mathrm{C}$. The sample was equilibrated at $15^{\circ} \mathrm{C}$ for 10 min prior to each different temperature measurement and kept for 2 minutes at the target temperature. Sampling was carried out at points every I $\mathrm{nm}$ with a total of 15 accumulations per measurement. Samples were dissolved in ultrapure water at $3.3 \mu \mathrm{M}$ and measured in a quartz cuvette $(\mathrm{d}=0.1 \mathrm{~cm})$. Data were smoothed using a 15pt Savitky-Golay filter. Deconvolution of the substructure was performed on smoothed curves using the BeStSel web server $^{391}$ to yield eight spectral components: helix (regular and distorted), irregular helix, anti-parallel (left-handed, relaxed and right-handed), parallel, 
turns, and others. The boundaries for parallel and anti-parallel strand arrangements were set to $0^{\circ}$ and $23^{\circ}$, respectively.

\subsubsection{Viscosity measurements}

Samples were dissolved to a concentration of $0.75 \mathrm{mM}$ at a temperature of $15^{\circ} \mathrm{C}$ and measured with an AR2000 (TA Instruments). Data were recorded using TRIOS software ( v4.I.I.33073).

Samples were normalized between measurements by equilibration at $15^{\circ} \mathrm{C}$ for at least 5 minutes before measurement. Viscosity measurements were performed in triplicate at $5,15,25$, and $35^{\circ} \mathrm{C}$. Samples were conditioned with a pre-shear of $0.1 \mathrm{rad} / \mathrm{s}$ for $60 \mathrm{~s}$, followed by a flow ramp from I to $1000 \mathrm{~s}^{-1}$. Samples at $35^{\circ} \mathrm{C}$ were only measured up to $300 \mathrm{~s}^{-1}$ to avoid disruption of the sample above the LCST.

\subsubsection{Rheological determination of low-temperature gelation}

Samples were dissolved to a concentration of $0.75 \mathrm{mM}$ at a temperature of $15^{\circ} \mathrm{C}$ and oscillatory shear measurements were performed using constant stress and an AR2000 apparatus (TA Instruments). Data were recorded using TRIOS software (v4.I.I.33073). A cooling and heating cycle was performed, cooling from $\mathrm{RT}$ to $2^{\circ} \mathrm{C}$, followed by a heating step to $50^{\circ} \mathrm{C}$ above the LCST. The evolution of the storage and loss moduli was recorded. 


\subsubsection{Contact Angle}

Contact angle measurements were performed using solvent films cast from $0.75 \mathrm{mM}$ aqueous solution after drying at $40^{\circ} \mathrm{C}$ overnight and incubation at the specified temperature for 5 minutes on a Peltier plate prior to $C A$ measurement. For each condition, 5 drops of ultrapure water were analyzed using a Data Physics OCA20 system instrument. The drop profile images for the advancing and receding drops during micro-syringe dispensation were recorded using an adapted CCD video camera. The three-phase contact line of the liquid drop was made to advance or retreat by adding or withdrawing the liquid and the advancing $(\theta a)$ and receding $(\theta r)$ contact angles were measured in the stable phase of advance or recoil on both sides of the drop.

\subsubsection{Transmission electron microscopy TEM}

Samples were prepared by placing a drop of the solution on a carbon-coated copper grid and, when needed, stained with uranyl acetate solution ( $1.0 \mathrm{wt}$ $\%)$, followed by water evaporation. Samples were incubated for I, 3, 7 and 28 days at a concentration of $125 \mu \mathrm{M}$ at 4 or $37^{\circ} \mathrm{C}$. C $300 \mathrm{Cu}$ Carbon coated TEM grids were loaded with the sample by incubation for $90 \mathrm{~s}$, followed by staining with uranyl acetate, as required. Images were taken using a Tecnai Thermoionic T20 microscope operated at 200kV. 


\subsubsection{Scanning electron microscopy SEM}

Samples were incubated for I, 3, 7 and 28 days at a concentration of 0.25 or $1.25 \mathrm{mM}$ and 4 or $37^{\circ} \mathrm{C}$. At specific time-points, samples were cryofractured in liquid $\mathrm{N}_{2}$ and lyophilized. Dried samples were mounted and coated with a $20 \mathrm{~nm}$ layer of carbon using the Leica EM ACE200 vacuum coater. Imaging of the ELR substrates was performed using an FEI Quanta 200 FEG instrument in low vacuum mode with a carbon coating. SEM images were employed to determine substrate characteristics and thickness as well as to check surface homogeneity. SEM captures were analyzed using the Image/ software.

\subsubsection{Spectrophotometric cloud point determination}

The absorbance of the ELR solutions was recorded using a Cary Series UVVis spectrophotometer (Agilent Technologies, USA). The ELR solutions were prepared in PBS $(125 \mu \mathrm{M})$ and recorded using the CaryWinUV Thermal Application (version 4.20(468) over a temperature interval ranging from 5 to $40^{\circ} \mathrm{C}$ at a heating rate of $1^{\circ} \mathrm{C} / \mathrm{min}$.

\subsubsection{Cell Culture}

HUVECs were cultured in EGM-2 supplemented with $1 \% \mathrm{P} / \mathrm{S}$ and HASMCs were cultured in Medium 23I supplemented with SGMS and I\% P/S. Cells were incubated at $37{ }^{\circ} \mathrm{C}$ under $5 \% \mathrm{CO}_{2}$ and their medium was replaced every two days. 
The relative number of metabolically active cells was evaluated using the

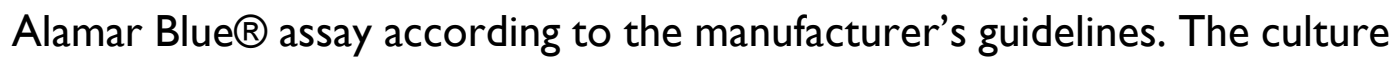
was incubated in a $10 \%$ Alamar Blue solution for $3 \mathrm{~h}$ at $37{ }^{\circ} \mathrm{C}$ and under a $5 \% \mathrm{CO}_{2}$ atmosphere. Cells were cultured in triplicate with medium containing $375 \mathrm{nM}$, or $750 \mathrm{nM}$ of the non-fluorescent substrates, for I, 3 and 7 days respectively. The datasets were normalized to cells of the same cell type and at the same time point grown on TCPS. A two-way ANOVA multiple Comparison was performed using the Holm-Sidak multiple

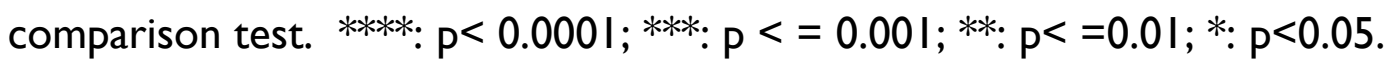

\subsubsection{FACS and Confocal Microscopy}

A total of 250,000 cultured cells per condition were incubated for $24 \mathrm{~h}$. Followed by incubation in serum-free media containing ELR ${ }^{\text {CTA }}$ (375 nM) for 18h. After incubation, cells were washed several times with cold DPBS to remove unbound ELRs, then trypsinized and resuspended in cold DPBS.

Flow cytometry analysis was performed to assess the amount of ELR ${ }^{\text {CTA }}$ positive cells. A total of 50,000 events were detected in the cytometer (Gallios flow cytometer, Beckman-Coulter). Quantification was performed using Kaluza software vI.2 (Beckman-Coulter), and for better quantification the fluorescent channel was presented on a logical scale with a linear region from -2 to 15 .

Samples used for FACS quantification were visualized using a Leica SP5 confocal microscope (Leica Microsystems, Heidelberg) with a $63 x$ lens. For better contrast in the merged image, the red channel was displayed in magenta. Z-slicing depth on selected cells was set to $0.4 \mu \mathrm{m}$. 
Cells prepared for FACS were cultured in 96-well plates to track ELR ${ }^{\text {CTA }}$ in living cells. Thus, 3000 cells incubated with ELR ${ }^{\text {CTA }}$ were imaged for $18 \mathrm{~h}$ at $0.56 \mathrm{mfps}$. Bright-field and fluorescence microscopy were performed using a NIKON Eclipse Ti fluorescence microscope equipped with a digital camera system (Digital sight DS-2MBWc) (Nikon, Japan). 

RESULTS

AND

DISCUSSION 



\section{Results and Discussion}

\subsection{CHAPTER 1: Development of a novel screening method for proteases based on proteolytically degradable ELR-acrylamide hydrogels}

Some of the concepts applied in this chapter are developed in the patent currently under revision:

Recombinant Biopolymer for Proteases Detection,

L. Poocza, M. Alonso Rodrigo, J.C. Rodríguez-Cabello, PCT/EP2019/068674 (Submitted: 04/I8).

And will be published in the article:

A fast, sensitive and cost-effective method for protease detection using nonfluorescent substrate

L. Poocza, M. Alonso Rodrigo, J.C. Rodriguez-Cabello in preparation. 
ACCESSING NEW BIOMEDICAL APPLICATIONS BY COMBINING GENETIC DESIGN AND CHEMICAL MODIFICATION OF ELASTIN-LIKE RECOMBINAMERS 
Zymography has become a standard technique for the detection of MMPs and other hydrolytic enzymes. Enzyme activities are determined based on the degradation degree of a substrate. The method requires conducting electrophoresis, and therefore it is troublesome in the procedures, and time-consuming in the detection. The majority of studies use gelatin as the substrate for the detection of MMP2 and/or MMP9. Nonetheless, other bands that appear in the zymogram are mainly of unkown origin, or ignored in publications. This is mainly due to the presence of a variety of possible targets in native proteins like gelatin, collagen, casein, plasminogen, fibrinogen, etc.. This leaves space for optimization of the existing techniques. In sensitivity and in the numbers of potential peptidase that can be detected. When referring to the EC-list of peptidases there are more than 13 subgroups of proteolytic enzyme classes with about 300 entries of different peptidases. All involved in the degradation of protein ${ }^{238}$. In the scope of tissue engineering and oncology one subclass moved into the focus, which is the class of MMPs, which are known to be secreted by cancer cells or normal cells surrounding cancers. Furthermore, these class of enzymes is able to degrade extracellular matrix proteins like collagen ${ }^{282}$. Type IV collagenases (MMP2 and MMP9) have been frequently reported to be accompanied by tumor invasion, metastasis and proliferation. Research carried out upon MMPs, increased, especially due to the relation of MMP activities in different types of cancer and diseases ${ }^{364}$, and on the other hand in tissue engineering, to introduce remodeling cues into the matrices. More recent methods and patents that involve zymographic detection are focused on the detection of certain forms of cancer.

From current zymographic methods, three prerequisites for more specific zymographic techniques can be derived. I- proteolyticly cleavable, including solubility in water, 2- stainability with Coomassiee BB or flourescence, 3- no unspecific cleavage sites, meaning stability of the protein backbone against 
proteolysis. These prerequisites are already met by specific fluorescently labeled peptide linkers in IVZ, but have not been translated to a protein substrate for IGZ purpose.

In this study we describe a way to more specific IGZ using elastin-like recombinamers (ELRs) as a substrate. Elastin is an extracellular matrix protein, that is widely distributed in vertebrate tissues, making it per se an ideal candidate for studying MMPs, but the native protein is insoluble in water. Therefore, ELRs consisting of repetitive sequences derived from elastin protein precursor tropoelastin were used to bypass solubility issues $^{7,13-17}$.

The repeated pentapetide VPGXG (with $X=\mathrm{V}, \mathrm{A}, \mathrm{I}$ and $\mathrm{G}$ ) of ELRs, has proven biostability and slow degradation rates ${ }^{108,392}$. Furthermore, genetic engineering based strategies facilitate the alteration of peptide chain length, consensus repeat sequence, as well as the introduction of additional functional groups or oligopeptide units, like specific enzymatically cleavable groups. For the detection and bining of Coomassie, positvely charged amino acids are needed, which were implemented in the $X$ position of selected pentapeptides in the final protein. For sufficient detection we implemented lysins into the protein structure, which were also used as nods for crosslinking to the zymography gel matrix ${ }^{106,109,110}$. Moreover, the sequences of the obtained proteins are uniform and completely controlled.

The appropriate choice of peptide sequence has led to the development of recombinant proteins that have been processed into materials for tissue engineering ${ }^{36,104,112,113}$, drug-delivery systems ${ }^{35-38}$, polymer dispersants ${ }^{39}$, physical gelling agents ${ }^{40, I I I}$, or biosensors ${ }^{4 I-43}$. However, we believe that the generation of meaningful elatstin-mimetic constructs for the screening of peptidases has not been stated. 
We describe herein a novel arrangement of elastin mimetic peptide building blocks into one protein, for the more specific detection of proteases than in conventional zymography substrates. The present invention comprises a design that is applied in a novel screening method for peptidases, without electrophoretic separation and denaturation of the sample.

\subsubsection{ELR IK-HEX gene Synthesis}

In an effort to obtain different molecular structures, diverse recombinant ELRs have been designed and produced. In this sense a set of genes with different proteolytic groups has been selected and designed in this work (Table 10).

Table 10: Amino acid sequence of the different building blocks employed in this work.

\begin{tabular}{|c|c|c|}
\hline Abbreviation & Sequence & $\begin{array}{l}\text { Mw } \\
(\mathrm{Da})\end{array}$ \\
\hline $\begin{array}{l}\mathrm{IK}_{24}(\text { ELR- } \\
\text { Control) }\end{array}$ & MESLLP $\left(\left((\text { VPGIG })_{2} \text { VPGKG }(\text { VPGIG })_{2}\right)_{24}\right.$ V & 51969 \\
\hline $\begin{array}{l}\text { IKHEX }_{10} \\
\text { (ELR-Ela I) }\end{array}$ & $\begin{array}{c}\text { MESLLP }\left(\left((\text { VPGIG })_{2} \text { VPGKG }(\text { VPGIG })_{2}\right)_{2}\right. \\
\left.(\text { VGVAPG })_{3}\right)_{10} \mathrm{~V}\end{array}$ & 57856 \\
\hline $\begin{array}{l}\mathrm{PITI}_{10}(\text { ELR- } \\
\text { Ela I+FN) }\end{array}$ & $\begin{array}{l}\text { MESLLP }\left((\text { VPGIG })_{2} \text { VPGKG }(\text { VPGIG })_{2}\right. \\
\text { EEIQIGHIPREDVDYHLYP }(\text { VPGIG })_{2} \text { VPGKG } \\
\left.(\text { VPGIG })_{2}(\text { VGVAPG })_{3}\right)_{10} \text { V }\end{array}$ & 80911 \\
\hline $\begin{array}{l}\mathrm{PIT}_{10}(\text { ELR- } \\
\mathrm{FN})\end{array}$ & $\begin{array}{l}\text { MESLLP }\left((\text { VPGIG })_{2} \text { VPGKG }(\text { VPGIG })_{2}\right. \\
\text { EEIQIGHIPREDVDYHLYP }(\text { VPGIG })_{2} \text { VPGKG } \\
\left.(\text { VPGIG })_{2}\right)_{10} \mathrm{~V}\end{array}$ & 66494 \\
\hline
\end{tabular}

The biopolymers were designed according to the techniques described in paragraph I.2. The pDrive cloning vector containing the genes for IK, PITI and PIT2 were avaible from previous studies. The plasmid cloning vector 
(pUC57) containing the sequences encoding the IKHEX domain was provided by GenScript.

Starting from the amino acid sequence of interest, the DNA sequence is translated by using the expression codons of the corresponding amino acids. The sequence is than reduced to a fragment $\sim 200 \mathrm{bp}$, further restriction sites for the restriction enzymes EcoRI and Earl are include to the front and the end of the sequence, enabling the extraction of the sequence of interest from the vector. For IKHEX this resulted in a final sequence of $24 \mathrm{I} \mathrm{bp}$ (sequence of interest plus restriction sites), with a total length of 204 bp, which was provided by GenScript embedded in the plasmid cloning vector pUC57.

\begin{tabular}{|c|c|c|c|c|c|c|c|c|c|c|c|c|c|c|}
\hline 1 & & & & 5 & & & & & 10 & & & & & 15 \\
\hline M & $\mathbf{E}$ & $S$ & $\mathbf{L}$ & $\mathbf{L}$ & $\mathbf{P}$ & V & $\mathbf{P}$ & G & I & G & V & $\mathbf{P}$ & G & I \\
\hline ATG & GAA & TCC & CTG & $\begin{array}{c}\text { CTG } \\
20\end{array}$ & CCG & GTA & CCG & GGT & ${ }_{25}^{\text {ATT }}$ & GGC & GTG & CCG & GGT & $\begin{array}{c}\text { ATC } \\
\mathbf{3 0}\end{array}$ \\
\hline G & V & $\mathbf{P}$ & G & K & G & V & $\mathbf{P}$ & G & I & G & V & $\mathbf{P}$ & G & I \\
\hline GGC & GTT & CCA & GGT & $\frac{\text { AAA }}{35}$ & GGG & GTG & CCG & GGC & $\begin{array}{c}\text { ATT } \\
40\end{array}$ & GGT & GTC & CCG & GGC & $\begin{array}{c}\text { ATC } \\
45 \\
\end{array}$ \\
\hline G & V & $\mathbf{P}$ & G & I & G & v & $\mathbf{P}$ & G & I & G & v & $\mathbf{P}$ & G & $\mathbf{K}$ \\
\hline GGT & GTG & CCG & GGC & $\begin{array}{c}\text { ATT } \\
50\end{array}$ & GGT & GTT & $\mathrm{CCT}$ & GGC & $\begin{array}{c}\text { ATA } \\
55\end{array}$ & GGT & GTA & CCG & GGG & $\frac{\text { AAA }}{60}$ \\
\hline G & V & $\mathbf{P}$ & G & I & G & V & $\mathbf{P}$ & G & I & G & v & G & V & A \\
\hline GGT & GTG & CCA & GGT & $\underset{65}{\text { ATT }}$ & GGC & GTG & CCT & GGG & $\begin{array}{c}\text { ATC } \\
70\end{array}$ & GGT & GTG & GGT & GTC & $\begin{array}{c}\text { GCA } \\
75\end{array}$ \\
\hline $\mathbf{P}$ & G & V & G & V & A & $\mathbf{P}$ & G & V & G & V & A & $\mathbf{P}$ & G & v \\
\hline CCG & GGG & GTA & GGC & GTT & $\mathrm{GCC}$ & CCG & GGC & GTC & GGT & GTT & GCG & CCA & GGC & GTA \\
\hline
\end{tabular}

Figure 15: DNA sequence of the 204 base pairs (white region) and the corresponding amino acid sequence.

For the multiplication of the sequence, the sequence was introduced into a cloning vector (pDrive), which can be opened by Sapl and Earl digestion. Earl digestion openes the vector before and after the sequence of interest, to remove it from the vector and Sapl digestion opens the vector behind 
the sequence of interest. The introduction of the sequence into the vector is obtained by ligation of the open pDrive together with the Ear I digested sequence of interest using T4 ligase. For the introduction of consecutive sequence blocks, ligation of a Sapl digested pDrive containing the 204 bp sequence of interest is performed together with the Earl digested sequence of interest. Increasing the concentration of the insert against the concentration of the vector leads to the introduction of multiple fragments into the vector. This resulted in sequences of the length $(204)_{x+1}$ base pairs, where $x$ is the number of inserted sequences. This process of ligation was repeated until the final sequence of $(204)_{10}$ base pairs was obtained. This sequence was then removed from the cloning vector by Earl digestion and transferred into an expression vector. Due to the design of the expression vector for a better expression of the protein of interest, the sequence MESSLP is added before the sequence of interest, and due to the use of Earl digestion a $V$ (grey shadows in Figure 15 ) is added to the end of the sequence of interest resulting in a final sequence of $206 \mathrm{I}$ base pairs. 


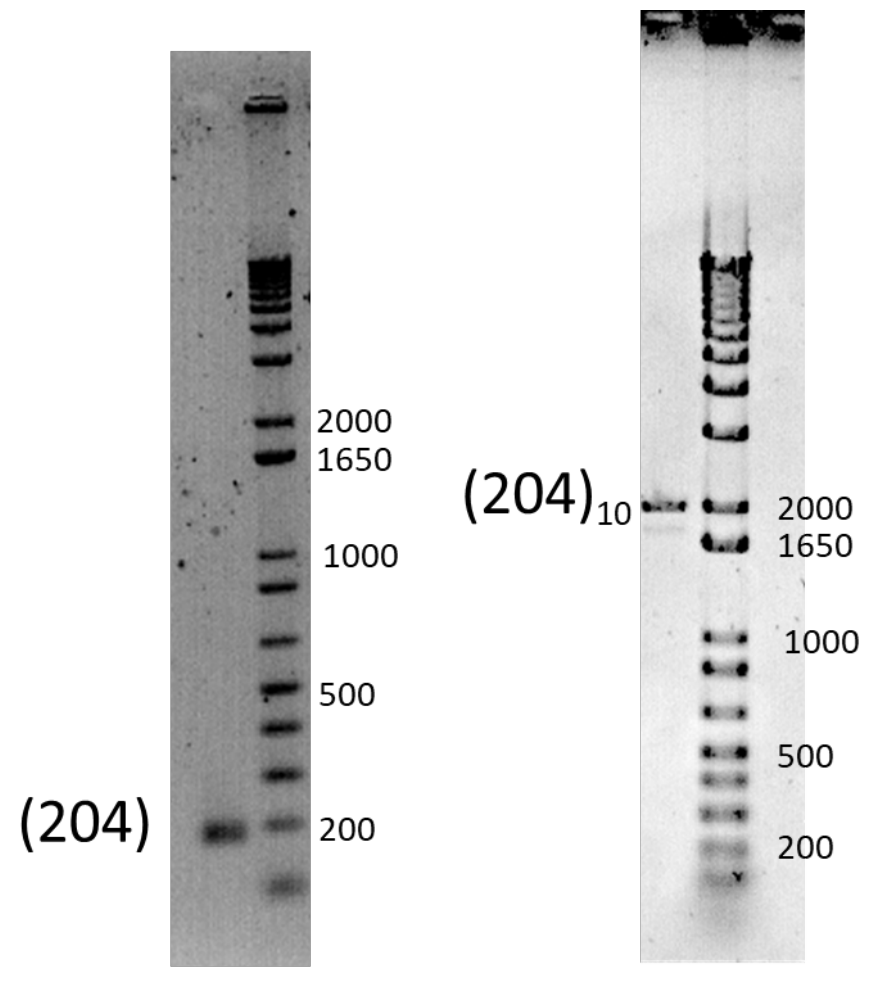

Figure 16: Agarose gels of the insert lkHex of 204 basepairs. Left gel corresponds to the unimer, as received from the supplier after Ear I digestion. Right gel corresponds to the decamer (204) 10 , obtained after several steps of ligation of the fragment.

The sequences at each step were validated using automated dideoxy DNA sequencing with fluorescent ddNTP and agarose gel electrophoresis.

Once the desired constructions were obtained and their sequences controlled their released inserts after enzymatic digestion with Earl and Dpnl, which is used in order to avoid the appearance of fragments with similar size to the segment of interest, were subcloned in the modified PET $25 b+$ vector PET 7 expression vector. These resulting vectors were used to transform E. coli expression strains as described in paragraph 1.2.3. 
ELRs expression and purification

The final gene constructions were transformed on the bacterial strain BLR (DE3) following the above mention protocol. The expression of the recombinamers was made as previously described The ELRs purification protocol was made based on the ITT (refer to paragraph I.2.4) consisting on three sequentially rounds of inverse transition cycling, which rendered highly pure and monodisperse polymers, as corroborated by SDS-PAGE.

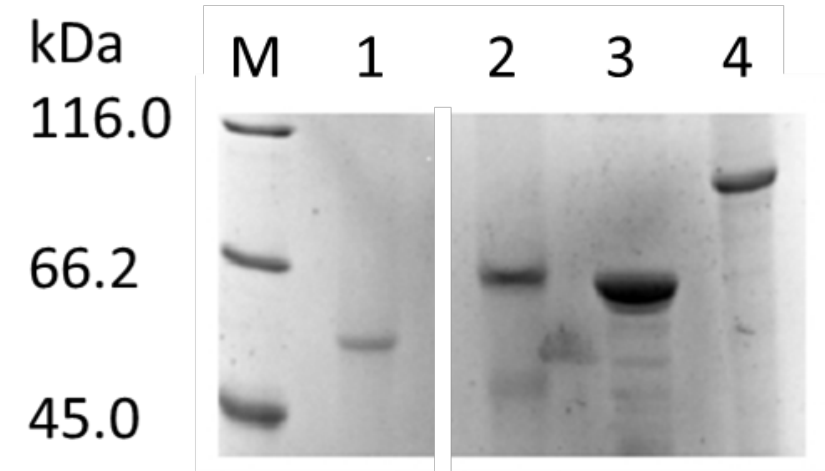

Figure 17: SDS-PAGE of ELRs to determine molecular weights. $M=$ marker, I = ELR-Control, $2=$ ELR-Ela, 3=ELR-FN, 4=ELR-Ela+FN

The electrophoretic pattern showed an excellent level of purity for all the ELRs with little degradational products in ELR-ELAI and ELR-FN, which are due to the proteolytically sensitive nature of these ELRs. No contaminant proteins form E.coli were found.

In order to confirm the recombinamer's molecular weight and amino acid composition, the samples underwent MALDI-TOF and amino acid analysis. 
Table I I: Theoretical and experimental molecularweight of ELRs and the corresponding amino acid sequence, obtained by amino acid quantification.

ELR-Ela+FN ELR-FN

ELR-Ela

ELR-control

\begin{tabular}{|c|c|c|c|c|c|c|c|c|}
\hline Mw theo & \multicolumn{2}{|c|}{80911.76} & \multicolumn{2}{|c|}{66494.83} & \multicolumn{2}{|c|}{57856.45} & \multicolumn{2}{|c|}{51969.82} \\
\hline Mw & 8050 & & 6617 & & 5740 & & 516 & \\
\hline $\begin{array}{l}\text { Amino } \\
\text { acids }\end{array}$ & $\begin{array}{l}\text { The } \\
\text { o. }\end{array}$ & Exp. & $\begin{array}{l}\text { The } \\
\text { o. }\end{array}$ & Exp. & $\begin{array}{l}\text { The } \\
\text { o. }\end{array}$ & Exp. & $\begin{array}{l}\text { The } \\
\text { o. }\end{array}$ & Exp. \\
\hline Ala (A) & 30 & $3|, 3|$ & 0 & 0 & 30 & 33,15 & 0 & 0,00 \\
\hline $\operatorname{Arg}(R)$ & 10 & 10,38 & 10 & 11,04 & 0 & 0,00 & 0 & 0,00 \\
\hline Asn $(\mathrm{N})$ & 0 & 0,00 & 0 & 0,0 & 0 & 0,00 & 0 & 0,00 \\
\hline Asp (D) & 20 & 21,23 & 20 & 21,21 & 0 & 0,00 & 0 & 0,00 \\
\hline Cys (C) & 0 & 0,00 & 0 & 0,00 & 0 & 0,00 & 0 & 0,00 \\
\hline$G \ln (\mathrm{Q})$ & 10 & 1402 & 10 & 1270 & 0 & 0,00 & 0 & 0,00 \\
\hline Glu (E) & 31 & 44,03 & 31 & 43,17 & I & 1,83 & I & 1,04 \\
\hline Gly (G) & 270 & 270,43 & 210 & 213,54 & 260 & 262,68 & 240 & 250,86 \\
\hline His $(H)$ & 20 & 16,86 & 20 & 16,18 & 0 & 0,00 & 0 & 0,00 \\
\hline Ile (I) & 110 & $|07,5|$ & 110 & 106,87 & 80 & 80,25 & 96 & 94,52 \\
\hline Leu (L) & 12 & II,85 & 12 & 11,98 & 2 & 2,91 & 2 & 2,12 \\
\hline Lys (K) & 20 & 17,60 & 20 & 16,99 & 20 & 15,75 & 24 & 19,46 \\
\hline Met (M) & 1 & 0,75 & I & 0,98 & I & 0,06 & 1 & 0,88 \\
\hline Phe (F) & 0 & 0,00 & 0 & 0,00 & 0 & 0,00 & 0 & 0,00 \\
\hline Pro (P) & $|5|$ & $15 \mid, 78$ & 121 & $|3|,||$ & $|3|$ & $|3|, 5 \mid$ & 121 & 121,78 \\
\hline $\operatorname{Ser}(S)$ & I & 0,70 & I & 0,84 & I & 0,98 & 1 & 0,76 \\
\hline $\operatorname{Thr}(T)$ & 0 & 0,00 & 0 & 0,00 & 0 & 0,00 & 0 & 0,00 \\
\hline $\operatorname{Trp}(W)$ & 0 & 0,00 & 0 & 0,00 & 0 & 0,00 & 0 & 0,00 \\
\hline $\operatorname{Tyr}(Y)$ & 20 & 21,00 & 20 & 20,80 & 0 & 0,00 & 0 & 0,00 \\
\hline $\operatorname{Val}(V)$ & I7I & 172,19 & 111 & 113,30 & 161 & 160,57 & 121 & 120,82 \\
\hline
\end{tabular}

Succesful expression of ELRs was performed by pre-expressional sequencation of the plasmid and NMR of the expressed proteins, moreover, the molecular weight of the expressed protein was correlated to theoretical mass by mass spectoscropy and SDS-PAGE (Figure 17). 


\subsubsection{Methacrylation of ELRs}

ELRs have been succesfully modified with methacrylamide groups by modification of $40-55 \%$ of lysines present in the protein, as characterized by MALDI-TOF and NMR, results are shown in Table 12.

Table 12: Results of characterization of ELR modification with methacrylate groups (MA) by NMR and MALDI-TOF. Spectra are shown below.

\begin{tabular}{|l|l|l|}
\hline & $\begin{array}{l}\text { \%age of lysines } \\
\text { modified (NMR) }\end{array}$ & $\begin{array}{l}\text { \%age of lysines modified } \\
\text { (MALDI-TOF) }\end{array}$ \\
\hline ELR-Control & 54,5 & 42,5 \\
\hline ELR-Ela & 46,0 & 54,1 \\
\hline ELR-FN & 46,0 & 36,6 \\
\hline ELR-Ela+FN & 45,5 & 42,5 \\
\hline
\end{tabular}




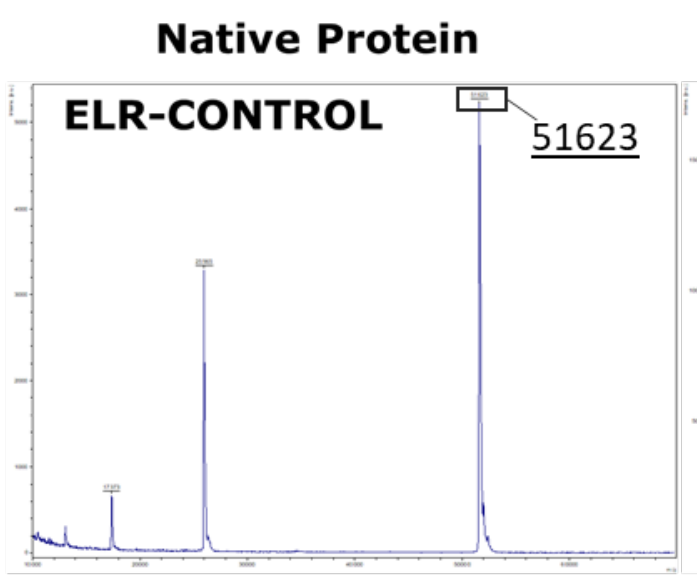

\section{Modified with MA}
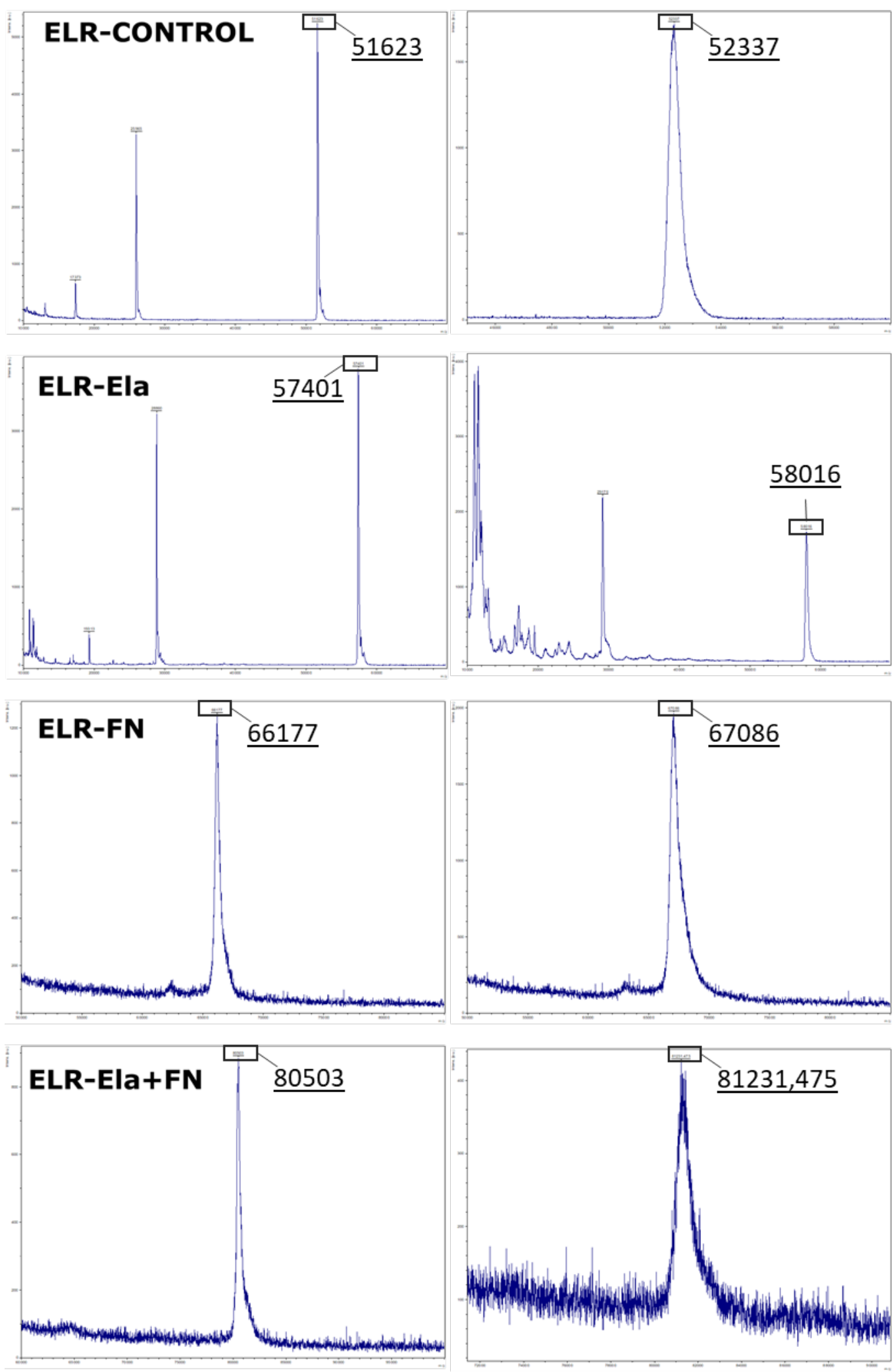

Figure 18: Mass spectra obtained by MALDI-TOF. The left column presents the pure ELRs and the right column shows mass after modification with methacrylic anhydride. 


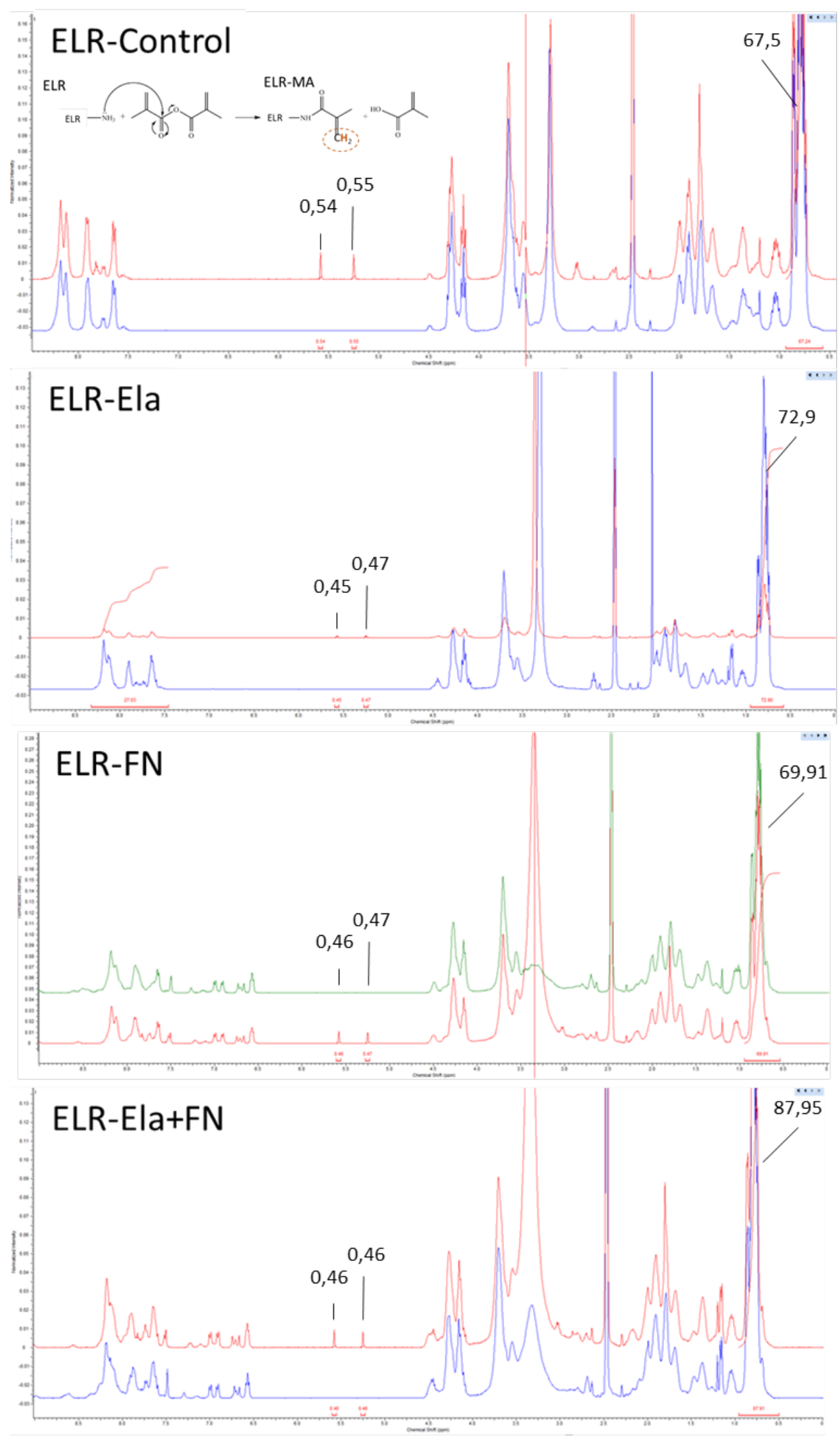

Figure 19: NMR spectra of modified and unmodified ELRs used in this study. Methacrylate signals are isolated singuletts at 5.25 and 5.60 ppm. 


\subsubsection{WORKING PRINCIPLE OF THE METHOD}

The present method uses the advantage of the spatial design of the ELR for the detection of proteases in a zymography-like manner. As a prerequisite, the ELR should consist of at least three domains, a degradable group (peptidase target), a mechanism of detection, and a stable cross-link to the acrylamide matrix. For better integrity with the matrix an additional block, which is not a target to most of the peptidases was implemented, as a spacer, to augment the molecular weight and to minimize sterical hindrance between cross-links and degradable groups. The process of detection is displayed in Figure 20A, in the first step, cross-linking motifs, in this study methacrylate groups, are added to a sufficient number of free lysins in the stainable region, and cross-linked to the substrate (acrylamide gel). The modification of lysines impairs stainability with coomassie BB as indicated by the grey boxes (Figure 20A), this is crucial since crosslinks will remain in the matrix gel and should not give a false positive signal, on the other hand a sufficient number of lysines has to remain unmodified for detection. In the next step the gel is incubated with an enzyme selective to the proteolytic group and stained after washing-off the degraded parts. This approach allows for calibration and quantification of protease activity. 
A

\section{Process of ELR Zymography}

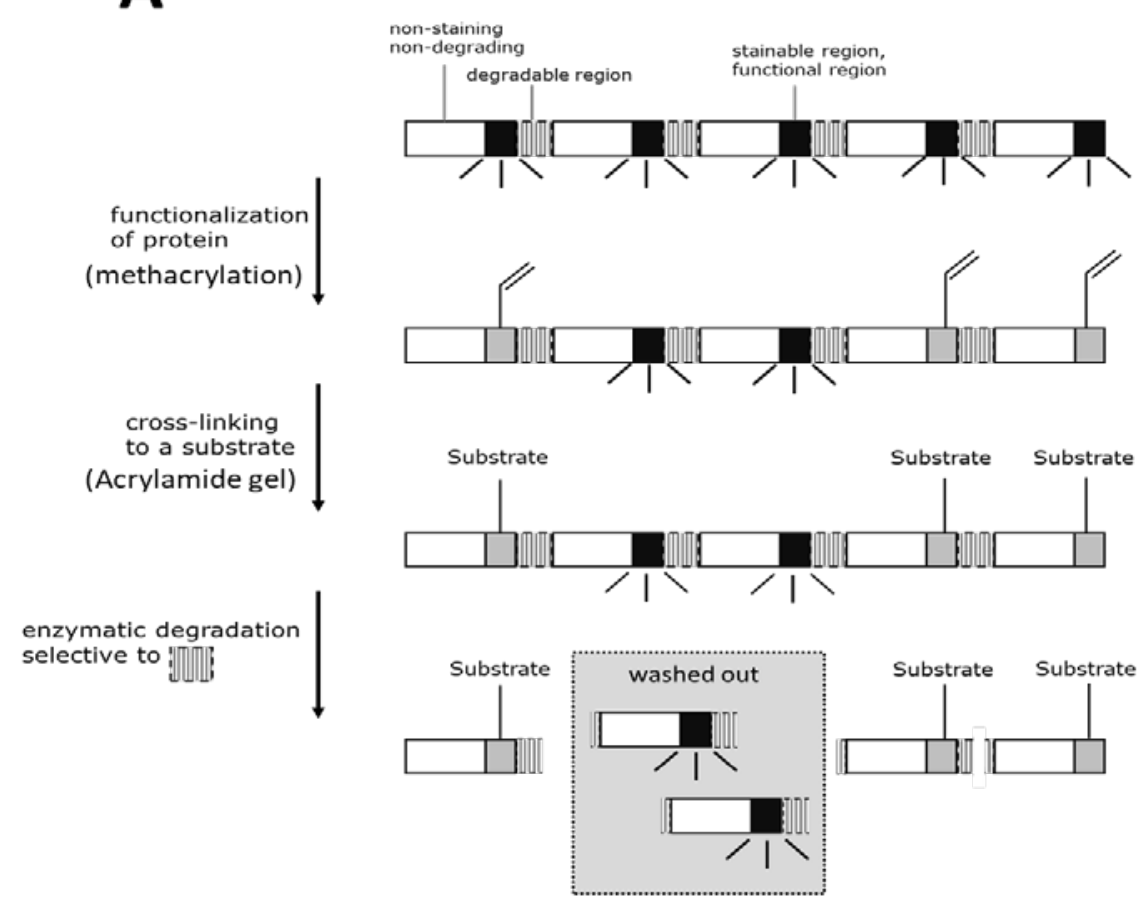

B

Library of ELRs

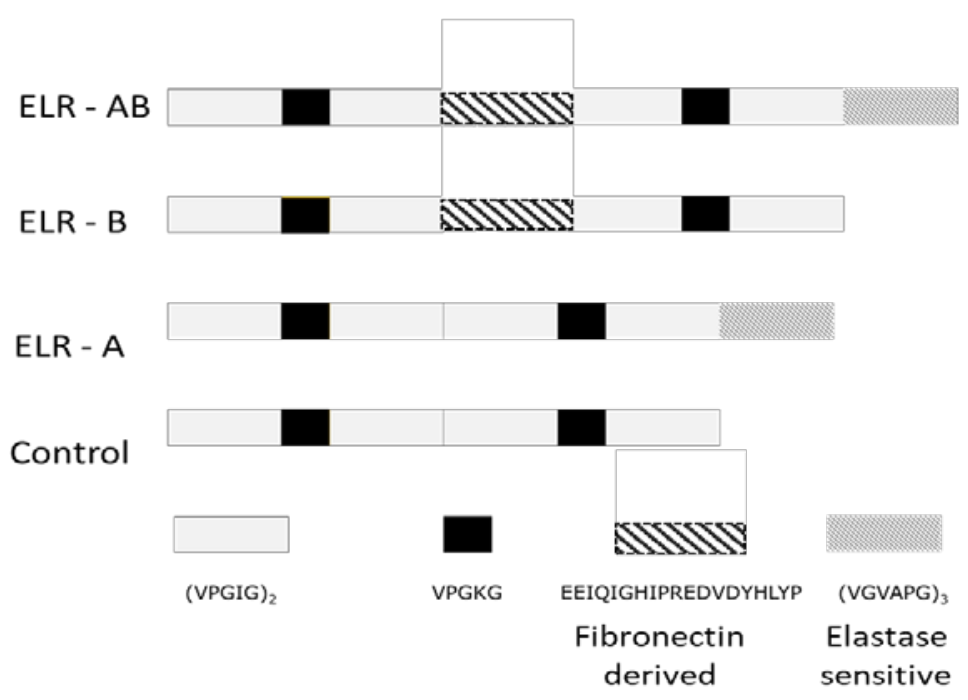

Figure 20: Design of recombinant protein for protease detection and mechanism of zymographic detection. The first step is the genetic design of the ELR consisting of non-staining, stainable and functional, and degradable region. The next step is the introduction of cross-linking features on free- lysins, which allow for cross-linking to the substrate and disable Coomassie BB detection of modified lysins. The ELR-substrate complex is than incubated with proteolytic enzymes and cleaved parts are washed off and the remaining gel is stained with Coomassie BB, and the efficiency of cleavage towards the presented group is monitored. 
For the screening of MMPs in this study, four ELRs (Figure 20B) have been designed only varying in the proteolytic domain, with a non-staining region of the sequence VPGIG which is not a known-target to proteases ${ }^{392}$, the staining region bears penta peptides of the structure VPGKG with lysines of positive charge for stainability with Coomassie BB, or to be modified with methacrylic anhydride, and a degradable domain bearing sequence as substrate to proteases. For this study we selected two degradable groups, one is known to be sensitive to elastolytic proteases (ELR-Ela) and the other is a fibronectin derived sequence (ELR-FN) which is sensitive towards a broader range of proteases capable to degrade ECM, additionally a negative control (ELR-control) and a positive control (ELR-Ela+FN) are part of the study. The specificity of the substrate ELRs, with just one cleavable group, allows for the preparation of an in-well zymography (IWZ) without the need for electrophoretic separation and denaturation of the proteases.

\subsubsection{ELR in gel zymography}

The sensitivity of ELR degradation in IGZ was controlled using a concentration screening. Due to the amounts of protease needed for IGZ and corresponding costs of recombinant derived MMPs, the initial screening for feasibility was performed with an unspecific serine protease trypsin (Figure 2l). The incubated gels revealed a clear band at $24 \mathrm{kDa}$ corresponding to the degradation with trypsin. The lower sensitivity limit of this method for trypsin was between $0.3-3 \mathrm{nM}$. 
ELR-Zymogram of Trypsin

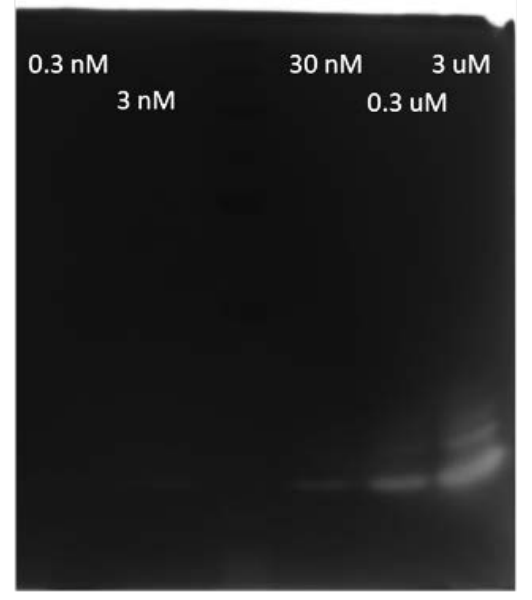

(after incubation and destaining)
Densitometry main band

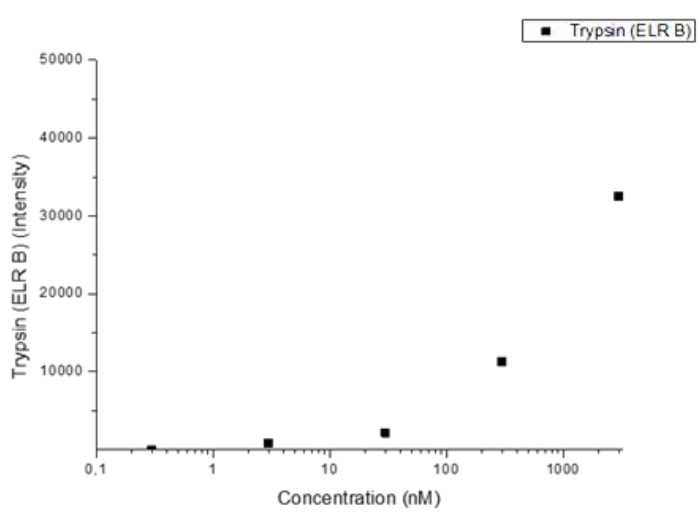

Sensitivity Trypsin 0,3 - 3 nM

Figure 21: ELR-Zymogramms: On the left developed gels after development and on the right, densitometry data obtained from the degradation of ELR-Ela+FN with different concentrations of trypsin (GIBCO) ranging from $0.3 \mathrm{nM}$ to $3 \mu \mathrm{M}$.

In an additional step all four ELR-gels were compared with two different

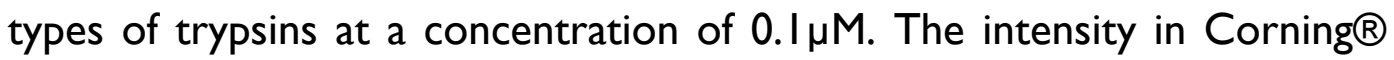
trypsin was approximately doubled compared to GIBCO $\mathbb{R}$ trypsin. In both trypsins ELR-Ela was slightly more degraded than ELR-FN, whereas ELREla+FN had the highest intensity. Gelatin zymogramm with trypsin showed strong degradation with a broad diffusion isolated bands could not be detected. The elastase sensitive group was more sensitive to the degradation with trypsin than the FN derived sequence. The results show that differences in peptidase concentrations can be measured with ELRs as the substrate and serine proteases which are more unselective upon degradation and thus cannot be detected with classic gelatin zymography, can be visualized. 


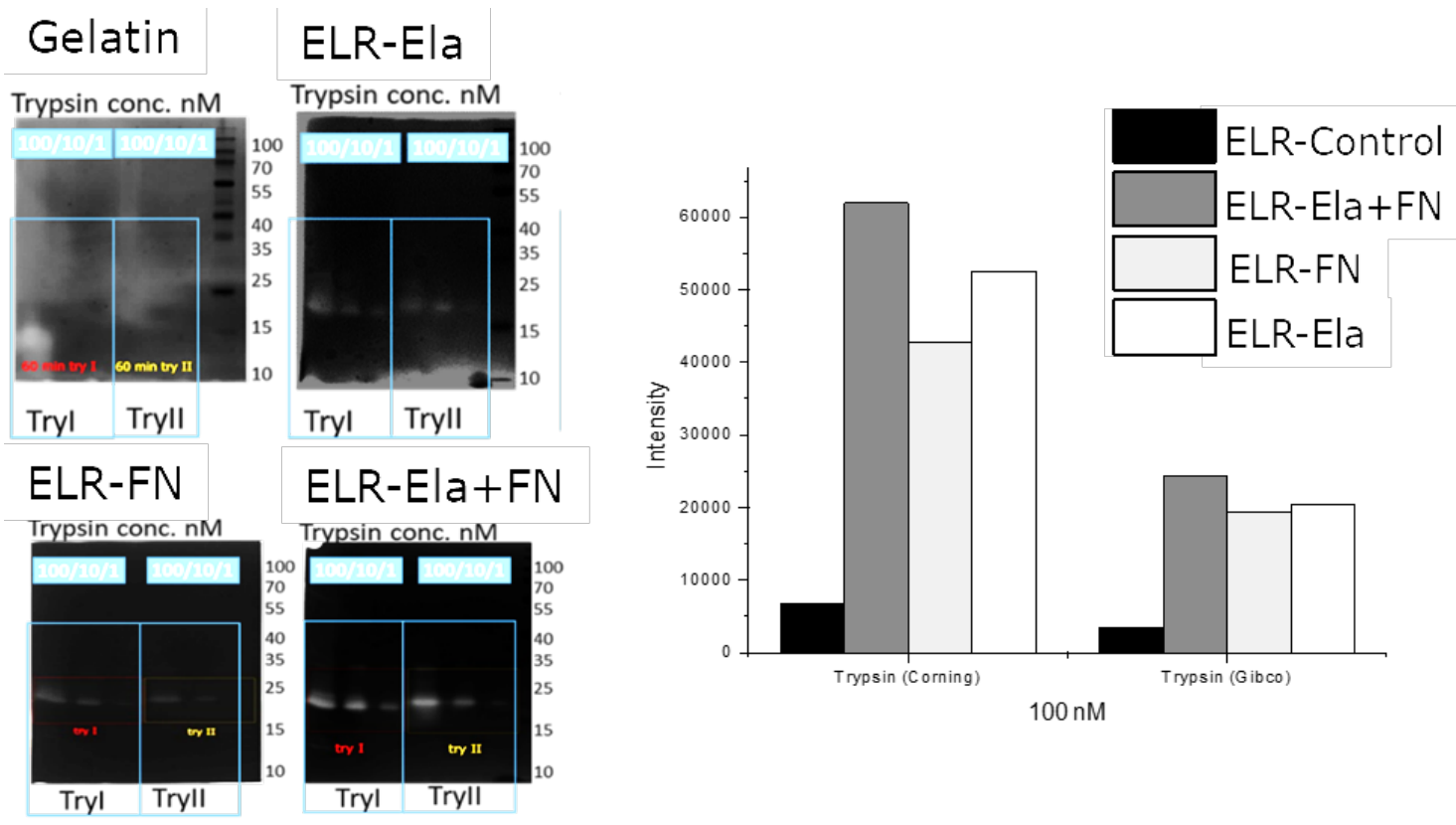

Figure 22: Comparison of ELR zymograms with two different types of trypsin and their densitometry profiles (right) (Tryl correspond to Corning® and Tryll to GIBCO® Trypsin).

For the feasibility studies with MMPs, ELR-Ela+FN was compared to ELRControl with MMP2 and 9, the standard substrates of gelatin zymography. The results revealed detectable degradations of both MMPs for ELR-IGZ. The sensitivity towards MMP9 was almost tenfold with ELR-Ela+FN as the substrate. The negative control without any proteolytic region was not degraded by the selected enzymes under the selected conditions. The complex set-up of zymography including gel preparation, loading, electrophoretic separation, renaturation, degradation, staining and destaining leads to a strong variation between different gels which does not allow for statistical correlation of separate gels. 

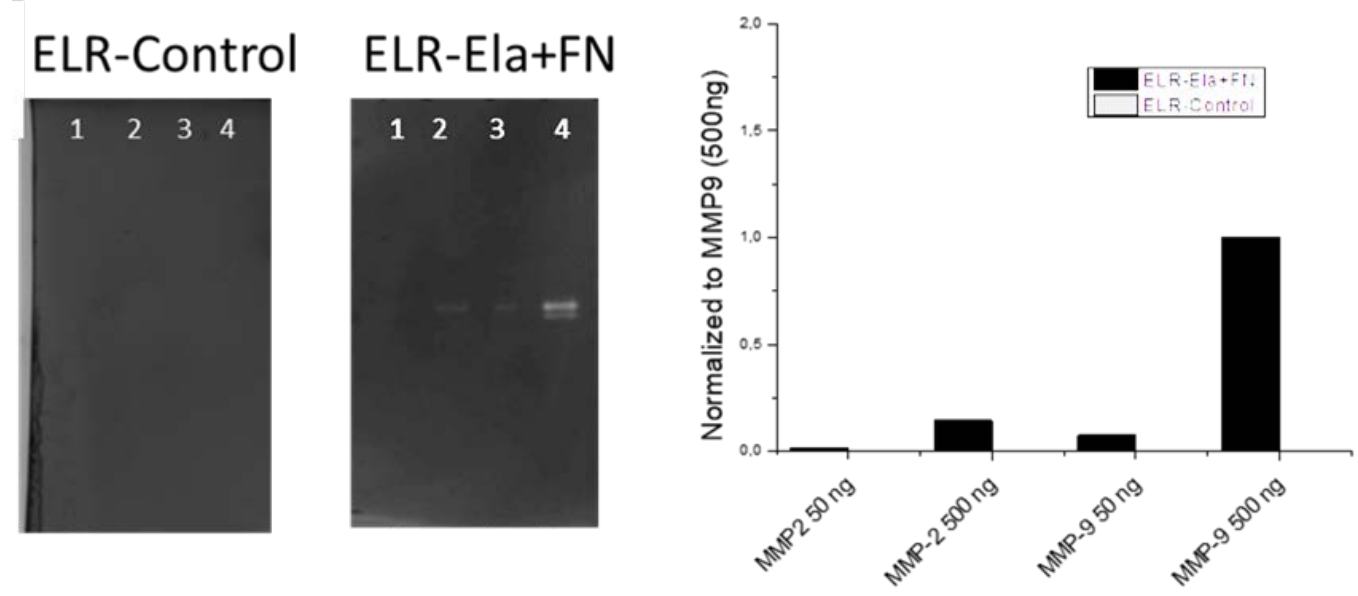

Figure 23: ELR zymogramms of the degradation of ELR-Control and ELR-Ela+FN with different concentrations of MMP 2 and 9 .

To avoid the drawbacks of electrophoretic separation and the denaturalization of the sample by detergents like SDS, we developed the ELRs in a way, that the specificity is not determined by the molecular weight of the sample, but by the degradable group of the substrate. This is in analogy with familiar methods that use fluorescent peptide-linkers for detection. The absence of fluorophores in this method might be less sensitive, but is more economical. Additionally, the cleaved group is presented in a more native protein surrounding, which is especially of interest when investigating exopeptidases. For the screening of MMPs in a 96-well plate set-up, acrylamide concentration, ELR concentration, gel volume and destaining protocol have been optimized in the following. 


\subsubsection{ELR in-well zymography (IWZ)}

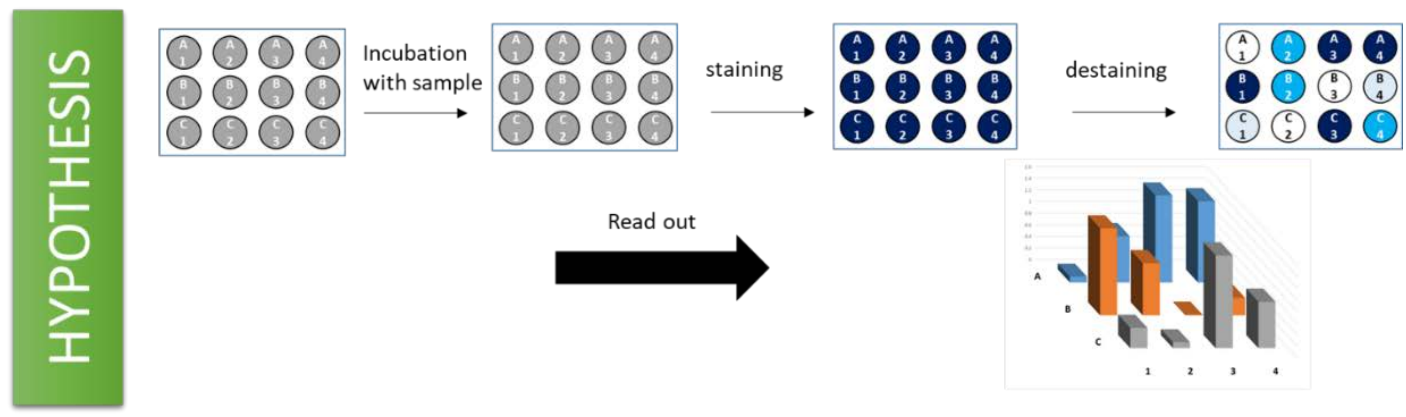

Figure 24: Schematic description of the hypothesis for the novel in-well zymography (IWZ) method.

Several concentrations of acrylamide gel with $0.1 \%$ ELR-Ela $+F N$ and $75 \mu \mathrm{L}$ gel volume per well have been prepared, stained and destained (no degradation) and measured for absorbance. The results are displayed in Figure 25 . Below $8 \%$ of acrylamide the gels became instable and could no longer be measured. Gels above $8 \%$ were stable and had a comparable maximum absorbance of 1.0. For better diffusability the lowest stable concentration of $8 \%$ was chosen for the following experiments. After setting the acrylamide concentration to $8 \%$, the gel volume per well was varied from 200-40 $\mu \mathrm{L}$. The correlation of absorbance and volume is linear which is in correlation with the amount of ELR present. The $200 \mu \mathrm{L}$ sample is slightly above the linear correlation due to limited diffusion in the step of destaining, and samples below $75 \mu \mathrm{L}$ were instable. This trend becomes more evident when looking at the absorbance at a different wavelength of all samples, which is divided into three populations, $40-50 \mu \mathrm{L}, 75-150 \mu \mathrm{L}$ and $200 \mu \mathrm{L}$, with a maximum in all volumes at $590 \mathrm{~nm}$. For further experiments gel volume of $75 \mu \mathrm{L}$ was chosen with an absorbance around I.0 which reduces slightly the sensitivity, due to the smaller window between I.0-0.0, but augments the reproducibility due to reduced destaining times at low volumes. In the final step, the $8 \%$ and $75 \mu \mathrm{L}$ acrylamide gels were subjected to varying amounts 
of ELR to define the concentration intensity correlation. The linearity at 590 $\mathrm{nm}$ had an $\mathrm{R}^{2}$ of 0.9925 , which allow for the quantification of protease activity (supporting information). For further experiments concentration of $0.1 \%$ was selected, which had an absorbance at $590 \mathrm{~nm}$ around 1.0 and which are most commonly used in other zymographic methods ${ }^{342,349-352}$.

A

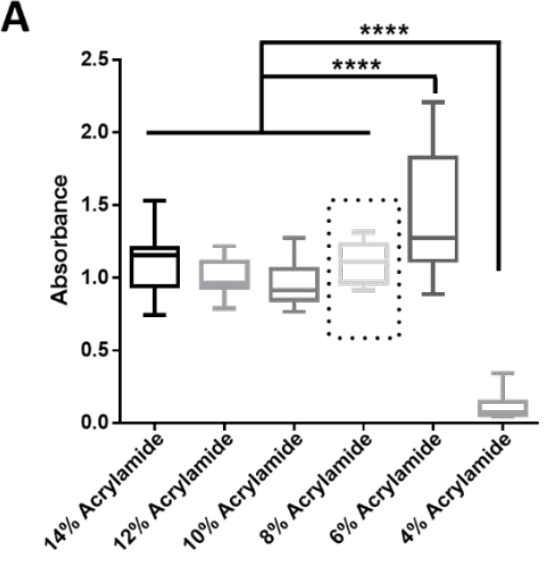

B

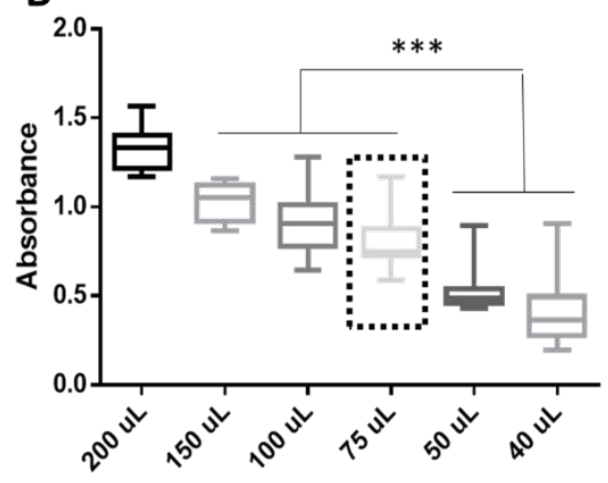

C
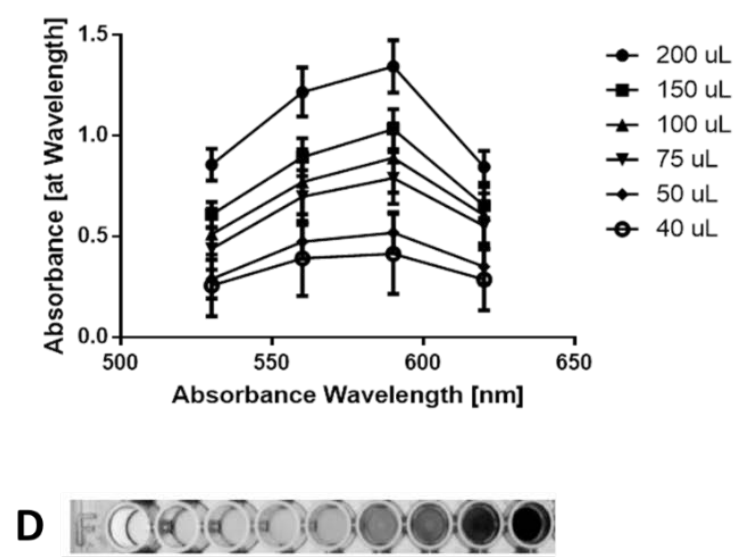

E

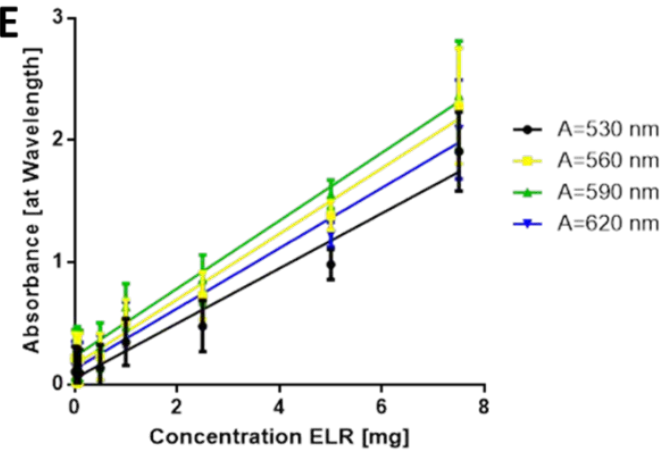

Figure 25: Optimization of parameters for the screening method. A: Optimization of Acrylamide concentration. B: Optimization of gel volume of $0.1 \%$ ELR-Ela+FN $8 \%$ acrylamide gels. C: Optimization of thewavelength of absorbance with different gel volumes. D: Absorbance image collected from wells of different ELR-Ela+FN concentrations, increasing from left to right, first well contains no ELR. E: plot of ELR concentration over absorbance at 4 different absorbance wavelength.

The optimized settings of $0.1 \%$ ELR concentration, $8 \%$ acrylamide and $75 \mu \mathrm{L}$ were used to apply a screening of MMPs I-20 with the four different ELRs, 
the results are shown in Figure 5. Missing MMPs 4, 5 and 6 have not been investigated or described in the literature, and are not commercially available. Additionally, MMP-I8 and MMP-19 seem to be identical ${ }^{393}$ which reduces the number of MMPs to 16 .

Table I3: Linearity of ELR-Calibration curve at different wavelengths of absorbance.

\begin{tabular}{|l|l|}
\hline $\mathbf{R}^{2}$ & Absorbance (nm) \\
\hline 0.9669 & 530 \\
\hline 0.9871 & 560 \\
\hline 0.9925 & 590 \\
\hline 0.9835 & 620 \\
\hline
\end{tabular}

The screening was set up to be measured in a 96-well plate in triplicates. The degradacion of sample was tracked over time and per time point a separate 96 well plate was measured. The arrangement of MMPs in the well is displayed in Figure 26, showing a clear difference in $590 \mathrm{~nm}$ absorption between 0 and $40 \mathrm{~h}$. 


\begin{tabular}{|c|c|c|c|}
\hline Control & MMP1 & MMP2 & MMP3 \\
\hline MMP7 & MMP8 & MMP9 & MMP10 \\
\hline MMP11 & MMP12 & MMP13 & MMP14 \\
\hline MMP15 & MMP16 & MMP17 & MMP19 \\
\hline MMP20 & & & \\
\hline
\end{tabular}
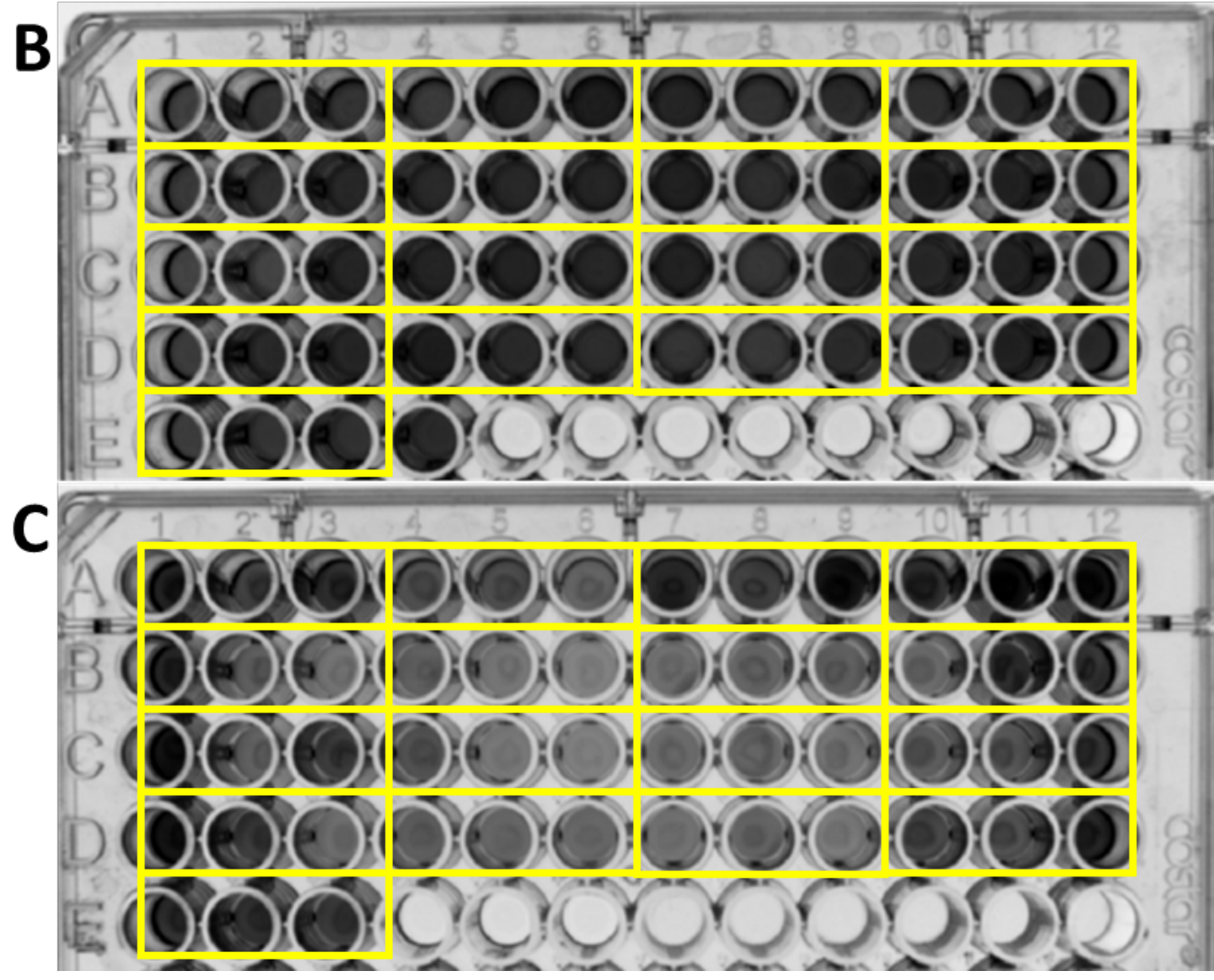

Figure 26: Comparison of ELR-Control and ELR-Ela+FN 40h of incubation after staining and destaining.

The results of the MMP screening after normalization to the non-degraded control are displayed in Figure 27 and Figure 28.

The sensitivity of the method, even though the complexity compared to IGZ was reduced by removing electrophoretic separation and denaturation of the sample, was limited to difference greater than $10 \%$ of the normalized 
un-degraded control (compare for example to the degradation of ELR-Ela by MMP7).
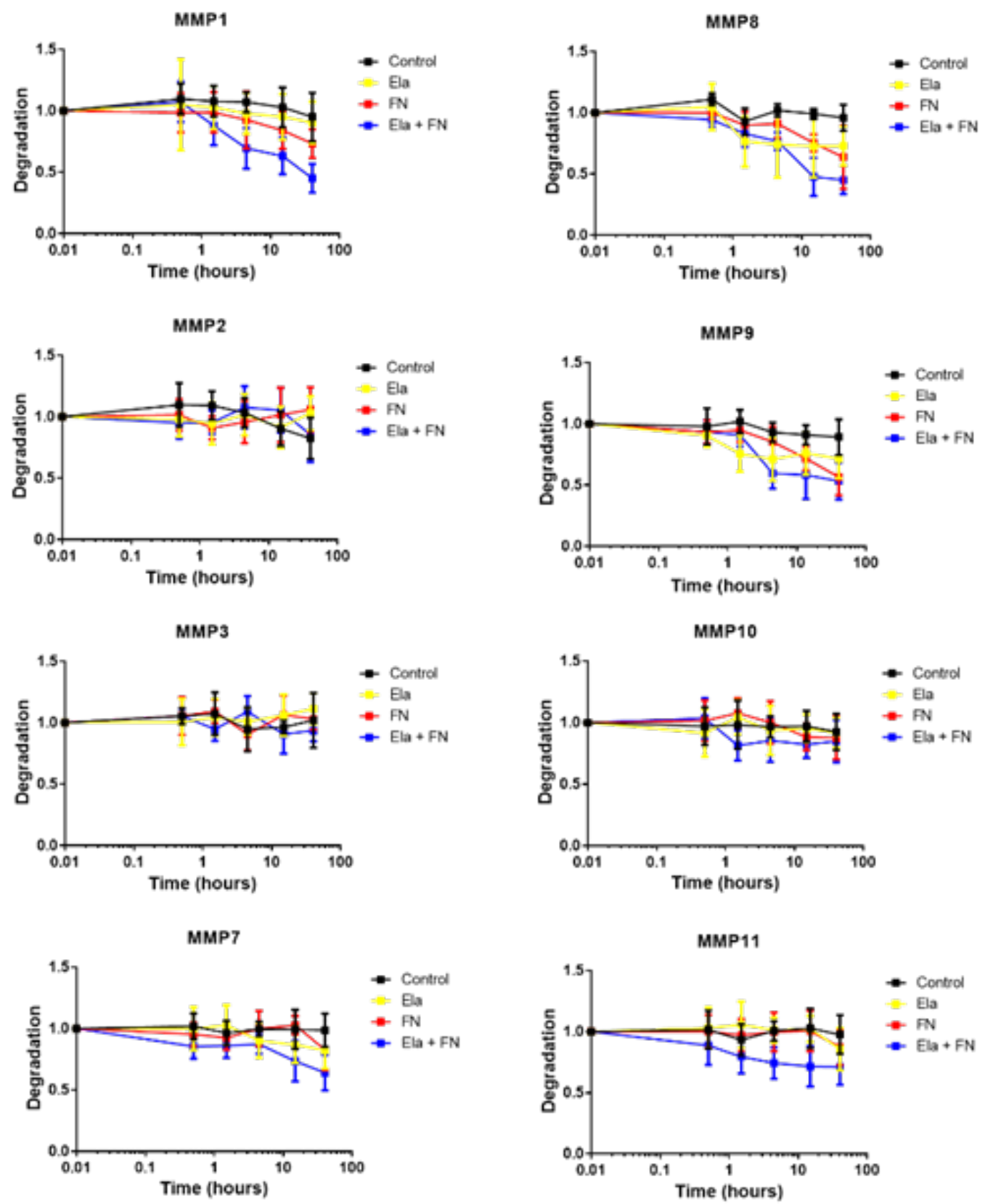

Figure 27:: Screening of MMPs I-I I with four different ELRs collected over time. 
In general, the control sample is not degraded by any of these MMPs meaning that the detected degradation corresponds to the inserted proteolytic fragments. On the other hand, in the case of degradation, degradation is most prominent in the sample containing both degradable groups ("positive control"). The difference in degradation could be detected and the amount of MMP needed for quantification was reduced from 50-500 ng in IGZ to 10 ng per sample. 
MMP12

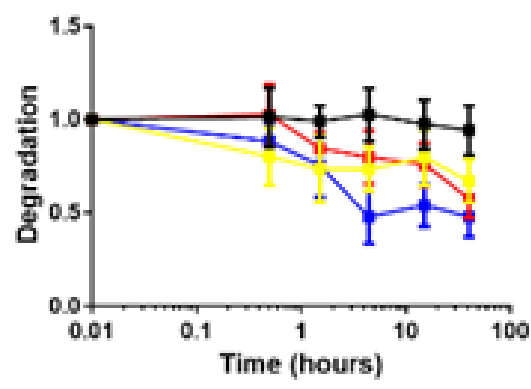

MMP13

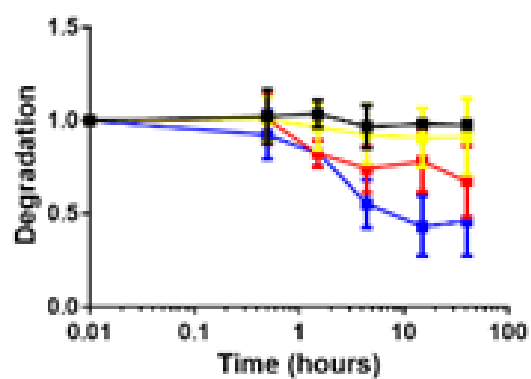

MMP14

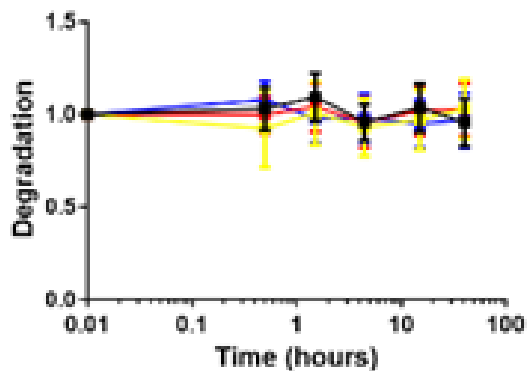

MMP15

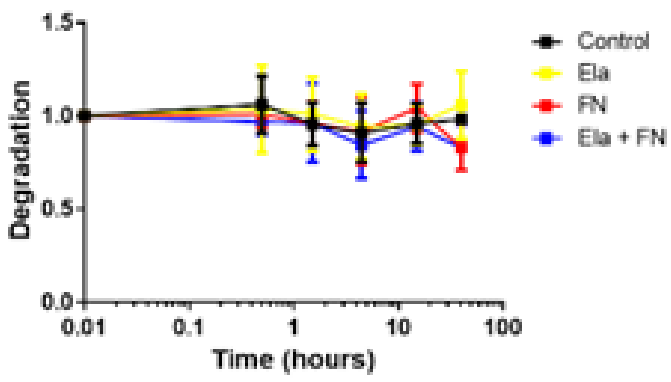

MMP16

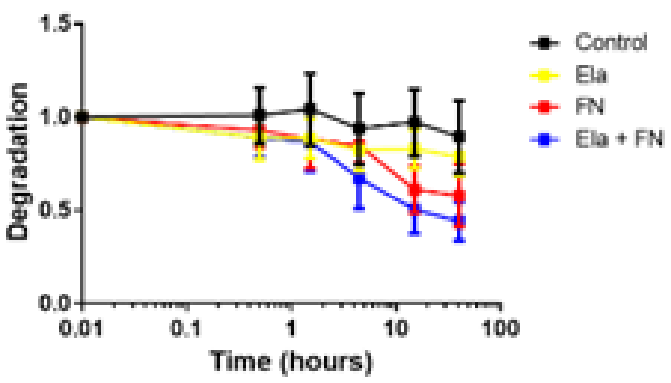

MMP17

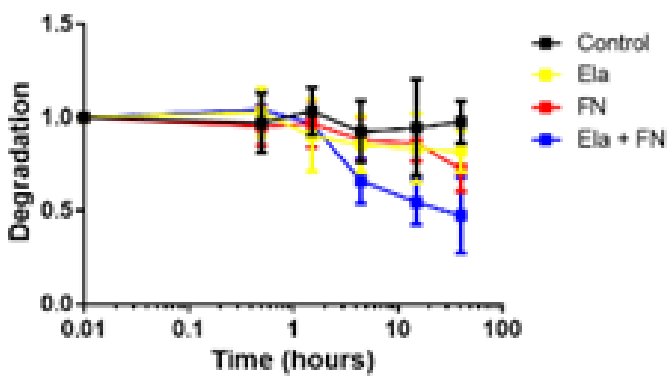

MMP19

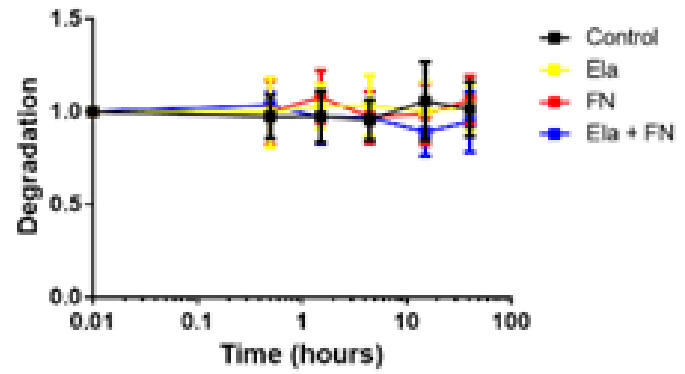

MMP20

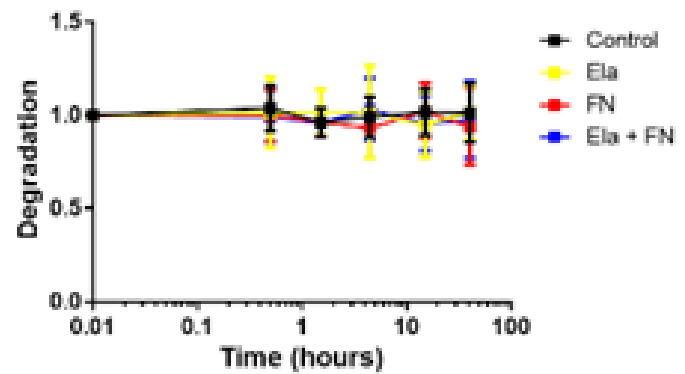

Figure 28: Screening of MMPs I2-20 with four different ELRs collected over time.

The results can be divided into four different groups, no degradation (MMPs 2, 3, 10, 14, 16, 19 and 20), FN mediated (MMPI, I3, I6), ELA mediated (MMP7), and unspecific for ELA and FN mediated degradation (MMP 8,9, I2, 17). Overall the obtained cleavage pattern for MMPs corresponds to the 
degradation targets of MMPs described in the literature. ELR-Ela was more specific and only cleaved by MMPs 7, 8,9, 12, and 17. MMP7, or matrylysin which is known to cleave FN, collagen and elastin, was the only example where the degradation is predominantly driven by the elastolytic sequence of the ELR. MMP7 and MMPI2 have been described to be upregulated in actinic damage ${ }^{394}$, which explains their capacity to degrade ELR-Ela. Moreover, MMPI2 also known as neutrophil elastase is able to degrade fibronectin as well as elastin at about 40 known cleavage sites, with a prevalence of domains rich in Ala/Gly, which is in line with the selected sequence ${ }^{395,396}$. MMP-8 and 9 are not specifically known to degrade elastin, or the sequence of ELR-Ela, but for both, a broad range of targets has been described in literature ${ }^{397-402}$. Fewer studies exist about the prevalence of MMPI7, but it was found a structural effect on elastin lamellae in MMPI7 deficient mice ${ }^{403,404}$. In terms of FN degrading MMPs there are numerous MMPs studies due to the importance and performance of $F N$ in tissue engineering and remodeling. MMPI, 8, and 13 are also called collagenases, and have been described to degrade collagens and fibronectin ${ }^{405}$, the fact that MMP2 is not degrading the fibronectin sequence, might be explained by the fact, that MMP2 is a more specific collagenase, that only cleaves collagen type $4^{393}$. MMP3 has been described to cleave FN, where the selected fragment of ELR-FN is not a target of selected MMP3. MMP-9 also known as gelatinolase is one of the most studied MMPs due to its performance in the cleavage of ECM ${ }^{396,406}$. MMPIO is involved in macrophage locomotion through fibronectin matrices ${ }^{407}, \mathrm{MMP}-\mathrm{II}$ is crucial in regulating fibronectin levels in zebrafish ${ }^{408}$, andMMPI6 is an inefficient type I collagenase but has been shown to cleave fibronectin 393,409 . 
ACCESSING NEW BIOMEDICAL APPLICATIONS BY COMBINING GENETIC DESIGN AND CHEMICAL MODIFICATION OF ELASTIN-LIKE RECOMBINAMERS 


\subsection{CHAPTER 2: Chemical Modification of ELRs with Cholesterol and Structural Mechanistics of Cholesteryl Group Mediated UCST Gelation}

Some of the concepts applied in this chapter are developed in the article:

Introduction of thermoreversible UCST gelation by hydrophobically hijacking LCST-related secondary structural motifs in a model elastin-like recombinamer Leander Poocza; Sergio Acosta; Matilde Alonso Rodrigo; José Carlos Rodríguez Cabello.

In preparation 
ACCESSING NEW BIOMEDICAL APPLICATIONS BY COMBINING GENETIC DESIGN AND CHEMICAL MODIFICATION OF ELASTIN-LIKE RECOMBINAMERS 
Interest in self-assembled biomaterials has increased considerably in the last few decades as a result of their complex spatial arrangement and the subsequent emergence of different functionalities. The direct implications of structure on self-assembly in amphiphilic block-polymers and proteins, and the possibility of generating hydrophobic ${ }^{26,27}$ and hydrophilic ${ }^{28,29}$ interactions, has enabled some degree of control over hierarchical structures, such as spherical or cylindrical micelles, vesicles, bimolecular membranes, and hydrogels ${ }^{30-33}$. Additionally, properties such as stimuli-responsiveness towards changes in temperature ${ }^{27,34}$ or $\mathrm{pH}^{35}$ have resulted in the applicability of these materials in tissue engineering ${ }^{36}$, drug-delivery systems ${ }^{35-38}$, polymer dispersants ${ }^{39}$, physical gelling agents ${ }^{40}$, or biosensors ${ }^{41-43}$. Thermoresponsiveness is the most investigated and best controlled feature for block-copolymers ${ }^{27,34}$ and, as such, has gained increased interest in cuttingedge recombinant protein design, especially in light of the findings by Urry regarding the LCST of elastin-mimetic peptides ${ }^{44-47}$. Furthermore, elastinlike recombinamers/polypeptides (ELR/ELPs), which are block-copolymer analogs with domains of differing hydrophilicity, have been explored as models for understanding the folding, self-assembly, and function of natural proteins ${ }^{46,47}$. The variety of protein-based features that can be added to ELRs makes them an ideal model for relating properties to structure. The majority of the ELRs described in the literature are based on the pentapeptide repeat sequence VPGXG, with blocks of different hydrophilicity being generated by incorporating either polar or apolar amino acids in the $X$ position ${ }^{48-50}$. The presence of equidistant prolines in the sequence predetermines the structure of the ELR and leads to a reversible phase transition characterized by a critical transition temperature $(\mathrm{Tt})$ that depends on the polarity of the amino acid residue ${ }^{48-50}$. Below the $\mathrm{Tt}$, the free polymer chains display a fully hydrated disordered structure that is not defined and is dominated by random coils, thus being best described as an intrinsically disordered protein 
$(\text { IDP })^{410}$. The contribution of proline and glycine to the solvation of ELRs governs their highly disordered nature. Thus, glycine adds an extremely high degree of chain mobility, which allows for conformational changes that are predetermined by the heterocyclic proline ${ }^{4 I I}$. In contrast, protein chain folding induced by hydrophobic interactions occurs above the $\mathrm{Tt}$, thus leading to conformational changes dominated by type II B-turns ${ }^{44,50}$. Although upper critical solution temperature (UCST)-type phase-separation behavior in water ${ }^{5-54}$ is expected to contribute to the creation of intrinsically ordered polymeric materials ${ }^{55-59}$, fewer examples of polymers that exhibit UCST-type phase separation have been reported ${ }^{412-414}$. Thus, although proteins such as abductin and resilin, which exhibit a UCST and LCST ${ }^{60,61}$, are known, to the best of our knowledge a UCST upon chemical modification of recombinant proteins, especially ELRs, has not been reported to date. UCST-type polymers self-assemble upon cooling via electrostatic interactions and the formation of hydrogen bonds between zwitterionic groups such as sulfobetaine ${ }^{415}$, glycinamide ${ }^{416}$, ureido moieties $^{417}$, or polymeric ionic liquids ${ }^{418,419}$.

Herein we augment the hydrophobic interaction of proteins by adding cholesteryl side-chains, which are known to foster intermolecular interactions in polymers ${ }^{229,231}$ to increase the order in the IDP and investigate how protein secondary structure is affected. For a better understanding of the determinants of hydrophobically induced gelation, the resulting cholesteryl-modified ELRs (CTAs) were further characterized in terms of their critical micelle concentration, contact angle, dynamic light scattering, circular dichroism, SEM and TEM imaging. It was found that the resulting CTAs (CTAx ( $\mathrm{x}=$ number of cholesteryl groups)) establish a novel and peculiar group of materials comprising of two sharp Tts with cool gelation at temperatures below UCST. Thus, a new feature, which might have future implications in biomedical applications such as smart surfaces, 
selective bioseparation, and strategic protein design, could be added to protein-based materials.

\subsubsection{Chemical Modification of ELRs}

Table 14: Overview of NMR-signals and the related conversion of functional groups.

\begin{tabular}{llll} 
& PI & P2 $(\mathbf{2 H})$ & \#BCN \\
& (normalized) & $\mathbf{2 . 8 5 - 2 . 9 5}$ & \\
& $\mathbf{0 . 6 - 1 . 0}$ & & \\
\hline VKV & 1335 & - & - \\
VKV-BCN & 1335 & $21.0 \mathrm{I}$ & 10.5 \\
(CTA0) & & & \\
\hline & PI & P3 (IH) & \#CTA \\
& $0.6-1.0 \mathrm{ppm}$ & $\mathbf{5 . 3 0 - 5 . 4 5} \mathrm{ppm}$ & \\
\hline CTAI & 1335 & $\mathrm{I} .19$ & $\mathrm{I}$ \\
CTA5 & 1335 & 4.03 & 4.03
\end{tabular}

We have demonstrated the successful modification of ELRs with the structure (MESLLP VG VPGVG [VPGKG(VPGVG) $]_{23}$ VPGKG VPGVG VPGVG VPGVG VPGV) (I; subsequently referred to as VKV) with cholesteryl groups in a two-step synthesis via BCN-mediated coupling of a cholesteryl-triethyleneglycol azide (CTA). In the first step, the BCN linker is introduced by way of a succinimide-induced amide coupling at 10/24 of the free lysines in the ELR, thereby resulting in $\mathbf{2}$ (subsequently referred to as CTA0). Due to solubility issues, the maximum number of cholesteryl groups that could be grafted was limited to 5 groups per ELR molecule. To characterize the influence of cholesteryl groups on the protein dynamics in 
solution, two modifications containing I (CTAI) or 5 (CTA5) cholesteryl groups, respectively, were synthesized.

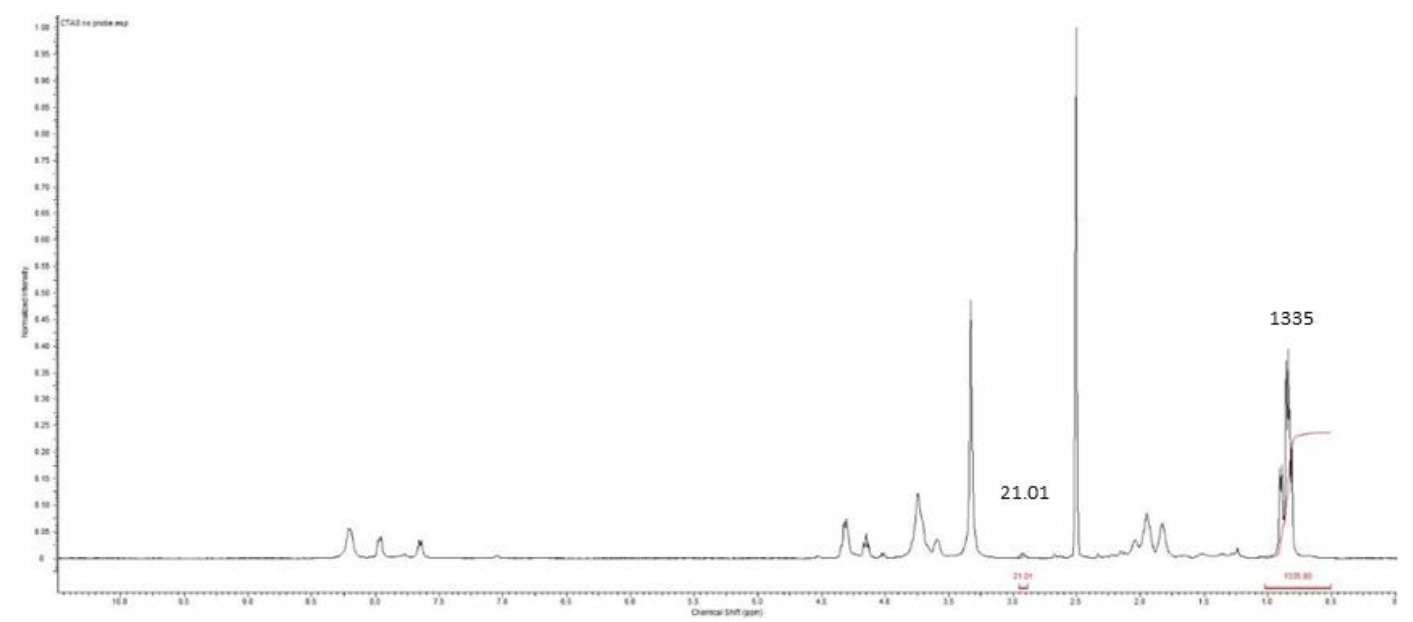

Figure 29: 'H- NMR Spectra of CTAO.

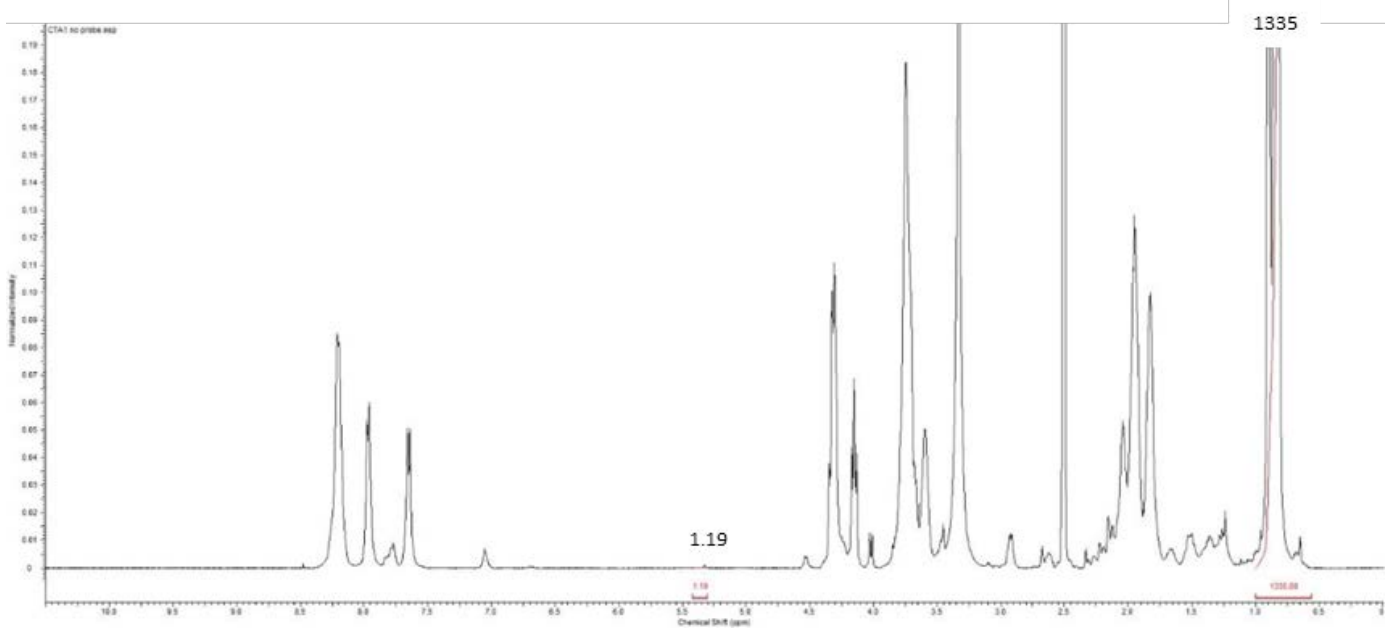

Figure 30: 'H- NMR Spectra of CTAI.

For quantification of the degree of modification the products were characterized by 'H-NMR and MALDI-TOF. For NMR analysis, signals were normalized to corresponding terminal alkyl protons in the region of $0.6-1.0$, which for this protein included 1335 protons, the final results can be seen in Table 14 and the spectras are displayed in Figure 29 - Figure 31. 


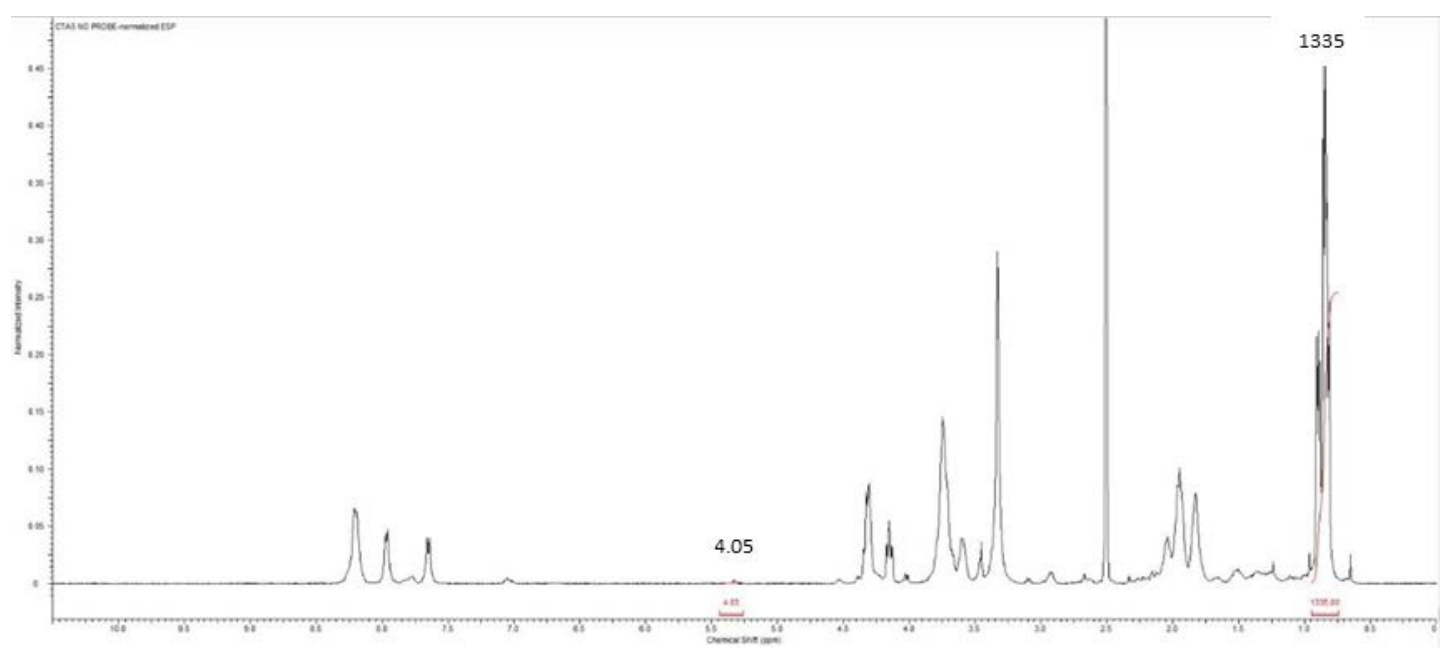

Figure 3 I: 'H- NMR Spectra of CTA5.

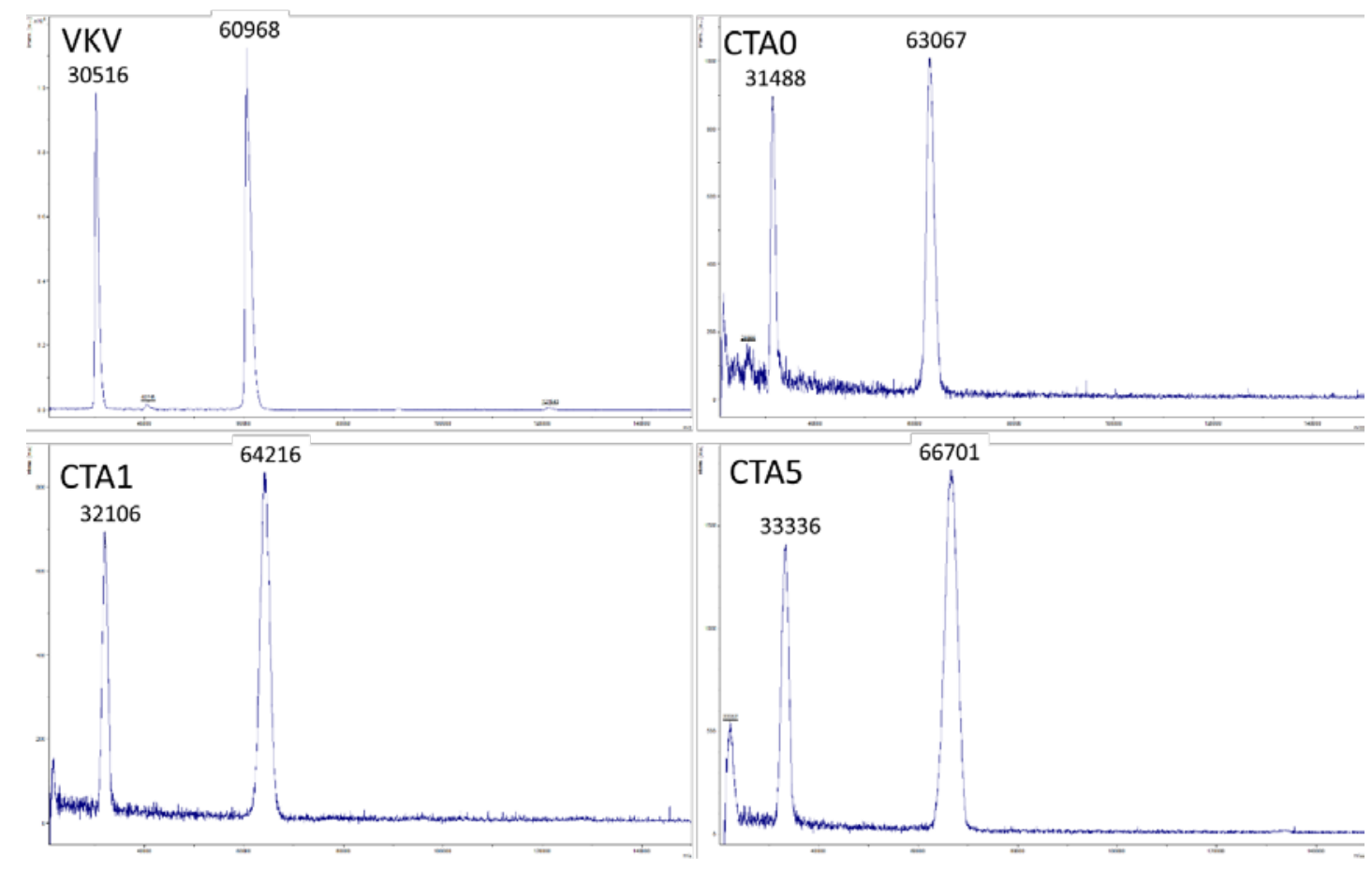

Figure 32: Results of MALDI-TOF for VKV,CTA0, CTAI and CTA5.

For MALDI-TOF quantification, the mass differences of the principal signals $\left(\mathrm{M}^{1+}\right)$ were determined and divided by the molecular weight of the added 
component. For CTAO the reference signal was VKV, and for the determination of cholesteryl modifications, CTAO served as the reference (Figure 32).

Due to the LCST, ELRs dissolve better in ice cold water. Interestingly, at low temperature, modified CTAI and-5 tend to form gels at a concentration as high as $5 \%$ which motivated the detailed characterization of ELR behavior in solution at both, low and high temperatures.
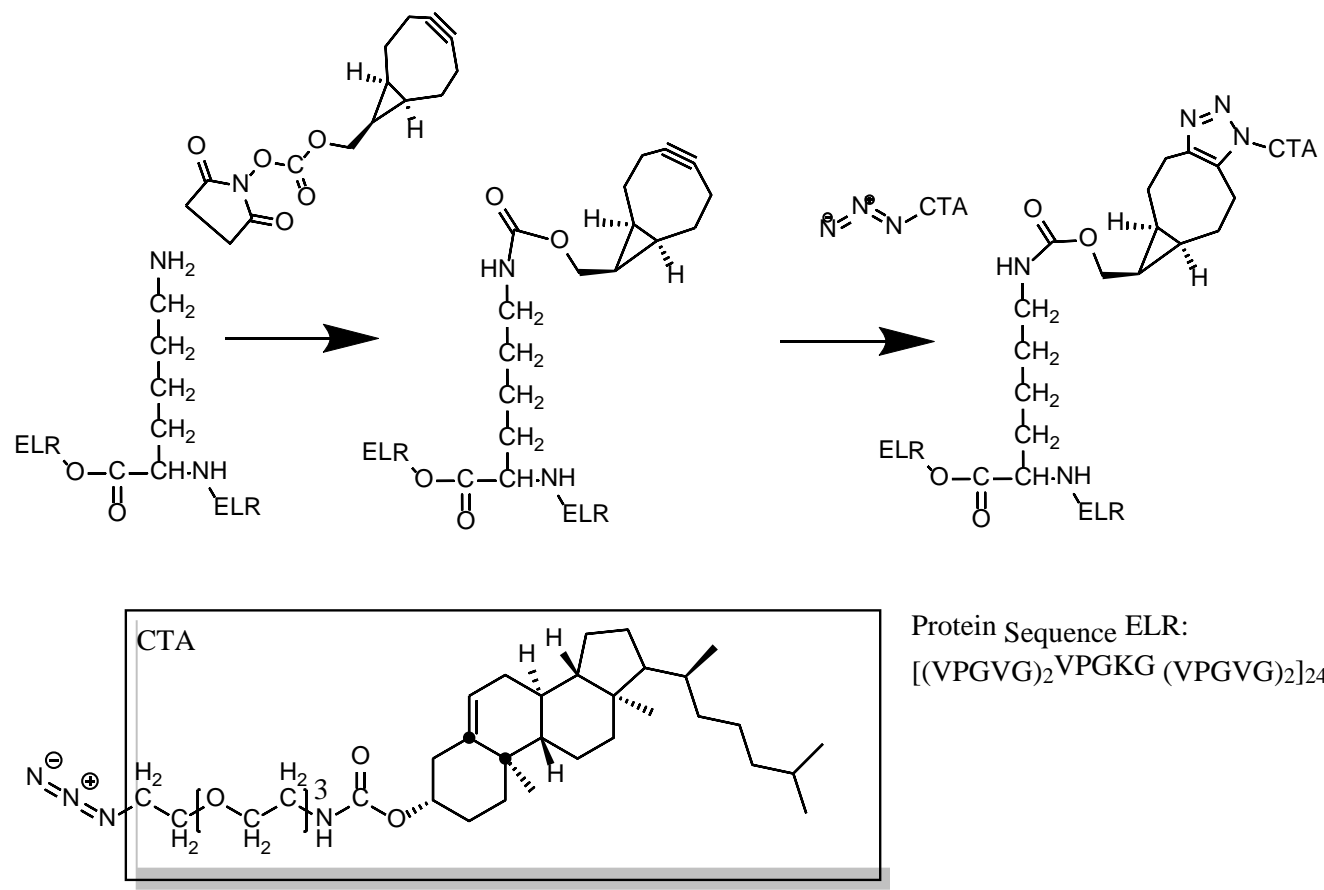

4.2.2 Characterization in solution 
The effects of modification on structural dynamics were characterized in solution by DLS, pendant drop and CD to gather information concerning the critical micelle concentration (CMC), micelle size, surface charge and secondary structure and relate them to changes in temperature. The CMC was determined using surface tension measurements at different temperatures $^{390}$ below the gelation temperature, above the LCST and inbetween (dissolved state). The critical micelle concentration of CTAO and CTAI was found to be around 2-4 $\mu \mathrm{M}$ for all temperatures, decreasing slightly at higher temperatures, which is in accordance with the temperature-dependence of the surface tension of water. CTAI exhibits slightly higher CMCs at all temperatures, which are more pronounced at $5^{\circ} \mathrm{C}$. CTA5 exhibits a fourfold higher $\mathrm{CMC}$ at $5^{\circ} \mathrm{C}$ (around $12 \mu \mathrm{M}$ ) and $35^{\circ} \mathrm{C}$ (around $6 \mu \mathrm{M})$, and the lowest $\mathrm{CMC}$ at $15^{\circ} \mathrm{C}(4.5 \mu \mathrm{M})$ is still higher than that for the control (Figure 34). Self-association of amphiphilic polymers is mainly driven by a decrease in free energy of the system due to the removal of hydrophobic fragments from the polar solution and their incorporation into the core of micelles ${ }^{420}$. Low CMCs represent more stable micelles formed even at very low concentrations, whereas the increase in CMCs at $5^{\circ} \mathrm{C}$ is in correlation with the number of hydrophobic moieties, thus indicating destabilization of the micelle towards dissociation into unimers ${ }^{411}$, or coagulation of micelles ${ }^{42 !}$, in other words exposure of cholesteryl groups 
to the solution, thus allowing intermolecular interactions to destabilize or hamper micelle formation.
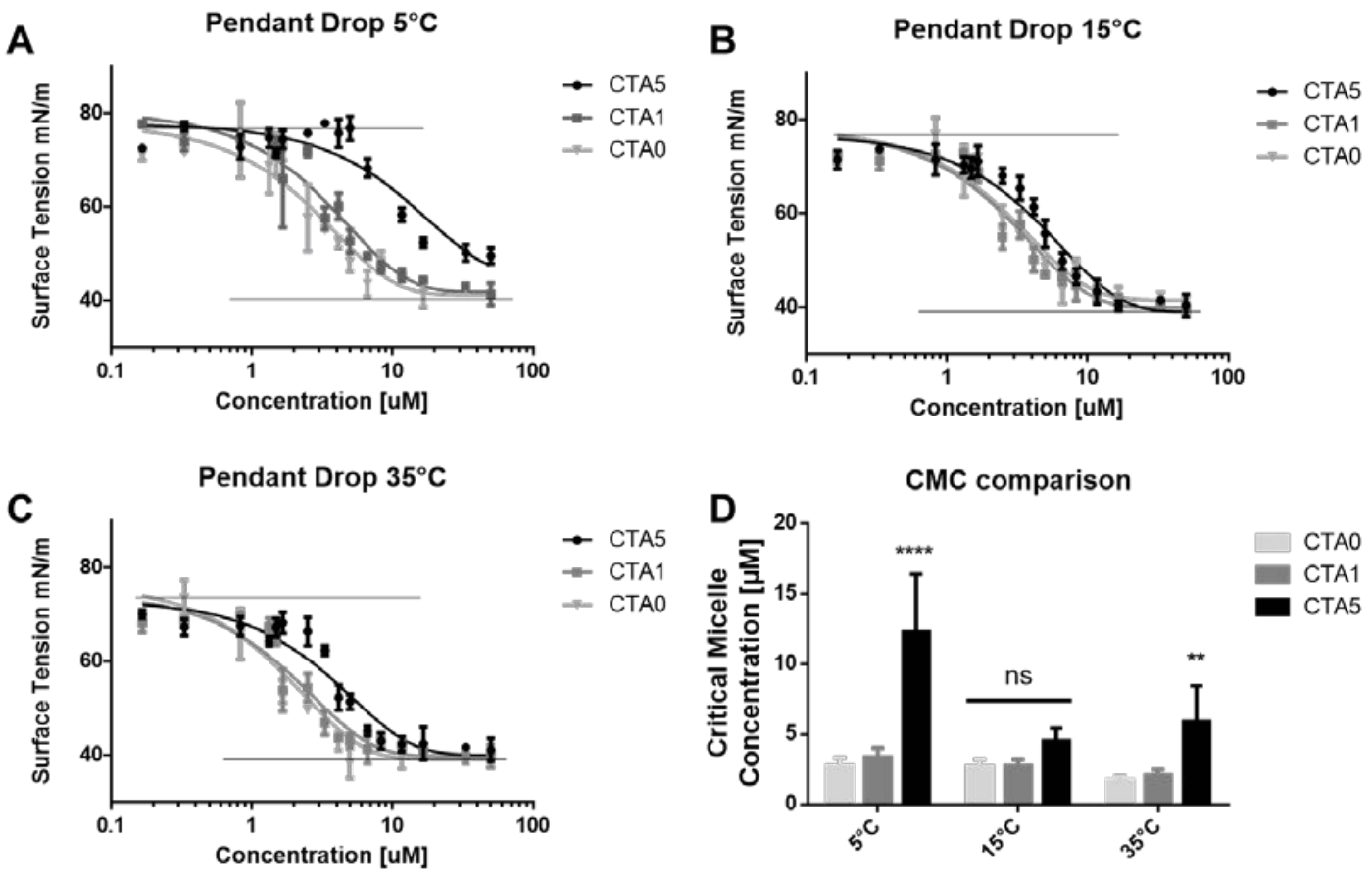

Figure 34: Determination of $\mathrm{CMC}$ by surface tension measurements revealing a different behavior for CTA5 which is most prominent at low temperatrues. A) at $5^{\circ} \mathrm{C}, \mathrm{B}$ ) at $15^{\circ} \mathrm{C}, \mathrm{C}$ ) at $35^{\circ} \mathrm{C}$ and $\mathrm{D}$ ) the resulting CMCs. Error bars represent SD.

DLS and zeta potential (ZP) measurements were performed to understand the influence of cholesteryl modification on the nanostructure of ELRs on the basis of their hydrodynamic diameters $\left(d_{H}\right)$ and surface potential. Although DLS measurements were performed at $15 \mu \mathrm{M}$, which is above the CMC for all conditions, it is noteworthy that the nanostructures found are unstable in solution for long-term incubation due to the formation of large aggregates, especially beyond their transition temperatures. In the pure $\mathrm{VKV}$, and to a lesser extent in CTA0, very small particles, ranging from unito decamers (Figure 35) are observed below the LCST as a result of the 
hydrophilic nature of the ELR at this temperature, with a mean $d_{H}$ of 20 or $60 \mathrm{~nm}$ respectively (Figure 36 ).

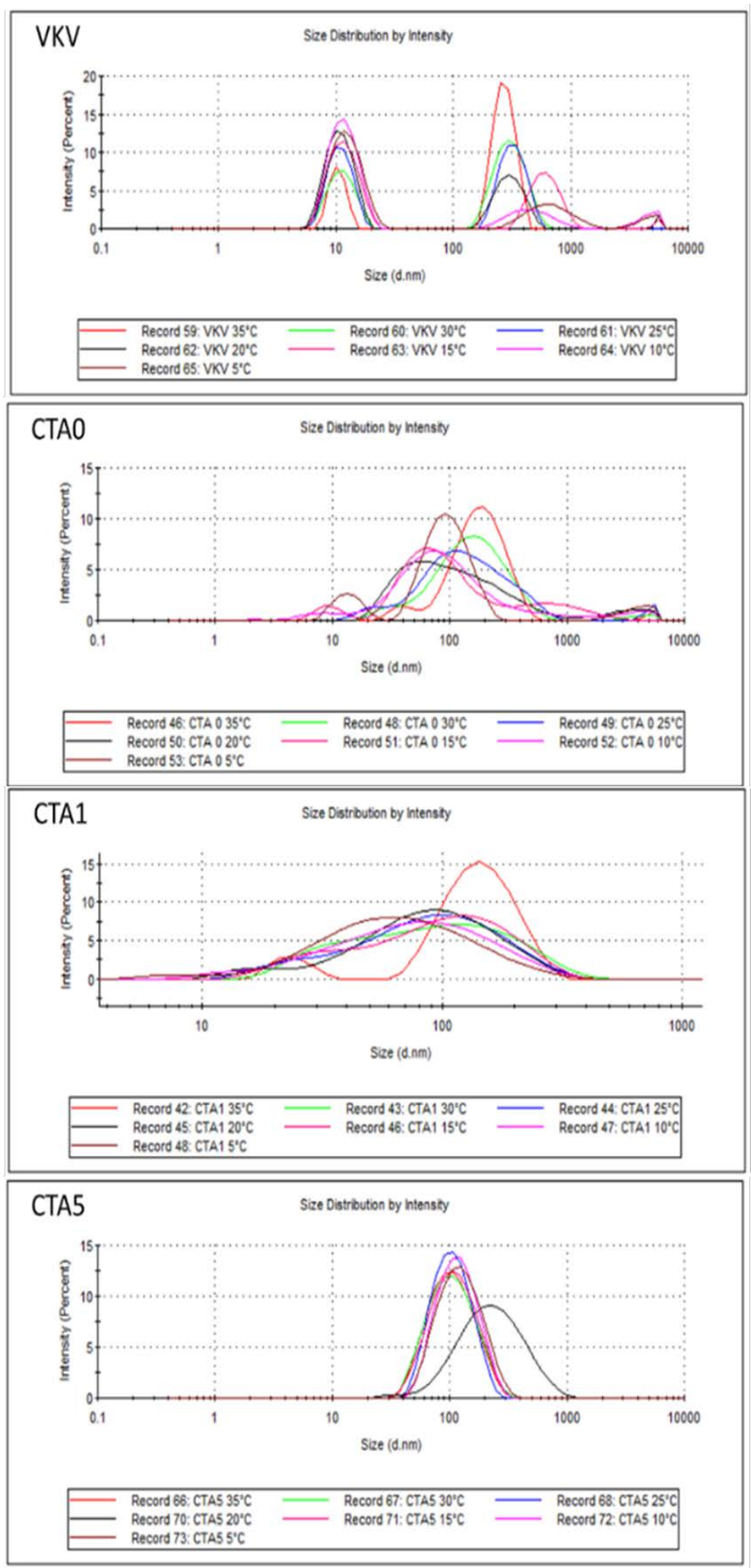


Figure 35: Intensity distributions of ELRs at different temperatures.

Above the LCST, hydrophobic blocks start to interact with each other via intra- and intermolecular interactions, thus meaning that particles fuse together and larger micellar aggregates are formed in the early stages of agglomeration (I 80 , or $150 \mathrm{~nm}$ respectively), which is accompanied by huge deviations in the transition region $\left(20-30^{\circ} \mathrm{C}\right)$. Likewise, the addition of one cholesteryl group (CTAI) increases the size of the aggregates below the LCST, although the difference with respect to CTAO is not significant, thus resulting in a smaller $\mathrm{d}_{\mathrm{H}}$ above $30^{\circ} \mathrm{C}(120 \mathrm{~nm})$. In contrast, the introduction of five cholesteryl groups (CTA5) completely changes the behavior of the recombinamer. Thus, below the LCST, CTA5 self-assembles into nanoparticles with a size of I $10 \mathrm{~nm}$, which are less thermosensitive, and with a slight decrease in $d_{H}$ with temperature in the range of $100 \pm 10 \mathrm{~nm}$ (Figure 36A). This effect is triggered by the cholesteryl groups, which form hydrophobic intra- and intermolecular interactions that are strong enough to prevent the formation of larger agglomerates in the initial stages. The introduction of hydrophobic groups $(\mathrm{BCN}<$ Cholesteryl) into the unmodified ELR leads to a leveling out of the relatively sharp increase in particle size observed with temperature, which mainly occurs as a result of the solvophobic compartments in the polypeptide backbone acting as anchors for intermolecular attraction. Nanoparticles of similar stability have also been observed in cholesteryl modified pullulan and have been described as poly-core stabilized particles ${ }^{229}$. However, none of the micelles are stable beyond the transition temperatures for long-term incubation as larger aggregates are formed as a result of interactions between the nanostructures. This may be a consequence of the lack of a strong electrostatic repulsion between the nanoparticles. The Zeta potential (ZP) values were in the unstable $\mathrm{ZP}$ range $(+30 /-30 \mathrm{mV})$ in all cases ${ }^{422}$. The ZP in 
the temperature regime studied remains essentially constant for all modifications, with a small increase in charge at higher temperatures. VKV and CTAO have similar values of around $+14 \mathrm{mV}$, meaning that the introduction of $12 \mathrm{BCN}$ groups has no significant effect on surface potential.The introduction of a single cholesteryl group decreases the ZP to +5 and the addition of five cholesteryl groups results in a negative ZP of -20 $\mathrm{mV}$ (Figure 36B). Although the influence of cholesterol side groups on the ZP is not yet well understood, it has been shown that cholesterol is able to drastically decrease the net charge of liposomes ${ }^{423}$, lipid bilayers ${ }^{424}$ phospholipid membranes ${ }^{424}$, low density lipoproteins (LDLP) ${ }^{425}$ and PLGA particles $^{424}$. It is believed that the repulsive surface potential and repulsive electrostatic force (or energy barrier) in membranes increase with the incorporation of cholesterol, which results in a decrease in the binding interaction between vesicular surfaces and polar solvent ${ }^{426}$.
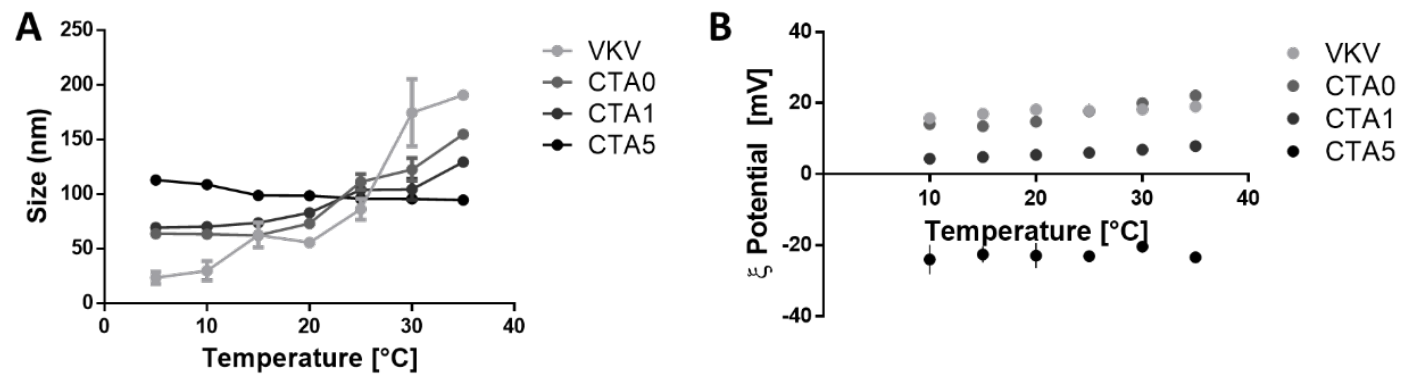

Figure 36: Dynamic light scattering measurements for CTAx at a concentration of $15 \mu \mathrm{M}$ and different temperatures. The addition of cholesteryl groups leads to less thermosensitive particles which are more negatively charged. A) hydrodynamic radii, B) Zeta potential. Error bars represent SD.

Another explanation derived from the Flory-Huggins theory assumes that excluded volume effects are responsible for the increase in surface charge upon addition of neutral molecules ${ }^{422}$, similar effects have been observed in PLGA most probably originating from the formation of a Helmholtz layer around the surface of particles bearing oriented carbony, l or amide dipoles, and the resulting electrostatic repulsion of the stabilizing double layer of 
counterions $\left(\mathrm{OH}-, \mathrm{Cl}^{-}\right.$, etc ${ }^{427,428}$. The $\mathrm{ZP}$ value obtained for CTA5 implies a similar behavior for cholesteryl groups in polypeptide-based micelles.
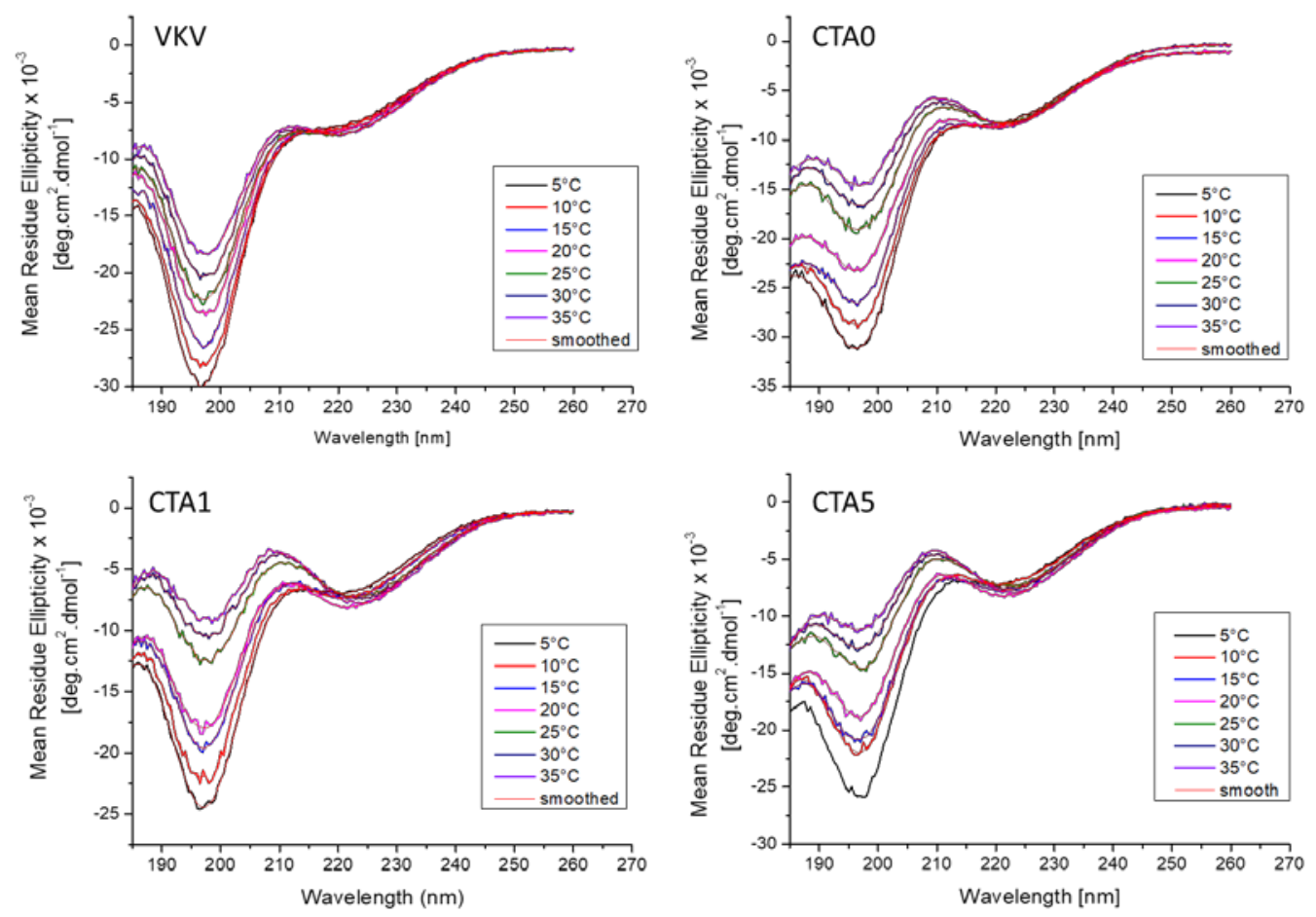

Figure 37: CD raw data before BeStSel fitting.

In general, some controversy still remains regarding the secondary structure of ELRs and, as in most IDPs, some structural features cannot be resolved. $\beta$-turns are the most widely studied structural feature of ELRs found in the literature as, in an ideal arrangement, they can form concatenated ordered $\beta$-helices that could explain the elastic properties of such materials and their thermomechanical behaviour $44,46,112,157,429$. Despite this, a quantitative estimation of protein secondary structures in IDPs remains challenging due to the huge morphological and spectral diversity of structures and their overlap in the CD spectra. As crystal-based X-ray structure determination and solution NMR spectroscopy cannot be used due to the sheer size of the ELR, a deconvolution of recorded CD spectra Figure 37 ) was performed to 
extract more information about substructures and to resolve the effect of the temperature transitions.

The BeStSel algorithm was selected as an approximation of the $\beta$-turn-rich $E \operatorname{Rs}^{44-47}$ as this algorithm has proven to be especially useful for resolving $\beta$ sheet-rich proteins, as well as the twisting angles between $\beta$-strands. Indeed, it improves secondary structure prediction in general, and specifically for $\beta$ structure-rich proteins and amyloid fibrils. Eight substructures, namely regular and distorted helices, turns, parallel and anti-parallel (left-, right-twisted or relaxed) structures and non-specified structures, were extracted ${ }^{391,430,431}$. Regular helices and left-twisted anti-parallel structures were not observed in any of the modifications and were thus excluded. The five sub-structures extracted are shown in Figure 39. Above the LCST of control samples VKV and CTA0, the formation of parallel and anti-parallel (relaxed) structures were observed, with this being directly related to the temperature transition of the ELR (LCST) as they form at the same temperature as the cloud point (supporting information Figure S4).
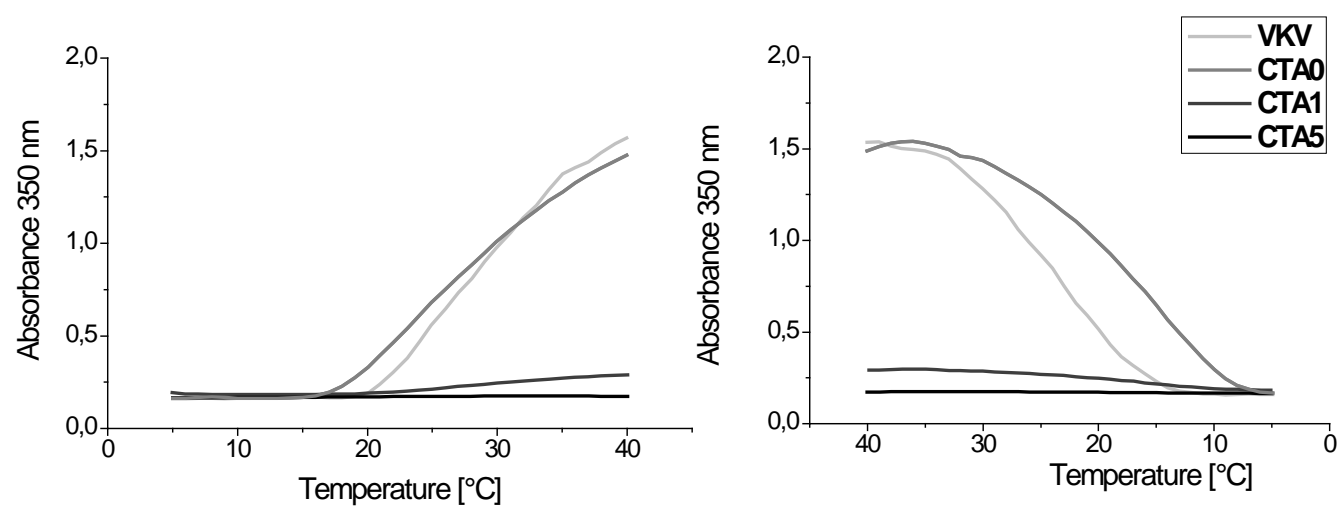

Figure 38: Cloud point determination of modified ELRs. Left heating, right cooling

Moreover, the content of secondary structures like anti-parallel (right twisted) and distorted helical features decreases above the LCST. Over the 
whole temperature range, turn and helical structures remain essentially constant in VKV, whereas a decrease in the onset of the LCST is found in the modified samples, with this being best resolved in CTA5. The amount of anti-parallel (right twisted) structures increased with decreasing temperature in all samples, and, for CTA5, below $10^{\circ} \mathrm{C}$ it dropped from $23 \%$ $\left(10^{\circ} \mathrm{C}\right)$ to $16 \%\left(5^{\circ} \mathrm{C}\right)$, a similar value to that observed for VKV and CTAO (above the LCST; $25-35^{\circ} \mathrm{C}$ ). Interestingly, CTA5 revealed similar a structural distribution of parallel, anti-parallel (relaxed), anti-parallel (right twisted) and distorted helical structures at $5^{\circ} \mathrm{C}$ as above the LCST, thus suggesting the presence of a UCST (The corresponding experimental and BeStSel fitten data points are presented in Table 18.

In general, temperature changes alter polymer-water interactions, which become unfavorable below the UCST and above the LCST, thereby minimizing exposure of the macromolecule to water ${ }^{4 / 2}$. In polymers presenting a UCST, this transition is enthalpy driven, related to partial hydration upon heating ${ }^{229}$ and the LCST is determined by the entropy of water (hydrophobic effect) ${ }^{432}$. As such, we predict a less-soluble material with a stronger tendency to form globules with a hydrophobic core. This explains the relatively constant hydrodynamic diameter of CTA5, supported by the hydrophobicity of cholesterol, which might lead to stabilized particles that are less affected by temperature changes. The structural analogy of LCST and UCST states in CTA5 further supports the hypothesis that the underlying ELR backbone determines structural flexibility driven by changes in the hydrophobicity either by entropy-driven exposure of the hydrophobic domains of the ELR (above the LCST), or by enthalpic intermolecular interactions between cholesteryl groups (below the UCST). 

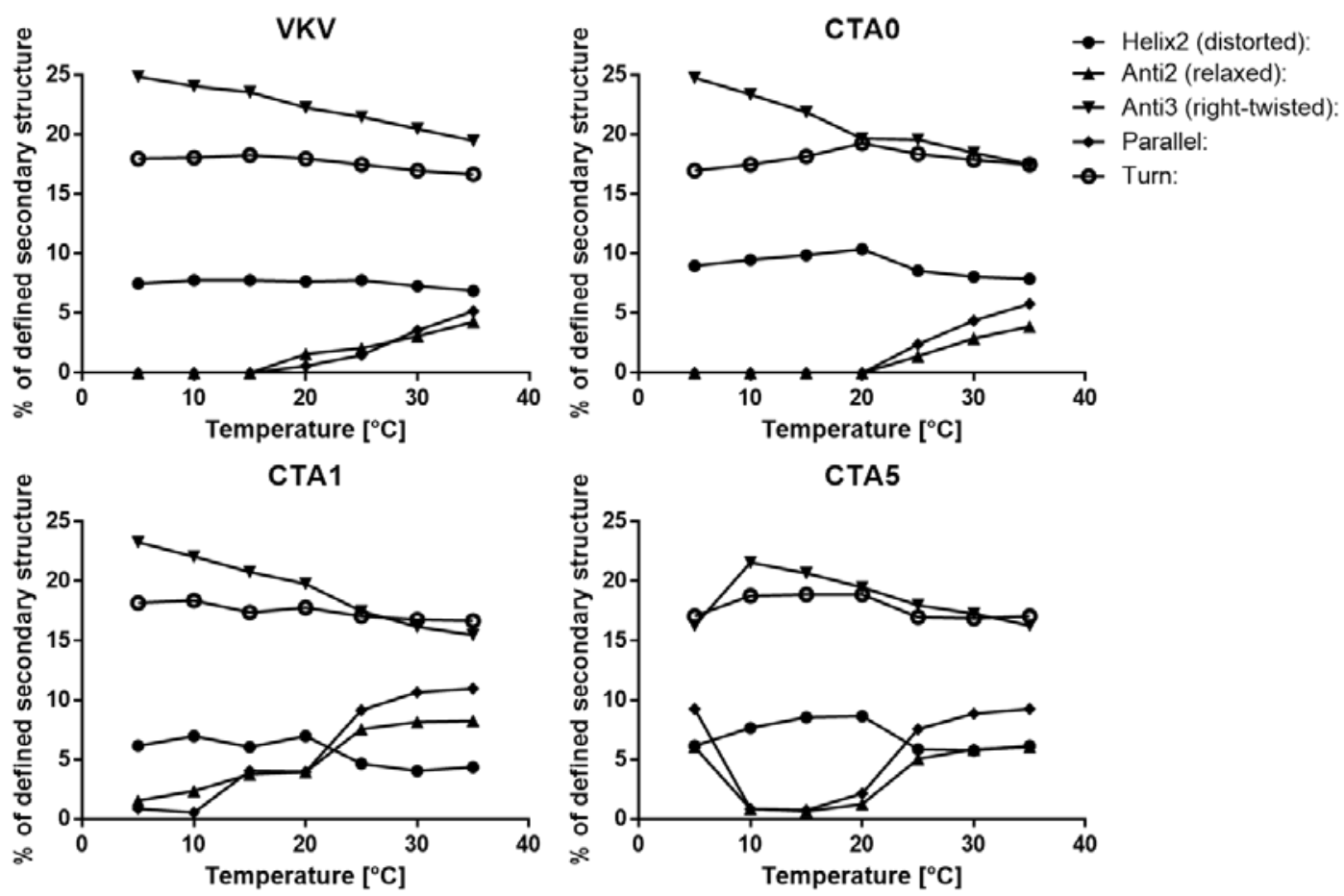

Figure 39: Results from circular dichroism, deconvoluted using the BeStSel algorithm, showing the relative distribution of distorted helix $(\bullet)$, relaxed $(\mathbf{\Delta})$ or right-twisted $(\boldsymbol{\nabla})$ anti-parallel betasheets, parallel beta sheets $(\diamond)$ or turns $(\circ)$. For VKV and CTA0 $\bullet$ and $\boldsymbol{\Delta}$ appear at temperatures between $20-25^{\circ} \mathrm{C}$ which is in correlation with observed LCST transitions, surprisingly the same is as well observed in CTA5 at temperatrues below $10^{\circ} \mathrm{C}$.

Herein, and to the best of our knowledge, we show for the first time that a UCST can be induced by side-chain modifications that foster a similar secondary structure distribution below the UCST as observed above the intrinsic LCST. Keeping in mind the theory of IDP, an order can be induced in all cholesteryl bearing protein samples by moving below the UCST or above the LCST (Figure 40). Surprisingly, in CTAI a higher order, characterized by a higher degree of parallel and anti-parallel (relaxed) structures, is obtained above the LCST than observed in CTA5. This reduced reorganization might be explained by the presence of less dynamic particles, which are held together intramolecularly by more than one cholesteryl group, thereby impairing fast reorganization at high 
temperatures, which is in accordance with the less dynamic particle sizes obtained by DLS. In contrast, below the UCST, parallel and anti-parallel (relaxed) structures only occur to a detectable extent in CTA5, thus resulting in a $U$-shaped temperature versus secondary structure profile (Figure 39). However, the algorithm has been applied to differentiate recombinant elastin-based polypeptides, and zwitterionic recombinant polypeptides recently ${ }^{433}$, but structural differences upon changes in charge were not stated.

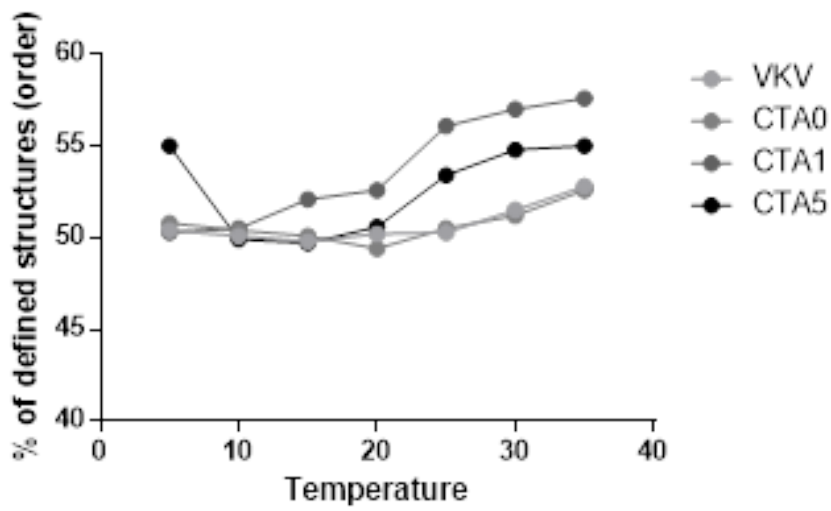

Figure 40: The accumulated percentage of secondary structures by CD defines the total order of proteins in solution. The missing percentage corresponds to random, or structural components unrecognized by the used algorithm.

\subsubsection{Characterization of gelation}

To characterize the cool gelation, solutions of higher concentration $(0.75$ $\mathrm{mM}$ ) were prepared and investigated using flow and oscillatory rheology techniques. Oscillatory measurements were performed using a heating and cooling cycle $\left(25-2-50^{\circ} \mathrm{C}\right)$ and showed a complete reversibility of gelation. In general, no gelation was observed in the absence of cholesteryl side groups and the strength of the gel, as expressed by the storage modulus, 
increased with the number of side groups (3I Pa for CTAI and $60 \mathrm{~Pa}$ CTA5; Figure 43A). Moreover, no increase in storage modulus was observed above the LCST, where coacervation of the ELR takes place. To determine the viscosity, flow experiments were performed with shear rates from 10 to $1000 \mathrm{~s}^{-1}$ at different temperatures. The viscosity and stress decreased with temperature or shear rate (viscosity vs. shear rate, supporting information Figures S7 and S8) in all samples.

Table 15: Comparison of viscosities obtained from flow measurements at a shear rate of $60 \mathrm{~s}$ '(Exp.) using parameters derived from the Bingham and Herschel-Bulkley models.

\begin{tabular}{|c|c|c|c|c|c|c|}
\hline \multicolumn{2}{|c|}{ Sample } & \multirow{2}{*}{$\begin{array}{l}\text { Exp.: } \\
\eta(\mathrm{Pa} \mathrm{s})\end{array}$} & \multicolumn{2}{|l|}{ Bingham } & \multicolumn{2}{|c|}{ Herschel-Bulkley } \\
\hline & $\begin{array}{l}\mathrm{T} \\
\left({ }^{\circ} \mathrm{C}\right)\end{array}$ & & $\sigma_{0}(\mathrm{~Pa})$ & $\mathrm{A}(\mathrm{Pa} \mathrm{s})$ & $\sigma_{0}(\mathrm{~Pa})$ & $\mathrm{n}$ \\
\hline CTAO & 5 & $0.0204 \pm 0.0009$ & $0.798 \pm 0.007$ & $0.0096 \pm 0.000 \mid$ & $0.798 \pm 0.007$ & -0.464 \\
\hline & 15 & $0.0203 \pm 0.0005$ & $0.786 \pm 0.012$ & $0.007 \mid \pm 0.0002$ & $0.786 \pm 0.012$ & -0.586 \\
\hline & 25 & $0.0173 \pm 0.0003$ & $0.769 \pm 0.014$ & $0.0055 \pm 0.0002$ & $0.769 \pm 0.014$ & -0.695 \\
\hline & 35 & $0.0098 \pm 0.0006$ & $0.259 \pm 0.003$ & $0.0096 \pm 0.0002$ & $0.259 \pm 0.003$ & -0.755 \\
\hline CTAI & 5 & $0.0213 \pm 0.0008$ & $0.840 \pm 0.017$ & $0.007 \mid \pm 0.0003$ & $0.840 \pm 0.017$ & -0.594 \\
\hline & 15 & $0.0203 \pm 0.0005$ & $0.769 \pm 0.014$ & $0.0079 \pm 0.0002$ & $0.769 \pm 0.014$ & -0.548 \\
\hline & 25 & $0.0177 \pm 0.0004$ & $0.856 \pm 0.010$ & $0.004 I \pm 0.0002$ & $0.856 \pm 0.010$ & -0.824 \\
\hline & 35 & $0.0093 \pm 0.0008$ & $0.248 \pm 0.004$ & $0.0043 \pm 0.0002$ & $0.248 \pm 0.004$ & -0.798 \\
\hline CTA5 & 5 & $0.1880 \pm 0.0165$ & $|2.935 \pm 0.39|$ & $0.0326 \pm 0.0067$ & $12.935 \pm 0.396$ & +0.052 \\
\hline & 15 & $0.0599 \pm 0.0008$ & $3.124 \pm 0.035$ & $0.0104 \pm 0.0006$ & $3.124 \pm 0.035$ & -0.432 \\
\hline & 25 & $0.0414 \pm 0.0005$ & $2.160 \pm 0.019$ & $0.0056 \pm 0.0003$ & $2.160 \pm 0.019$ & -0.690 \\
\hline & 35 & $0.0236 \pm 0.0014$ & $1.323 \pm 0.010$ & $0.0038 \pm 0.0005$ & $1.323 \pm 0.010$ & -0.850 \\
\hline
\end{tabular}

With respect to the function-valued nature of rheologically complex material properties, fitting to the Herschel-Bulkley and Bingham models gave low-dimensional representations, thus allowing for a better 
comparison. Thus, the yield stress $\left(\sigma_{0}\right)$ and plastic viscosity $(A)$ were obtained by fitting to the Bingham model:

$$
\sigma=\sigma_{0}+A x
$$

The three-parameter Herschel-Bulkley model is typically written as:

$$
\sigma=\sigma_{0}+K x^{n}
$$

where $\sigma_{0}$ is the yield stress of the material, $K$ is the consistency factor, and $n$ is the flow behavior index. Essentially, the behavior of the material is governed by these three Herschel-Bulkley parameters. The results are displayed in Table 15.

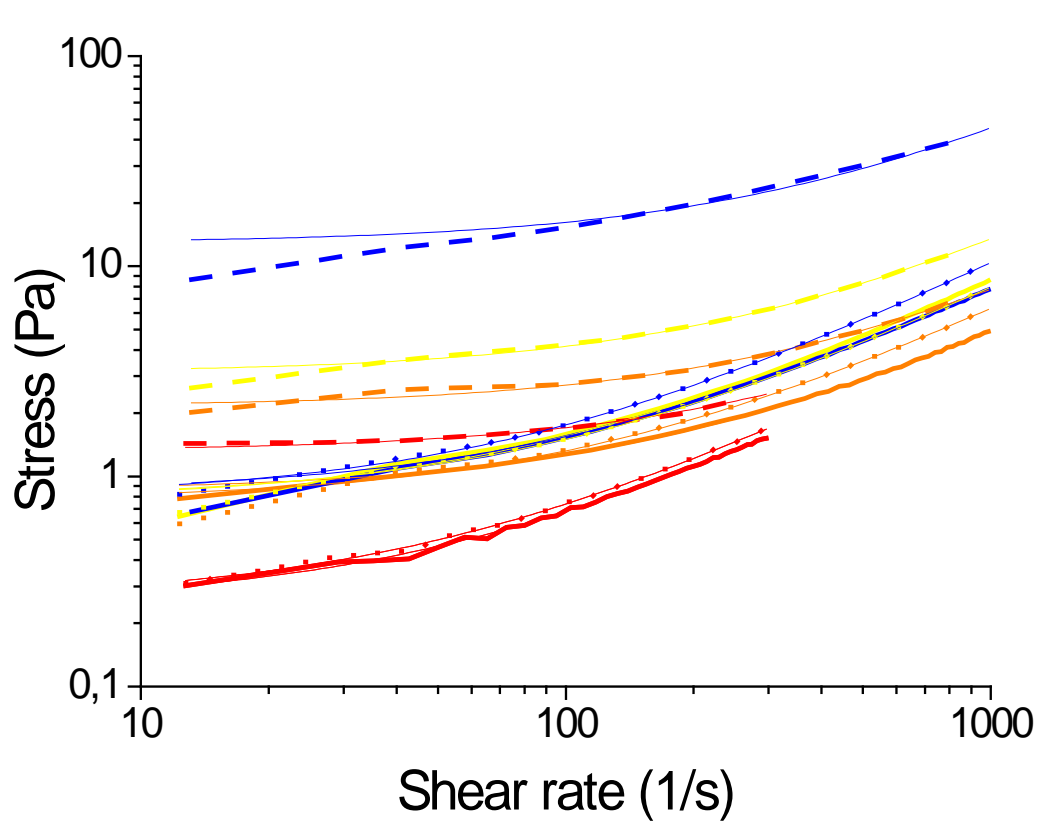

CTAO

$-35^{\circ} \mathrm{C}$

$-25^{\circ} \mathrm{C}$

$-15^{\circ} \mathrm{C}$

$5^{\circ} \mathrm{C}$

CTA1

$\cdots 35^{\circ} \mathrm{C}$

$\ldots 25^{\circ} \mathrm{C}$

$15^{\circ} \mathrm{C}$

$\cdots 5^{\circ} \mathrm{C}$

CTA5

$-35^{\circ} \mathrm{C}$

$--25^{\circ} \mathrm{C}$

$-15^{\circ} \mathrm{C}$

$--5^{\circ} \mathrm{C}$

Figure 4I: Stress over shear rate raw data with Herschel Bulkley Fit (thin line). 


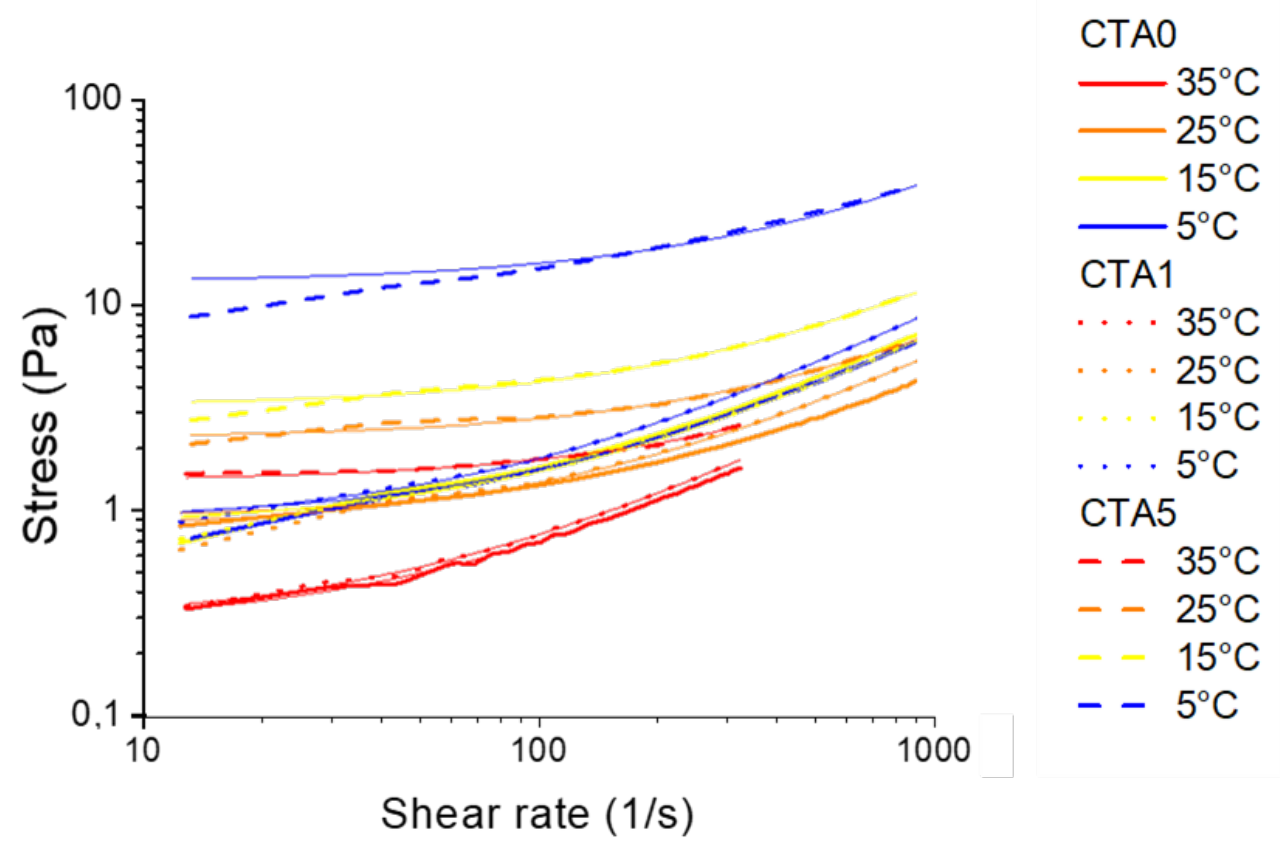

Figure 42: Stress over shear rate raw data with Bingham Fit (thin line).

A

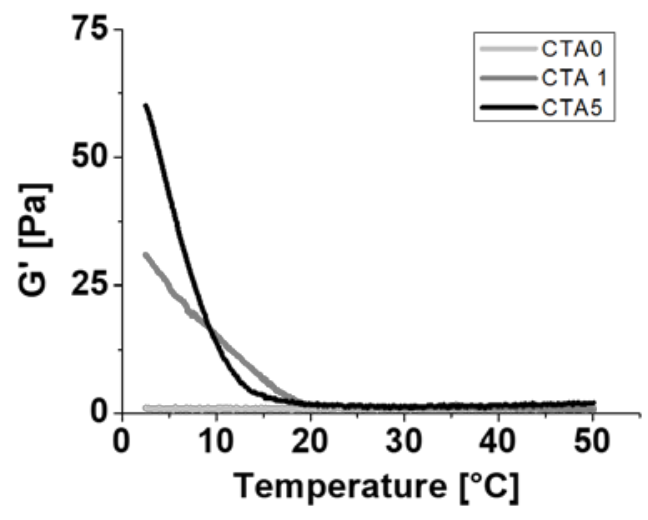

B

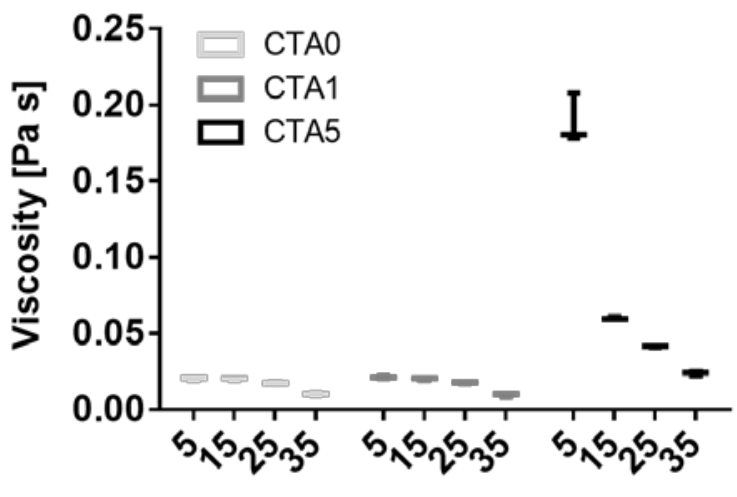

Temperature $\left[{ }^{\circ} \mathrm{C}\right]$

Figure 43: Rheological characterization of samples under gelling conditions (0.75 mM). A) Oscillatory measurement, the evolution of G' with temperature. B) Flow measurement, values displayed for a shear rate of $60 \mathrm{~s}^{-1}$ (complete dataset available as supporting information).

At a shear rate of $60 \mathrm{~s}^{-1}$, CTA0 and CTAI behave quite similarly, with CTAI having a slightly higher viscosity at $5^{\circ} \mathrm{C}$. As the temperature decreases below 
$10^{\circ} \mathrm{C}$, into the gelation window of CTA5, the viscosity rises dramatically, yielding values more than one order of magnitude higher than for CTA0. A similar trend, albeit with smaller values, was obtained for the plastic viscosity derived from the Bingham model. The yield stresses were essentially constant) for CTAO and CTAI in the temperature range $5-25^{\circ} \mathrm{C}$, with a small variation from $0.769-0.856 \pm 0.037 \mathrm{~Pa}$. A more significant decrease by approximately $66 \%$ was observed at $35^{\circ} \mathrm{C}$, with no difference between the two models. CTA5 had significantly higher yield stress (fivefold higher) of $13 \mathrm{~Pa}$ at $5^{\circ} \mathrm{C}$, decreasing with temperature to $2-3 \mathrm{~Pa}$ at $15-25^{\circ} \mathrm{C}$ (still 3-4 fold higher than for $\mathrm{CTA} 0$ ), and to I.3 $\mathrm{Pa}$ at $35^{\circ} \mathrm{C}$. Higher yield stresses and viscosity upon changes in secondary structure have been reported previously in solutions of carrageen, a polysaccharide that exhibit comparable high yield stresses and $n$-indices at its $\mathrm{UCST}^{416}$, upon reducing the temperature, which is also driven by an increase in order (random coil to helix) ${ }^{434}$.

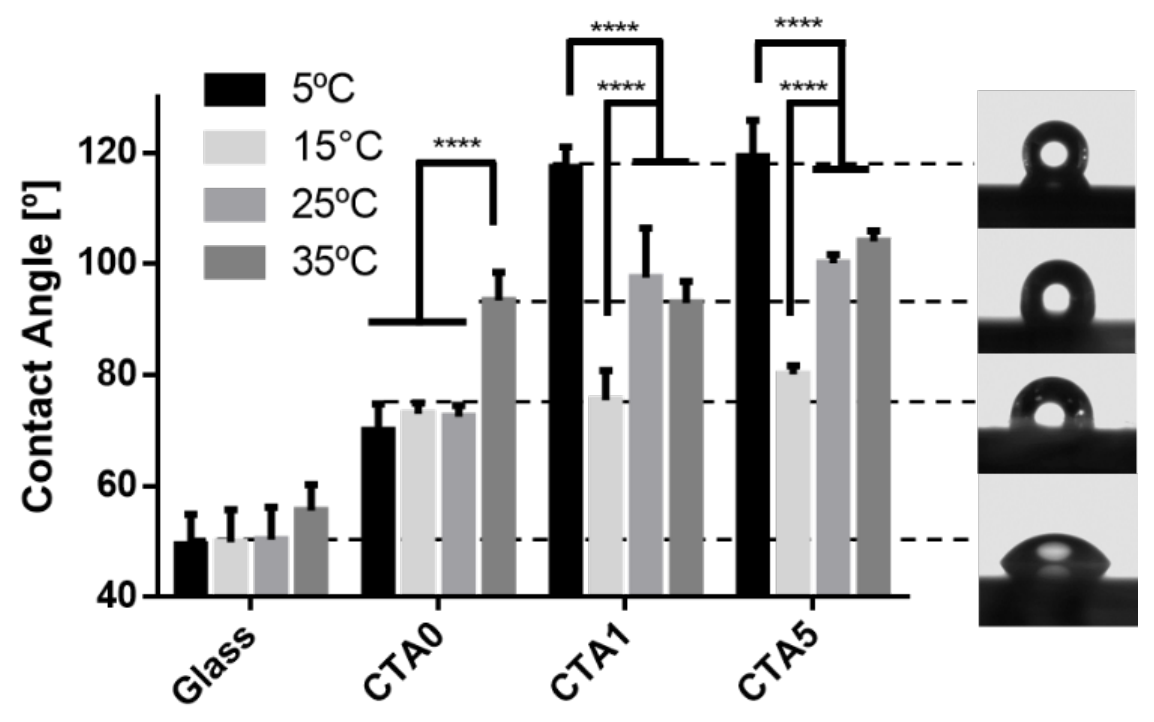

Figure 44: Contact-angle measurements for solvent-cast CTA samples at different temperatures. Representative images of drops correspond to contact angles for the corresponding dashed lines. 
To support the hypothesis of outward-facing cholesteryl groups, contactangle measurements were performed on solvent-cast films at varying temperatures to investigate the temperature dependence of the surface hydrophobicity.

In CTA0, the hydrophobicity of the substrate only changed (from $72^{\circ}$ to around $95^{\circ}$ ) when heating above $25^{\circ} \mathrm{C}$. The cholesteryl-containing samples had three states of hydrophobicity, with the first at around $72^{\circ}$ at $15^{\circ} \mathrm{C}$ (comparable to CTA0 below $25^{\circ} \mathrm{C}$ ), the second at around $95-100^{\circ}$ at 25 and $35^{\circ} \mathrm{C}$ (comparable to CTAO above $25^{\circ} \mathrm{C}$ ), and the third at around $120^{\circ}$ below the supposed UCST at $5^{\circ} \mathrm{C}$. In cholesteryl-containing samples at low temperatures, the hydrophobicity increases in such a way that noncondensing films with hydrophobicities of $120^{\circ}$ and higher were obtained. Although the transition temperature of hydrophobicity measurements between 25 and 35, are slightly higher than the measured cloud point values, temperature transition seems to be the key driver, considering the results of the CD. We believe, that these films support the formation of gels at the same temperature driven by hydrophobic interactions, which become more accessible due to the structural change. A closer look at other UCST-type polymers with low-temperature gelation properties shows that they all exhibit a betaine-like zwitterionic-phenotype $\mathrm{e}^{415-419}$. The combination of the negative surface potential of the CTA samples together with the positively charged lysine residues means that these systems can be considered to be a pseudo-zwitterionic phenotype, which would be in agreement with the formation of other UCST gels. Furthermore, we believe that low temperature gelation/aggregation is fostered by structural changes that increase hydrophobic (cholesterol-cholesterol) interactions, thus meaning that an increase in temperature would deteriorate the physical stability and disrupt the gel. Additionally, CA and ZP experiments also suggest a lower electrostatic repulsive and higher hydrophobic attractive surface potential 
between the micelles. Other cholesterol-bearing materials that exhibit nano-aggregation into hydrogels, like pullulan ${ }^{229,231}$ and antimicrobial peptides, or deoxycholic acid modified heparin ${ }^{232}$ and chitosan ${ }^{233}$, were described by the poly-core model ${ }^{229}$ as self-aggregated nanoparticle forming non-covalently cross-linked supramolecular hydrogel structures mediated by hydrophobic association of cholesterol moieties. Furthermore, the characteristic temperature to cause a structural change decreased with the degree of cholesteryl substituions ${ }^{229}$. It is noteworthy, that based on the findings of Morishima et al. this effect of self-association is more probable to occur in bulky hydrophobic groups such as cholesterol or deoxycholic acid, than in long alkyl hydrocarbon chain ${ }^{229,234}$. Due to the structural analogy of materials, the model is suitable to illustrate the structure of the selfaggregation of nanoparticle into the observed CTA hydrogels at low temperatures.

\subsubsection{Evolution of macrostructures below the UCST}

From the obtained results a phase behavior of CTA5 with two transitions around 10 and $20^{\circ} \mathrm{C}$ with an intermediate region of solubility can be derived. Here solubility is mainly characterized by the absence of parallel and antiparallel (relaxed) secondary structure (Figure 45), The LCST of ELRs is accompanied by structural changes resulting in an increase of these substructures, which seems to be as well the drivers of UCST-type gelation. Since gelation and ordered secondary structures are indicators for hierarchical self-assembly,the long-term effect of cholesteryl ELR was monitored, samples were incubated for I, 3, 7 and 28 days below the UCST 
or above the LCST and then imaged by TEM (I $25 \mu \mathrm{M})$ and SEM (0.25 and I.25 mM).

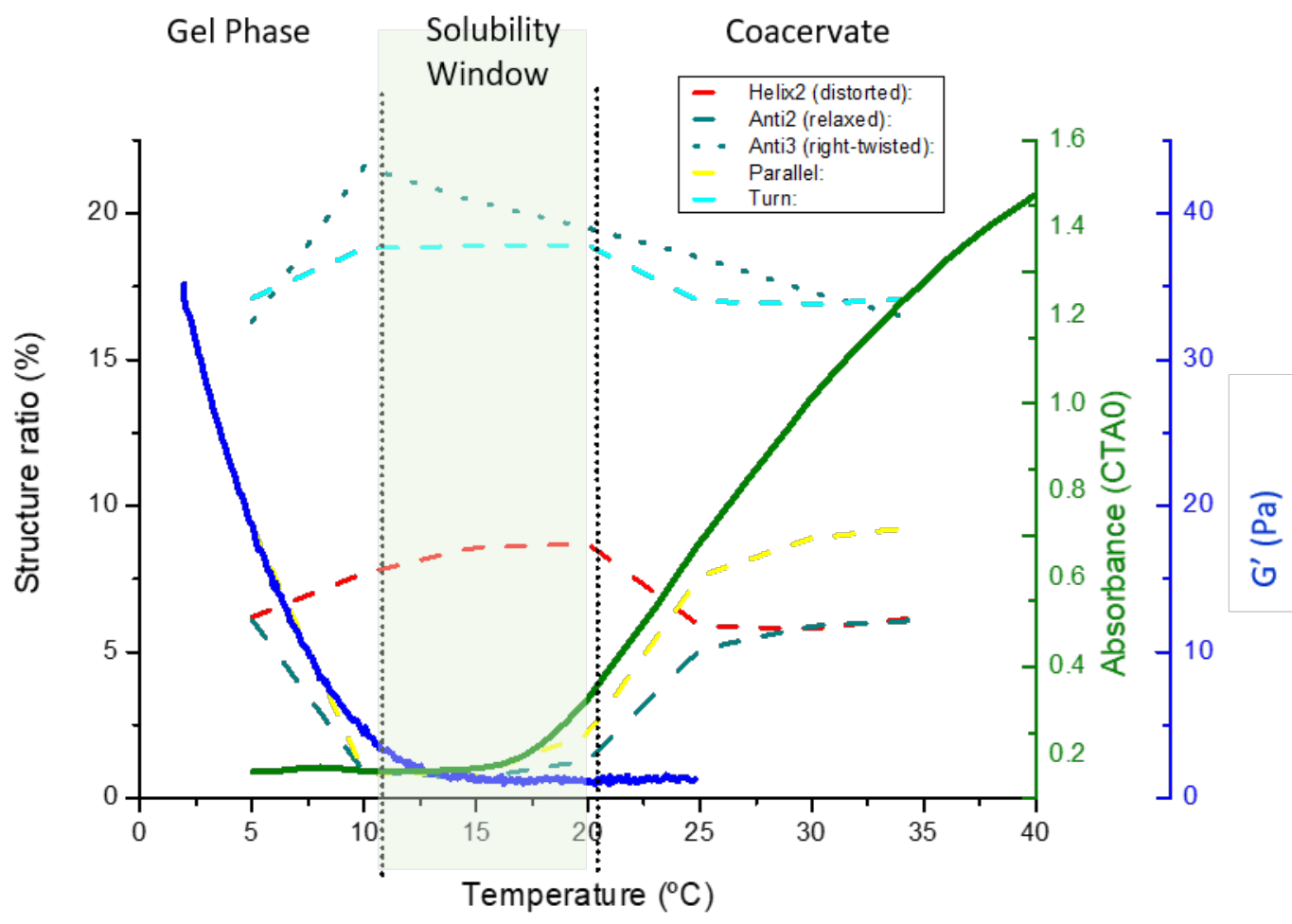

Figure 45: Phasediagram for CTA5,derived from CD data, Absorbance and rheology. Changes in the secondary structure are in correlation with observed solubility in water. For absorbance CTAO curve was plotted due to the absence of cloudpoint in CTA5 even though secondary structural changes of CTAO and CTA5 above $20^{\circ} \mathrm{C}$ are in accordance.

The evolution of nano-/microstructures over time in low concentration samples below the UCST is shown in Figure 9. In CTAI and 5, the formation of linear nanofibers with diameters ranging from 70 to $100 \mathrm{~nm}$, which seem to originate from spherical micelles, was observed. These nanofibers vary in length from 200 (two spheres) up to several micrometers, with a tendency to form branched structures containing oriented nanofibers (9; D28). In CTA0, self-assembly into linear structures was not observed after 3 days 
two populations of particles, with diameters of $7-10$ and $60 \mathrm{~nm}$, respectively, were observed (in accordance with populations obtained by DLS, Figure S6). Over time (from D7 onwards), these phases separated into domains rich in either type of particles. The $60 \mathrm{~nm}$ and $70-100 \mathrm{~nm}$ micelles correlate with the size obtained by DLS for CTAO and CTA5, respectively. The increased size of cholesterol-bearing ELRs and their stability with temperature has also been demonstrated in cholesteryl-stabilized pullulan colloids, which aggregate above a critical concentration as a result of hydrophobic interactions $^{435}$.

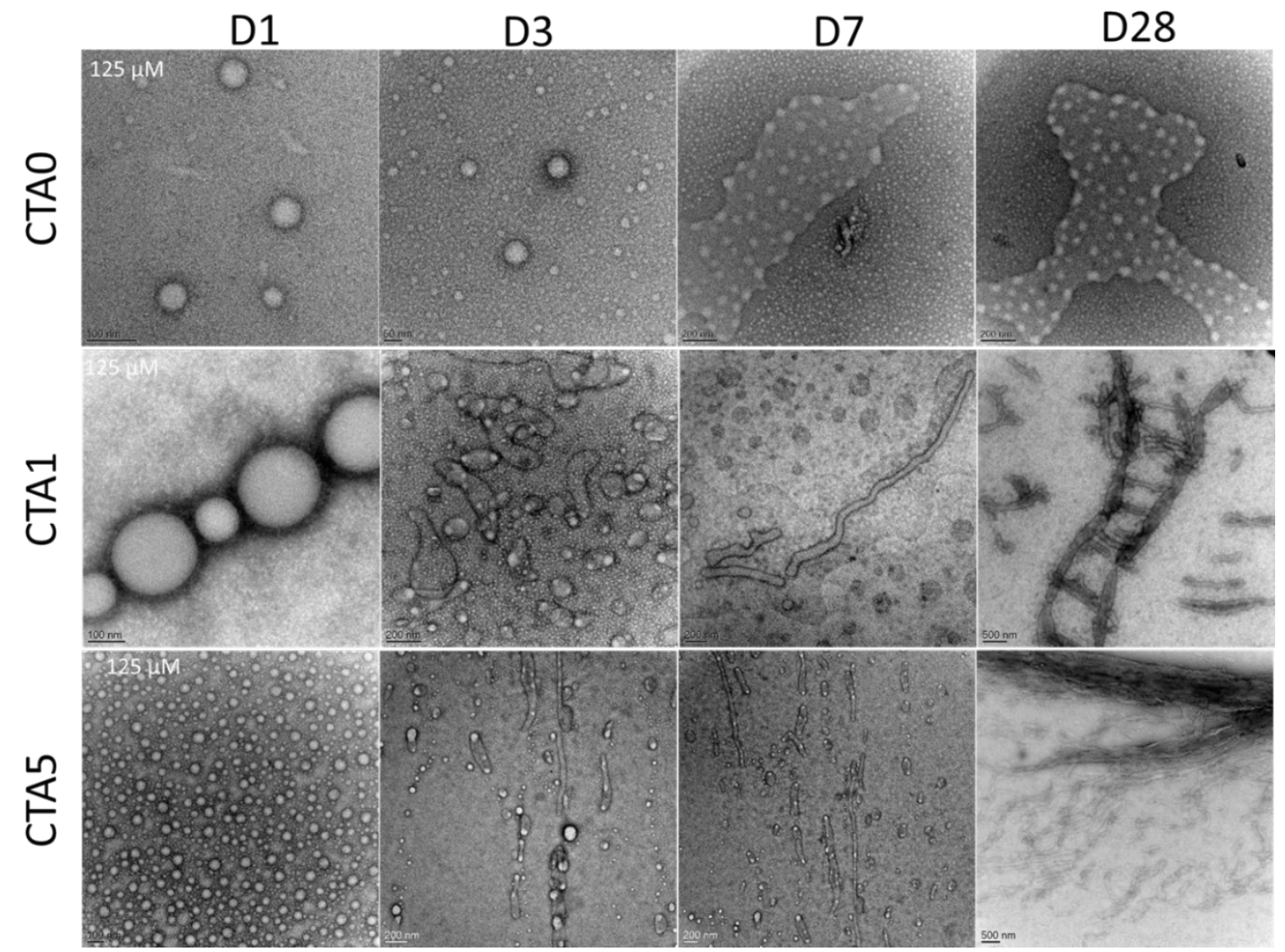

Figure 46: TEM images of CTA samples (I $25 \mu \mathrm{M})$ incubated at $4^{\circ} \mathrm{C}$ for $24 \mathrm{~h}, 3,7$ or 28 days.

When increasing the concentration to $0.25 \mathrm{mM}$, the formation of bundled linear structures was observed by SEM, with these structures evolving into 
small platelets (approx. $5 \mu^{2}$ ) after $24 \mathrm{~h}$. In CTA5, these domains organized over time into bigger planar structures (D3-D7), thus resulting in a honeycomb-like arrangement (D28; Figure 47). The presence of 60-100 nm micelles at the periphery of these planes and bundles indicate their origin as a consequence of micellar coagulation. In all samples, a fivefold increase in concentration led to porous structures from day I onwards. To distinguish between samples, a pore area quantification of an area of $3000 \mu^{2}$ was performed. This study revealed that the pore area tends towards smaller pores over time, with complete depletion of pores bigger than $2.5 \mu \mathrm{m}^{2}$ in CTAI and -5 after 7 days (Figure 48).

D1

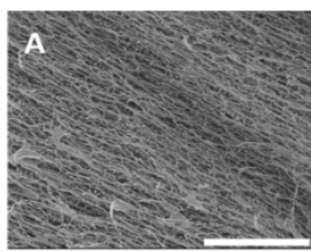

CTAO

CTA1

CTA5
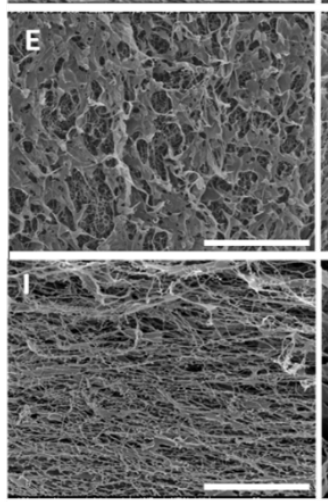

D3

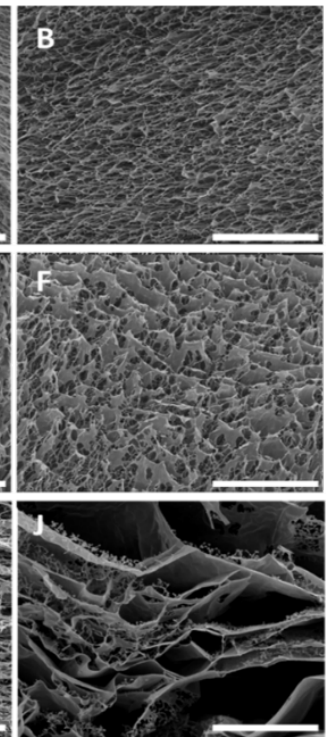

D7

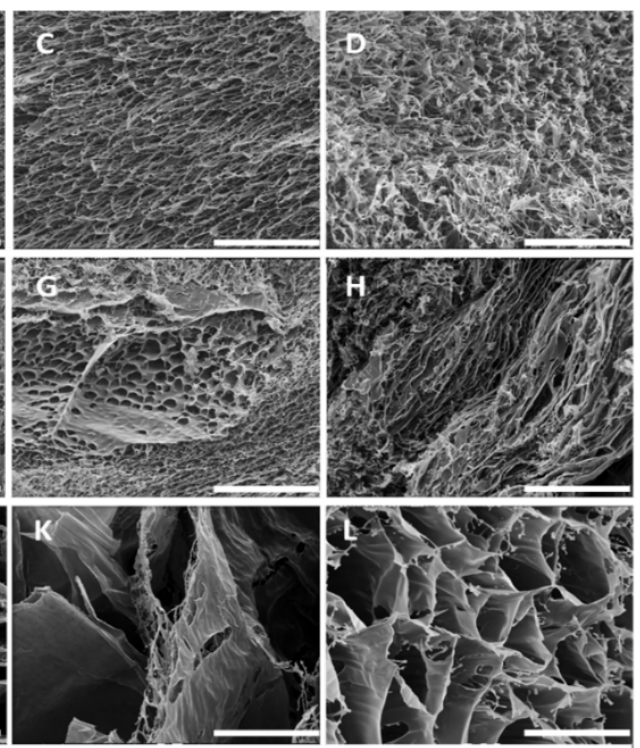

Figure 47: SEM images of CTA samples $(0.25 \mathrm{mM})$ incubated at $4^{\circ} \mathrm{C}$ for $24 \mathrm{~h}, 72 \mathrm{~h}, 7$ days or 28 days. Scale bar: $5 \mu \mathrm{m}$.

Cholesteryl-containing block-copolymers based on amphiphilic glycopolymers with galactose and cholesterol grafts has been shown to form similar self-assembled structures and to form nanofibers similar to those observed in CTAI and CTA5 after cold incubation for 7 days (Figure 46) ${ }^{436}$. Reversible sol-gel formation upon cooling in organic solvents was also 
observed for some cholesteryl modified chiral molecules, with van der Waals forces and $\pi-\pi$ stacking as the main drivers of gelation ${ }^{437}$, which is attributed to the chiral protein backbone of CTAs and a preference for secondary structures below the UCST. Additionally, some proteins such as abductin and resilin, and their corresponding protein-like polypeptides, have been reported to exhibit both a UCST and an LCST ${ }^{60,61}$. When comparing TEM images of a tyrosine-rich resilin-like polypetide below the UCST $\left(4^{\circ} \mathrm{C}\right.$ $10 \mathrm{mg} / \mathrm{mL}$ ) with CTAI and -5 (Figure 46), a similar interconnected gelparticle network is formed, possibly driven by $\Pi-\Pi$ stacking of tyrosines ${ }^{60,438}$. 
D1

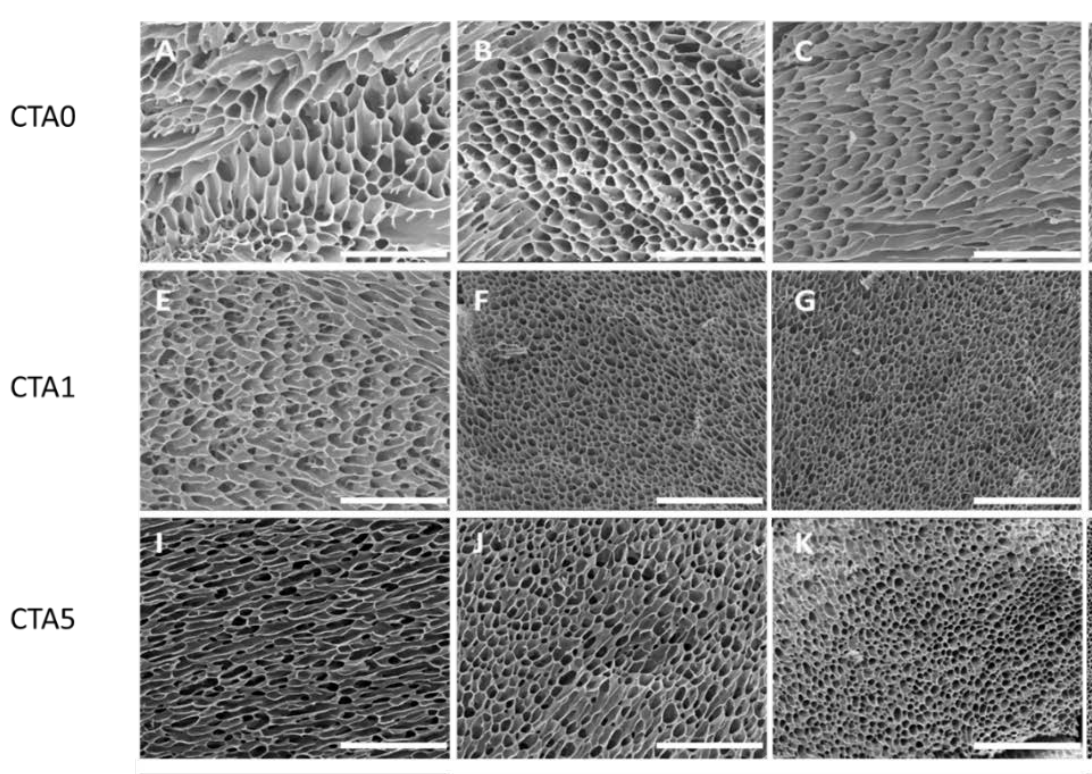

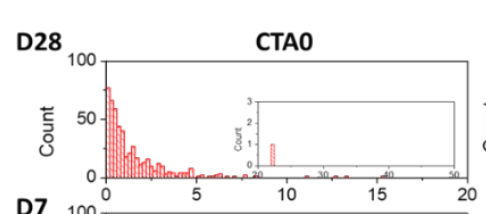
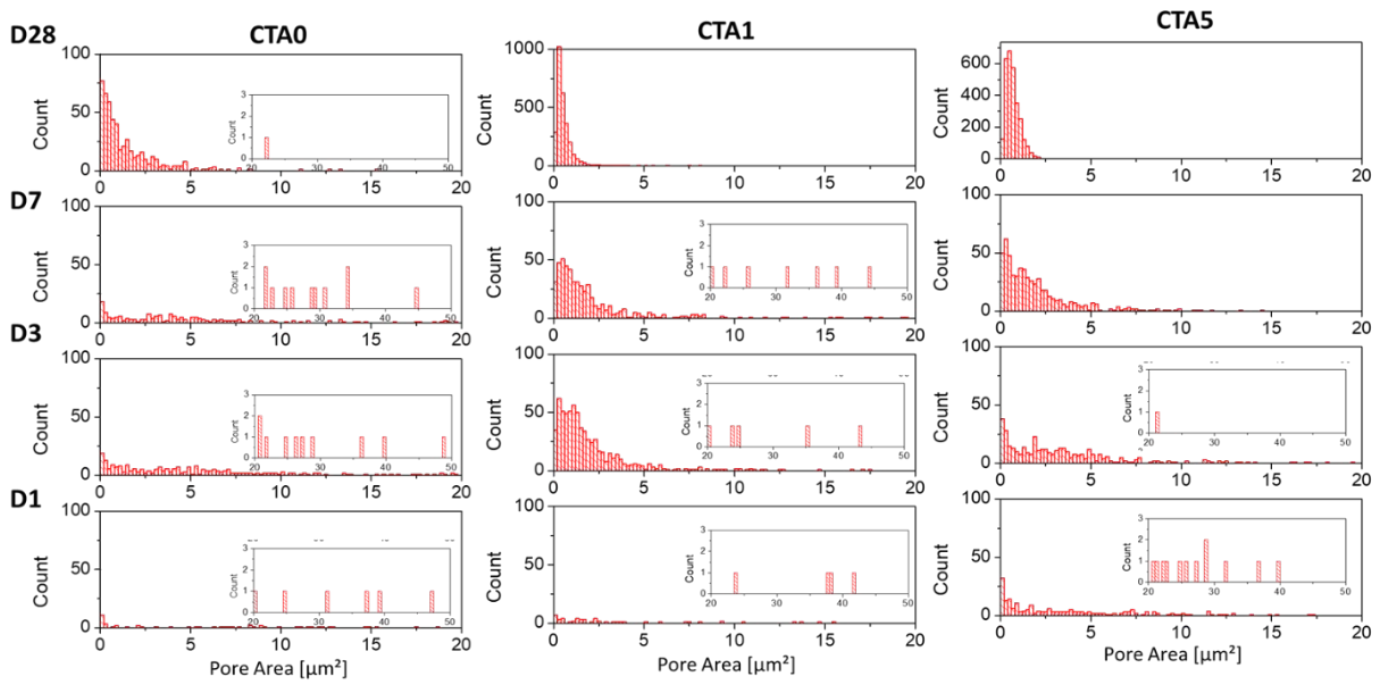

Figure 48: Top: SEM images of CTA samples (I.25 mM)d at $4^{\circ} \mathrm{C}$ for $24 \mathrm{~h}, 72 \mathrm{~h}, 7$ days or 28 days. Scale bar: $10 \mu \mathrm{m}$. Bottom: Pore-size analysis of an area of $3000 \mu \mathrm{m}^{2}$.

\section{Evolution of macrostructures above the LCST}

The structures observed above the LCST, at $37^{\circ} \mathrm{C}$, are characterized by agglomeration, coagulation and precipitation from solution induced by the 
hydrophobic effect in all samples, with no clear differences over time (see Figure 49$)^{439}$

D1
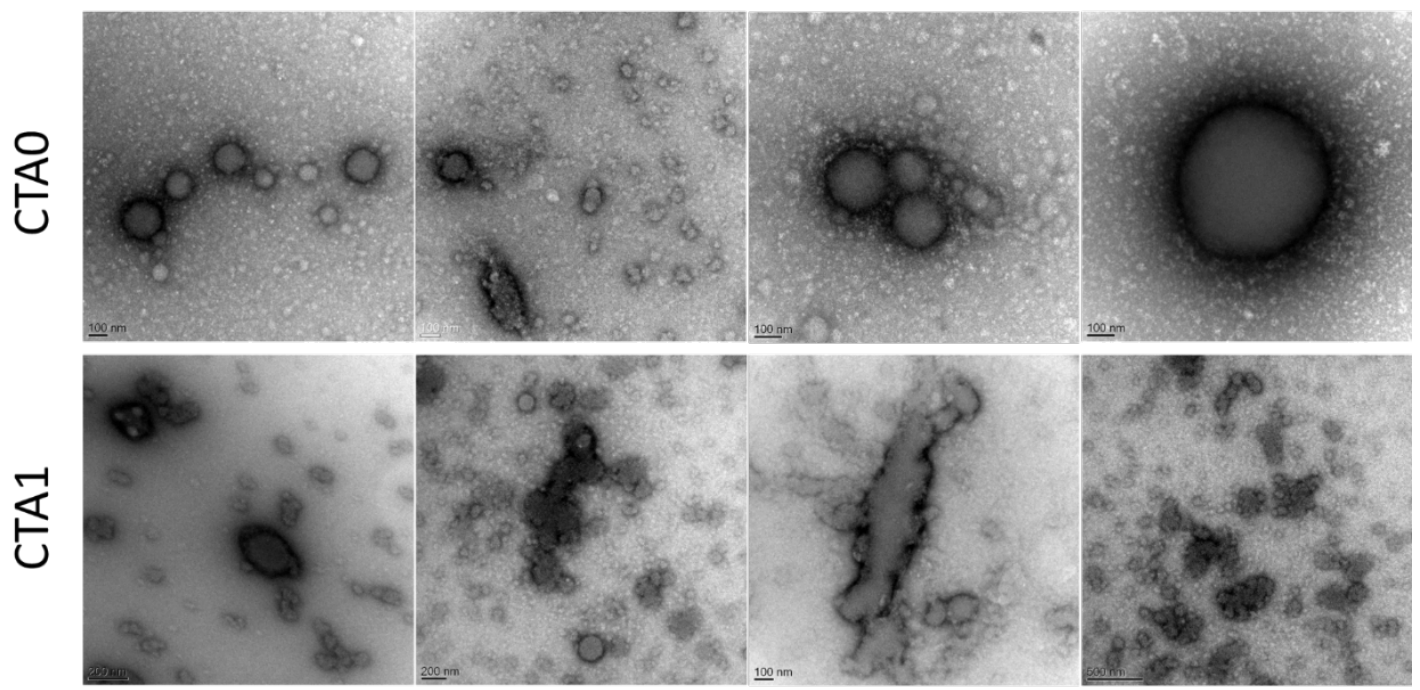

\section{过}

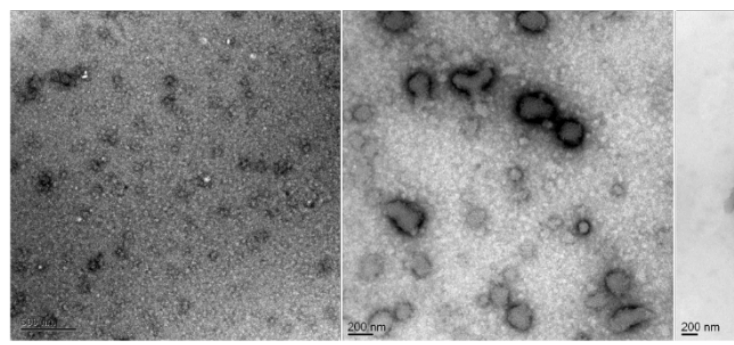

D7

D28

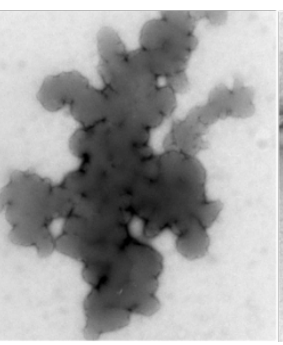

Figure 49: TEM images of CTA samples (I $25 \mu \mathrm{M})$ incubated at $37^{\circ} \mathrm{C}$ for $24 \mathrm{~h}, 3,7$ or 28 days.

Increasing the concentration to $0.25 \mathrm{mM}$ results in more organized structures similar to those obtained below the UCST in the first 7 days of incubation (Figure 50 A-C; E-G; I-K). After 28 days, CTAO tends to form domains with a microphase separation, similar to the separation observed at low concentrations in TEM (Figure $50 \mathrm{D}$ ), whereas in CTAI and CTA5 the structures form a more laminar phenotype (Figure $50 \mathrm{H}$ and $\mathrm{L}$ ). An increase in concentration at $37^{\circ} \mathrm{C}$ leads to the development of pore-like honeycomb structures over time similar to those observed at $4^{\circ} \mathrm{C}$ and, once again, these comprise small micelles and fibers with diameters of approx. 90 $\mathrm{nm}$. Interestingly, in the cholesteryl-rich sample CTA5, these pores develop 
into grooves over time, thus resulting in well-defined parallel polymer platelets with a larger and less quantifiable pore area (Figure $5 \mathrm{I} \mathrm{I}-\mathrm{L}$ ). However, for CTAO and CTAI the pore areas develop towards smaller pores over time, with complete depletion of pores larger than $10 \mu \mathrm{m}^{2}$, comparable to the observations below the UCST.

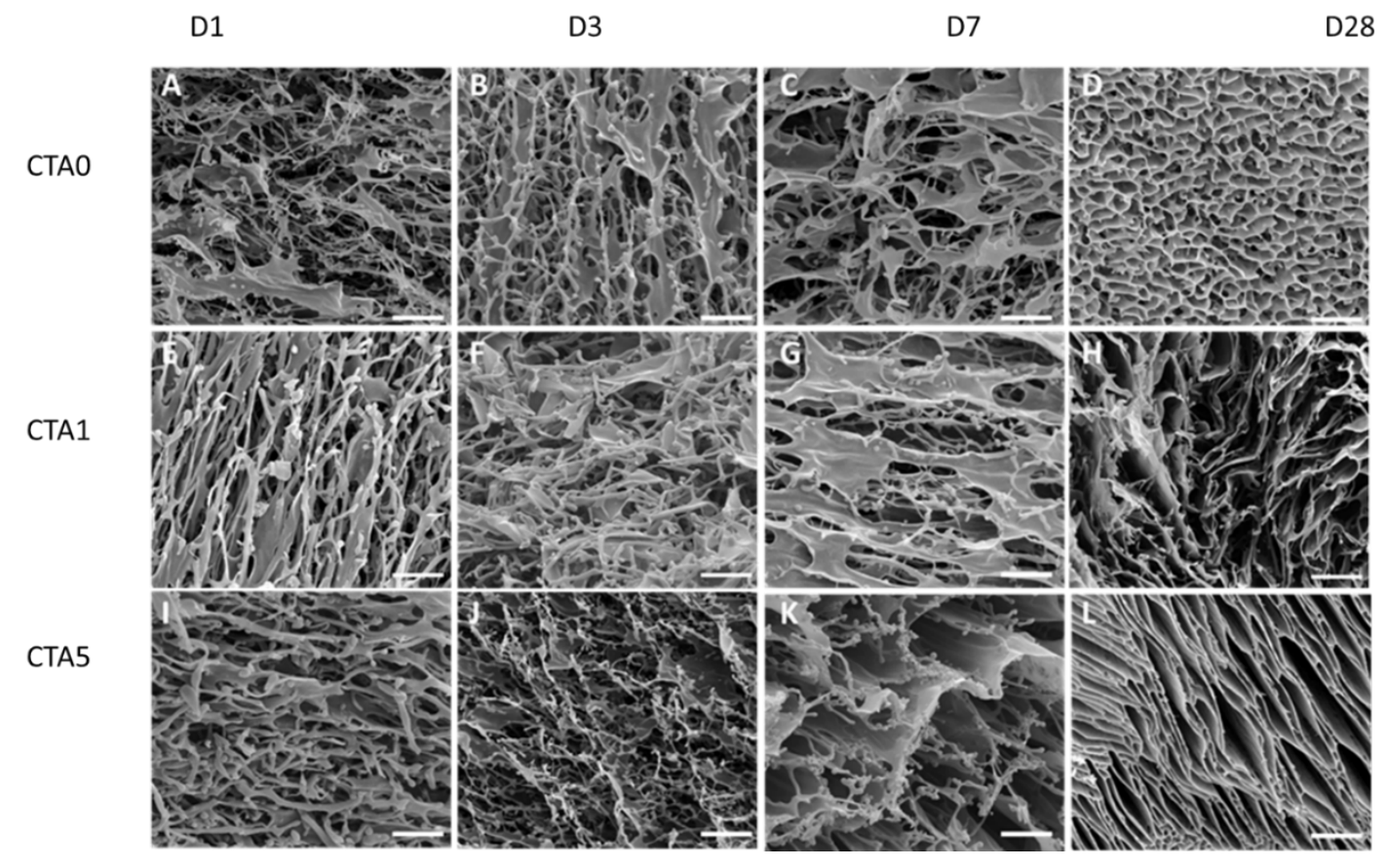

Figure 50: SEM images of CTA samples $(0.25 \mathrm{mM})$ incubated at $37^{\circ} \mathrm{C}$ for $24 \mathrm{~h}, 72 \mathrm{~h}, 7$ days or 28 days. Scale bar: $5 \mu \mathrm{m}$.

CTA5 has a special distribution of hydrophobic and hydrophilic groups, which results in two competing structures (laminar vs. pores). The formation of laminar structures might correlate to the favored formation of orientated nanofibers, whereas branches, which would give rise to pores, are thermodynamically unfavored. At $4^{\circ} \mathrm{C}$, two effects might be responsible for the preference of pores: I) structural exposure of cholesteryl groups leads to stronger intermolecular interactions, thereby augmenting branching towards more and smaller pores, 2) low thermal energy in the systems, which decreases the speed of reorganization towards the 
thermodynamically favored parallel grooves, considering the fact that such grooves are formed after 28 days of hot incubation.

D1
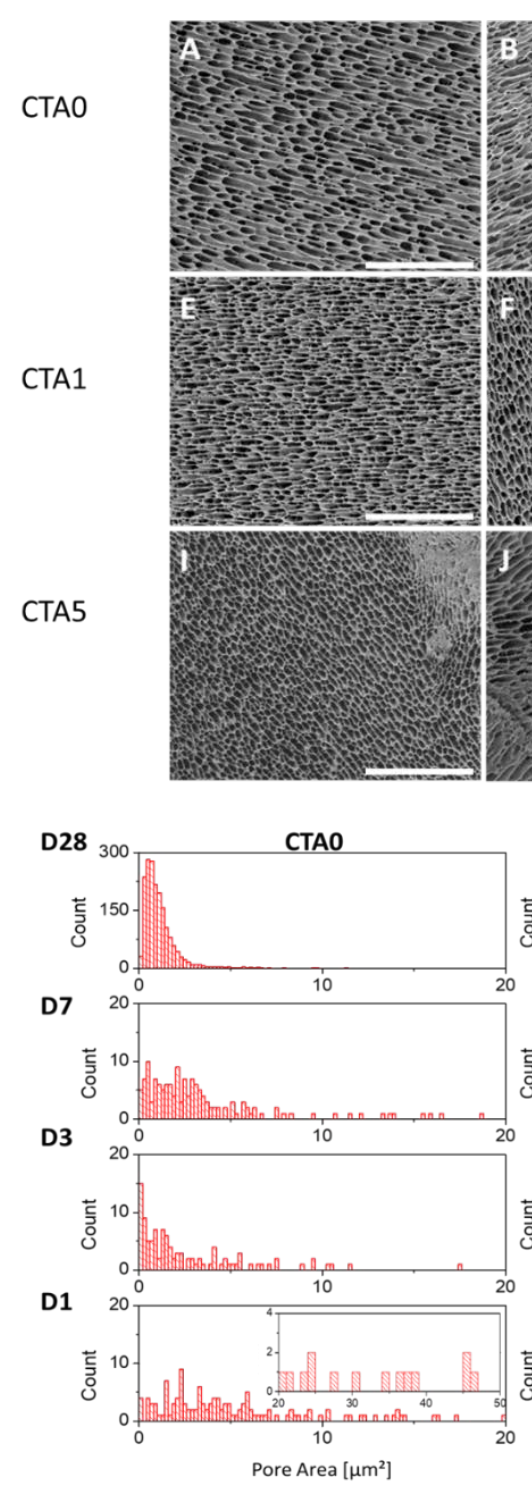

D3
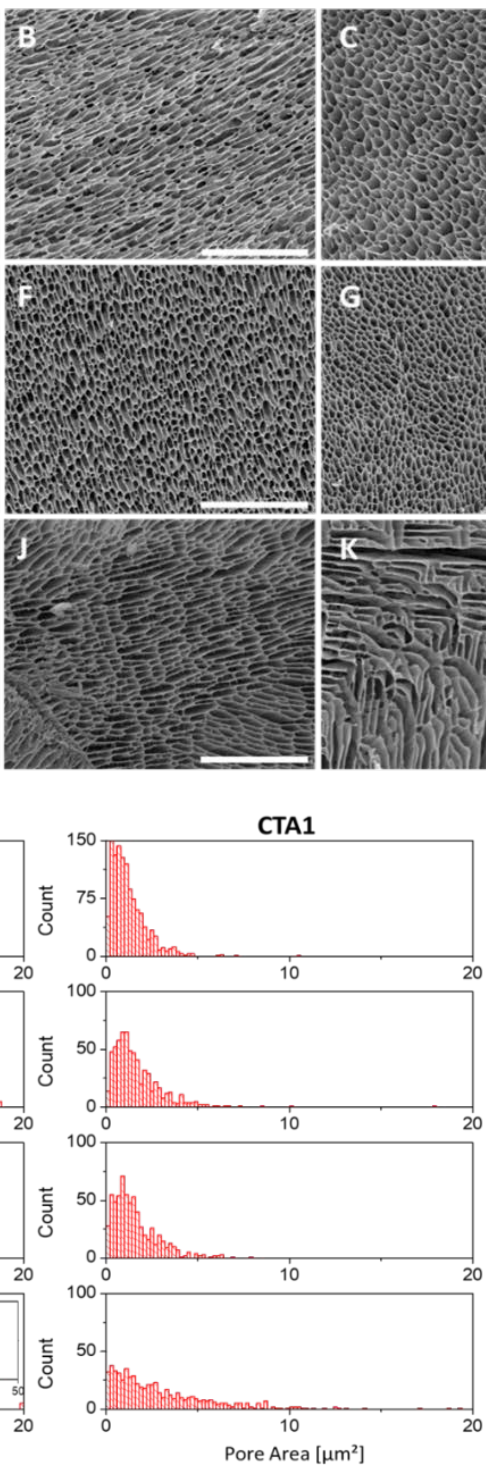

D7
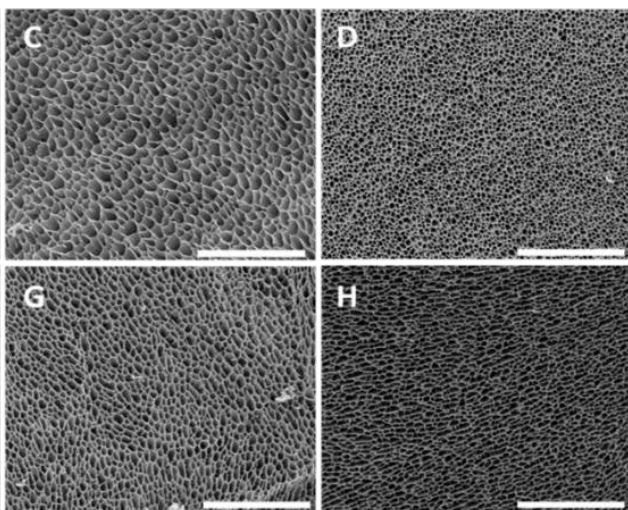

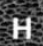
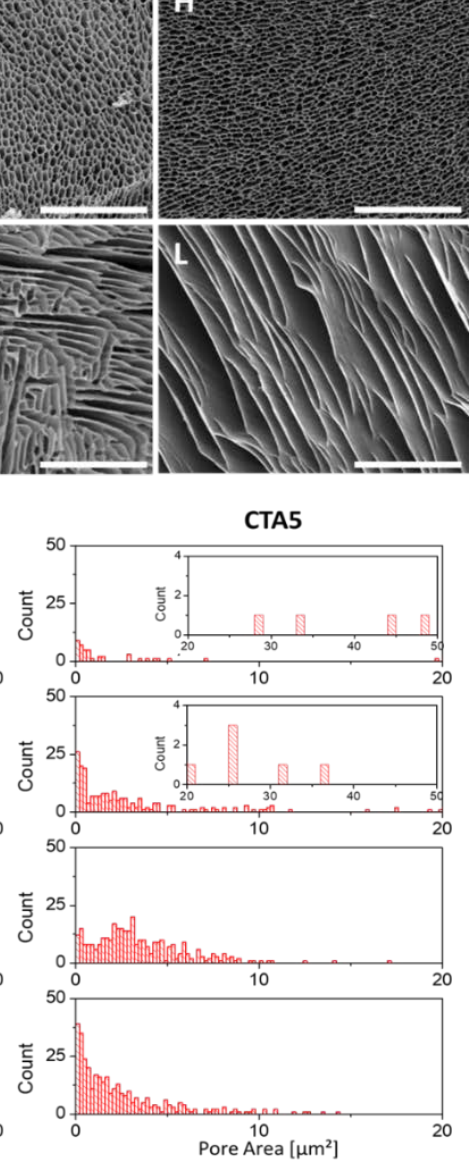

Figure 5 I: Top: SEM images of CTA samples (1.25 mM) incubated at $37^{\circ} \mathrm{C}$ for $24 \mathrm{~h}, 72 \mathrm{~h}, 7$ days or 28 days, Scale bar: $10 \mu \mathrm{m}$. Bottom: Pore-size analysis of an area of $3000 \mu \mathrm{m}^{2}$. 
4.2 CHAPTER 2: Chemical Modification of ELRs with Cholesterol and

Structural Mechanistics of Cholesteryl Group Mediated UCST Gelation 
ACCESSING NEW BIOMEDICAL APPLICATIONS BY COMBINING GENETIC DESIGN AND CHEMICAL MODIFICATION OF ELASTIN-LIKE RECOMBINAMERS 


\subsection{CHAPTER 3: ELR - Cell interaction triggered by hydrophobic modification}

Some of the concepts applied in this chapter are developed in the article:

Hydrophobic cholesteryl moieties trigger substrate cell-membrane interaction of elastin-mimetic protein coatings in vitro Leander Poocza; Sergio Acosta; Matilde Alonso; José Carlos Rodríguez Cabello.

Published in ACS Omega: ACS OMEGA, 2019, 4, 6, 10818-27

DOI: $10.1021 /$ acsomega.9b00548 
ACCESSING NEW BIOMEDICAL APPLICATIONS BY COMBINING GENETIC DESIGN AND CHEMICAL MODIFICATION OF ELASTIN-LIKE RECOMBINAMERS 
Modification of the cellular surface with natural or synthetic polymers allows for new opportunities in tissue regeneration and biomedical engineering. As such, control of the cellular microenvironment has become an important tool for controlling cell growth, cell-cell interactions, cytokine expression, stem cell differentiation and extracellular assembly. Here, the patterning and chemical modification of surfaces ${ }^{440-442}$, the expansion into 3D by using biomimetic or natural hydrogels ${ }^{443-445}$, or Layer-by-Layer (LbL) assemblies onto the cells are the focus of current research ${ }^{90,91,446-448}$. Generally, substrates are bound to the cell membrane via covalent conjugation, hydrogen bonding and electrostatic, dipole-dipole, or hydrophobic interactions. When mimicking the natural interaction of materials with cells, three key events need to be considered: (I) the composition of the material, (2) cell-membrane interactions, and (3) the composition of the cell membrane itself.

The membrane bilayer is a physical barrier that defines the frontier of the cells and segregates the interior into distinct compartments with specialized functions. The amphiphilic nature of the membrane leads to a negatively charged outer surface and a hydrophobic core inside the membrane, which serves as an anchor for membrane and transmembrane proteins. Consequently, cells have the ability to bind substrates via integrin binding, electrostatic interactions, hydrogen bonds, or hydrophobic interactions. Moreover, the membrane contains a variety of compounds and proteins that are crucial for cellular function. One of the most abundant molecules in the membrane is cholesterol, which is found inside the membrane due to its hydrophobicity. Cholesterol is responsible for membrane integrity and cell signaling and accounts for up to $20 \%$ of the membrane's mass ${ }^{63}$. Cholesterol, among the many lipid constituents of mammalian cell membranes, is a key regulator of membrane fluidity and contributes to the formation of caveolae, and in maintaining caveolae microdomain ${ }^{64,65}$. Caveolae are specialized 
domains of the plasma membrane that are found in most cell types ${ }^{66}$. However, they are more abundant in cells like adipocytes, endothelial cells, fibroblasts, and muscle cells ${ }^{67}$. In addition to the influence of membrane fluidity, cholesterol is important for cell structure and function, it is essential in locomotion and serves as a metabolic precursor for several signaling molecules, including oxysterols ${ }^{68}$, steroids ${ }^{228}$ and bile acids ${ }^{65,69,70}$.

The majority of substrates or hydrogels focus on integrin binding sites, in particular the RGD binding site, to generate cell binding, or infiltration. Synthetic materials with covalently bound RGD residues nevertheless struggle to meet the results of native ECM protein materials ${ }^{71}$. Other research for the fabrication of 3D-tissue constructs has focused on cell sheet engineering ${ }^{62}$, magnetic liposomes ${ }^{72}$, cell beads ${ }^{73}$, and cells containing gel layers ${ }^{74-76}$. In particular, the creation of cell type specific and target tissue specific nano- and microdomains using biological interactions, such as avidin-biotin $^{77-80}$, antibody-antigen ${ }^{81,82}$, lectin-polysaccharides ${ }^{83,84}$, or ECM proteins like fibronectin, collagen and/or gelatin ${ }^{74,75,85-89}$, has shown promising results in "hierarchical-cell manipulation" in vitro $85,88,90,91$.

In this approach, a cell coating based on hydrophobic interactions with the cell membrane is presented. To reduce the batch-to-batch and other hostspecific variations of organism-derived proteins, an ECM analog elastin-like recombinamer (ELR) is used as a model protein for the tissue-inductive coating. The main objective is the creation of a well-distributed initial layer of protein on the cells. As such, the potential of hydrophobic groups as intramembranous anchors for cellular coatings is determined. Cholesteryl side groups were selected as hydrophobic anchors to mimic the intramembranous situation and to facilitate the mobility and distribution of the proteins in the membrane. For better interaction of the cholesterol material with the membrane, caveolin-rich cell types like human umbilical vein endothelium-derived cells (HUVEC) and human aortic smooth muscle cells 
(HASMC), which are involved in lipid uptake from sanguine fluid and in processes such as stenosis, were selected ${ }^{67}$.

\subsubsection{ELR Modification}

Modification of the ELR with the BCN linker, fluorophore and CTA groups was successfully performed by a two-step synthesis (Scheme I). The number of incorporations was followed by NMR spectroscopy integrating P3 for the determination of cholesteryl incorporations, or P4 for the degree of Eterneon incoproations, results are displayed in Table 14. The efficiency of fluorescence was further visualized by UV irradiation of the sample.

Scheme I: Synthetic route of cholesteryl modification of ELR at free lysine's through BCN mediated cycloaddition .
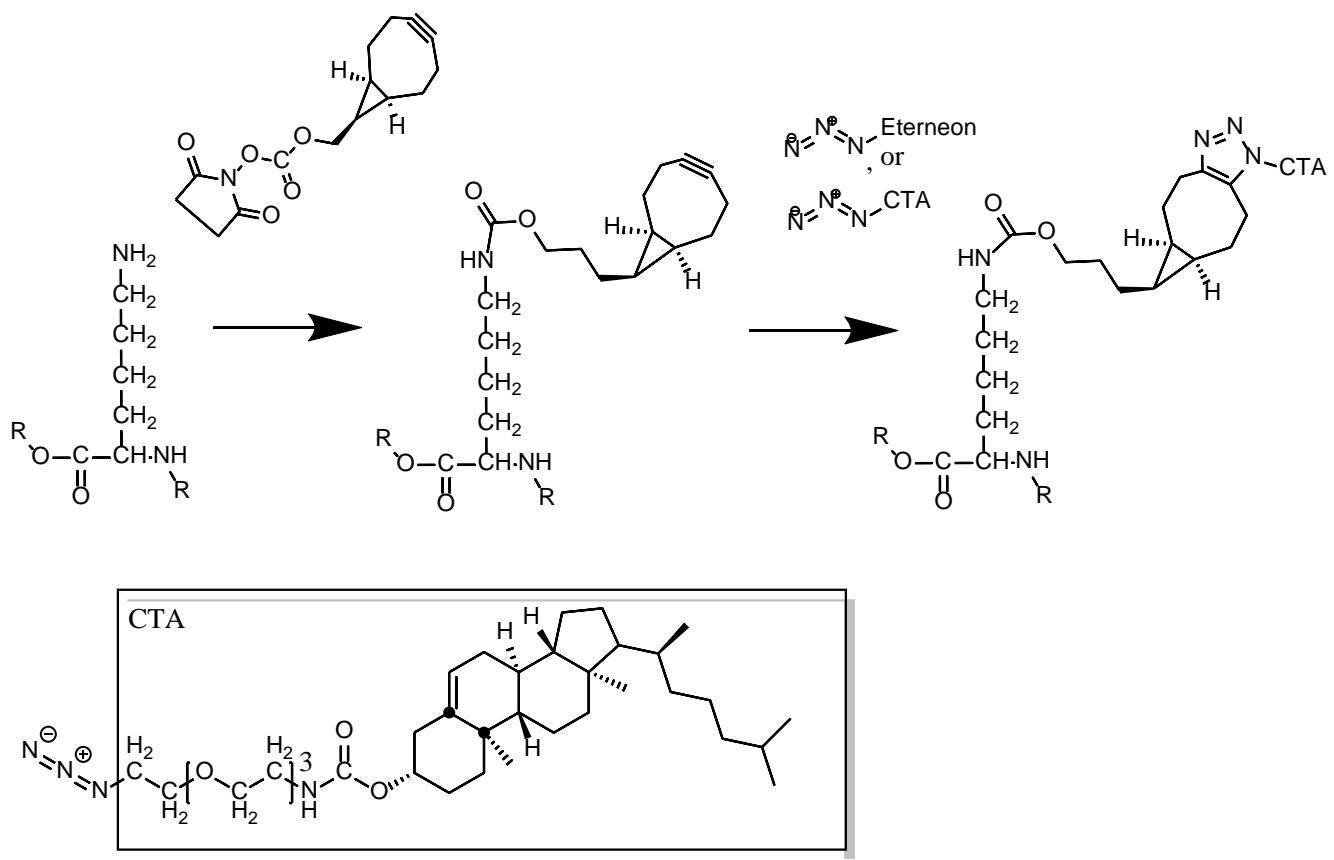


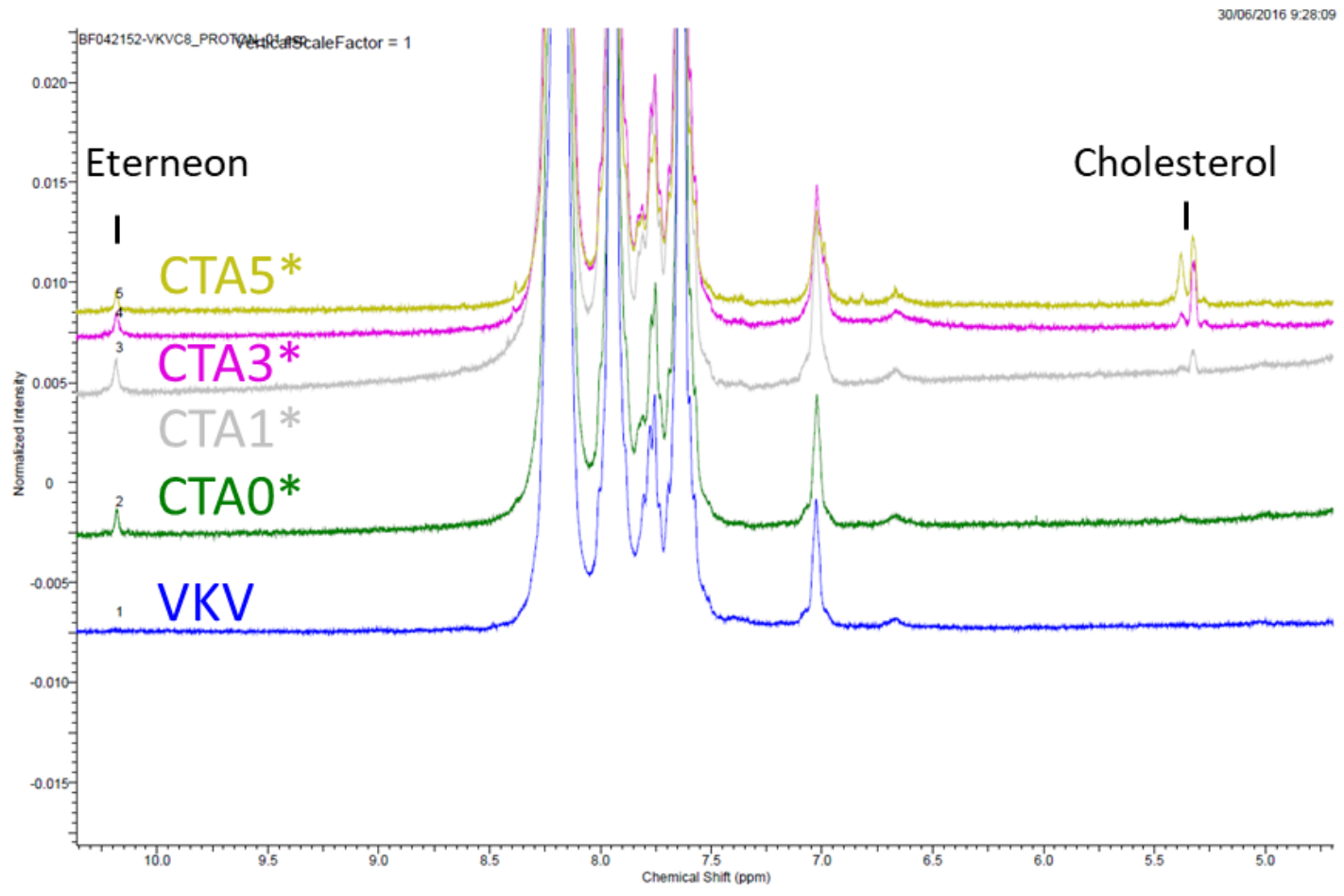

Figure 52: Signals of Eterneon and Cholesterol in NMR spectras of CTAx*. Signals were normalized to PI (for complete Spectra refer to Figure 29 to Figure 31).

The results revealed I0.5 BCN groups for CTA0 with an addition of I.I9 and 0.95 cholesteryl groups for CTAI and CTAI*, 3.03 and 3.33 cholesteryl groups for CTA3 and CTA3* and 4.03 and 6.09 cholesteryl groups for CTA5. Besides the NMR analysis, samples were characterized by MALDITOFF (Figure 53), and the results yielding comparable values are displayed in Table 17. 
Table 16: Overview of NMR signals and the related conversion of functional groups.PI serves as internal reference, representing $-\mathrm{CH} 3$ and $-\mathrm{CH}$ 2- protons of amino acid residues $(\mathrm{G}, \mathrm{E}, \mathrm{L}, \mathrm{K}, \mathrm{M}, \mathrm{P}$, $\mathrm{S}, \mathrm{V})$; $\mathrm{P} 2$ represents $\mathrm{H} 2 \mathrm{C}-\mathrm{O}(\mathrm{C}=\mathrm{O}) \mathrm{O}$ - of the $\mathrm{BCN}$ linker; $\mathrm{P} 3$ represents $\mathrm{C}=\mathrm{C}-\mathrm{H}$ proton of the cholesteryl residue; P4 is an isolated signal from the ETERNEON fluorophore (structure not known).Complete spectra are provided as Supplementary Information.

$$
\begin{array}{lll}
\begin{array}{l}
\text { PI } \\
\text { (normalized) }
\end{array} & \text { P2 } & \text { \#BCN } \\
0.6-1.0 & 2.85-2.95 &
\end{array}
$$

\begin{tabular}{llll}
\hline VKV & 1335 & - & - \\
VKV- & 1335 & 21.01 & 10.5 \\
BCN & & &
\end{tabular}

(CTAO)

\begin{tabular}{lllll}
\hline & PI & P3 & \#CTA & P4 \\
& $\mathbf{0 . 6 - 1 . 0 ~ p p m ~}$ & $\begin{array}{l}\mathbf{5 . 3 0 - 5 . 4 5} \\
\mathbf{p p m}\end{array}$ & & $10.1-10.3$ \\
\hline CTA0* & 1335 & - & 0 & 0.91 \\
CTAI & 1335 & 1.19 & 1.19 & - \\
CTAI* & 1335 & 0.95 & 0.95 & 1.59 \\
CTA3 & 1335 & 3.03 & 3.03 & - \\
CTA3* & 1335 & 3.33 & 3.33 & 1.54 \\
CTA5 & 1335 & 4.03 & 4.03 & - \\
CTA5* & 1335 & 6.09 & 6.09 & 1.10
\end{tabular}



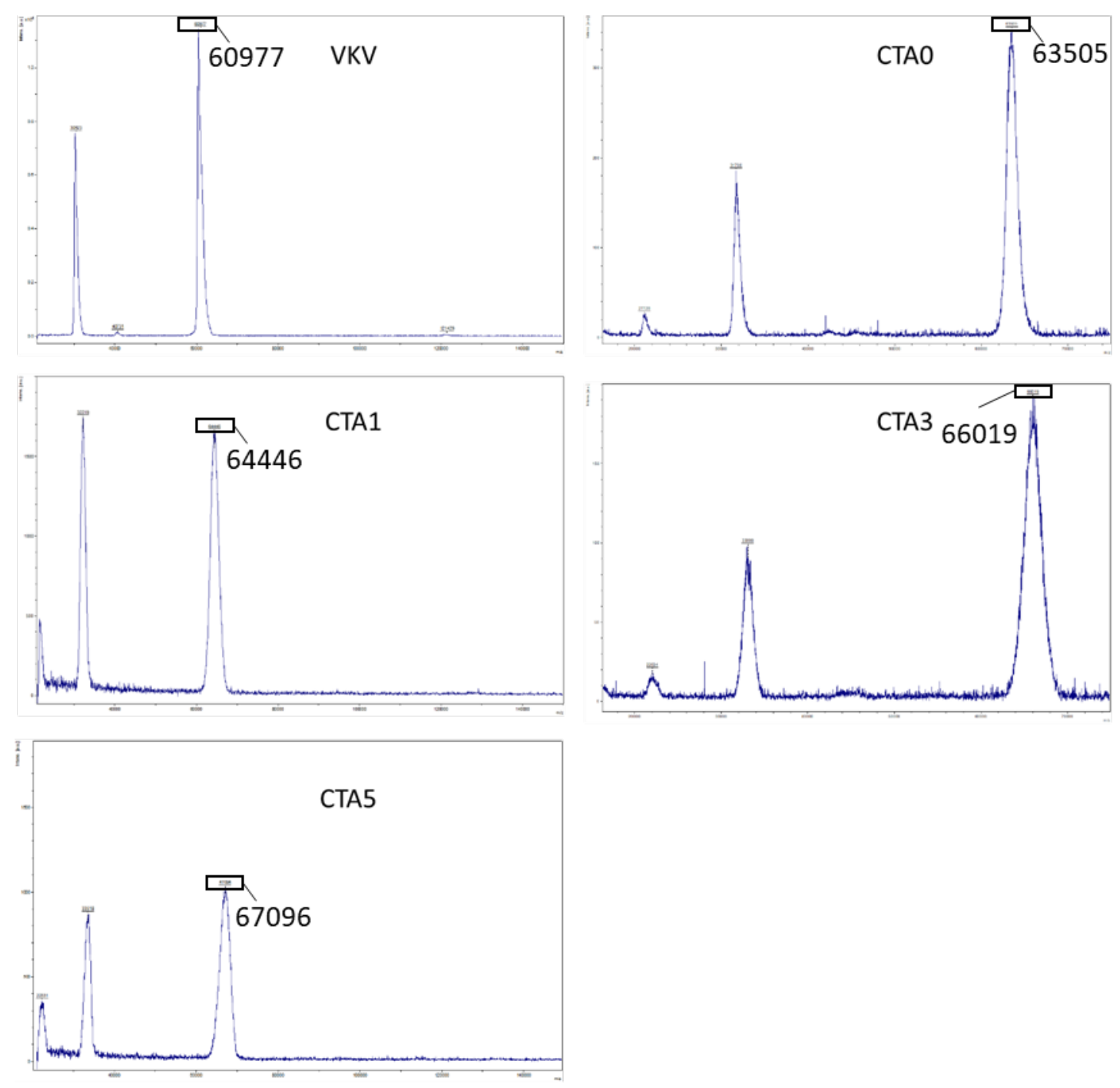

Figure 53: MALDI-TOF Spectra of modified ELRs.

The mass analysis revealed slightly higher values for all modifications, where ELR ${ }^{\text {CTA0 }}$ with 13.14 groups compared to 10.5 groups (NMR) showed the biggest variance. All other values were in good agreement with NMR data. 
Table 17: Degree of modification, calculated from the mass analysis.

Mw (MALDI-TOF) Calculated

BCN/CTA groups

$\begin{array}{lll}\text { VKV } & 60977 & \\ \text { CTA0 } & 63505 & \text { BCN: I3, I46 } \\ \text { CTAI } & 64446 & \text { CTA: I,49 } \\ \text { CTA3 } & 66019 & \text { CTA: } 3,98 \\ \text { CTA5 } & 67096 & \text { CTA: } 5,69\end{array}$

\subsubsection{Characterization in solution}

The hydrodynamic radii of ELR ${ }^{\text {CTA }}$ in PBS was determined by DLS. However, as the multi-modality of the sample above the LCST did not allow for sizeaverage comparison, the volume intensities were plotted (Figure 54). Moreover, volume intensities allow for small particle detection in a complex precipitating sample. All samples have a similar size at $4^{\circ} \mathrm{C}$, ranging between 3 and $7 \mathrm{~nm}$, which corresponds to 2-10 ELR molecules according to the size-mass calibration. An additional population of $2 \mathrm{~nm}$ particles, which might correspond to unimers is observed in ELR ${ }^{\text {CTA5 }}$. Above the LCST, ELR ${ }^{\text {CTA0 }}$ agglomerates into larger structures and precipitates from solution, starting with $30 \mathrm{~nm}$ particles and larger micrometer-sized populations in the initial stage of precipitation. Upon cholesteryl addition, a significant shift towards smaller particles is observed above the LCST in the volume intensities, as well confirmed by a left shift of the correlation function (Figure 55). The addition of more CTA groups leads to a reduction in the number of larger particles, which is most prominent in ELR ${ }^{\text {CTA5 }}$, similar to conditions below the LCST. 
$4^{\circ} \mathrm{C}$
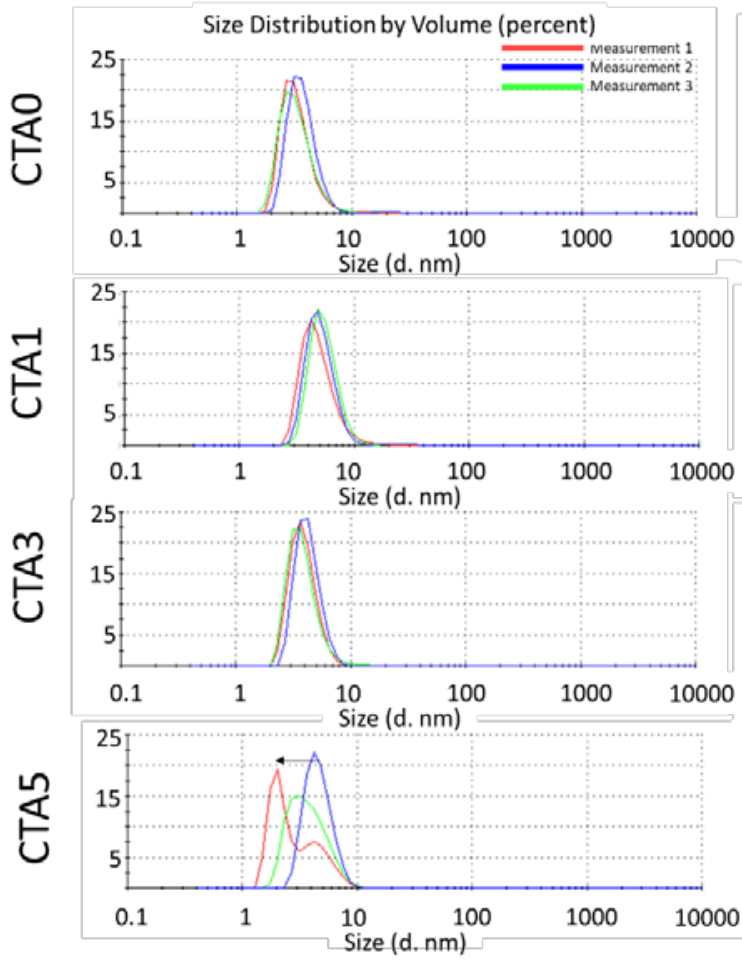

$37^{\circ} \mathrm{C}$
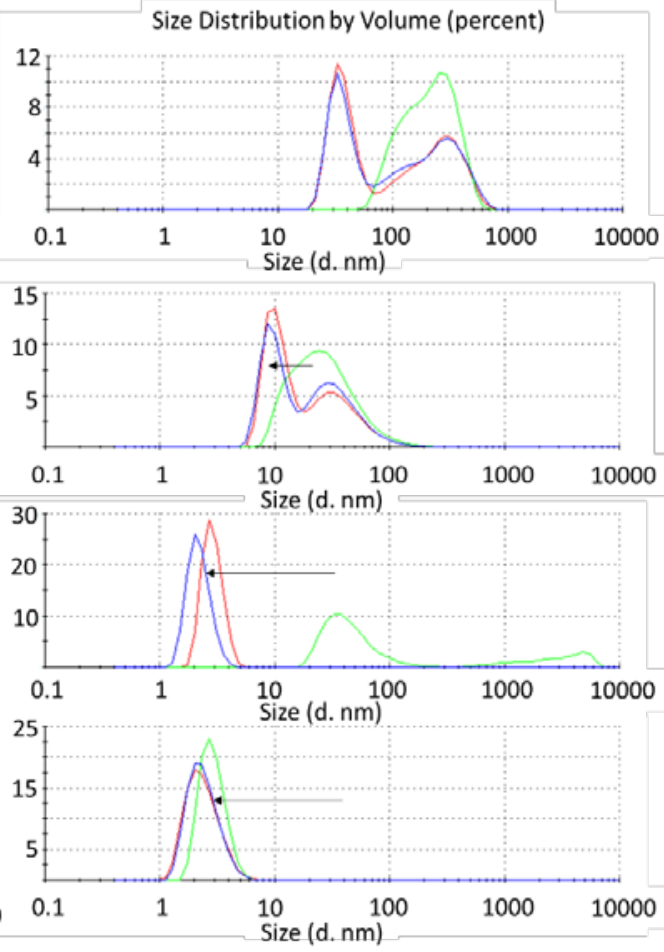

Figure 54: Volume Intensities of cholesteryl ELRs in PBS at different temperatures. Graphs show an overlay of three individual measurements. Black arrows mark the size shift of distribution.
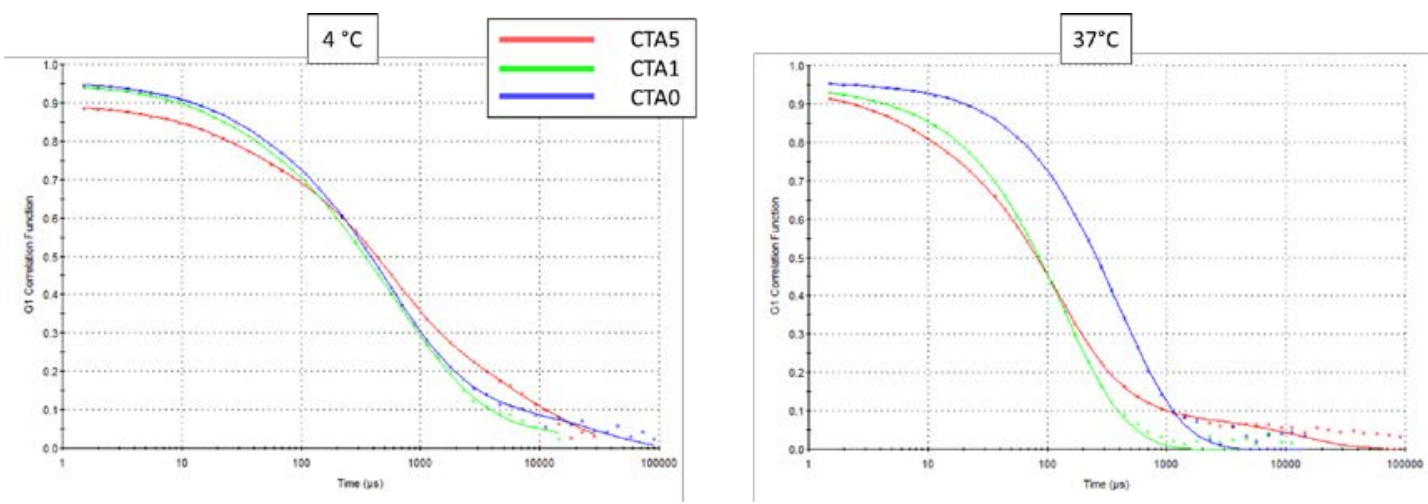

Figure 55: Correlation function of ELR ${ }^{\mathrm{CTA} \text {, I, and } 5}$ at 4 and $37^{\circ} \mathrm{C}$. Most prominent is the left shift of ELR ${ }^{\mathrm{CTAl}}$ and $E L R^{\mathrm{CTA5}}$ at $37^{\circ} \mathrm{C}$ indicating the presence of smaller aggregates/particles (ELR ${ }^{\mathrm{CTA} 3}$ was removed for better visibility). 
The cloud point of the samples was determined as the derivative of the absorbance versus temperature profile of ELR ${ }^{C T A}$. A significant increase in turbidity and related absorbance was only observed in CTA0, which was already drastically reduced in CTAI, with a transition temperature $\left(T_{t}\right)$ of 23.9 and $26.0^{\circ} \mathrm{C}$ and a maximum absorbance of 1.6 and 0.3 , respectively. No changes in absorbance were observed for ELR ${ }^{\text {CTA3 }}$ and ELR ${ }^{\text {CTA5 }}$ in the temperature range $5-40^{\circ} \mathrm{C}$ (Figure 56), which is in accordance with the decrease in the number of larger agglomerates observed by DLS.
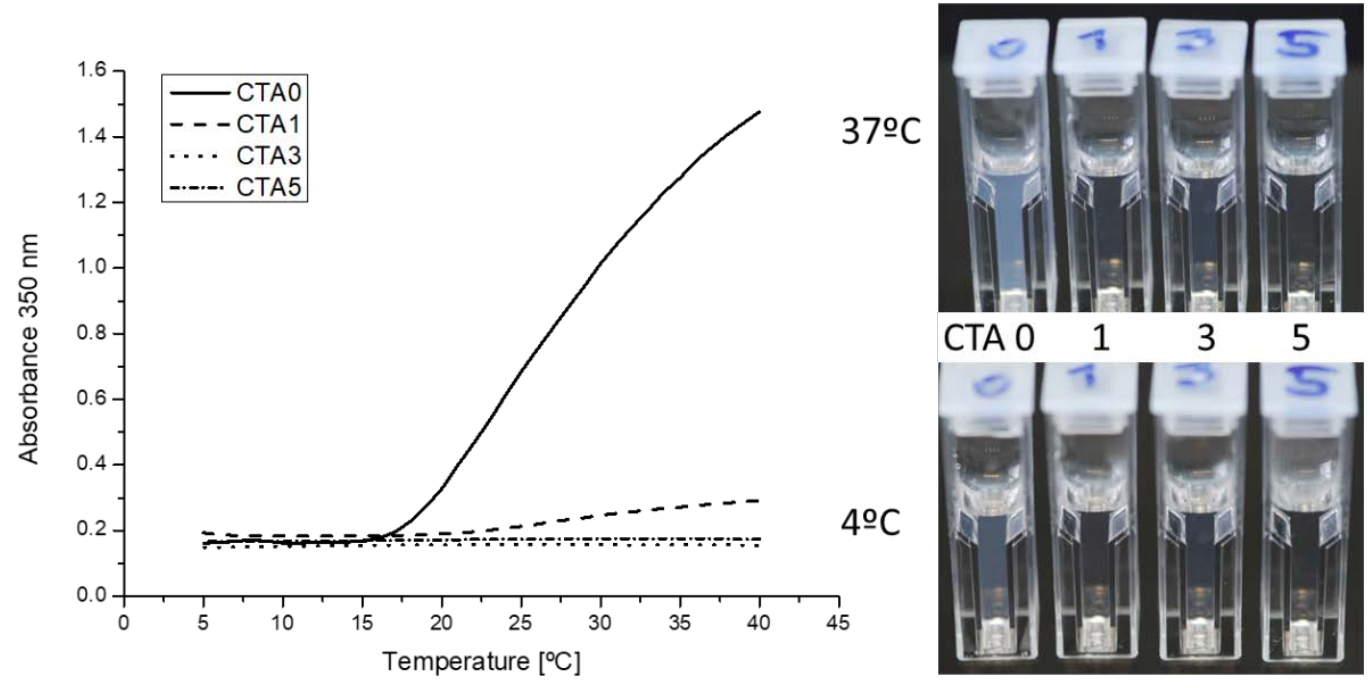

Figure 56: Cloudpoint determination of ELRs. The cholesteryl-modified ELRs show markedly reduced to no absorbance above the LCST of ELR ${ }^{\text {CTAO }}$.

\subsubsection{Cytotoxicity of ELR particles}

The different substrates were tested for their effect on cell proliferation over 7 days using the AlamarBlue $\AA$ assay at concentrations of 375 and 750 $\mathrm{nM}$. The values were normalized to non-conditioned cells grown on TCPS for better visibility. HUVECs showed no significant differences in 
proliferation under all conditions (Figure $57 \mathrm{~A}$ ), whereas for HASMCs, treatment with cholesteryl ELRs (ELR ${ }^{\mathrm{CTA}}$ ) at $750 \mathrm{nM}$ led to a decreased proliferation for ELR ${ }^{\mathrm{CTAO}}$ and ELR ${ }^{\mathrm{CTAI}}$ at day $\mathrm{I}$ and at day 3 and 7 for all conditioned samples, becoming more significant with time (Figure 57 B). Moreover, the cytostatic effect is more pronounced in ELR ${ }^{\text {CTA0 }}$ and ELR ${ }^{\text {CTAI }}$ on day $\mathrm{I}$ and day 7. The lower concentration (375 nM) had no negative effect on proliferation.

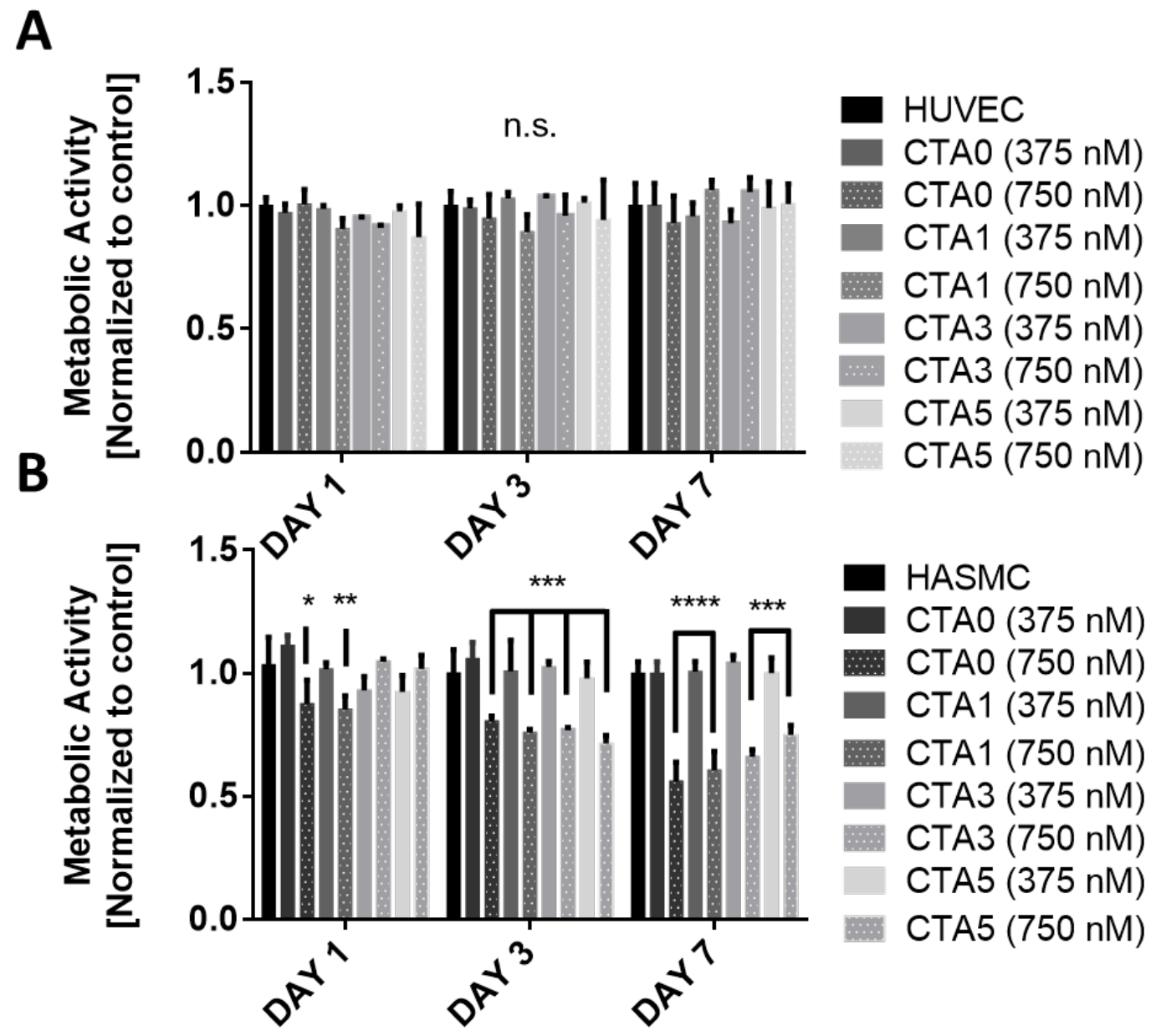

Figure 57: Metabolic activity of cells incubated with ELRs and ELR-CTA at 375 and $750 \mathrm{nM}$. A) HUVEC cells; and B) HASMC. P values refer to cells cultured on TCPS (* $\mathrm{P}<0.05$;** $\mathrm{P}<0.01$; $* * * \mathrm{P}<0.00 \mathrm{I})$. 
All subsequent incubation studies were performed at concentrations of 375 $\mathrm{nM}$ as the proliferation of both cell lines was unaffected at this concentration.

\subsubsection{ELR - cell Interactions}

The cell-ELR interaction was quantified by FACS, therefore the resulting events were first analysed by plotting forward and sideward scatter intensities (FS INT vs. SS INT) which gives information about size and complexity of the detected events going from small samples like cellular debris (low values of FS and SS) towards di- to oligomerized cells (high FS and SS). To select only single cells the results were gated as characterized by the pentagons in Figure 58 and Figure 59, respectively. As can be seen by the amounts of gated cells, approximately $60 \%$ of HASMC were gated, whereas $93 \%$ of HUVEC cells were gated. Considering the fact that $60 \%$ of 50.000 events that were collected reflects 30.000 events, together with the comparability of differences in cellular debris and more complex events throughout the whole sequence of ELR ${ }^{\text {CTAx }}$ with HASMC cells, this drop in selected cells can be neglected for this study and is just an expression of a cell aliquot of intermediate quality. 
A
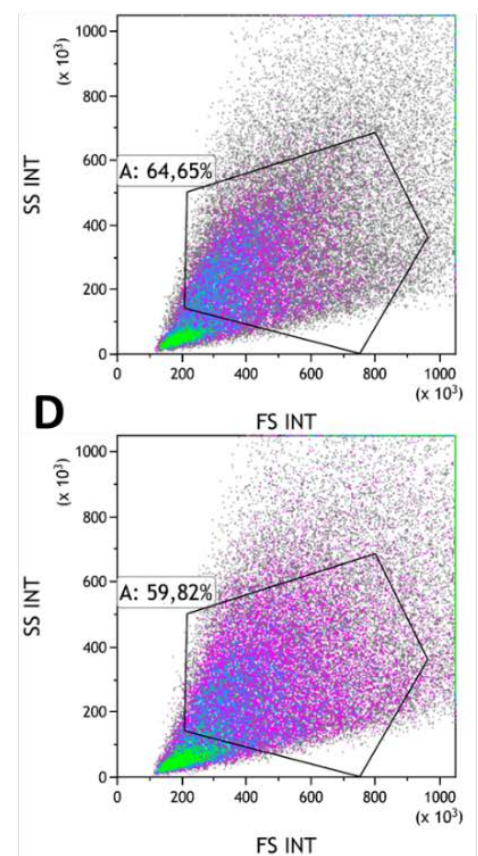

B

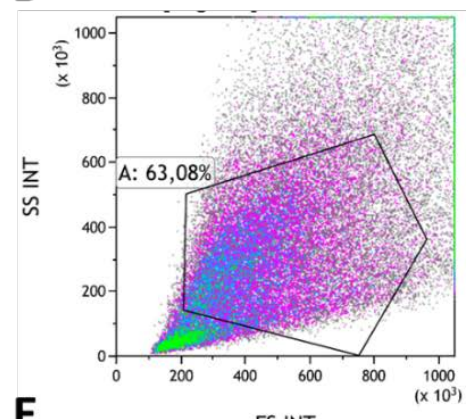

E

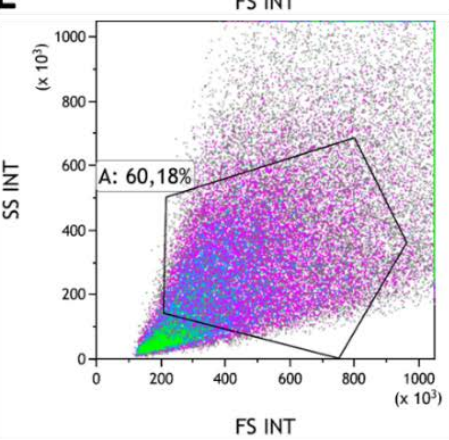

C

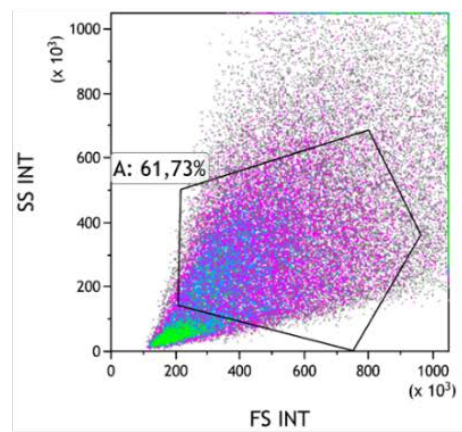

HASMC

A: Control

B: CTAO

C: CTA1

D: CTA3

E: CTA5

Figure 58: Flow Cytometry forward vs side scatter and gated single HASMC cell population (A) used for quantification of fluorescence. 
A
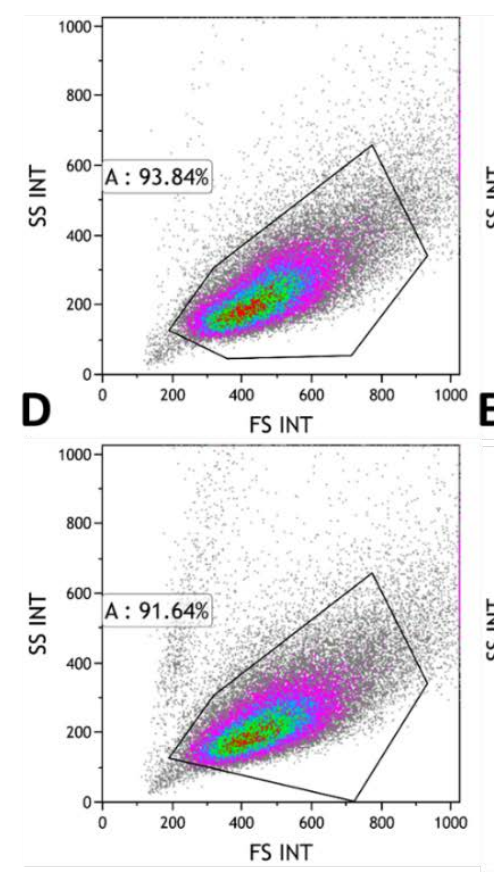

B
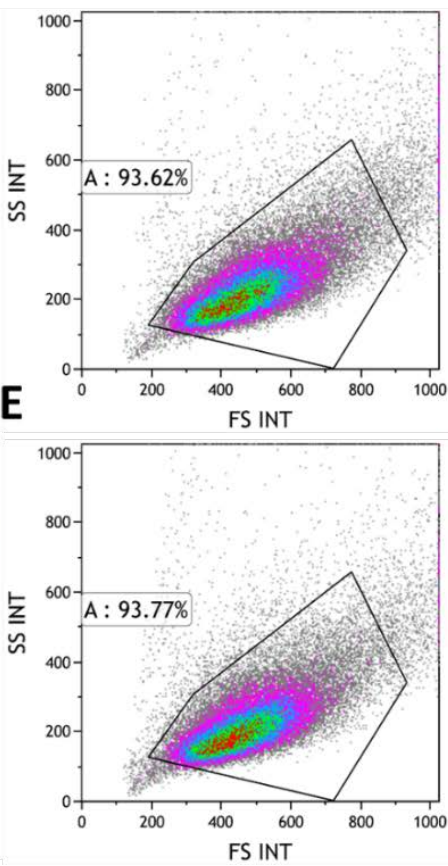

C

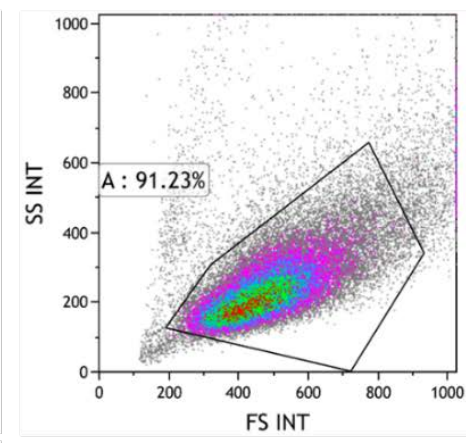

HUVEC

A: Control

B: CTAO

C: CTA1

D: CTA3

E: CTA5

Figure 59: Flow Cytometry forward vs side scatter and gated single HUVEC cell population (A) used for quantification of fluorescence.
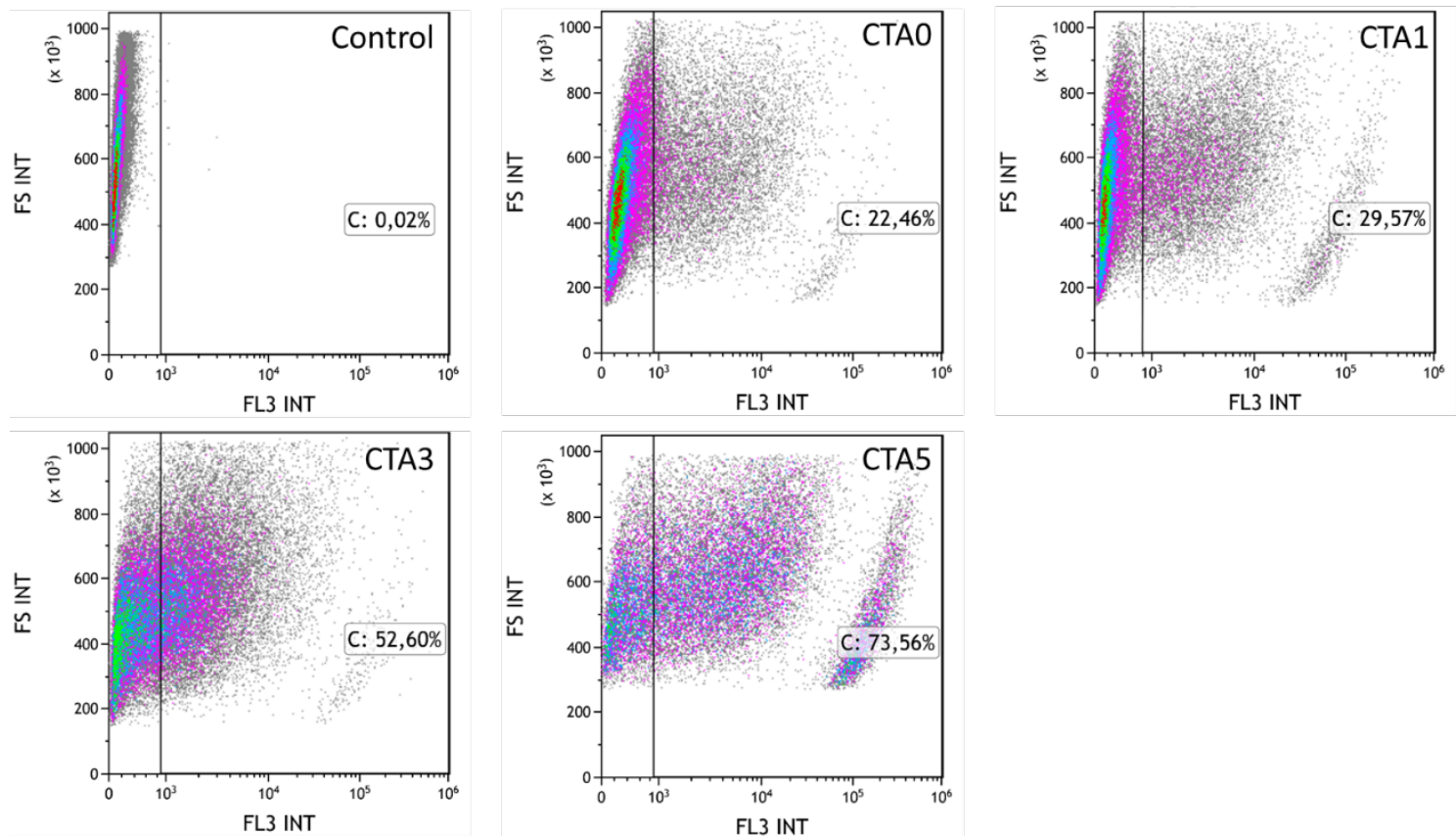

Figure 60: Forward scatter intensity (FS INT) vs. fluorescence (FL3 INT) of HASMC cells treated with CTA samples. 
In the consecutive step the gated cells were plotted by FS INT vs fluorescence (FL3 INT) with the number of fluorescent events increasing from ELR ${ }^{\text {CTA0 }}$ to ELR ${ }^{\text {CTA5 }}$, as indicated by a right shift in the dot plots from $10 \%$ to $80 \%$ (HUVEC), or from $20 \%$ to $85 \%$ (HASMC), fluorescent cells (Figure 60 and Figure $6 \mathrm{I}$ A-E). HASMC cells interact with the material to a higher extent at low cholesteryl contents, increasing from $20 \%$ to $60 \%$ from $E L R^{\mathrm{CTA0}}$ to ELR ${ }^{\mathrm{CTA} 3}$, whereas the coating efficiency of these ELRs remains below $30 \%$ with HUVEC cells (Figure 6IF).

A

D
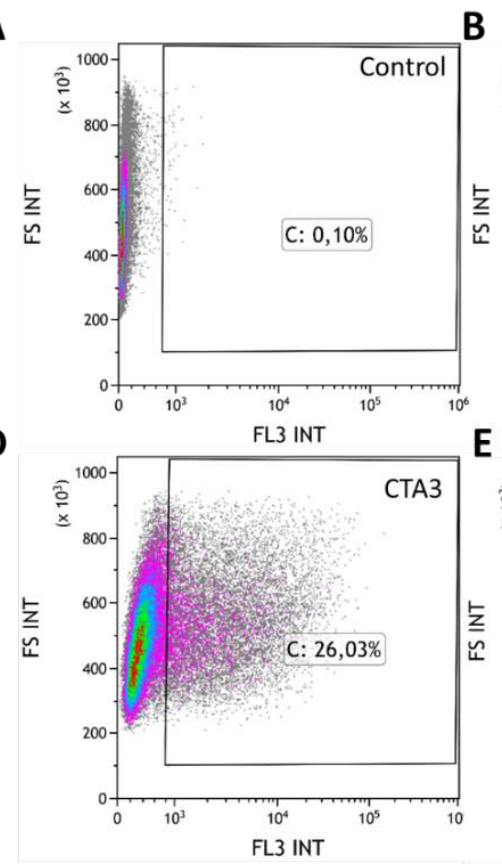

B
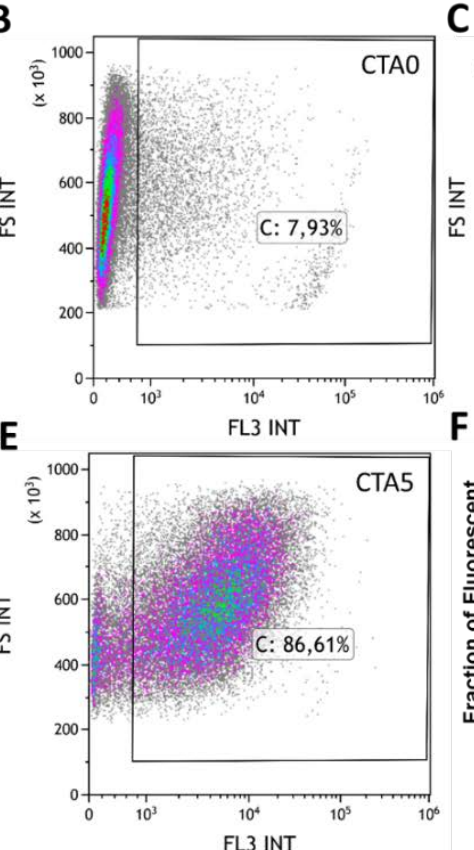

C
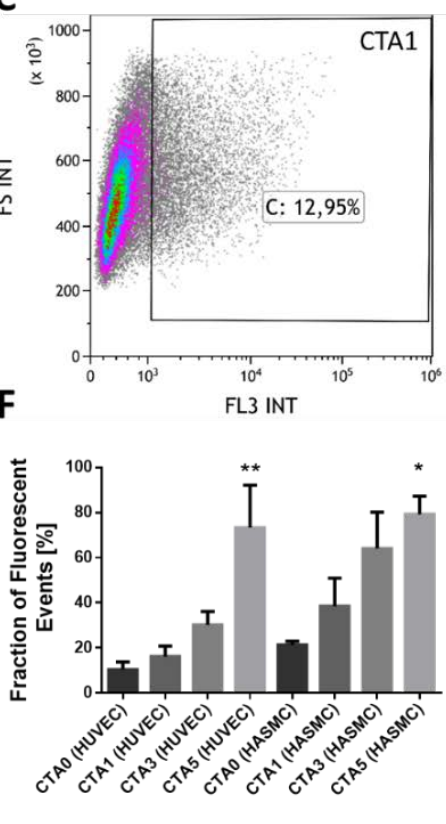

Figure 6I: Forward scatter intensity (FS INT) vs. fluorescence (FL3 INT) of HUVEC cells treated with ELR ${ }^{\text {CTA }}$ samples, obtained by flow cytometry. A) untreated HUVEC cells; B) HUVEC cells

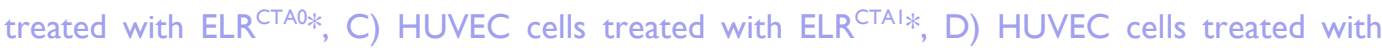

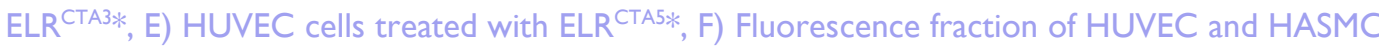
cells. See the supporting information for HASMC dot plots. P values refer to cells treated with

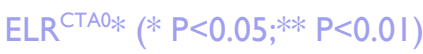




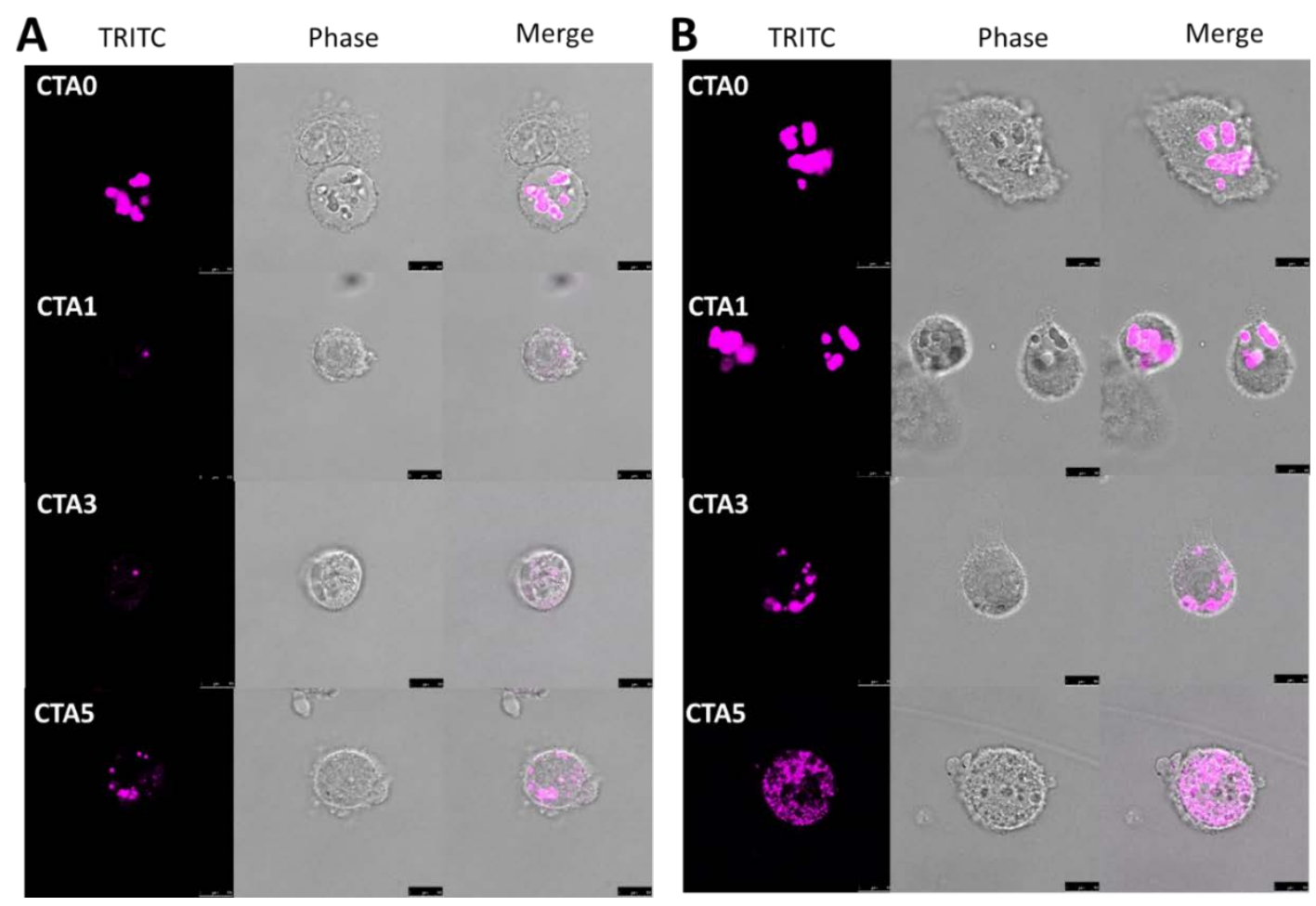

Figure 62: Confocal images of HUVEC (A) and HASMCs (B) after incubation with CTAx samples. From left to right: texas red (displayed color was changed to magenta for better visibility of small particles), phase, and merge. Top to bottom: ELR ${ }^{\mathrm{CTA} 0 *}$, ELR ${ }^{\mathrm{CTA} *} *, \mathrm{ELR}^{\mathrm{CTA} 3 *}$ and ELR ${ }^{\mathrm{CTA} 5 *}$. The scale bars represent $7.5 \mu \mathrm{m}$.

Confocal images of trypsinized cells after incubation revealed a change in ELR distribution on the cell membrane that is dependent on the cholesteryl content, ranging from more agglomerated micron-sized particles towards finely dispersed sub-micron dots, with this being found for both cell lines (Figure 62). Additionally, a Z-scan was performed for the sample with dispersed fluorescence to determine the fluorescence distribution. The localized presence of ELR ${ }^{\text {CTA }}$ in the cell center (first five layers), followed by the depletion of fluorescence in the center (subsequent layers), indicates binding of ELR to the membrane (Figure 63). Live cell imaging further revealed an increased aggregation of bound ELRs in HASMC (CTAO and 
CTAI) and increased dispersion of ELR in both HUVEC and HASMC (CTA5) (results are shown in the right part of Figure 73).

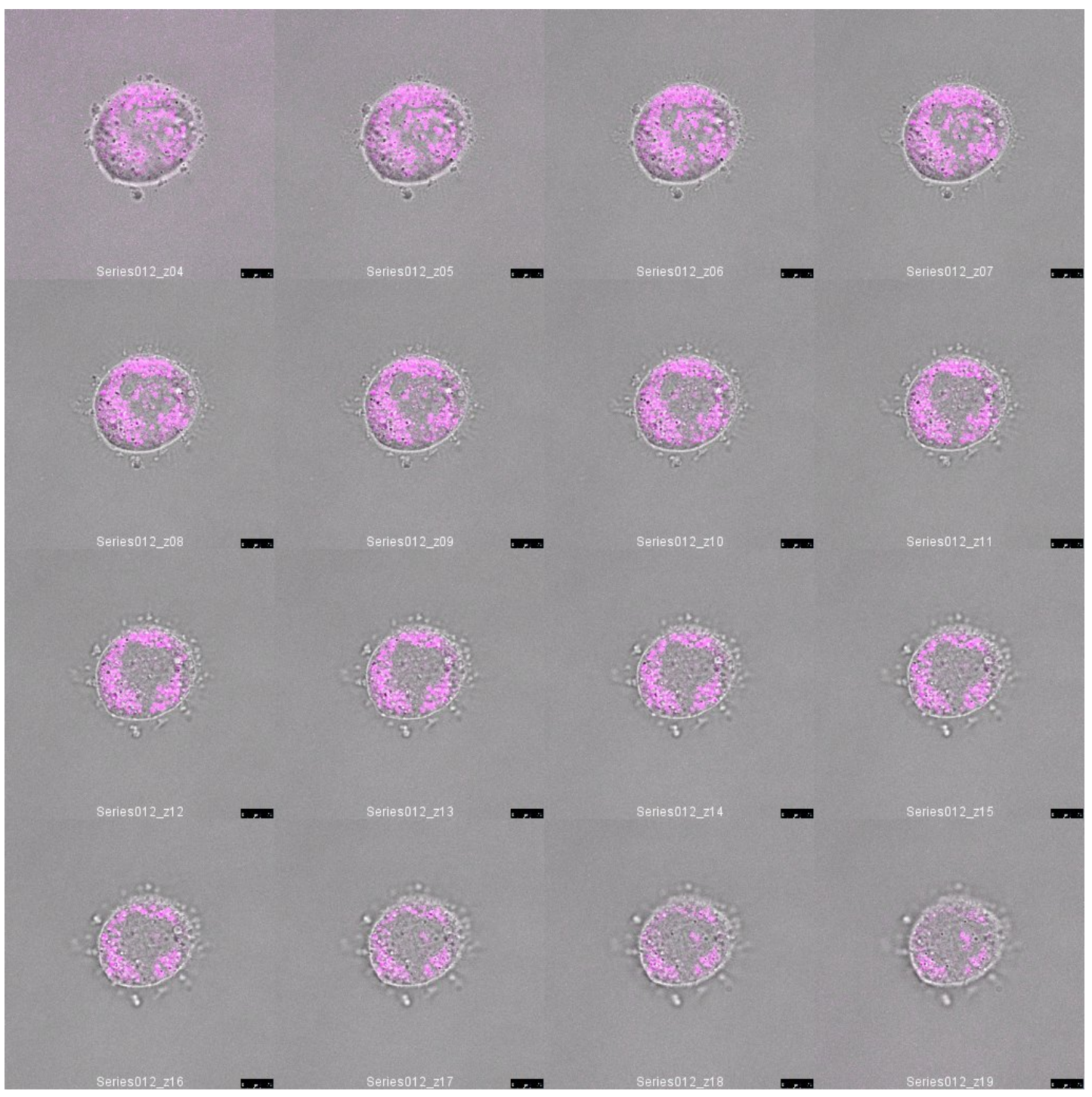

Figure 63: Z-slicing of HUVEC cell with ELR ${ }^{\mathrm{CTA} 5 *}$. Slices are from top to bottom starting from the top left (z04) to the bottom right image (z|9). ELR fluorescence in the top image covers most of the cell surface, whereas in the lower slices the ELR is more concentrated at the perimeter of the cell, thus indicating that the ELR is not incorporated into the cells. The scale bars represent 7.5 $\mu \mathrm{m}$, slicing depth is $0.4 \mu \mathrm{m}$.

Several studies concerning polymer-membrane interactions and internalization have been published in recent years ${ }^{75,449}$. Indeed, it is well 
documented that biophysical properties such as net charge, hydrophobicity, and protein-driven cell-ligand (integrin binding) interactions influence the interaction of polymers, proteins or peptides with model membranes and biological cells ${ }^{450}$. Most polymer modifications have focussed on the introduction of a positive charge to foster electrostatic interactions with the membrane (polycations) ${ }^{75}$, or on the insertion of integrin-binding domains (like RGD) ${ }^{449}$. Since integrin-binding amino acid sequences frequently contain charged residues, both these approaches increase the net-charge and hydrophilicity of the material. The basis for this study was an antagonistic approach that makes use of a set of carefully designed ELRs of varying hydrophobicities to trigger membrane-substrate interactions. For the introduction of hydrophobic moieties, a strategy of post-expressional modification with cholesteryl groups was used to keep other peptide properties, such as peptide charge and charge distribution, unchanged. Cholesteryl groups were selected as cell-anchor moieties due to the abundance and importance of cholesterol in cell structure, function, and locomotion; furthermore, the ability of membranes to stabilize cholesteryl groups is thought to assist the coordination of hydrophobic ELRs to the membrane. The main objective was to generate a defined cellular coating of a recombinant protein that allows for total sequence control and less host or batch-to-batch variation as a substitute for existing coatings such as alginate $^{74}$, polyelectrolytes ${ }^{75}$, collagens and fibronectin ${ }^{87-89}$.

An in vitro cell binding assay was used to quantify cell-membrane interactions. Thus, HUVEC and HASMC were incubated with molecular probes of varying cholesteryl concentrations (Figure I). At $37^{\circ} \mathrm{C}$, ELR ${ }^{\mathrm{CTAO}}$ and ELR ${ }^{C T A}$ are above their LCST of 23.9 and $26^{\circ} \mathrm{C}$, respectively, therefore precipitation and hydrophobic ELR-ELR interactions are more favored and agglomeration occurs. 
This agglomeration can be prevented upon the introduction of cholesteryl side chains, which hamper aggregation and lead to the disappearance of the LCST transition. Although more hydrophobic, agglomeration of ELR ${ }^{\text {CTA }}$ was not observed. For a better understanding of LCST disappearance in ELR ${ }^{C T A}$ samples, $C D$ spectra were recorded at $37^{\circ} \mathrm{C}$, which showed a slight decrease of random coil signal at $197 \mathrm{~nm}$ upon cholesteryl addition, indicating an increased order towards beta-turn ${ }^{451}$ and alpha helical structures ${ }^{452}$, which is consistent with studies on cholesteryl modified polylysine ${ }^{453}$. Nevertheless, besides slightly augmented order, overall spectra were quite similar (Figure 64) and give no explanation on diminished precipitation. Consequently, we assume that the shift in particle size towards uni- and oligomers are due to a destabilization of micelles in ionic solutions such as PBS, which, given their size, are non-absorbent even above the LCST.

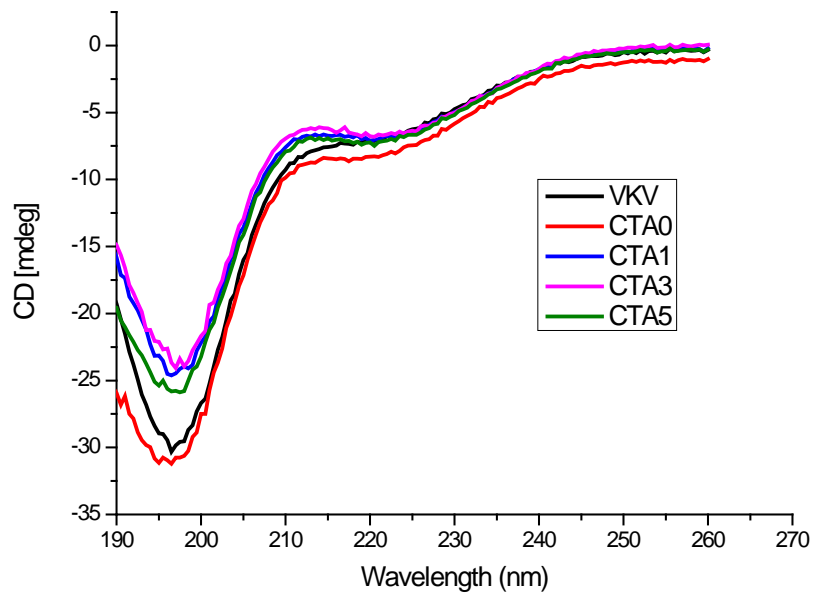


Furthermore, the probes with higher amounts of cholesterol showed a significant increase in ELR binding to the cell membrane as hydrophobic interactions with the membrane lead to a better distribution of the material in the membrane. It is believed that the abundance of cholesterol in the cell membrane and its hydrophobic nature further foster the cell-ELR ${ }^{\text {CTA }}$ interaction. The hypothesized mechanism of cellular ELR association relates to the cholesterol content (Figure 73). Thus, in the absence of cholesteryl groups, the ELR agglomerates over time to form micron-sized particles as a result of hydrophobic and electrostatic interactions, whereas increasing numbers of cholesteryl groups lead to a weakening of the ELR ${ }^{\text {CTA }}-E^{2} R^{\text {CTA }}$ interaction and to an increased ELR-Membrane interaction under physiological conditions, thus resulting in distribution of the ELR in the cell membrane.

$$
\begin{gathered}
\operatorname{Interaction}(E L R-E L R)>\operatorname{Interaction}(E L R-\text { Membrane }) \\
\text { Interaction }\left(E L R^{C T A}-E L R^{C T A}\right)<\operatorname{Interaction}\left(E L R^{C T A}-M e m b r a n e\right)
\end{gathered}
$$

Cells were followed for $18 \mathrm{~h}$ in culture to analyze the behavior of cell substrate interaction. The results for better visibility one image per $3 \mathrm{~h}$ is presented. 


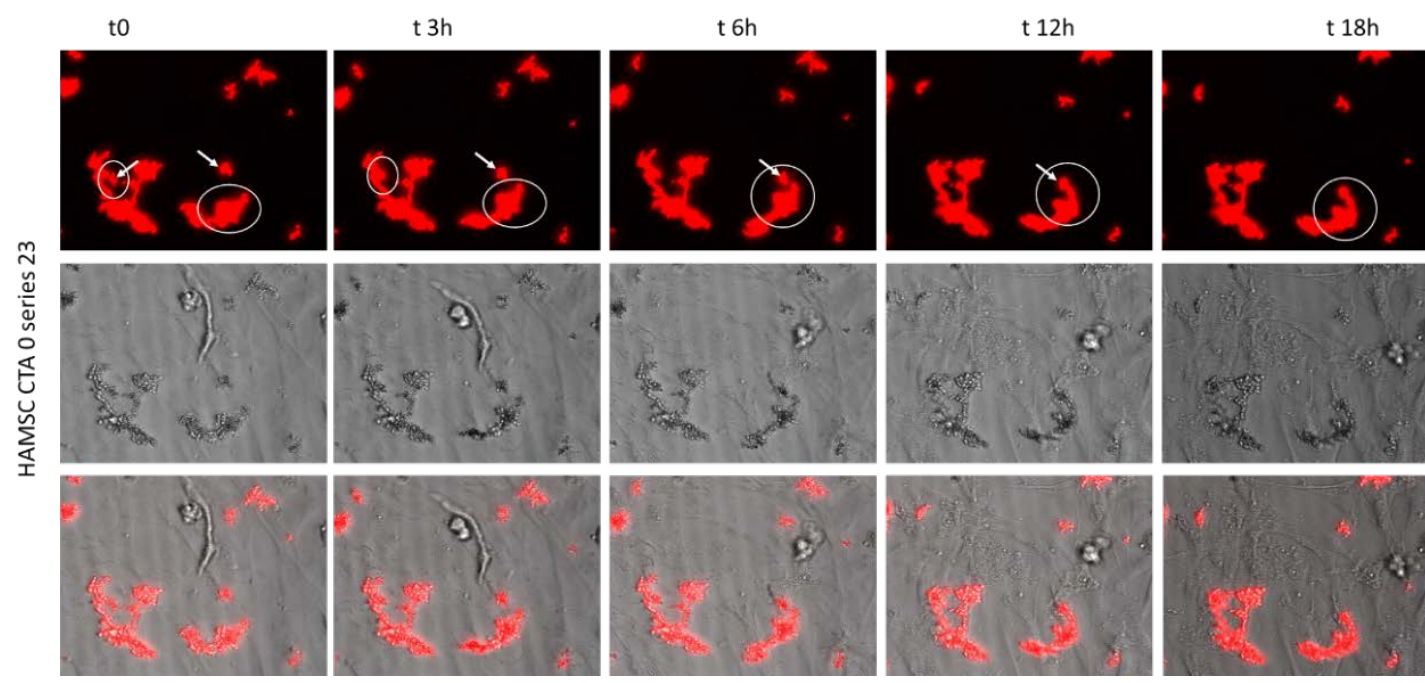

Figure 65: Life cell imaging of HASMC cells incubated with 375 nM ELR ${ }^{\text {CTA0* }}$ over a period of I8h, circle and arrow highlight movement and fusion of ELR agglomerates into bigger agglomerates.

to
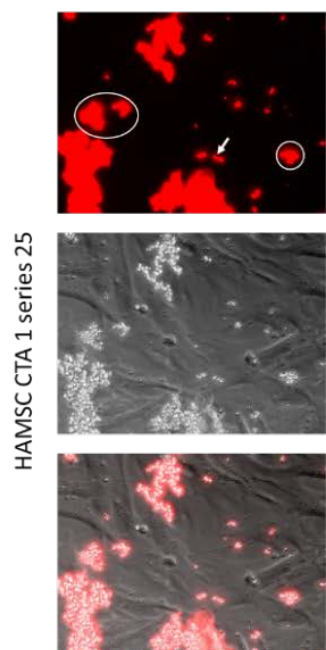

t $3 h$
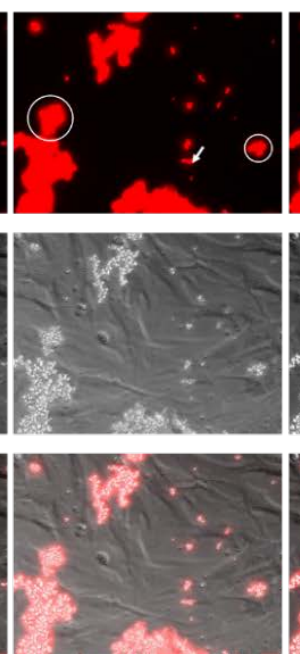

t $6 \mathrm{~h}$

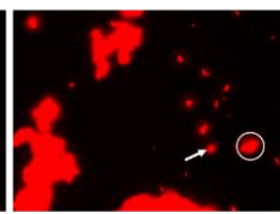

t $12 \mathrm{~h}$
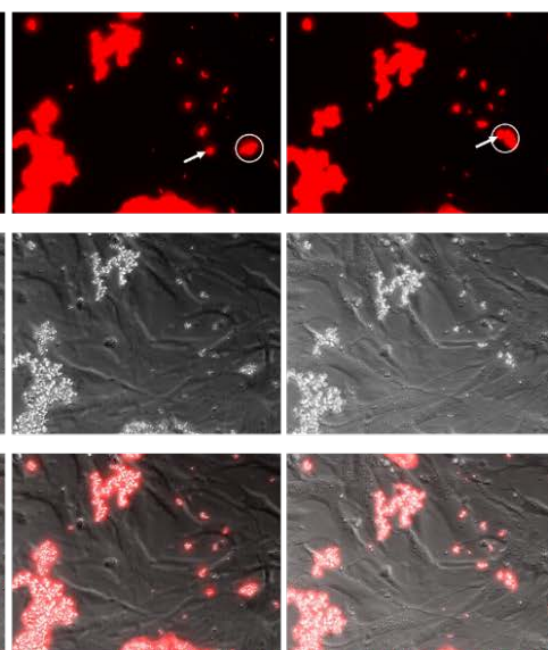

t $18 \mathrm{~h}$
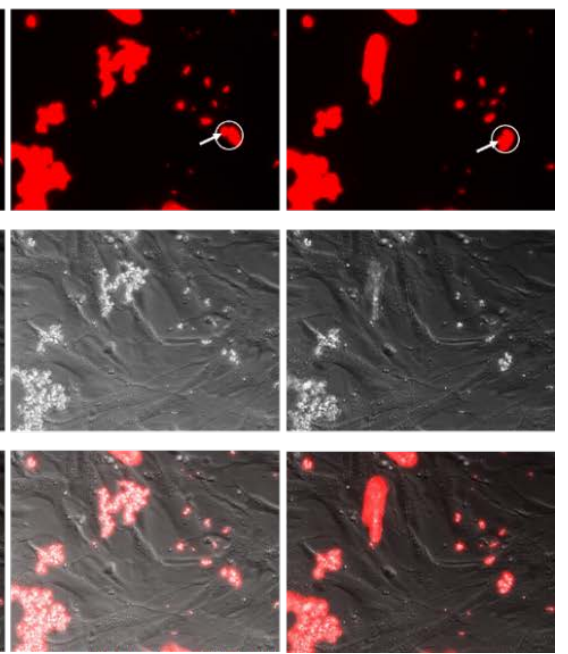

Figure 66: Life cell imaging of HASMC cells incubated with 375 nM ELR ${ }^{\text {CTAl* }}$ over a period of I8h.

HASMCs incubated with ELR ${ }^{\mathrm{CTA} A}$ and ELR ${ }^{\mathrm{CTAI}}$ revealed a similar behavior, the ELRs are above there LCST are in a collapsed state and agglomerates are moved around by cellular movement. Interestingly, upon contact of ELR particles with them self, they fuse together and over time bigger agglomerates are obtained, which are still attached to the cells (Figure 65 and Figure 66). 


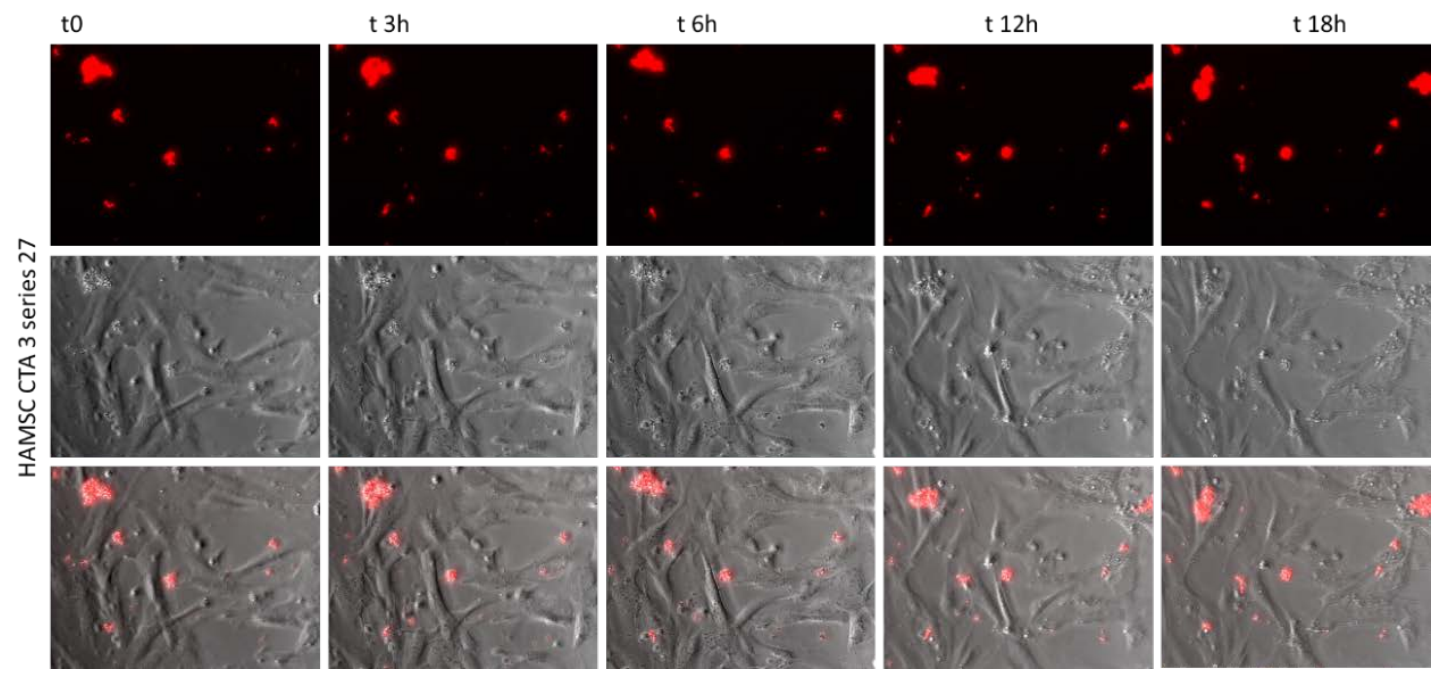

Figure 67: Life cell imaging of HASMC cells incubated with 375 nM ELR ${ }^{\text {CTA3* }}$ over a period of I8h.

t0

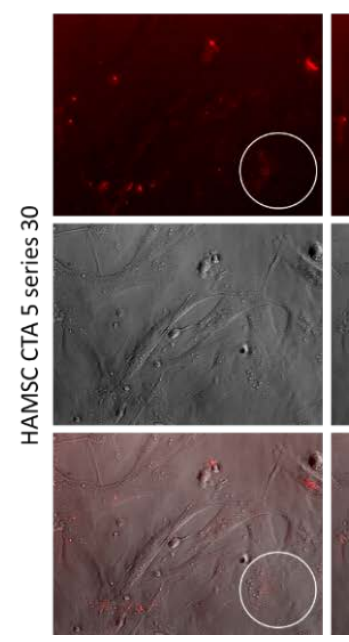

$\mathrm{t} 3 \mathrm{~h}$
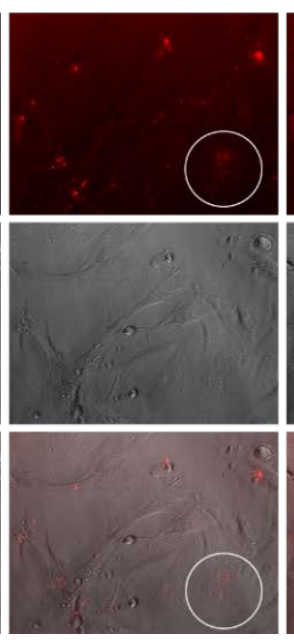

t $6 \mathrm{~h}$

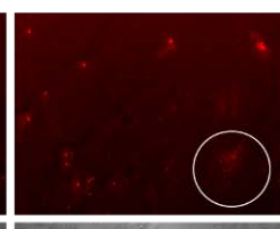

$\mathrm{t} 12 \mathrm{~h}$
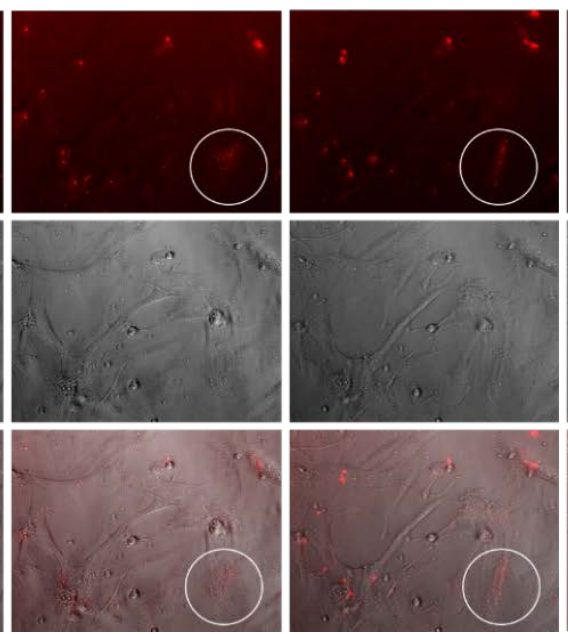

t18
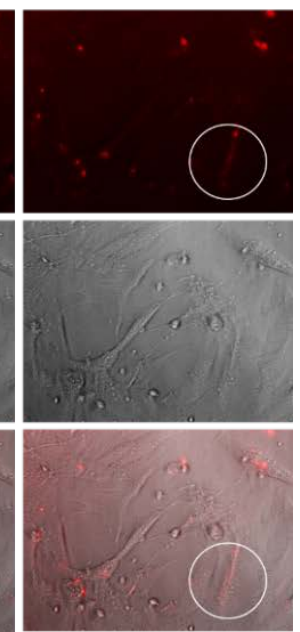

Figure 68: Life cell imaging of HASMC cells incubated with 375 nM ELR ${ }^{\text {CTA5* }}$ over a period of I8h.

Upon interaction with ELR ${ }^{\mathrm{CTA} 3}$ and ELR ${ }^{\mathrm{CTA} 5}$ a different behavior is obsereved. Initially, the ELR particles are more aggregated and over time a distribution within the cellular membrane is observed (Figure 67 and Figure 68). 


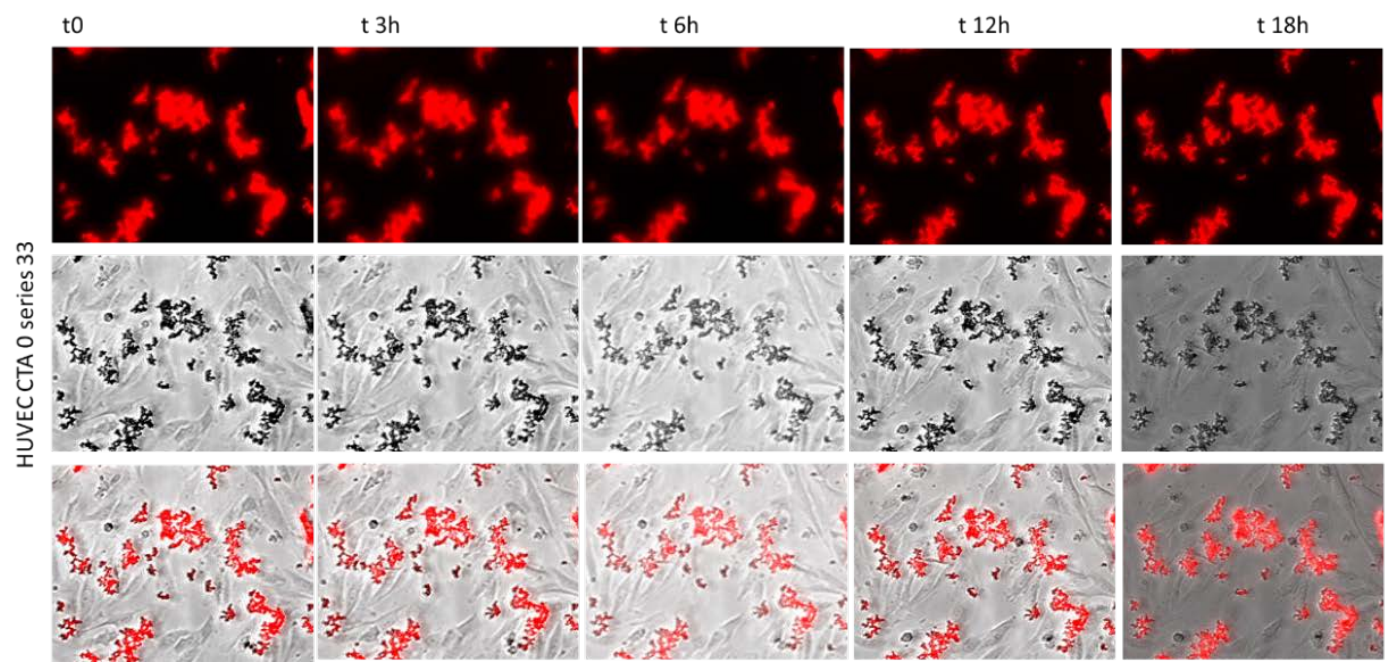

Figure 69: Life cell imaging of HUVEC cells incubated with 375 nM ELR ${ }^{\text {CTA0* }}$ over a period of I8h.
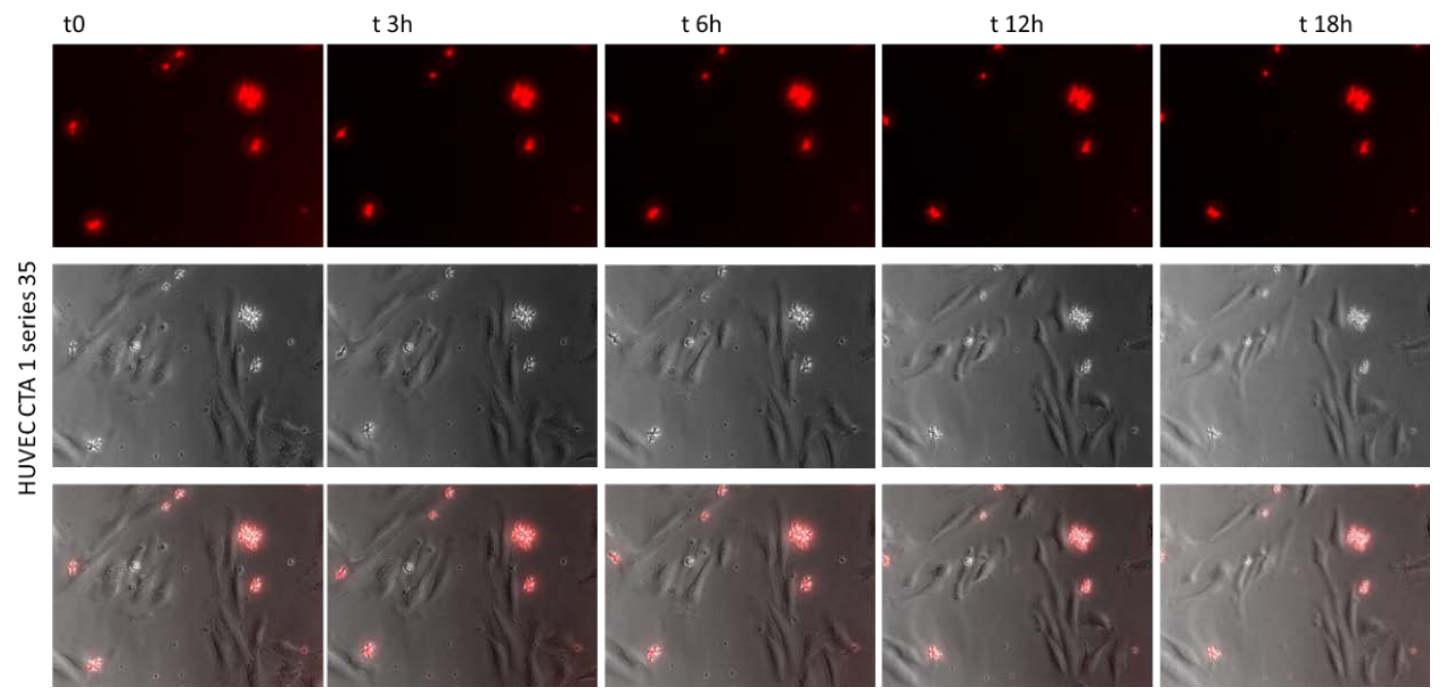

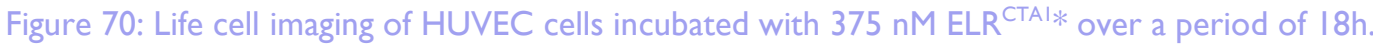




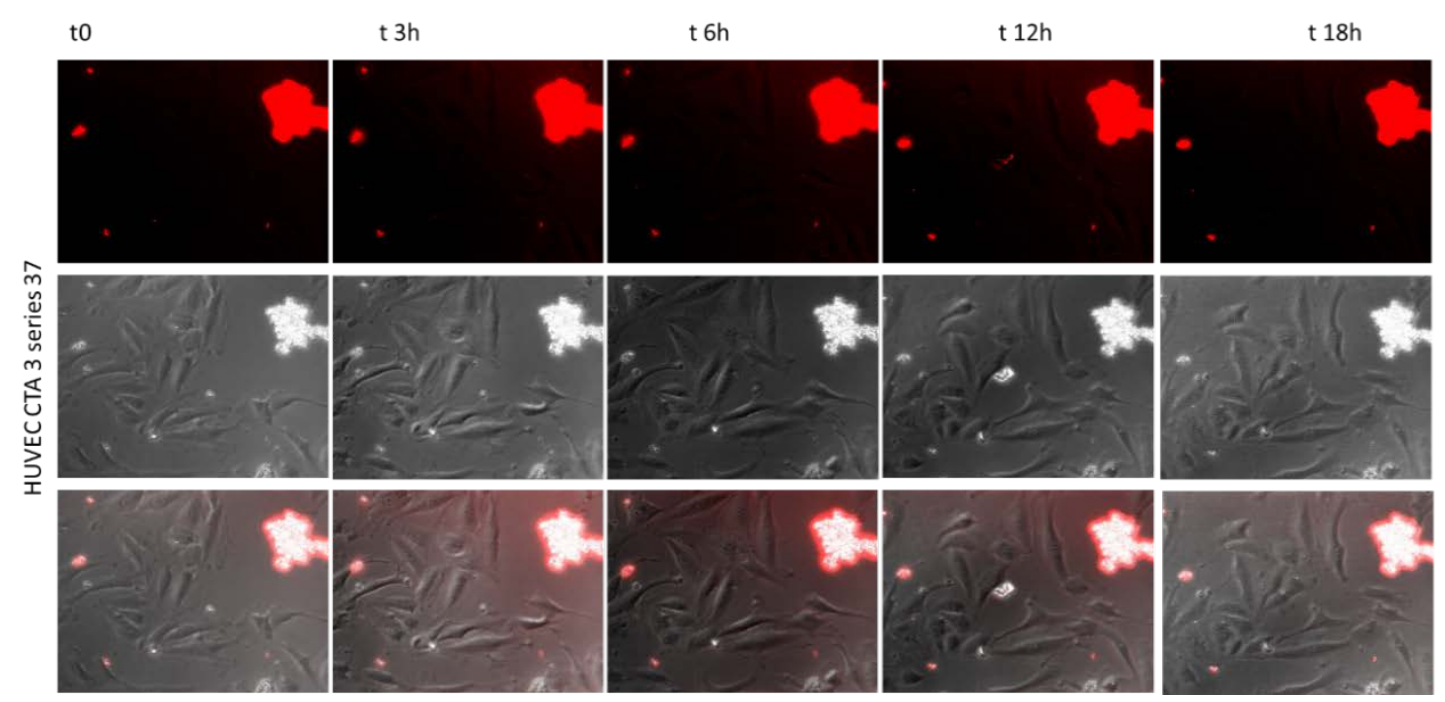

Figure 7I: Life cell imaging of HUVEC cells incubated with 375 nM ELR ${ }^{\text {TA3* }^{*}}$ over a period of I8h.

HUVECs showed no interaction with ELR ${ }^{\mathrm{CTA0}}$, ELR ${ }^{\mathrm{CTAl}}$ and ELR ${ }^{\mathrm{CTA3}}$ as visualized by the flourescent particles sticked rather to the TCPS of the cultureplate than to the cells, and their unchanged localization over time (Figure 69, Figure 70, and Figure 7I).

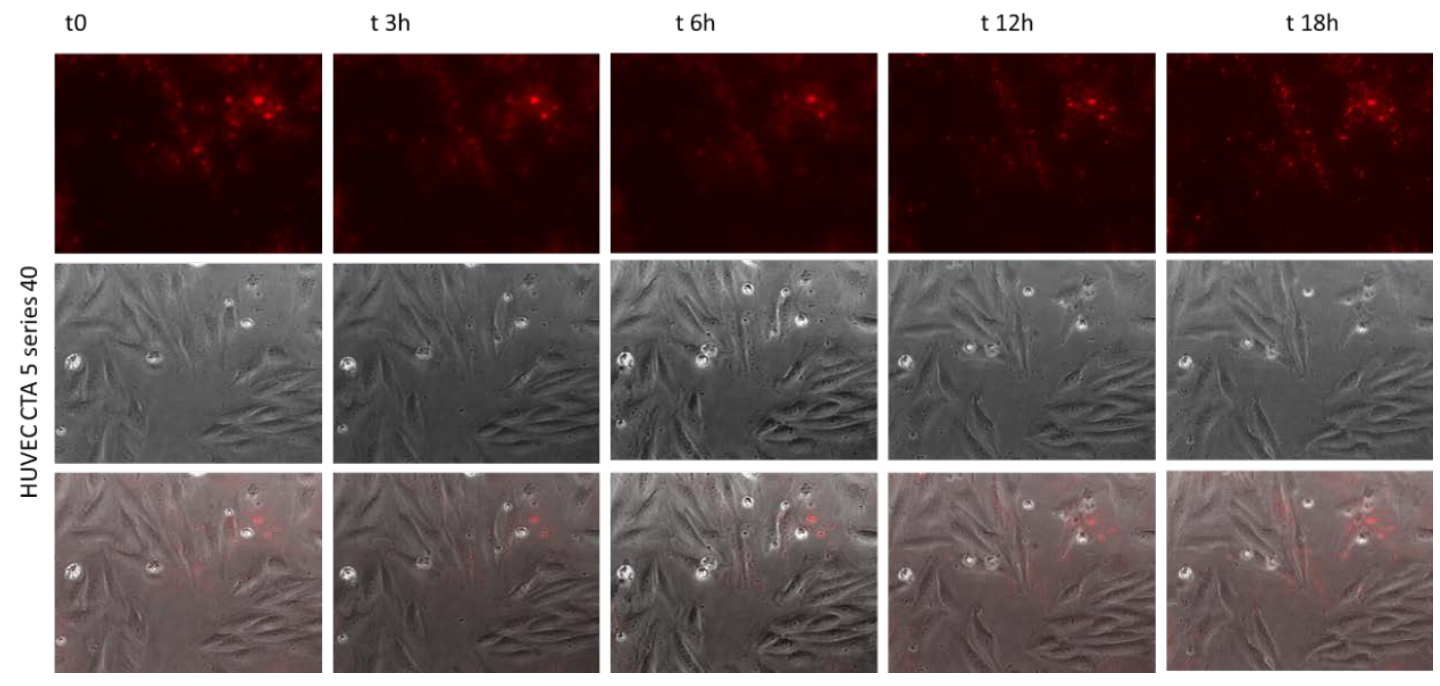

Figure 72:Life cell imaging of HUVEC cells incubated with 375 nM ELR ${ }^{\text {CTA5* }}$ over a period of I8h. 
Incubation of HUVECs with ELR ${ }^{\text {CTA5 }}$ on the other hand revealed a similar distribution of ELR in the cell membrane as observed in HASMCs (Figure 72). In general, live cell imaging of all cell types supported the hypothesis whereby the larger agglomerates, which bind to the cell membranes, are still mobile and tend to bind to each other upon contact. High cholesteryl contents led to ELRs very finely dispersed throughout the membrane. The marked mobility of the ELR ${ }^{\mathrm{CTA}} \mathrm{s}$ in the cell membrane indicates that the interaction with the membrane does not reduce cell mobility. Moreover, HUVEC cells did not interact with ELRs CTA $<3$ and the agglomerated ELR, with these ELRs binding to the well-plate and their organization remaining unchanged over time (Figure 69 and Figure 70), which is in accordance with the FACS data. In contrast, in HASMC cells the ELR fragments adhere to the membrane and are moved around by the cells, thus resulting in the growth of the agglomerates as a result of increased probability of ELR-ELR contacts, together with the reduced proliferation in HASMC cells with ELRs $C T A<3$ the bigger agglomerates on the cell surface might increase morbidity of cells or hamper proliferation. The increased membrane affinity for cholesteryl groups overcomes the ELR-ELR interaction, thus resulting in more dispersed particles in solution as well as on the membrane and increasing the number of fluorescent-positive cells. HASMCs are less selective than HUVECs and actively bind low cholesteryl ELRs (Figure 65 and Figure 66), with the amount of bound ELR per cell appearing to be higher, as characterized by a second population of right-shifted cells with a fluorescent intensity of $10^{2}-10^{3}$. However, the tendency of ELR ${ }^{\text {CTA3 }}$ and $E L R^{C T A 0}$ to be dispersed in the membrane was observed in both cell lines (Figure 68 Figure 72). The distribution of the ELRs is shown in detail in the confocal images, which show how the agglomerates of ELR ${ }^{\mathrm{CTA} 0}$ or ELR ${ }^{\mathrm{CTAl}}$ are bound to the membrane as micrometer-sized particles, changing with increasing cholesterol content into a myriad of submicron-sized small ELR 
dots ELR ${ }^{\mathrm{CTAO}}$ within the membrane. Confocal imaging also supports the fact that most of the ELR remains in close proximity to the membrane and is not fully incorporated into the cells. In light of the data obtained from flow cytometry, the incorporation of ELRs into the membrane, or the association of ELR with the membranes, does not negatively affect cell proliferation, as would be indicated by an increased amount of cell debris in ungated dot plots.
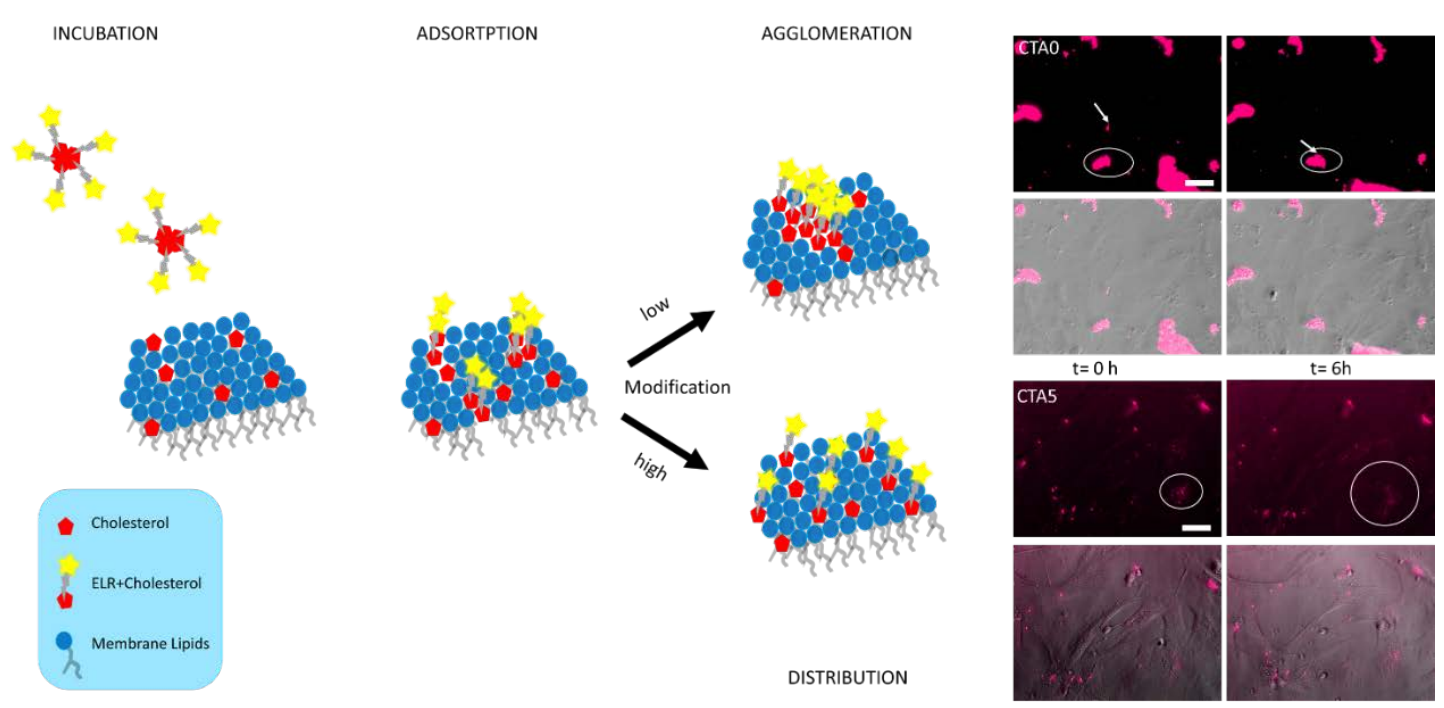

Figure 73: Schematic interaction of cholesteryl ELR with the cell membrane. Upon incubation the cholesteryl-ELR adsorbs to the membrane. Over time the ELR either agglomerates on the cell membrane or are further distributed on the membrane. Top right: ELR ${ }^{\text {CTA } 0 *}$ incubated with HASMC, ELR ${ }^{\text {CTAO } *}$ sticks to the membrane and agglomerated due to ELR-ELR contacts. Bottom

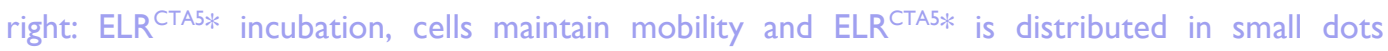
throughout the membrane. The left images indicate t0 after incubation, the right images $\mathrm{t}=6 \mathrm{~h}$.

Although elastin-like proteins (ELPs, also referred to as ELRs) with a similar constitution to ELR ${ }^{\mathrm{CTA} 0}$ presented herein have been reported to be tunable in terms of membrane interactions due to changes in temperature, thereby resulting in changes of hydrophobicity and the good interaction of ELR ${ }^{\text {CTAO }}$ $(T>T t)$ with HASMC cells, it should be noted that much lower 
concentrations were used in our work ${ }^{449}$. Simnick et al. further showed that integrin receptor-like interactions could be used to further increase cellligand interactions ${ }^{449}$. The augmented affinity to cell membranes with cholesteryl anchors was further reported with modified hyaluronan ${ }^{454}$, or $D_{N A}^{455}$. The differences in CTA groups on cellular uptake might be explained by the involvement of cells in lipid uptake. Cholesterol can interact with other proteins via both covalent ${ }^{456}$ and non-covalent mechanisms ${ }^{457,458}$, thereby regulating protein stability, localization ${ }^{426}$ and activity ${ }^{70}$. Cholesterol accumulation is one of the primary events in atherosclerosis within specific and specialized cell types such as SMCs, where it results in uncontrolled uptake, whereas endothelial cells maintain tight cholesterol homeostasis ${ }^{459}$, which might explain the selectivity of HUVECs for high ELR ${ }^{\text {CTA }}$ concentrations. Furthermore, it has been shown that, in contrast to SMCs, endothelial cells do not undergo the foam cell phenotypic change in atherosclerotic plaques, a change characterized by the unrestricted accumulation of cellular cholesterol ${ }^{460}$, which would explain the cytostatis of HASMC at 750 nM ELR ${ }^{\text {CTA }}$. It should be noted that ELR ${ }^{\text {CTA0 }}$ and ELR ${ }^{\text {CTAI }}$ have a more cytostatic effect on HASMCs, which in turn means that cholesteryl groups improve the cytocompatibility of ELR ${ }^{\mathrm{CTAO}}$. Although the interaction of ELR ${ }^{\text {CTAO }}$ and ELR ${ }^{\text {CTAI }}$ with cells is possibly mediated by electrostatic interactions with the remaining free lysines of the ELR, this interaction is not strong enough to disrupt the hydrophobic ELR-ELR interaction above the LCST, thus resulting in the growth of bound aggregates over time. 
4.3 CHAPTER 3: ELR - Cell interaction triggered by hydrophobic 



$$
\text { 5. CONCLUSIONS }
$$





\section{Conclusions}

\subsection{ELR Zymography}

We could demonstrate, that by the meticulous design of protein sequence, a substrate for IGZ was generated, that allows for embedding into gel matrices, $\mathrm{CBB}$ detection and displays a single specific proteolytic sequence. Already with the presented two different groups, differences in serin protease and MMP activity could be revealed. It is worth to mention that, ELR-Control is not a target of selected MMPs but was slightly degraded by trypsin in the control experiment, which was possibly due to the presence of lysines which are important for the detection with $C B B$, since lysines are a favored target of serine proteases. For the binary output of this method, specificity is of importance, that is why the method might be limited to MMPs only.

Additionaly, we presented a new method for the screening of proteases by translating the IGZ into a well-plate zymography (IWZ), allowing for fast and quantitative read-out. We could show that already with two different functional groups we could determine differences in degradation profiles by IWZ, where positive and negative control served as an additional feed-back loop in terms of derived pattern. Degradation over-time could be tracked enabling the measurement of distinct kinetics by this method. The specificity of the substrate brings several advancements to gel-based zymographic techniques, due to the binarity of the results, even without electrophoretic separation, samples can be analyzed in terms of "if" or "if-not" they target to the presented substrate. 
The presented method has the potential as a protease screening, which gains significance directly proportional to the number of protease targets (ELRs) used. The presented IWZ method has a high throughput potential, therefore, further substrates are currently developed to generate a library of substrates that allow discovering new cleavage patterns of proteases, and might have relevance to detect abnormalities in clinical samples. Since diffusion out of a static well plate gel is an issue, trans-well systems are part of future investigations.

\subsection{Structural deductions of cholesterol modified ELRS}

Recombinant protein-based materials have attracted increasing attention over the past few years due to their natural origin and the fact that myriad properties can be incorporated. We have demonstrated that novel properties such as self-assembly and thermoreversible gel formation can be achieved by selective modification of IDPs with tandem repeats of low complexity, thereby resulting in novel materials that can exhibit both UCST and LCST behavior in which the ordered secondary structure is favored both above the LCST and below the UCST for enhanced cholesterylcholesteryl interactions. On the basis of our results, cholesteryl groups appear to act as structural mediators, in this case either as micelle stabilizers under entropy-driven conditions above the LCST, or as exposed micelle connectors under enthalpy-driven conditions below the UCST. In both cases, cholesteryl groups accelerate the structural organization of ELRs over time. The fact that similar secondary structures are obtained with either inward- or outward-facing cholesteryl groups might be explained by the underlying protein backbone, which governs the structural motifs that can 
be accessed. This can further be fostered by the repetitiveness of the protein sequence, with lysines at every $30^{\text {th }}$ amino acid residue, which lead even with randomly distributed cholesteryl residues to potentially higher probabilities of equidistant cholesteryl side-chains, thereby improving intermolecular cholesteryl-cholesteryl ח-ா-like stacking of the oligocyclic steroid backbone. Although maintenance of the secondary structure while changing cholesteryl orientation seems counterintuitive, the low number of cholesteryl groups driving organization compared with the size of the polypetide backbone, which is intrinsically disordered below the LCST, has to be considered along with the relatively small degree of order added by those groups (approx. $+5 \%$, below and above the UCST/LCST). The low-temperature formation of UCST-type gels induced by a pseudo-zwitterionic cholesteryl phenotype was supported by ZP, CMC, Herschel-Bulkley index, viscosity and storage modulus, along with the underlying changes in secondary structure derived from deconvoluted $C D$ data. Although these data have been reported in part in other studies related to cholesteryl modification, or UCST gels, herein we present a model system that sheds light on the various effects resulting from the incorporation of cholesteryl side-chains by relating structural changes to macroscopic observations. The possibility to introduce a thermo-reversible gel transition into protein-based materials will have potential applications in biomedical applications such as smart bioactive surfaces, selective bioseparation, phase separation immunoassays, enzyme recycling, protein chromatography, controlled bioadhesion, hyperthermiainduced drug delivery, and tissue engineering ${ }^{438}$. Moreover, such modifications could be used to forge micelle interactions, thus making macroscopic hierarchical structures accessible. The effect of cholesteryl side-chains on proteins as potential membrane-anchored cell coatings is the subject of ongoing studies. suitable for trapping the hydrophobic drugs. ${ }^{231}$ 


\subsection{Cellular interactions with Cholesteryl-ELRs}

The general mechanisms of cell-substrate binding are based on Integrinsubstrate binding, or polycation LbL coatings, and phagocytosis of positively charged polyplexes. However, this work provides an additional cue by using hydrophobic entities as mediators of cell-substrate interactions. In this work, cholesterol groups are used as a cellular anchor to enhance the membrane substrate interaction of an elastin-like recombinamer (ELR). The resulting materials showed enhanced cellular recognition and matrix distribution, in line with the number of CTA groups incorporated.

To the best of our knowledge, hydrophobic moieties that function as cellular membrane anchors for proteins have not yet been investigated to date. Since no negative proliferative effect on cells was observed in selected cell types at concentrations resulting in $>60 \%$ of fluorescently labeled cells, the present system may lead to a better understanding of hydrophobic membranesubstrate interactions and the development of novel hydrophobicity driven cell coatings that could potentially replace current coatings. Furthermore, these novel materials and their versatility in terms of protein sequence have high potential as cellular markers, drug carriers, or hydrophobic cell-binding domains. The cell specificity also allows for further optimization of the process by varying concentrations, incubation times and the number of cholesteryl groups. This system may also help to understand the mechanisms by which vascular endothelial cells maintain tight cholesterol homeostasis and may shed light on the mechanisms of cellular sterol transport, or highdensity lipoprotein (HDL)-dependent RCT. Future studies will focus on ELR-cholesteryl systems with fewer ELR-ELR attractions at $37^{\circ} \mathrm{C}$ to extract 
the driving force of membrane distribution and the related contribution of cholesteryl groups, or the ELRs themselves. 

6. REFERENCES 



\section{References}

(I) Nam, K. T.; Kim, D.-W.; Yoo, P. J.; Chiang, C.-Y.; Meethong, N.; Hammond, P. T.; Chiang, Y.-M.; Belcher, A. M. Virus-Enabled Synthesis and Assembly of Nanowires for Lithium lon Battery Electrodes. Science 2006, 3/2 (5775), 885-888. https://doi.org//0.1 I26/science. I I227/6.

(2) Rodríguez-Cabello, J. C.; Pierna, M.; Fernández-Colino, A.; García-Arévalo, C.; Arias, F. J. Recombinamers: Combining Molecular Complexity with Diverse Bioactivities for Advanced Biomedical and Biotechnological Applications. In Advances in biochemical engineering/biotechnology; 2010; Vol. I25, pP 145-179. https://doi.org//0.1007//10_2010_94.

(3) Chow, D.; Nunalee, M. L.; Lim, D. W.; Simnick, A. J.; Chilkoti, A. Peptide-Based Biopolymers in Biomedicine and Biotechnology. Mater. Sci. Eng. R. Rep. 2008, 62 (4), I25155. https://doi.org// 0.1016/j.mser.2008.04.004.

(4) Nair, L. S.; Laurencin, C. T. Biodegradable Polymers as Biomaterials. Prog. Polym. Sci. 2007, 32 (8-9), 762-798. https://doi.org/I0.1016/J.PROGPOLYMSCI.2007.05.0I7.

(5) Urry, D. W. Protein Elasticity Based on Conformations of Sequential Polypeptides: The Biological Elastic Fiber. J. Protein Chem. 1984, 36 (5).

(6) Debelle, L.; Tamburro, A. M. Elastin: Molecular Description and Function. Int. J. Biochem. Cell Biol. 1999, 3 I (2), 26I-272. https://doi.org/I 0.10I6/SI357-2725(98)00098-3.

(7) Urry, D. W. Characterization of Soluble Peptides of Elastin by Physical Techniques. Methods Enzymol. 1982, 82, 673-7/6. https://doi.org/I0.1016/0076-6879(82)82096-X.

(8) Khaled, M. A.; Prasad, K. U.; Venkatachalam, C. M.; Urry, D. W. Nuclear Magnetic Resonance and Conformational Energy Characterization of Repeat Peptides of Elastin: The Cyclohexadecapeptide, CycZo-( L-Val I- -Pro2-Gly3-Gly4)4. J . Am. Chem. SOC 1985, 107, 7|39-7/45.

(9) Urry, D. W.; Long, M. M.; Harris, R. D.; Prasad, K. U. Temperature-Correlated Force and Structure Development in Elastomeric Polypeptides: The llel Analog of the Polypentapeptide of Elastin. Biopolymers 1986, 25 (10), 1939-1953. https://doi.org// 0.1002/bip.36025I009.

(10) Tamburro, A. M.; Guantieri, V.; Scopa, A.; Drabble, J. M. Polypeptide Models of Elastin: CD and NMR Studies on Synthetic Poly(X-Gly-Gly). Chirality 199I, 3 (4), 318-323. https://doi.org//0.1002/chir.5300304I7.

(II) GUANTIERI, V.; TAMBURRO, A. M.; CABROL, D.; BROCH, H.; VASILESCU, D. Conformational Studies on Polypeptide Models of Collagen. Poly(Gly-Pro-Val), Poly(GlyPro-Met), Poly(Gly-Val-Pro) and Poly(Gly-Met-Pro). Int. J. Pept. Protein Res. 2009, 29 (2), 216-230. https://doi.org/I0.1 I I I/j.1399-30I I.1987.tb02248.x.

(12) Altunbas, A.; Pochan, D. J. Peptide-Based and Polypeptide-Based Hydrogels for Drug Delivery and Tissue Engineering. In Topics in current chemistry; 20I I; Vol. 310, PP I35-167. https://doi.org/I0.1007//28_20II_206.

(I3) Sandberg, L. B.; Soskel, N. T.; Leslie, J. G. Elastin Structure, Biosynthesis, and Relation to Disease States. N. Engl. J. Med. 198I, 304, 566.

(14) Urry, D. W.; Haynes, B.; Harris, R. D. Temperature Dependence of Length of Elastin and Its Polypentapeptide. Biochem. Biophys. Res. Commun. 1986, I4I (2), 749-755. https://doi.org/I0.1016/S0006-29IX(86)80236-4.

(I5) Sandberg, L. B.; Gray, W. R.; Foster, J. A.; Torres, A. R.; Alvarez, V. L.; Janata, J. Primary Structure of Porcine Tropoelastin; Springer, Boston, MA, 1977; PP 277-284. https://doi.org// 0.1007/978-I-4684-9093-0_25.

(16) Gray, W. R.; Sandberg, L. B.; Foster, J. A. Molecular Model for Elastin Structure and Function. Nature 1973, 246 (5434), 46I-466.

(17) Khaled, M. A.; Renugopalakrishnan, V.; Urry, D. W. Proton Magnetic Resonance and Conformational Energy Calculations of Repeat Peptides of Tropoelastin: The Tetrapeptide. J. Am. Chem. Soc. 1976, 98 (24), 7547-7553.

(18) Alix, A. J. A Turning Point in the Knowledge of the Structure-Function-Activity Relations of Elastin. J. la Sociéte Biol. 200 I, 195 (2), I8I-193. 
(19) Girotti, A.; Reguera, J.; Rodríguez-Cabello, J. C.; Arias, F. J.; Alonso, M.; Testera, A. M. Design and Bioproduction of a Recombinant Multi(Bio)Functional Elastin-like Protein Polymer Containing Cell Adhesion Sequences for Tissue Engineering Purposes. J. Mater. Sci. Mater. Med. 2004, I5 (4), 479-484. https://doi.org/I 0.1023/B:JMSM.000002I I 24.58688.7a.

(20) Urry, D. W.; Pattanaik, A.; Xu, J.; Woods, T. C.; McPherson, D. T.; Parker, T. M. Elastic Protein-Based Polymers in Soft Tissue Augmentation and Generation. J. Biomater. Sci. Polym. Ed. 1998, 9 (10), 1015-1048.

(2I) Nicol, A.; Channe Gowda, D.; Urry, D. W. Cell Adhesion and Growth on Synthetic Elastomeric Matrices Containing ARG-GLY-ASP-SER-3. J. Biomed. Mater. Res. I992, 26 (3), 393-4/3. https://doi.org//0.1002/jbm.820260309.

(22) Mykles, D. L. Intracellular Proteinases of Invertebrates: Calcium-Dependent and Proteasome/Ubiquitin-Dependent Systems. In International review of Cytology; 1998; pp I57289. https://doi.org/I0.1016/S0074-7696(08)62181-6.

(23) Frederiks, W. M.; Mook, O. R. F. Metabolic Mapping of Proteinase Activity with Emphasis on In Situ Zymography of Gelatinases. J. Histochem. Cytochem. 2004, 52 (6), 7II-722. https://doi.org/I0.1369/jhc.4R625I.2004.

(24) Granelli-Piperno, A.; Reich, E. A Study of Proteases and Protease-Inhibitor Complexes in Biological Fluids. J Exp Med 1978, I 48 (I), 223-234. https://doi.org/I 0.1 084/jem. I 48.I.223. Hunter, R. L.; Market, C. L. Histochemical Demonstration of Enzymes Separated by Zone Electrophoresis in Starch Gels. Science (80-. ). 1957, I 25 (326I).

(26) Booth, C.; Attwood, D.; Price, C. Self-Association of Block Copoly(Oxyalkylene)s in Aqueous Solution. Effects of Composition, Block Length and Block Architecture. Phys. Chem. Chem. Phys. 2006, 8 (31), 36I2. https://doi.org//0.1039/b605367j.

(27) Chen, L.; Ci, T.; Yu, L.; Ding, J. Effects of Molecular Weight and Its Distribution of PEG Block on Micellization and Thermogellability of PLGA-PEG-PLGA Copolymer Aqueous $\begin{array}{lllll}\text { Solutions. } & \text { Macromolecules } & \text { 2015, } & 48 & \text { (II), }\end{array}$ https://doi.org/10.102I/acs.macromol.5b00168.

(28) Muller, J.; Marchandeau, F.; Prelot, B.; Zajac, J.; Robin, J.-J.; Monge, S. Self-Organization in Water of Well-Defined Amphiphilic Poly(Vinyl Acetate)-b-Poly(Vinyl Alcohol) Diblock Copolymers. Polym. Chem. 20 I 5, 6 (16), 3063-3073. https://doi.org/I0.1039/C5PY0009IB.

(29) Rakhmatullina, E.; Braun, T.; Chami, M.; Malinova, V.; Meier, W. Self-Organization Behavior of Methacrylate-Based Amphiphilic Di- and Triblock Copolymers. Langmuir 2007, 23 (24), |237|-12379. https://doi.org/10.1021/la7023 | 32.

(30) Torchilin, V. P. Micellar Nanocarriers: Pharmaceutical Perspectives. Pharm. Res. 2006, 24 (I), I-I6. https://doi.org//0.1007/s I 1095-006-9/32-0.

(31) Discher, D. E.; Eisenberg, A. Polymer Vesicles. Science (80-. ). 2002, 297 (5583), 967-973. https://doi.org/I0.II26/science.1074972.

(32) Ringsdorf, H.; Schlarb, B.; Venzmer, J. Molecular Architecture and Function of Polymeric Oriented Systems: Models for the Study of Organization, Surface Recognition, and Dynamics of Biomembranes. Angew. Chemie Int. Ed. English 1988, 27 (I), II3-I58. https://doi.org//0.1002/anie.19880II3I.

(33) Whitesides, G. M.; Mathias, J. P.; Seto, C. T. Molecular Self-Assembly and Nanochemistry: A Chemical Strategy for the Synthesis of Nanostructures. Science I 99 I, 254 (5036), I3 I 21319.

(34) Qin, S.; Geng, Y.; Discher, D. E.; Yang, S. Temperature-Controlled Assembly and Release from Polymer Vesicles of Poly(Ethylene Oxide)-Block- Poly(N-lsopropylacrylamide). Adv. Mater. 2006, I8 (2I), 2905-2909. https://doi.org/I0.1002/adma.20060I0I9.

(35) Baler, K.; Michael, R.; Szleifer, I.; Ameer, G. A. Albumin Hydrogels Formed by Electrostatically Triggered Self-Assembly and Their Drug Delivery Capability. Biomacromolecules 20 I 4, I5 (I0), 3625-3633. https://doi.org/l0.102 I/bm500883h.

(36) Song, F.; Li, X.; Wang, Q.; Liao, L.; Zhang, C. Nanocomposite Hydrogels and Their Applications in Drug Delivery and Tissue Engineering. J. Biomed. Nanotechnol. 20 I 5, II (I), 40-52.

(37) Xiong, X.-B.; Falamarzian, A.; Garg, S. M.; Lavasanifar, A. Engineering of Amphiphilic Block Copolymers for Polymeric Micellar Drug and Gene Delivery. J. Control. Release 20 I I, I 55 (2), 248-26 I. https://doi.org/I 0.10 I6/j.jconrel.20I I.04.028.

(38) Oshiro, A.; da Silva, D. C.; de Mello, J. C.; de Moraes, V. W. R.; Cavalcanti, L. P.; Franco, 
M. K. K. D.; Alkschbirs, M. I.; Fraceto, L. F.; Yokaichiya, F.; Rodrigues, T.; et al. Pluronics FI27/L-8I Binary Hydrogels as Drug-Delivery Systems: Influence of Physicochemical Aspects on Release Kinetics and Cytotoxicity. Langmuir 2014, 30 (45), I3689-13698. https://doi.org/l0.102I/la50302 Ic.

(39) Chang, T. Polymer Characterization by Interaction Chromatography. J. Polym. Sci. Part B Polym. Phys. 2005, 43 (I 3), I59I-1607. https://doi.org/I0.1002/polb.20440.

(40) He, C.; Kim, S. W.; Lee, D. S. In Situ Gelling Stimuli-Sensitive Block Copolymer Hydrogels for Drug Delivery. J. Control. Release 2008, 127 (3), 189-207. https://doi.org/10.1016/j.jconrel.2008.01.005.

(4I) Kim, J. H.; Lim, S. Y.; Nam, D. H.; Ryu, J.; Ku, S. H.; Park, C. B. Self-Assembled, Photoluminescent Peptide Hydrogel as a Versatile Platform for Enzyme-Based Optical Biosensors. Biosens. Bioelectron. 20II, 26 (5), 1860-1865. https://doi.org/10.1016/j.bios.2010.01.026.

(42) Benavidez, T. E.; Capra, R. H.; Alvarez, C. I.; Baruzzi, A. M. Amperometric Biosensor Based on Immobilization of Oxalate Oxidase in a Mucin/Chitosan Matrix. Electroanalysis 2009, 2 I (7), NA-NA. https://doi.org// 0.1002/elan.200804482.

(43) Gawel, K.; Barriet, D.; Sletmoen, M.; Stokke, B. T. Responsive Hydrogels for Label-Free Signal Transduction within Biosensors. Sensors (Basel). 2010, 10 (5), 438I-4409. https://doi.org// 0.3390/s I0050438I.

(44) Urry, D. W. Molecular Machines: How Motion and Other Functions of Living Organisms Can Result from Reversible Chemical Changes. Angew. Chemie Int. Ed. English 1993, 32 (6), 819-841. https://doi.org/I0.1002/anie.199308I91.

(45) Ribeiro, A.; Arias, F. J.; Reguera, J.; Alonso, M.; Rodríguez-Cabello, J. C. Influence of the Amino-Acid Sequence on the Inverse Temperature Transition of Elastin-Like Polymers. Biophys. J. 2009, 97 (I), 312-320. https://doi.org// 0.1016/j.bpj.2009.03.030.

(46) Rodriguez-Cabello, J. C.; Ibáñez Fonseca, A.; Alonso, M.; Poocza, L.; Cipriani, F.; González de Torre, I. Elastin-Like Polymers: Properties, Synthesis, and Applications. In Encyclopedia of Polymer Science and Technology; John Wiley \& Sons, Inc.: Hoboken, NJ, USA, 2017; pP I36. https://doi.org//0.1002/047| 440264.pst656.

(47) Rodríguez Cabello, J. C.; De Torre, I. G.; Cipriani, F.; Poocza, L. Elastin-like Materials for Tissue Regeneration and Repair. Pept. Proteins as Biomater. Tissue Regen. Repair 2018, 309327. https://doi.org/10.1016/B978-0-08-100803-4.00012-7.

(48) Reguera, J.; Fahmi, A.; Moriarty, P.; Girotti, A.; Rodríguez-Cabello, J. C. Nanopore Formation by Self-Assembly of the Model Genetically Engineered Elastin-like Polymer [(VPGVG)2(VPGEG)(VPGVG)2] I5. J. Am. Chem. Soc. 2004, I26 (4I), I32I2-I32I3. https://doi.org//0.102I/ja0474I7f.

(49) Fernández-Colino, A.; Arias, F. J.; Alonso, M.; Rodríguez-Cabello, J. C. Self-Organized ECMMimetic Model Based on an Amphiphilic Multiblock Silk-Elastin-Like Corecombinamer with a Concomitant Dual Physical Gelation Process. Biomacromolecules 2014, 15 (10), 378I3793. https://doi.org/I0.102 I/bm50105It.

(50) Martín, L.; Castro, E.; Ribeiro, A.; Alonso, M.; Rodríguez-Cabello, J. C. TemperatureTriggered Self-Assembly of Elastin-Like Block Co-Recombinamers:The Controlled Formation of Micelles and Vesicles in an Aqueous Medium. Biomacromolecules 20 I 2, 13 (2), 293-298. https://doi.org/l0.1021/bm201436y.

(5I) Aoshima, S.; Kanaoka, S. Synthesis of Stimuli-Responsive Polymers by Living Polymerization: Poly(N-Isopropylacrylamide) and Poly(Vinyl Ether)S; Springer, Berlin, Heidelberg, 2007; PP 169-208. https://doi.org/10.1007//2_2007_120.

(52) Aoshima, S.; Oda, H.; Kobayashi, E. Synthesis of Thermally-Induced Phase Separating Polymer with Well-Defined Polymer Structure by Living Cationic Polymerization. I. Synthesis of Poly(Vinyl Ether)s with Oxyethylene Units in the Pendant and Its Phase Separation Behavior in Aqueous Solution. J. Polym. Sci. Part A Polym. Chem. I992, 30 (II), 2407-24I3. https://doi.org/I0.1002/pola.1992.08030III5.

(53) Uyama, H.; Kobayashi, S. A Novel Thermo-Sensitive Polymer. Poly(2- Iso -Propyl-2Oxazoline). Chem. Lett. 1992, 2 I (9), I643-1646. https://doi.org/I0.I246/cl.1992.1643.

(54) Schild, H. G. Poly(N-Isopropylacrylamide): Experiment, Theory and Application. Prog. Polym. Sci. 1992, I 7 (2), I63-249. https://doi.org// 0.1016/0079-6700(92)90023-R.

(55) Weaver, J. V. M.; Armes, S. P.; Bütün, V. Synthesis and Aqueous Solution Properties of a 
Well-Defined Thermo-Responsive Schizophrenic Diblock Copolymer. Chem. Commun. 2002, 0 (I8), 2I22-2I23. https://doi.org/I0.1039/B20725IN.

(56) Ueki, T.; Watanabe, M. Macromolecules in lonic Liquids: Progress, Challenges, and $\begin{array}{lllll}\text { Opportunities. } & \text { Macromolecules } & \text { 2008, } & 4 \text { (II), }\end{array}$ https://doi.org/10.102I/ma80017lk.

(57) Arotçaréna, M.; Heise, B.; Ishaya, S.; Laschewsky, A. Switching the Inside and the Outside of Aggregates of Water-Soluble Block Copolymers with Double Thermoresponsivity. J. Am. Chem. Soc. 2002, 124, 3787. https://doi.org/10.102I/JA012167D.

(58) Yang, W.; Chen, S.; Cheng, G.; Vaisocherová, H.; Xue, H.; Li, W.; Zhang, J.; Jiang, S. Film Thickness Dependence of Protein Adsorption from Blood Serum and Plasma onto Poly(Sulfobetaine)-Grafted Surfaces. Langmuir 2008, 24 (I7), 921I-9214. https://doi.org/I0.1021/la801487f.

(59) Chang, Y.; Chen, S.; Zhang, Z.; Jiang, S. Highly Protein-Resistant Coatings from WellDefined Diblock Copolymers Containing Sulfobetaines. Langmuir 2006, 22 (5), 2222-2226. https://doi.org/I0.102I/LA052962V.

(60) Dutta, N. K.; Truong, M. Y.; Mayavan, S.; Roy Choudhury, N.; Elvin, C. M.; Kim, M.; Knott, R.; Nairn, K. M.; Hill, A. J. A Genetically Engineered Protein Responsive to Multiple Stimuli. Angew. Chemie Int. Ed. 20 I I, 50 (I9), 4428-443I. https://doi.org//0.1002/anie.201007920.

(6I) Renner, J. N.; Cherry, K. M.; Su, R. S.-C.; Liu, J. C. Characterization of Resilin-Based Materials for Tissue Engineering Applications. Biomacromolecules 20 I 2, I 3 (I I), 3678-3685. https://doi.org/10.1021/bm301 I29b.

(62) Sekine, H.; Shimizu, T.; Sakaguchi, K.; Dobashi, I.; Wada, M.; Yamato, M.; Kobayashi, E.; Umezu, M.; Okano, T. In Vitro Fabrication of Functional Three-Dimensional Tissues with Perfusable Blood Vessels. Nat. Commun. 2013, 4, 1399. https://doi.org/10.1038/ncomms2406.

(63) Alberts, B.; Johnson, A.; Lewis, J.; Raff, M.; Roberts, K.; Walter, P. Molecular Biology of the Cell; Garland Science, 2002.

(64) Schroeder, F.; Huang, H.; Mclntosh, A. L.; Atshaves, B. P.; Martin, G. G.; Kier, A. B. Caveolin, Sterol Carrier Protein-2, Membrane Cholesterol-Rich Microdomains and Intracellular Cholesterol Trafficking. In Cholesterol Binding and Cholesterol Transport Proteins; Springer, Dordrecht, 2010; pp 279-318. https://doi.org/10.1007/978-90-481-8622-8_10.

(65) Li, S.; Song, K. S.; Lisanti, M. P. Expression and Characterization of Recombinant Caveolin. J. Biol. Chem. 1996, 27 I (I), 568-573.

(66) Glauert, A. M. Fixation, Dehydration and Embedding of Biological Specimens.; North-Holland Pub. Co.; New York, American Elsevier Pub. Co, 1975.

(67) Severs, N. J. Caveolae: Static Inpocketings of the Plasma Membrane, Dynamic Vesicles or Plain Artifact? J. Cell Sci. 1 988, 90, 34I-348.

(68) Russell, D. W. Oxysterol Biosynthetic Enzymes. Biochim. Biophys. Acta 2000, I529 (I-3), I26-135.

(69) Russell, D. W. Fifty Years of Advances in Bile Acid Synthesis and Metabolism. J. Lipid Res. 2009, 50 Suppl (Suppl), SI 20-5. https://doi.org/I0.I I94/jlr.R800026-JLR200.

(70) Hulce, J. J.; Cognetta, A. B.; Niphakis, M. J.; Tully, S. E.; Cravatt, B. F. Proteome-Wide Mapping of Cholesterol-Interacting Proteins in Mammalian Cells. Nat. Methods 2013, 10 (3), 259-264. https://doi.org/I 0.1038/nmeth.2368.

(7I) Nishiguchi, A.; Yoshida, H.; Matsusaki, M.; Akashi, M. Rapid Construction of ThreeDimensional Multilayered Tissues with Endothelial Tube Networks by the CellAccumulation Technique. Adv. Mater. 20II, 3506-35I0. https://doi.org/10.1002/adma.201 101787.

(72) Akiyama, H.; Ito, A.; Sato, M.; Kawabe, Y.; Kamihira, M. Construction of Cardiac Tissue Rings Using a Magnetic Tissue Fabrication Technique. Int. J. Mol. Sci. 20 I 0, II (8), 2910 2920. https://doi.org/I0.3390/ijms I I0829I0.

(73) Morimoto, Y.; Tanaka, R.; Takeuchi, S. Construction of 3D, Layered Skin, Microsized Tissues by Using Cell Beads for Cellular Function Analysis. Adv. Healthc. Mater. 2013, 2 (2), 26I-265. https://doi.org//0.1002/adhm.20I200I89.

(74) Lim, F.; Sun, A. M. Microencapsulated Islets as Bioartificial Endocrine Pancreas. Science I 980, 210 (4472), 908-9I0. https://doi.org/I0.I I 26/SCIENCE.6776628.

(75) Muhr, P.; Likussar, W.; Schubert-Zsilavecz, M. Structure Investigation and Proton and 
Carbon-13 Assignments of Digitonin and Cholesterol Using Multidimensional NMR Techniques. Magn. Reson. Chem. I 996, 34 (2), I 37-I42. https://doi.org/I 0. I002/(SICI) I097458X(199602)34:2<137::AID-OMR841>3.0.CO;2-Q.

(76) Grossin, L.; Cortial, D.; Saulnier, B.; Félix, O.; Chassepot, A.; Decher, G.; Netter, P.; Schaaf, P.; Gillet, P.; Mainard, D.; et al. Step-by-Step Build-Up of Biologically Active Cell-Containing Stratified Films Aimed at Tissue Engineering. Adv. Mater. 2009, 21 (6), 650-655. https://doi.org/I0.1002/adma.20080I54I.

(77) Jun-ichi Anzai, *; Yuka Kobayashi; Nobuyuki Nakamura; Masahiro Nishimura, and; Hoshi, T. Layer-by-Layer Construction of Multilayer Thin Films Composed of Avidin and BiotinLabeled Poly(Amine)S. 1998. https://doi.org/10.102 I/LA980743M.

(78) Müller, W.; Ringsdorf, H.; Suci, P.; Herron, J. N.; Ebato, H.; Okahata, Y. Docking of a Second Functional Protein Layer to a Streptavidin Matrix on a Solid Support: Studies with a Quartz Crystal Microbalance. Angew. Chemie Int. Ed. English 1992, 31 (8), I087-1090. https://doi.org/10.1002/anie.19921087I.

(79) Decher, G.; Lehr, B.; Lowack, K.; Lvov, Y.; Schmitt, J. New Nanocomposite Films for Biosensors: Layer-by-Layer Adsorbed Films of Polyelectrolytes, Proteins or DNA. Biosens. Bioelectron. 1994, 9 (9-10), 677-684. https://doi.org/I0.1016/0956-5663(94)80065-0.

(80) He, P.-G.; Takahashi, T.; Hoshi, T.; Anzai, J.; Suzuki, Y.; Osa, T. Preparation of Enzyme Multilayers on Electrode Surface by Use of Avidin and Biotin-Labeled Enzyme for Biosensor Applications. Mater. Sci. Eng. C 1994, 2 (I-2), 103-106. https://doi.org/10.1016/0928493 I (94)90037-X.

(8I) Bourdillon, C.; Demaille, C.; Moiroux, J.; Saveant, J.-M. Catalysis and Mass Transport in Spatially Ordered Enzyme Assemblies on Electrodes. J. Am. Chem. Soc. 1995, II 7 (46), | |499-I| 506. https://doi.org//0.102 I/ja00 I 5 Ia0 I3.

(82) Bourdillon, C.; Demaille, C.; Moiroux, J.; Saveant, J.-M. Step-by-Step Immunological Construction of a Fully Active Multilayer Enzyme Electrode. J. Am. Chem. Soc. 1994, I I6 (22), 10328-10329. https://doi.org/10.1021/ja00 I0 la074.

(83) Anzai, J.; Kobayashi, Y.; Nakamura, N. Alternate Deposition of Concanavalin A and Mannose-Labelled Enzymes on a Solid Surface to Prepare Catalytically Active Enzyme Thin Films. J. Chem. Soc. Perkin Trans. 2 1 998, 0 (3), 46 I-462. https://doi.org/l 0.1039/a709286e. Zhu, Y.; Tong, W.; Gao, C. Molecular-Engineered Polymeric Microcapsules Assembled from Concanavalin A and Glycogen with Specific Responses to Carbohydrates. Soft Matter 20 I I, 7 (I2), 5805. https://doi.org//0.1039/cl sm05047h.

(85) Matsusaki, M.; Akashi, M. Control of Extracellular Microenvironments Using Polymer / Protein Nanofilms for the Development of Three-Dimensional Human Tissue Chips. 20 I 4, 46 (9), 524-536. https://doi.org//0.1038/pj.2014.20.

(86) Mhanna, R. F.; Vörös, J.; Zenobi-Wong, M. Layer-by-Layer Films Made from Extracellular Matrix Macromolecules on Silicone Substrates. Biomacromolecules 201 I, I2 (3), 609-6I6. https://doi.org/l0.1021/bm I0I2772.

(87) Liu, C.-Y.; Matsusaki, M.; Akashi, M. The Construction of Cell-Density Controlled ThreeDimensional Tissues by Coating Micrometer-Sized Collagen Fiber Matrices on Single Cell Surfaces. RSC Adv. 2014, 4 (86), 46I4I-46I44. https://doi.org/I0.1039/C4RA09085C.

(88) Matsusaki, M.; Kadowaki, K.; Nakahara, Y.; Akashi, M. Fabrication of Cellular Multilayers with Nanometer-Sized Extracellular Matrix Films. Angew. Chemie Int. Ed. 2007, 46 (25), 4689-4692. https://doi.org/10.1002/anie.200701089.

(89) Matsusaki, M.; Amemori, S.; Kadowaki, K.; Akashi, M. Quantitative 3D Analysis of Nitric Oxide Diffusion in a 3D Artery Model Using Sensor Particles. Angew. Chemie Int. Ed. 20 I I, 50 (33), 7557-756I. https://doi.org/10.1002/anie.201008204.

(90) Nishiguchi, A.; Matsusaki, M.; Asano, Y.; Shimoda, H.; Akashi, M. Effects of Angiogenic Factors and 3D-Microenvironments on Vascularization within Sandwich Cultures. Biomaterials 20 I 4, 35 (I7), 4739-4748. https://doi.org/I0.10 I6/j.biomaterials.2014.01.079. Nishiguchi, A.; Yoshida, H.; Matsusaki, M.; Akashi, M. Rapid Construction of ThreeDimensional Multilayered Tissues with Endothelial Tube Networks by the CellAccumulation Technique. Adv. Mater. 20II, 23 (3I), 3506-35I0. https://doi.org/10.1002/adma.201101787.

(92) Huebsch, N.; Mooney, D. J. Inspiration and Application in the Evolution of Biomaterials. Nature 2009, 462 (7272), 426-432. https://doi.org/10.1038/nature0860I. 
(93) Li, M.; Ober, C. K. Block Copolymer Patterns and Templates. Mater. Today 2006, 9 (9), 30-39. https://doi.org/I0.10 I6/SI369-702 I (06)7I620-0.

(94) Herrero-Vanrell, R.; Rincon, A. C.; Alonso, M.; Reboto, V.; Molina-Martinez, I. T.; Rodriguez-Cabello, J. C. Self-Assembled Particles of an Elastin-like Polymer as Vehicles for Controlled Drug Release. J. Control. Release 2005, 102 (I), II3-122. https://doi.org/I0.1016/j.jconrel.2004.10.00I.

(95) Debelle, L.; Alix, A. J. P.; Wei, S. M.; Jacob, M. P.; Huvenne, J. P.; Berjot, M.; Legrand, P. The Secondary Structure and Architecture of Human Elastin. Eur. J. Biochem. 1998, 258 (2), 533-539. https://doi.org/10.1046/j. I432-1327.1998.2580533.x.

(96) Uitto, J. Biochemistry of the Elastic Fibers in Normal Connective Tissues and Its Alterations in Diseases. J. Invest. Dermatol. 1979, 72 (I), I-10.

(97) Nair, L. S.; Laurencin, C. T. Biodegradable Polymers as Biomaterials. Prog. Polym. Sci 2007, 32, 762-798. https://doi.org/I0.1016/j.progpolymsci.2007.05.017.

(98) Chow, D.; Nunalee, M. L.; Lim, D. W.; Simnick, A. J.; Chilkoti, A. Peptide-Based Biopolymers in Biomedicine and Biotechnology. Mater. Sci. Eng. R Reports 2008, 62 (4), 125-155. https://doi.org//0.1016/j.mser.2008.04.004.

(99) Debelle, L.; Tamburro, A. M. Elastin: Molecular Description and Function. Int. J. Biochem. Cell Biol. 1999, 3 I (2), 26I-272.

(100) Mithieux, S. M.; Weiss, A. S. Elastin. In Advances in protein chemistry; 2005; Vol. 70, pp 43746I. https://doi.org/I0.1016/S0065-3233(05)700I3-9.

(IOI) Urry, D. W.; Hugel, T.; Seitz, M.; Gaub, H. E.; Sheiba, L.; Dea, J.; Xu, J.; Parker, T. Elastin: A Representative Ideal Protein Elastomer. Philos. Trans. R. Soc. Lond. B. Biol. Sci. 2002, 357 (1418), 169-184. https://doi.org/l0.1098/rstb.200I.I023.

(102) Miao, M.; Bellingham, C. M.; Stahl, R. J.; Sitarz, E. E.; Lane, C. J.; Keeley, F. W. Sequence and Structure Determinants for the Self-Aggregation of Recombinant Polypeptides Modeled after Human Elastin. J. Biol. Chem. 2003, 278 (49), 48553-48562. https://doi.org// 0.1074/jbc.M308465200.

(103) McPherson, D. T.; Xu, J.; Urry, D. W. Product Purification by Reversible Phase Transition Following Escherichia Coli Expression of Genes Encoding up to 251 Repeats of the Elastomeric Pentapeptide GVGVP. Protein Expr. Purif. 1996, 7 (I), 5I-57. https://doi.org/I0.1006/prep.1996.0008.

(104) Panitch, A.; Yamaoka, T.; Fournier, M. J.; Mason, T. L.; Tirrell, D. A. Design and Biosynthesis of Elastin-like Artificial Extracellular Matrix Proteins Containing Periodically Spaced Fibronectin CS5 Domains. Macromolecules 1999, 32 (5), I70I-I703.

(105) McMillan, R. A.; Caran, K. L.; Apkarian, R. P.; Conticello, V. P. High-Resolution Topographic Imaging of Environmentally Responsive, Elastin-Mimetic Hydrogels. Macromolecules I999, 32 (26), 9067-9070.

(106) McMillan, R. A.; Conticello, V. P. Synthesis and Characterization of Elastin-Mimetic Protein Gels Derived from a Well-Defined Polypeptide Precursor. Macromolecules 2000, 33 (I3), 4809-482 I. https://doi.org/I0.102I/ma992109I.

(107) McPherson, D. T.; Morrow, C.; Minehan, D. S.; Wu, J.; Hunter, E.; Urry, D. W. Production and Purification of a Recombinant Elastomeric Polypeptide, G-(VPGVG) I9-VPGV, from Escherichia Coli. Biotechnol. Prog. 1992, 8 (4), 347-352. https://doi.org//0.1021/bp00016a012.

(108) Urry, D. W.; Trapane, T. L.; Prasad, K. U. Phase-Structure Transitions of the Elastin Polypentapeptide-Water System within the Framework of Composition-Temperature Studies. Biopolymers 1985, 24 (I2), 2345-2356. https://doi.org/I0.1002/bip.36024I 2 I2.

(109) Nagapudi, K.; Brinkman, W. T.; Leisen, J. E.; Huang, L.; McMillan, R. A.; Apkarian, R. P.; Conticello, V. P.; Chaikof, E. L. Photomediated Solid-State Cross-Linking of an ElastinMimetic Recombinant Protein Polymer. Macromolecules 2002, 35 (5), 1730-1737. https://doi.org/10.1021/ma01 1429t.

(I I0) Kagans, H. M.; Williams, M. A.; Williamson, P. R.; Anderson4, J. M. Influence of Sequence and Charge on the Specificity of Lysyl Oxidase toward Protein and Synthetic Peptide Substrates. J. Biol. Chem. I984, 259 (I8), I I203-I I 207 I.

(III) Petka, W. A.; Harden, J. L.; McGrath, K. P.; Wirtz, D.; Tirrell, D. A. Reversible Hydrogels from Self-Assembling Artificial Proteins. Science 1998, 28 I (5375), 389-392.

(I I2) Misbah, M. H.; Quintanilla, L.; Alonso, M.; Rodríguez-cabello, J. C. Evolution of Amphiphilic 
Elastin-like Co-Recombinamer Morphologies from Micelles to a Lyotropic Hydrogel. Polymer (Guildf). 20 I 5, 8I, 37-44. https://doi.org/I0.1016/j.polymer.2015.II.0I3.

(II3) Yu, S. M.; Conticello, V. P.; Zhang, G.; Kayser, C.; Fournier, M. J.; Mason, T. L.; Tirrell, D. A. Smectic Ordering in Solutions and Films of a Rod-like Polymer Owing to Monodispersity of Chain Length. Nature, Publ. online I I Sept. 1997; | doil 0.1038/I0.1038/38254 I997, 389 (6647), 167. https://doi.org// 0.1038/38254.

(II4) Krejchi, M. T.; Atkins, E. D.; Waddon, A. J.; Fournier, M. J.; Mason, T. L.; Tirrell, D. A. Chemical Sequence Control of Beta-Sheet Assembly in Macromolecular Crystals of Periodic Polypeptides. Science 1994, 265 (5I77), 1427-I432.

(I I5) Urry, D. W. Molecular Machines: How Motion and Other Functions of Living Organisms Can Result from Reversible Chemical Changes. Angew. Chemie Int. Ed. English I993, 32 (6), 819-84I. https://doi.org/10.1002/anie.199308191.

(I I6) Manno, M.; Emanuele, A.; Martorana, V.; San Biagio, P. L.; Bulone, D.; Palma-Vittorelli, M. B.; McPherson, D. T.; Xu, J.; Parker, T. M.; Urry, D. W. Interaction of Processes on Different Length Scales in a Bioelastomer Capable of Performing Energy Conversion. Biopolymers 200 I, 59 (I), 5I-64. https://doi.org/ 10.1002/I097-0282(200 I07)59: I <5 I::AIDBIPI005>3.0.CO;2-8.

(I I7) Venkatachalam, C. M.; Urry, D. W. Development of a Linear Helical Conformation from Its Cyclic Correlate. $\beta$-Spiral Model of the Elastin Poly(Pentapeptide) (VPGVG)N. Macromolecules I98 I, I 4 (5), I225-1229. https://doi.org/I0.102I/ma50006a0 I7.

(I I8) Urry, D.; Trapane, T. L.; Prasad, K. U. Phase-Structure Transitions of the Elastin Polypentapeptide-Water System within the Framework of Composition-Temperature Studies. Biopolymers I 985, 24 (I2), 2345-2356.

(II9) Reguera, J.; Urry, D. W.; Parker, T. M.; McPherson, D. T.; Rodríguez-Cabello, J. C. Effect of $\mathrm{NaCl}$ on the Exothermic and Endothermic Components of the Inverse Temperature Transition of a Model Elastin-like Polymer. Biomacromolecules 2007, 8 (2), 354-358. https://doi.org/10.1021/BM060936L.

(I20) Ribeiro, A.; Arias, F. J.; Reguera, J.; Alonso, M.; Rodríguez-Cabello, J. C. Influence of the Amino-Acid Sequence on the Inverse Temperature Transition of Elastin-like Polymers. Biophys. J. 2009, 97 (I), 312-320. https://doi.org/I0.1016/j.bpj.2009.03.030.

(I2I) Meyer, D. E.; Chilkoti, A. Quantification of the Effects of Chain Length and Concentration on the Thermal Behavior of Elastin-like Polypeptides. Biomacromolecules 2004, 5, 846-85I.

(122) Alessandra Girotti, †; Javier Reguera, †; Francisco Javier Arias, ‡; Matilde Alonso, §; Ana María Testera, $\perp$ and; José Carlos Rodríguez-Cabello*, $\dagger$. Influence of the Molecular Weight on the Inverse Temperature Transition of a Model Genetically Engineered Elastin-like PHResponsive Polymer. 2004.

(I23) Cho, Y.; Zhang, Y.; Christensen, T.; Sagle, L. B.; Chilkoti, A.; Cremer, P. S. Effects of Hofmeister Anions on the Phase Transition Temperature of Elastin-like Polypeptides. J. Phys. Chem. B 2008, I I 2 (44), I3765-1377I. https://doi.org/I0.1021/jp8062977.

(I24) Pinedo-martín, G.; Santos, M.; Testera, A. M.; Alonso, M.; Rodríguez-cabello, J. C. The Effect of $\mathrm{NaCl}$ on the Self-Assembly of Elastin-like Block Co-Recombinamers : Tuning the Size of Micelles and Vesicles. Polymer (Guildf). 2014, 55 (2I), 5314-532I. https://doi.org/10.1016/j.polymer.2014.08.053.

(I25) Luan, C.-H.; Parker, T. M.; Prasad, K. U.; Urry, D. W. Differential Scanning Calorimetry Studies of $\mathrm{NaCl}$ Effect on the Inverse Temperature Transition of Some Elastin-Based Polytetra-, Polypenta-, and Polynonapeptides. Biopolymers I99 I, 3I (5), 465-475. https://doi.org/10.1002/bip.360310502.

(I26) Ribeiro, A.; Arias, F. J.; Reguera, J.; Alonso, M.; Rodríguez-Cabello, J. C. Influence of the Amino-Acid Sequence on the Inverse Temperature Transition of Elastin-Like Polymers. Biophys. J. 2009, 97 (I), 312-320. https://doi.org//0.1016/J.BPJ.2009.03.030.

(I27) Urry, D. W. Molecular Machines: How Motion and Other Functions of Living Organisms Can Result from Reversible Chemical Changes. Angew. Chemie Int. Ed. English I993, 32 (6), 819-84I. https://doi.org/I0.1002/anie.199308I9I.

(I28) Meyer, D. E.; Chilkoti, A. Quantification of the Effects of Chain Length and Concentration on the Thermal Behavior of Elastin-like Polypeptides. Biomacromolecules 2004, 5 (3), 84685I. https://doi.org/I0.102I/BM0342I5N.

(129) Hofmeister, F. Zur Lehre von Der Wirkung Der Salze. Arch. für Exp. Pathol. und 
Pharmakologie 1888, 24 (4-5), 247-260. https://doi.org//0.1007/BF0|9|8I9I.

(I30) Lippow, S. M.; Aha, P. M.; Parker, M. H.; Blake, W. J.; Baynes, B. M.; Lipovsek, D. Creation of a Type IIS Restriction Endonuclease with a Long Recognition Sequence. Nucleic Acids Res. 2009, 37 (9), 306 I-3073. https://doi.org// 0.1093/nar/gkpl 82.

(I3I) Altunbas, A.; Pochan, D. J. Peptide-Based and Polypeptide-Based Hydrogels for Drug Delivery and Tissue Engineering. Top. Curr. Chem. 2012, 3/0, 135-167. https://doi.org//0.1007//28_20II_206.

(132) Hyde, S. Chapter 3: Molecular Forces and Self-Assembly. In The Language of shape: the role of curvature in condensed matter-physics, chemistry and biology; Amsterdam [Netherlands] New York Elsevier, 1997; pp 87-I40.

(133) Liu, X.; Ma, P. X. Polymeric Scaffolds for Bone Tissue Engineering. Ann. Biomed. Eng. 2004, 32 (3), 477-486.

(134) Rodríguez-Cabello, J. C.; Martín, L.; Alonso, M.; Arias, F. J.; Testera, A. M.; Rodr??guezCabello, J. C.; Mart??n, L.; Alonso, M.; Arias, F. J.; Testera, A. M. "Recombinamers" as Advanced Materials for the Post-Oil Age. Polymer (Guildf). 2009, 50 (22), 5I59-5I69. https://doi.org// 0.1016/j.polymer.2009.08.032.

(135) Cappello, J.; Crissman, J.; Dorman, M.; Mikolajczak, M.; Textor, G.; Marquet, M.; Ferrari, F. Genetic Engineering of Structural Protein Polymers. Biotechnol. Prog. 1990, 6 (3), 198-202. https://doi.org//0.102I/bp00003a006.

(136) Girotti, A.; Reguera, J.; Rodríguez-Cabello, J. C.; Arias, F. J.; Alonso, M.; Matestera, A. Design and Bioproduction of a Recombinant Multi(Bio)Functional Elastin-like Protein Polymer Containing Cell Adhesion Sequences for Tissue Engineering Purposes. J. Mater. Sci. Mater. Med. 2004, 15 (4), 479-484.

(137) Mi, L. Molecular Cloning of Protein-Based Polymers. Biomacromolecules 2006, 7 (7), 20992107. https://doi.org//0.1021/BM050158H.

(138) Sharp, P. M.; Cowe, E.; Higgins, D. G.; Shields, D. C.; Wolfe, K. H.; Wright, F. Codon Usage Patterns in Escherichia Coli, Bacillus Subtilis, Saccharomyces Cerevisiae, Schizosaccharomyces Pombe, Drosophila Melanogaster and Homo Sapiens; a Review of the Considerable within-Species Diversity. Nucleic Acids Res. 1988, 16 (17), 8207-82II. https://doi.org// 0.1093/nar/16.17.8207.

(139) Hershberg, R.; Petrov, D. A. Selection on Codon Bias. Annu. Rev. Genet. 2008, 42 (I), 287299. https://doi.org//0.I I46/annurev.genet.42.I 10807.09/442.

(140) McPherson, D. T.; Morrow, C.; Minehan, D. S.; Wu, J.; Hunter, E.; Urry, D. W. Production and Purification of a Recombinant Elastomeric Polypeptide, G-(VPGVG) I9-VPGV, from Escherichia Coli. Biotechnol. Prog. 1992, $8 \quad$ (4), 347-352. https://doi.org//0.102I/bp00016a0I2.

(14I) Lewis, R. V.; Hinman, M.; Kothakota, S.; Fournier, M. J. Expression and Purification of a Spider Silk Protein: A New Strategy for Producing Repetitive Proteins. Protein Expr. Purif. 1996, 7 (4), 400-406. https://doi.org//0.1006/prep.1996.0060.

(142) Rabotyagova, O. S.; Cebe, P.; Kaplan, D. L. Protein-Based Block Copolymers. Biomacromolecules 201 I, 12 (2), 269-289. https://doi.org// 0.102 I/bm 100928x.

(143) Roberts, R. J.; Vincze, T.; Posfai, J.; Macelis, D. REBASE--Restriction Enzymes and DNA Methyltransferases. Nucleic Acids Res. 2004, 33 (Database issue), D230-D232. https://doi.org//0.1093/nar/gki029.

(144) Rodríguez-Cabello, J. C.; Girotti, A.; Ribeiro, A.; Arias, F. J. Synthesis of Genetically Engineered Protein Polymers (Recombinamers) as an Example of Advanced Self-Assembled Smart Materials. In Methods in molecular biology (Clifton, N.J.); 20I2; Vol. 8II, Pp 17-38. https://doi.org/I0.1007/978-I-6/779-388-2_2.

(145) Goeden-Wood, N. L.; Conticello, V. P.; Muller, S. J.; Keasling, J. D. Improved Assembly of Multimeric Genes for the Biosynthetic Production of Protein Polymers. Biomacromolecules 2002, 3 (4), 874-879. https://doi.org/I 0.102I/BM0255342.

(146) Sallach, R. E.; Cui, W.; Balderrama, F.; Martinez, A. W.; Wen, J.; Haller, C. A.; Taylor, J. V.; Wright, E. R.; Long, R. C.; Chaikof, E. L. Long-Term Biostability of Self-Assembling Protein Polymers in the Absence of Covalent Crosslinking. Biomaterials 20I0, 3I (4), 779-79I. https://doi.org//0.1016/j.biomaterials.2009.09.082.

(147) Asenjo, J. A.; Andrews, B. A. Protein Purification Using Chromatography: Selection of Type, Modelling and Optimization of Operating Conditions. J. Mol. Recognit. 2009, 22 (2), 65-76. 
https://doi.org//0.1002/jmr.898.

(148) Meyer, D. E.; Chilkoti, A. Protein Purification by Inverse Transition Cycling. In Protein Interactions; Golemis, E., Adams, P. D., Eds.; Cold Spring Harbour, 2002; p 329.

(149) Meyer, D. E.; Chilkoti, A. Purification of Recombinant Proteins by Fusion with ThermallyResponsive Polypeptides. Nat. Biotechnol. 1999, 17 (II), III2-III5. https://doi.org//0.1038/I5100.

(150) Hassouneh, W.; Christensen, T.; Chilkoti, A. Elastin-Like Polypeptides as a Purification Tag for Recombinant Proteins. In Current Protocols in Protein Science; John Wiley \& Sons, Inc.: Hoboken, NJ, USA, 2010; Vol. Chapter 6, PP 6.II.I-6.11.16. https://doi.org/I0.1002/047 I |40864.ps06 I Is6I.

(15I) Kopecěk, J. Hydrogel Biomaterials: A Smart Future? Biomaterials 2007, 28, 5I85-5I92. https://doi.org// 0.1016/j.biomaterials.2007.07.044.

(152) Peppas, N. A. Edith Mathiowitz, Donald E. Chickering III, and Claus-Michael Lehr. J. Control. Release 2000, 68 (I), I35. https://doi.org/I0.1016/S0168-3659(00)00217-0.

(153) Hoffman, A. S. Hydrogels for Biomedical Applications. Adv. Drug Deliv. Rev. 2002, 54, 3-12.

(154) Kopeček, J.; Yang, J. Hydrogels as Smart Biomaterials. Polym. Int. 2007, 56 (9), 1078-1098. https://doi.org//0.1002/pi.2253.

(155) Nowak, A. P.; Breedveld, V.; Pakstis, L.; Ozbas, B.; Pine, D. J.; Pochan, D.; Deming, T. J. Rapidly Recovering Hydrogel Scaffolds from Self-Assembling Diblock Copolypeptide Amphiphiles. Nature 2002, 417 (6887), 424-428. https://doi.org/ I0.1038/417424a.

(156) Xu, C.; Breedveld, V.; Kopecek, J. Reversible Hydrogels from Self-Assembling Genetically Engineered Protein Block Copolymers. Biomacromolecules 2005, 6 (3), 1739-1749. https://doi.org/l0.102I/bm050017f.

(157) Urry, D. W. Physical Chemistry of Biological Free Energy Transduction As Demonstrated by Elastic Protein-Based Polymers. J. Phys. Chem. B 1997, 101 (5I), II007-II028. https://doi.org//0.1021/jp972/67t.

(158) Prince, J. T.; McGrath, K. P.; Carla DiGirolamo, J. M.; Kaplana, D. L. Construction, Cloning, and Expression of Synthetic Genes Encoding Spider Dragline Silk. Biochemistry 1995, 34, 10879-10885.

(159) Fernadez-Colino, A.; Arias, F. J.; Alonso, M.; Rodríguez-Cabello, J. C.; Bioforge, G. I. R. SelfOrganized ECM-Mimetic Model Based on an Amphiphilic Multiblock Silk-Elastin-Like Corecombinamer with a Concomitant Dual Physical Gelation Process. 2Biomacromolecules 2014, 15, 378I-3793. https://doi.org/l0.102I/bm50105It.

(160) Campoccia, D.; Doherty, P.; Radice, M.; Brun, P.; Abatangelo, G.; Williams, D. F. Semisynthetic Resorbable Materials from Hyaluronan Esterification. Biomaterials 1998, 19 (23), 210I-2/27. https://doi.org/I0.1016/S0I42-96/2(98)00042-8.

(16I) Prestwich, G. D.; Marecak, D. M.; Marecek, J. F.; Vercruysse, K. P.; Ziebell, M. R. Controlled Chemical Modification of Hyaluronic Acid: Synthesis, Applications, and Biodegradation of Hydrazide Derivatives. J. Control. Release 1998, 53, 93-103.

(162) Miyata, T.; Asami, N.; Uragami, T. A Reversibly Antigen-Responsive Hydrogel. Nature 1999, 399 (6738), 766-769. https://doi.org/10.1038/21619.

(163) Wang, C.; Kopecek, J.; Stewart, R. J. Hybrid Hydrogels Cross-Linked by Genetically Engineered Coiled-Coil Block Proteins. Biomacromolecules 200I, 2 (3), 9|2-920.

(164) Ulbrich, K.; Strohalm, J.; Kopecek, J. Polymers Containing Enzymatically Degradable Bonds. VI.Hydrophilic Gels Cleavable by Chymotrypsin. Biomaterials 1982, 3 (3), I50-154. https://doi.org/I0.1016/0142-9612(82)90004-7.

(165) McMillan, R. A.; Caran, K. L.; Apkarian, R. P.; Conticello, V. P. High-Resolution Topographic Imaging of Environmentally Responsive, Elastin-Mimetic Hydrogels. Macromolecules 1999, 32 (26), 9067-9070. https://doi.org/10.1021/ma991119z.

(166) Holmes, T. C.; de Lacalle, S.; Su, X.; Liu $h^{n}$, G.; Rich $\breve{h}$, A.; Zhang, S. Extensive Neurite Outgrowth and Active Synapse Formation on Self-Assembling Peptide Scaffolds.

(167) Zhang, S. Fabrication of Novel Biomaterials through Molecular Self-Assembly. Nat. Biotechnol. 2003, 2 I (10), II7I-I I78. https://doi.org/I0.1038/nbt874.

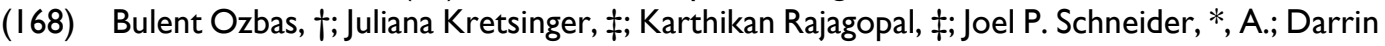
J. Pochan*, $\dagger$. Salt-Triggered Peptide Folding and Consequent Self-Assembly into Hydrogels with Tunable Modulus. 2004.

(169) Yeo, G. C.; Keeley, F. W.; Weiss, A. S. Coacervation of Tropoelastin. Adv. Colloid Interface 
Sci. 201 I, 167, 94-103. https://doi.org/I0.1016/j.cis.2010.10.003.

(170) Costa, R. R.; Custódio, C. A.; Arias, F. J.; Rodríguez-Cabello, J. C.; Mano, J. F. Layer-byLayer Assembly of Chitosan and Recombinant Biopolymers into Biomimetic Coatings with Multiple Stimuli-Responsive Properties. Small 20II, 7 (I8), 2640-2649. https://doi.org/I0.1002/smll.20I I00875.

(I7I) Sallach, R. E.; Cui, W.; Balderrama, F.; Martinez, A. W.; Wen, J.; Haller, C. A.; Taylor, J. V.; Wright, E. R.; Long, R. C.; Chaikof, E. L. Long-Term Biostability of Self-Assembling Protein Polymers in the Absence of Covalent Crosslinking. Biomaterials 2010, 3I (4), 779-79I. https://doi.org/10.1016/j.biomaterials.2009.09.082.

(I72) Rodríguez-Cabello, J. C.; Martín, L.; Girotti, A.; García-Arévalo, C.; Arias, F. J.; Alonso, M. Emerging Applications of Multifunctional Elastin-like Recombinamers. Nanomedicine 20 I I, 6 (I), III-I22. https://doi.org/10.22I7/nnm.10.14I.

(I73) Li, M.; Ober, C. K. Block Copolymer Patterns and Templates. Mater. Today 2006, 9 (9), 30-39. https://doi.org/I0.10I6/SI369-702I(06)7I620-0.

(174) Tetsuo Asakura, *, §; Juming Yao, §; Tsutomu Yamane, §; Kosuke Umemura, § and; Ulrich $\dagger$, A. S. Heterogeneous Structure of Silk Fibers from Bombyx Mori Resolved by I3C SolidState NMR Spectroscopy. 2002.

(175) Takahashi, Y.; Gehoh, M.; Yuzuriha, K. Structure Refinement and Diffuse Streak Scattering of Silk (Bombyx Mori). Int. J. Biol. Macromol. 1999, 24 (2), I27-I38. https://doi.org//0.1016/S0I4I-8I30(98)00080-4.

(I76) Takahashi, Y.; Gehoh, M.; Yuzuriha, K. Crystal Structure of Silk (Bombyx Mori). J. Polym. Sci. Part B Polym. Phys. I 99 I, 29 (7), 889-89I. https://doi.org/I0.1002/polb. I99I.0902907|4.

(177) Shimura, K.; Kikuchi, A.; Ohtomo, K.; Katagata, Y.; Hyodo, A. Studies on Silk Fibroin of Bombyx Mori. I. Fractionation of Fibroin Prepared from the Posterior Silk Gland. J. Biochem. 1976, 80 (4), 693-702.

(178) Omenetto, F. G.; Kaplan, D. L. New Opportunities for an Ancient Material. Science 2010, 329 (599 I), 528-53 I. https://doi.org/I0.I I 26/science. I I 88936.

(179) Kundu, B.; Rajkhowa, R.; Kundu, S. C.; Wang, X. Silk Fibroin Biomaterials for Tissue Regenerations. Adv. Drug Deliv. Rev. 2013, 65 (4), 457-470. https://doi.org/10.1016/j.addr.2012.09.043.

(180) Zhou, J.; Cao, C.; Ma, X.; Hu, L.; Chen, L.; Wang, C. In Vitro and in Vivo Degradation Behavior of Aqueous-Derived Electrospun Silk Fibroin Scaffolds. Polym. Degrad. Stab. 2010 , 95 (9), 1679-1685. https://doi.org//0.1016/j.polymdegradstab.2010.05.025.

(18I) Panilaitis, B.; Altman, G. H.; Chen, J.; Jin, H.-J.; Karageorgiou, V.; Kaplan, D. L. Macrophage Responses to Silk. Biomaterials 2003, 24 (I8), 3079-3085. https://doi.org/I0.1016/S0I429612(03)00158-3.

(182) Fan, H.; Liu, H.; Toh, S. L.; Goh, J. C. H. Anterior Cruciate Ligament Regeneration Using Mesenchymal Stem Cells and Silk Scaffold in Large Animal Model. Biomaterials 2009, 30 (28), 4967-4977. https://doi.org/10.1016/j.biomaterials.2009.05.048.

(I83) Tanaka, K.; Inoue, S.; Mizuno, S. Hydrophobic Interaction of P25, Containing Asn-Linked Oligosaccharide Chains, with the H-L Complex of Silk Fibroin Produced by Bombyx Mori. Insect Biochem. Mol. Biol. 1999, 29 (3), 269-276. https://doi.org/10.1016/S0965I748(98)00।35-0.

(184) Hardy, J. G.; Römer, L. M.; Scheibel, T. R. Polymeric Materials Based on Silk Proteins. Polymer (Guildf). 2008, 49, 4309-4327. https://doi.org/I 0.10 I6/j.polymer.2008.08.006.

(185) Vinson, C.; Myakishev, M.; Acharya, A.; Mir, A. A.; Moll, J. R.; Bonovich, M. Classification of Human B-ZIP Proteins Based on Dimerization Properties. Mol. Cell. Biol. 2002, 22 (I8), 632I-6335.

(186) Vinson, C. R.; Sigler, P. B.; McKnight, S. L. Scissors-Grip Model for DNA Recognition by a Family of Leucine Zipper Proteins. Science 1989, 246 (4932), 911-916. https://doi.org//0.1 I 26/science.2683088.

(187) Abel, T.; Maniatis, T. Action of Leucine Zippers. Nature 1989, 34 I (6237), 24-25. https://doi.org/10.1038/341024a0.

(188) Woolfson, D. N. The Design of Coiled-Coil Structures and Assemblies. Adv. Protein Chem. 2005, 70, 79-II2. https://doi.org/10.1016/S0065-3233(05)70004-8.

(189) Yang, J.; Xu, C.; Kopečková, P.; Kopeček, J. Hybrid Hydrogels Self-Assembled from HPMA Copolymers Containing Peptide Grafts. Macromol. Biosci. 2006, 6 (3), 20I-209. 
https://doi.org// 0.1002/mabi.200500208.

(190) Harbury, P. B.; Zhang, T.; Kim, P. S.; Alber, T. A Switch between Two-, Three-, and FourStranded Coiled Coils in GCN4 Leucine Zipper Mutants. Science 1993, 262 (5I38), I40I| 407. https://doi.org//0.1 I26/science.8248779.

(19I) Moitra, J.; Szilak, L.; Krylov, D.; Vinson, C. Leucine Is the Most Stabilizing Aliphatic Amino Acid in the d Position of a Dimeric Leucine Zipper Coiled Coil. Biochemistry 1997, 36 (4I), |2567-|2573. https://doi.org//0.102 I/bi97|424h.

(192) Tripet, B.; Wagschal, K.; Lavigne, P.; Mant, C. T.; Hodges, R. S. Effects of Side-Chain Characteristics on Stability and Oligomerization State of a de Novo-Designed Model Coiled-Coil: 20 Amino Acid Substitutions in Position “D.” J. Mol. Biol. 2000, 300 (2), 377402. https://doi.org// 0.1006/jmbi.2000.3866.

(193) Krylov, D.; Mikhailenko, I.; Vinson, C. A Thermodynamic Scale for Leucine Zipper Stability and Dimerization Specificity: $E$ and $g$ Interhelical Interactions. EMBO J. 1994, 13 (I2), 2849$286 \mathrm{I}$.

(194) Alber, T. Structure of the Leucine Zipper. Curr. Opin. Genet. Dev. 1992, 2 (2), 205-2 10.

(195) Krylov, D.; Barchi, J.; Vinson, C. Inter-Helical Interactions in the Leucine Zipper Coiled Coil Dimer: Ph and Salt Dependence of Coupling Energy between Charged Amino Acids. J. Mol. Biol. 1998, 279 (4), 959-972. https://doi.org//0.1006/jmbi.1998. 1762.

(196) Litowski, J. R.; Hodges, R. S. Designing Heterodimeric Two-stranded A-helical Coiled-coils: The Effect of Chain Length on Protein Folding, Stability and Specificity. J. Pept. Res. 200I, 58 (6), 477-492. https://doi.org/I0.1034/J.1399-30II.200I.10972.X.

(197) De Crescenzo, G.; Litowski, J. R.; Hodges, R. S.; O'Connor-McCourt, M. D. Real-Time Monitoring of the Interactions of Two-Stranded de Novo Designed Coiled-Coils: Effect of Chain Length on the Kinetic and Thermodynamic Constants of Bindingt. Biochemistry 2003, $42,1754$.

(198) Huang, C.-C.; Ravindran, S.; Yin, Z.; George, A. 3-D Self-Assembling Leucine Zipper Hydrogel with Tunable Properties for Tissue Engineering. Biomaterials 20 I4, 35 (20), 5316 5326. https://doi.org//0.1016/j.biomaterials.2014.03.035.

(199) Rodríguez-Cabello, J. C.; Reguera, J.; Girotti, A.; Alonso, M.; Testera, A. M. Developing Functionality in Elastin-like Polymers by Increasing Their Molecular Complexity: The Power of the Genetic Engineering Approach. Prog. Polym. Sci. 2005, 30 (II), III9-II45. https://doi.org// 0.1016/j.progpolymsci.2005.07.004.

(200) Rodríguez-Cabello, J. C.; Alonso, A.; Guiscardo, L.; Reboto, V.; Girotti, A. AmplifiedPhotoresponse Ofap-PhenylazobenzeneDerivative OfanElastin-LikePolymerbyaCyclodextrin: TheAmplifiedDTtMechanism. Adv. Mater. 2002, I4 (16), ||5|-II54. https://doi.org// 0.1002/I52I-4095(200208/6) I4:163.0.CO;2-Y.

(201) Trabbic-Carlson, K.; Setton, L. A.; Chilkoti, A. Swelling and Mechanical Behaviors of Chemically Cross-Linked Hydrogels of Elastin-like Polypeptides. Biomacromolecules 2003, 4 (3), 572-580.

(202) Hennink, W. .; van Nostrum, C. . Novel Crosslinking Methods to Design Hydrogels. Adv. Drug Deliv. Rev. 2002, 54 (I), 13-36. https://doi.org/I0.1016/S0169-409X(01)00240-X.

(203) Hoare, T. R.; Kohane, D. S. Hydrogels in Drug Delivery: Progress and Challenges. Polymer (Guildf). 2008, 49 (8), 1993-2007. https://doi.org/I0.1016/j.polymer.2008.01.027.

(204) De Nooy, A. E. J.; Masci, G.; Crescenzi, V. Versatile Synthesis of Polysaccharide Hydrogels Using the Passerini and Ugi Multicomponent Condensations. 1998. https://doi.org//0.1021/ma98I5455.

(205) Huglin, M. R. Hydrogels in Medicine and Pharmacy. Br. Polym. J. 1989, 2 I (2), 184-184. https://doi.org//0.1002/pi.4980210223.

(206) Garcia, Y.; Hemantkumar, N.; Collighan, R.; Griffin, M.; Rodriguez-Cabello, J. C.; Pandit, A. In Vitro Characterization of a Collagen Scaffold Enzymatically Cross-Linked with a Tailored Elastin-like Polymer. Tissue Eng. Part A 2009, 15 (4), 887-899. https://doi.org//0.1089/ten.tea.2008.0104.

(207) Westhaus, E.; Messersmith, P. B. Triggered Release of Calcium from Lipid Vesicles: A Bioinspired Strategy for Rapid Gelation of Polysaccharide and Protein Hydrogels. Biomaterials 200I, 22, 453-462.

(208) Garcia, Y.; Collighan, R.; Griffin, M.; Pandit, A. Assessment of Cell Viability in a ThreeDimensional Enzymatically Cross-Linked Collagen Scaffold. J. Mater. Sci. Mater. Med. 2007, 
I8 (I0), | 199|-200I. https://doi.org//0.1007/s 10856-007-309|-9.

(209) Ravi, S.; Caves, J. M.; Martinez, A. W.; Haller, C. A.; Chaikof, E. L. Incorporation of Fibronectin to Enhance Cytocompatibility in Multilayer Elastin-like Protein Scaffolds for Tissue Engineering. J. Biomed. Mater. Res. Part A 2013, I0IA (7), 1915-1925. https://doi.org// 0.1002/jbm.a.34484.

(2I0) Testera, A. M.; Girotti, A.; de Torre, I. G.; Quintanilla, L.; Santos, M.; Alonso, M.; RodríguezCabello, J. C. Biocompatible Elastin-like Click Gels: Design, Synthesis and Characterization. J. Mater. Sci. Mater. Med. 20 I 5, 26 (2), I05. https://doi.org// 0.1007/s I0856-0I5-5435-I.

(2II) Patterson, J.; Martino, M. M.; Hubbell, J. A. Biomimetic Materials in Tissue Engineering. Mater. Today 20 I0, 13 (I), I4-22. https://doi.org/I0.1016/SI369-702I(I0)700I3-4.

(2I2) González de Torre, I.; Santos, M.; Quintanilla, L.; Testera, A.; Alonso, M.; Rodríguez Cabello, J. C. Elastin-like Recombinamer Catalyst-Free Click Gels: Characterization of Poroelastic and Intrinsic Viscoelastic Properties. Acta Biomater. 2014, 10 (6), 2495-2505. https://doi.org//0.1016/j.actbio.2014.02.006.

(213) de Torre, I. G.; Wolf, F.; Santos, M.; Rongen, L.; Alonso, M.; Jockenhoevel, S.; RodríguezCabello, J. C.; Mela, P. Elastin-like Recombinamer-Covered Stents: Towards a Fully Biocompatible and Non-Thrombogenic Device for Cardiovascular Diseases. Acta Biomater. 2015, I2, I46-155. https://doi.org//0.1016/j.actbio.2014.10.029.

(214) Janib, S. M.; Pastuszka, M.; Aluri, S.; Folchman-Wagner, Z.; Hsueh, P.-Y.; Shi, P.; Yi-An; Cui, H.; Mackay, J. A. A Quantitative Recipe for Engineering Protein Polymer Nanoparticles. Polym. Chem. 2014, 5 (5), 16/4-1625. https://doi.org/10.1039/C3PY00537B.

(215) Costa, R. R.; Cust??dio, C. A.; Testera, A. M.; Arias, F. J.; Rodr??guez-Cabello, J. C.; Alves, N. M.; Mano, J. F. Stimuli-Responsive Thin Coatings Using Elastin-like Polymers for Biomedical Applications. Adv. Funct. Mater. 2009, 19 (20), 3210-3218. https://doi.org// 0.1002/adfm.200900568.

(216) Xia, X. X.; Wang, M.; Lin, Y.; Xu, Q.; Kaplan, D. L. Hydrophobic Drug-Triggered SelfAssembly of Nanoparticles from Silk-Elastin-like Protein Polymers for Drug Delivery. Biomacromolecules 20 I4, I5 (3), 908-9/4. https://doi.org/I0.102I/bm40I7594.

(217) Dreher, M. R.; Simnick, A. J.; Fischer, K.; Smith, R. J.; Patel, A.; Schmidt, M.; Chilkoti, A. Temperature Triggered Self-Assembly of Polypeptides into Multivalent Spherical Micelles. J. Am. Chem. Soc. 2008, 130 (2), 687-694. https://doi.org// 0. I021/ja0764862.

(218) Ghoorchian, A.; Vandemark, K.; Freeman, K.; Kambow, S.; Holland, N. B.; Streletzky, K. A. Size and Shape Characterization of Thermoreversible Micelles of Three-Armed Star Elastinlike Polypeptides. J. Phys. Chem. B 2013, 117 (29), 8865-8874. https://doi.org//0.102I/jp3/259lj.

(219) Sallach, R. E.; Wei, M.; Biswas, N.; Conticello, V. P.; Lecommandoux, S.; Dluhy, R. A.; Chaikof, E. L. Micelle Density Regulated by a Reversible Switch of Protein Secondary Structure. J. Am. Chem. Soc. 2006, 128 (36), 12014-12019. https://doi.org//0.102I/ja0638509.

(220) Ghoorchian, A.; Cole, J. T.; Holland, N. B. Thermoreversible Micelle Formation Using a Three-Armed Star Elastin-like Polypeptide. Macromolecules 2010, 43 (9), 4340-4345. https://doi.org//0.102I/mal00285v.

(22I) Patel, N. U.; Purser, C. A.; Baker, R. C.; Janorkar, A. V. Effect of Processing Temperature on the Morphology and Drug-Release Characteristics of Elastin-like Polypeptide-Collagen Composite Coatings. Biomacromolecules 2013, 14 (8), 289I-2899. https://doi.org// 0.1021/bm4007425.

(222) Pinedo-mart, G.; Castro, E.; Mart, L.; Alonso, M.; Rodr, J. C. Effect of Surfactants on the Self-Assembly of a Model Elastin-like Block Corecombinamer: From Micelles to an Aqueous Two-Phase System. 2014.

(223) McDaniel, J. R.; Weitzhandler, I.; Prevost, S.; Vargo, K. B.; Appavou, M. S.; Hammer, D. A.; Gradzielski, M.; Chilkoti, A. Noncanonical Self-Assembly of Highly Asymmetric Genetically Encoded Polypeptide Amphiphiles into Cylindrical Micelles. Nano Lett. 201 4, 14 (I I), 65906598. https://doi.org// 0.102I/nl50322 Ip.

(224) Salvagni, E.; Berguig, G.; Engel, E.; Rodriguez-cabello, J. C.; Coullerez, G.; Textor, M.; Planell, J. A.; Gil, F. J.; Aparicio, C. A Bioactive Elastin-like Recombinamer Reduces Unspecific Protein Adsorption and Enhances Cell Response on Titanium Surfaces. Colloids Surfaces $B$ Biointerfaces 20 I 4, I/ 4, 225-233. https://doi.org//0.1016/j.colsurfb.2013.10.008. 
(225) Ryu, J. S.; Raucher, D. Elastin-like Polypeptide for Improved Drug Delivery for Anticancer Therapy: Preclinical Studies and Future Applications. Expert Opin. Drug Deliv. 20 I 4, 12 (05), I-I5. https://doi.org/10.15I7//7425247.2015.974546.

(226) Andrew Mackay, J.; Chilkoti, A. Temperature Sensitive Peptides: Engineering Hyperthermia-Directed Therapeutics. Int. J. Hyperth. 2008, 24 (6), 483-495. https://doi.org/I0.1080/02656730802 I49570.

(227) Chilkoti, A.; Dreher, M. R.; Meyer, D. E.; Raucher, D. Targeted Drug Delivery by Thermally Responsive Polymers. Adv. Drug Deliv. Rev. 2002, 54 (5), 6I3-630.

(228) McLean, K. J.; Hans, M.; Munro, A. W. Cholesterol, an Essential Molecule: Diverse Roles Involving Cytochrome P450 Enzymes. Biochem. Soc. Trans. 2012, 40 (3), 587-593. https://doi.org/10.1042/BST20120077.

(229) Akiyoshi, K.; Deguchi, S.; Tajima, H.; Nishikawa, T.; Sunamoto, J. Microscopic Structure and Thermoresponsiveness of a Hydrogel Nanoparticle by Self-Assembly of a Hydrophobized Polysaccharide. Macromolecules 1997, 30, 857-86I. https://doi.org/I0.I02 I/MA960786E.

(230) AKIYOSHI, K.; Deguchi, S.; Tajima, H.; Nishikawa, T.; Sunamoto, J. Self-Assembly of Hydrophobized Polysaccharide of Hydrogel Nanoparticle and Complexation with Organic Compounds Division. Proc. Jpn. Acad. 1995, 7IB, I5-I8.

(23I) Wang, Y.-S.; Liu, L.-R.; Jiang, Q.; Zhang, Q.-Q. Self-Aggregated Nanoparticles of Cholesterol-Modified Chitosan Conjugate as a Novel Carrier of Epirubicin. Eur. Polym. J. 2007, 43 (I), 43-5I. https://doi.org/I0.10I6/J.EURPOLYMJ.2006.09.007.

(232) Park, K.; Kim, K.; Kwon, I. C.; Kim, S. K.; Lee, S.; Lee, D. Y.; Byun, Y. Preparation and Characterization of Self-Assembled Nanoparticles of Heparin-Deoxycholic Acid Conjugates. Langmuir 2004, 20, II 726-I I 73I. https://doi.org/I 0.102 I/LA048646I.

(233) Lee, K. Y.; Jo, W. H.; Kwon, I. C.; Kim, Y.-H.; Jeong, S. Y. Structural Determination and Interior Polarity of Self-Aggregates Prepared from Deoxycholic Acid-Modified Chitosan in Water. Macromolecules I 998, 3 I (2), 378-383. https://doi.org/I 0. I02 I/MA97I I 304.

(234) Morishima, Y.; Nomura, S.; Ikeda, T.; Seki, M.; Kamachi, M. Characterization of Unimolecular Micelles of Random Copolymers of Sodium 2-(Acrylamido)-2Methylpropanesulfonate and Methacrylamides Bearing Bulky Hydrophobic Substituents. Macromolecules I 995, 28 (8), 2874-288 I. https://doi.org/I0. I02 I/ma00 I I 2a037.

(235) Whitehouse, W. L.; Noble, J. E.; Ryadnov, M. G.; Howorka, S. Cholesterol Anchors Enable Efficient Binding and Intracellular Uptake of DNA Nanostructures. Bioconjug. Chem. 20I9, 30 (7), 1836-1844. https://doi.org/10.1021/acs.bioconjchem.9b00036.

(236) Mozhdehi, D.; Luginbuhl, K. M.; Dzuricky, M.; Costa, S. A.; Xiong, S.; Huang, F. C.; Lewis, M. M.; Zelenetz, S. R.; Colby, C. D.; Chilkoti, A. Genetically Encoded Cholesterol-Modified Polypeptides. J. Am. Chem. Soc. 2019, I4I (2), 945-95I. https://doi.org//0.1021/jacs.8b 10687.

(237) Fu, F. F.; Zhou, B. Q.; Ouyang, Z. J.; Wu, Y. L.; Zhu, J. Y.; Shen, M. W.; Xia, J. D.; Shi, X. Y. Multifunctional Cholesterol-Modified Dendrimers for Targeted Drug Delivery to Cancer Cells Expressing Folate Receptors. Chinese J. Polym. Sci. (English Ed. 2019, 37 (2), I29-I35. https://doi.org/10.1007/s10118-019-2172-9.

(238) Barrett, A. J. Proteolytic Enzymes. In Biochemical Education; 2000; PP I-20. https://doi.org/10.1016/0307-44I2(90)90038-P.

(239) Bergmann, M.; Ross, W. F. ON PROTEOLYTIC ENZYMES X. TEE ENZYMES OF PAPAIN AND THEIR ACTIVATION. J. Biol. Chem. 1936, I/4, 717.

(240) Hartley, B. S. Proteolytic Enzymes. Annu. Rev. Biochem. 1960, 29 (I), 45-72. https://doi.org/I0.I I46/annurev.bi.29.070I60.00040I.

(24I) Neurath, H. Proteolytic Enzymes Past and Present: The Second Golden Era. Protein Sci. 1994, 3, I734-I739.

(242) Neurath, H.; Walsh, K. A. Role of Proteolytic Enzymes in Biological Regulation (A Review) *. Proc. Natl. Acad. Sci. USA 1976, 73 (I I), 3825-3832.

(243) Diegelmann, R. F.; Evans, M. C. Wound Healing: An Overview of Acute, Fibrotic and Delayed Healing. Front. Biosci. 2004, 9, 283-289.

(244) Berg, J.; Tymoczko, J.; Stryer, L. Regulatory Strategies: Enzymes and Hemoglobin. In Biochemistry; WH Freeman: New York, 2002; pp 26I-267.

(245) Chen, W.-T. Membrane Proteases: Roles in Tissue Remodeling and Tumour Invasion. Curr. Opin. Cell Biol. I 992, 4 (5), 802-809. https://doi.org/10.1016/0955-0674(92)90I03-J. 
(246) Pollanen, J.; Saksela, O.; Salonen, E.-M.; Andreasen, P.; Nielsen, L.; Dan0, K.; Vaheri, A. Distinct Localizations of Urokinase-Type Plasminogen Activator and Its Type I Inhibitor under Cultured Human Fibroblasts and Sarcoma Cells. J. Cell Biol. 1987, 104, I085-1096.

(247) Rheinwald, J. G.; Jorgensen, J. L.; Hahn, W. C.; Terpstra, A. J.; O’Connell, T. M.; Plummer, K. K. Mesosecrin: A Secreted Glycoprotein Produced in Abundance by Human Mesothelial, Endothelial, and Kidney Epithelial Cells in Culture. J. Cell Biol. 1987, 104 (2).

(248) Roman, J.; LaChance, R. M.; Broekelmann, T. J.; Kennedy, C. J.; Wayner, E. A.; Carter, W. G.; McDonald, J. A. The Fibronectin Receptor Is Organized by Extracellular Matrix Fibronectin: Implications for Oncogenic Transformation and for Cell Recognition of Fibronectin Matrices. J. Cell Biol. I 989, 108 (6), 2529-2543.

(249) Knudsen, B. S.; Harpel, P. C.; Nachman, R. L. Plasminogen Activator Inhibitor Is Associated with the Extracellular Matrix of Cultured Bovine Smooth Muscle Cells. J. Clin. Invest. 1987, 80 (4), 1082-1089. https://doi.org/ I0. I I72/JCII I 3 I 64.

(250) Mimuro, J.; Schleef, R.; Loskutoff, D. Extracellular Matrix of Cultured Bovine Aortic Endothelial Cells Contains Functionally Active Type I Plasminogen Activator Inhibitor. Blood 1987, 70 (3).

(25I) Unkeless, J. C.; Gordon, S.; Reich, E. SECRETION OF PLASMINOGEN ACTIVATOR BY STIMULATED MACROPHAGES. J. Exp. Med. 1974, 139 (4).

(252) Quigley, J. P. Association of a Protease (Plasminogen Activator) with a Specific Membrane Fraction Isolated from Transformed Cells. J. Cell Biol. I 976, 7 I (2).

(253) Vassalli, J. D.; Baccino, D.; Belin, D. A Cellular Binding Site for the Mr 55,000 Form of the Human Plasminogen Activator, Urokinase. J. Cell Biol. 1985, 100 (I).

(254) Reich, E.; Rifkin, D. B.; Shaw, E. Proteases and Biological Control; Cold Spring Harbor Laboratory, 1975.

(255) Liotta, L. A.; Goldfarb, R. H.; Brundage, R.; Siegal, G. P.; Terranova, V.; Garbisa, S. Effect of Plasminogen Activator (Urokinase), Plasmin, and Thrombin on Glycoprotein and Collagenous Components of Basement Membrane. Cancer Res. I98 I, 4 I (I I Pt I), 46294636.

(256) Balian, G.; Click, E. M.; Bornstein, P. THE JOURNAL OF BIOLOGICAL CHEMISTRY Location of a Collagen-Binding Domain in Fibroneetin*. I 980, 255 (8), 323-3236.

(257) Danø, K.; Andreasen, P. A.; Grøndahl-Hansen, J.; Kristensen, P.; Nielsen, L. S.; Skriver, L. Plasminogen Activators, Tissue Degradation, and Cancer. Adv. Cancer Res. I 985, 44, I39266.

(258) Werb, Z.; Mainardi, C. L.; Vater, C. A.; Harris, E. D. Endogenous Activation of Latent Collagenase by Rheumatoid Synovial Cells. N. Engl. J. Med. I977, 296 (I8), I0I7-1023. https://doi.org/I0.1056/NEJMI9770505296I80I.

(259) Stricklin, G. P.; Welgus, H. G.; Bauer, E. A. Human Skin Collagenase in Recessive Dystrophic Epidermolysis Bullosa. Purification of a Mutant Enzyme from Fibroblast Cultures. J. Clin. Invest. I 982, 69 (6), I373-I383. https://doi.org/ I0. I I 72/jci I I0577.

(260) O'Grady, R. L.; Upfold, L. I.; Stephens, R. W. Rat Mammary Carcinoma Cells Secrete Active Collagenase and Activate Latent Enzyme in the Stroma via Plasminogen Activator. Int. J. Cancer I 98I, 28 (4), 509-5I5. https://doi.org/I0.1002/ijc.29I02804I8.

(26I) Nagase, H. Activation Mechanisms of Matrix Metalloproteinases. Biol. Chem. 378 (3-4), I5I-I60.

(262) Massova, I.; Kotra, L. P.; Fridman, R.; Mobashery, S. Matrix Metalloproteinases: Structures, Evolution, and Diversification. FASEB J. 1998, I 2 (I2), 1075-I095.

(263) Wilkesman, J.; Kurz, L. Protease Analysis by Zymography: A Review on Techniques and Patents. Recent Pat. Biotechnol. 2009, 3 (3), 175-I84. https://doi.org/l 0.2174//87220809789389/62.

(264) Hasty, K. A.; Hibbs, M. S.; Kang, A. H.; Mainardi, C. L. Secreted Forms of Human Neutrophil Collagenase. J. Biol. Chem. Secreted Forms Hum. I 986, 26 I (I2), 5645-5650.

(265) Hibbs, M. S.; Hasty, K. A.; Seyer, J. M.; Kang, A. H.; Mainardi, C. L. Biochemical and Immunological Characterization of the Secreted Forms of Human Neutrophil Gelatinase. J. Biol. Chem. I 985, 260 (4), 2493-2500.

(266) Miller, E. J.; Harris, E. D.; Chung, E.; Finch, J. E.; McCroskery, P. A.; Butler, W. T. Cleavage of Type II and III Collagens with Mammalian Collagenase: Site of Cleavage and Primary Structure at the NH2-Terminal Portion of the Smaller Fragment Released from Both 
Collagens. Biochemistry 1976, 15 (4), 787-792.

(267) MATRISIAN, L.; HOGAN, B. 8 Growth Factor-Regulated Proteases and Extracellular Matrix Remodeling during Mammalian Development. Curr. Top. Dev. Biol. 1990, 24, 219 259. https://doi.org/10.1016/S0070-2153(08)60089-7.

(268) Chin, J. R.; Murphy, G.; Werb, Z. Stromelysin, a Connective Tissue-Degrading Metalloendopeptidase Secreted by Stimulated Rabbit Synovial Fibroblasts in Parallel with Collagenase. Biosynthesis, Isolation, Characterization, and Substrates. J. Biol. Chem. I985, 260, 12367-12376.

(269) Bildyug, N.; Hou, G.; Sabatini, P.; Bendeck, M.; Tamaki, Y.; Ogino, T.; Santavirta, S.; Salo, J.; Pliego, M. Del; Sabanero, M.; et al. Matrix Metalloproteinases: An Emerging Role in Regulation of Actin Microfilament System. In Biomolecular Concepts; De Gruyter, 2016; Vol. 7, pp 332-34I. https://doi.org/I0.15I5/bmc-2016-0022.

(270) Atkinson, J. J.; Senior, R. M. Matrix Metalloproteinase-9 in Lung Remodeling. Am. J. Respir. Cell Mol. Biol. 2003, 28 (I), I2-24. https://doi.org/l 0.I I65/rcmb.2002-0 I66TR.

(27I) Butler, G. S.; Will, H.; Atkinson, S. J.; Murphy, G. Membrane-Type-2 Matrix Metalloproteinase Can Initiate the Processing of Progelatinase A and Is Regulated by the Tissue Inhibitors of Metalloproteinases. Eur. J. Biochem. I997, 244 (2), 653-657. https://doi.org/I0.1 I I I/j.I432-1033.1997.t0I-I-00653.x.

(272) Takino, T.; Sato, H.; Shinagawa, A.; Seiki, M. Identification of the Second Membrane-Type Matrix Metalloproteinase (MT-MMP-2) Gene from a Human Placenta CDNA Library. MTMMPs Form a Unique Membrane-Type Subclass in the MMP Family. J. Biol. Chem. 1995, 270 (39), 230 I3-23020. https://doi.org/I0.I074/JBC.270.39.230।3.

(273) Pei, D. Identification and Characterization of the Fifth Membrane-Type Matrix Metalloproteinase MT5-MMP. J. Biol. Chem. I999, 274 (I3), 8925-8932. https://doi.org/I0.1074/JBC.274.13.8925.

(274) Ohuchi, E.; Imai, K.; Fujii, Y.; Sato, H.; Seiki, M.; Okada, Y. Membrane Type I Matrix Metalloproteinase Digests Interstitial Collagens and Other Extracellular Matrix Macromolecules. J. Biol. Chem. I997, 272 (4), 2446-245I. https://doi.org// 0.1074/JBC.272.4.2446.

(275) D’ortho, M.-P.; Will, H.; Atkinson, S.; Butler, G.; Messent, A.; Gavrilovic, J.; Smith, B.; Timpl, R.; Zardi, L.; Murphy, G. Membrane-Type Matrix Metalloproteinases I and 2 Exhibit BroadSpectrum Proteolytic Capacities Comparable to Many Matrix Metalloproteinases. Eur. J. Biochem. I 997, 250 (3), 75 I-757. https://doi.org/I0.I I I I/j. I432-I033.1997.0075 I.x.

(276) Shimada, T.; Nakamura, H.; Ohuchi, E.; Fujii, Y.; Murakami, Y.; Sato, H.; Seiki, M.; Okada, Y. Characterization of a Truncated Recombinant Form of Human Membrane Type 3 Matrix Metalloproteinase. Eur. J. Biochem. 1999, 262 (3), 907-9|4. https://doi.org//0.1046/j. I4321327.1999.00459.x.

(277) Itoh, Y.; Kajita, M.; Kinoh, H.; Mori, H.; Okada, A.; Seiki, M. Membrane Type 4 Matrix Metalloproteinase (MT4-MMP, MMP-17) is a Glycosylphosphatidylinositol-Anchored Proteinase. J. Biol. Chem. 1999, $274 \quad$ (48), 34260-34266. https://doi.org// 0.1074/JBC.274.48.34260.

(278) Wang, Y.; Johnson, A. R.; Ye, Q. Z.; Dyer, R. D. Catalytic Activities and Substrate Specificity of the Human Membrane Type 4 Matrix Metalloproteinase Catalytic Domain. J. Biol. Chem. 1 999, 274 (46), 33043-33049. https://doi.org/10.1074/JBC.274.46.33043.

(279) Pei, D.; Kang, T.; Qi, H. Cysteine Array Matrix Metalloproteinase (CA-MMP)/MMP-23 Is a Type II Transmembrane Matrix Metalloproteinase Regulated by a Single Cleavage for Both Secretion and Activation. J. Biol. Chem. 2000, 275 (43), 33988-33997. https://doi.org/I0.1074/jbc.M006493200.

(280) Velasco, G.; Pendás, A. M.; Fueyo, A.; Knäuper, V.; Murphy, G.; López-Otín, C. Cloning and Characterization of Human MMP-23, a New Matrix Metalloproteinase Predominantly Expressed in Reproductive Tissues and Lacking Conserved Domains in Other Family Members. J. Biol. Chem. I 999, 274 (8), 4570-4576.

(28I) Firestein, G. S.; Budd, R. C.; Gabriel, S. E.; Mclnnes, I. B.; O’Dell, J. R.; Kelley, W. N. Kelley \& Firestein's Textbook of Rheumatology, 10th ed.; 2017.

(282) Khademhosseini, A.; Langer, R. A Decade of Progress in Tissue Engineering. Nat. Protoc. 2016, II (I0), I775-I78I. https://doi.org/I0.1038/nprot.2016.123.

(283) Okita, K.; Ichisaka, T.; Yamanaka, S. Generation of Germline-Competent Induced 
Pluripotent Stem Cells. Nature 2007, $448 \quad$ (7I5I), 313-317. https://doi.org/I0.1038/nature05934.

(284) Yu, J.; Vodyanik, M. A.; Smuga-Otto, K.; Antosiewicz-Bourget, J.; Frane, J. L.; Tian, S.; Nie, J.; Jonsdottir, G. A.; Ruotti, V.; Stewart, R.; et al. Induced Pluripotent Stem Cell Lines Derived from Human Somatic Cells. Science (80-. ). 2007, $3 / 8$ (5858), 1917-1920. https://doi.org/I0.II26/science. II5I526.

(285) DeForest, C. A.; Polizzotti, B. D.; Anseth, K. S. Sequential Click Reactions for Synthesizing and Patterning Three-Dimensional Cell Microenvironments. Nat. Mater. 2009, 8 (8), 659664. https://doi.org// 0.1038/nmat2473.

(286) DeForest, C. A.; Anseth, K. S. Cytocompatible Click-Based Hydrogels with Dynamically Tunable Properties through Orthogonal Photoconjugation and Photocleavage Reactions. Nat. Chem. 20I I, 3 ( I 2), 925-93I. https://doi.org/I0.1038/nchem. I I 74.

(287) Poocza, L.; Gottschaldt, M.; Markweg, E.; Hauptmann, N.; Hildebrand, G.; Pretzel, D.; Hartlieb, M.; Reichardt, C.; Kübel, J.; Schubert, U. S.; et al. Optimized Photoinitiator for Fast Two-Photon Absorption Polymerization of Polyester-Macromers for Tissue Engineering**. https://doi.org/I0.1002/adem.201600686.

(288) Kang, H.-W.; Lee, S. J.; Ko, I. K.; Kengla, C.; Yoo, J. J.; Atala, A. A 3D Bioprinting System to Produce Human-Scale Tissue Constructs with Structural Integrity. Nat. Biotechnol. 2016 , 34 (3), 3|2-319. https://doi.org/10.1038/nbt.34I3.

(289) Ober, T. J.; Foresti, D.; Lewis, J. A. Active Mixing of Complex Fluids at the Microscale. Proc. Natl. Acad. Sci. 201 5, I I 2 (40), I 2293-I 2298. https://doi.org/I0.1073/pnas. I 509224 I I 2.

(290) Colosi, C.; Shin, S. R.; Manoharan, V.; Massa, S.; Costantini, M.; Barbetta, A.; Dokmeci, M. R.; Dentini, M.; Khademhosseini, A. Microfluidic Bioprinting of Heterogeneous 3D Tissue Constructs Using Low-Viscosity Bioink. Adv. Mater. 2016, 28 (4), 677-684. https://doi.org/10.1002/adma.20I503310.

(29I) Murphy, S. V; Atala, A. 3D Bioprinting of Tissues and Organs. Nat. Biotechnol. 20 I 4, 32 (8), 773-785. https://doi.org/10.1038/nbt.2958.

(292) Kolesky, D. B.; Truby, R. L.; Gladman, A. S.; Busbee, T. A.; Homan, K. A.; Lewis, J. A. 3D Bioprinting of Vascularized, Heterogeneous Cell-Laden Tissue Constructs. Adv. Mater. 20 I 4, 26 (I9), 3124-3 |30. https://doi.org//0.1002/adma.20I305506.

(293) Miller, J. S.; Stevens, K. R.; Yang, M. T.; Baker, B. M.; Nguyen, D.-H. T.; Cohen, D. M.; Toro, E.; Chen, A. A.; Galie, P. A.; Yu, X.; et al. Rapid Casting of Patterned Vascular Networks for Perfusable Engineered Three-Dimensional Tissues. Nat. Mater. 20 I 2, II (9), 768-774. https://doi.org/10.1038/nmat3357.

(294) Khalil, S.; Nam, J.; Sun, W. Multi-Nozzle Deposition for Construction of 3D Biopolymer Tissue Scaffolds. https://doi.org/I0.I I 08/I35525405 I 0573347.

(295) Cohen, D. L.; Malone, E.; Lipson, H.; Bonassar, L. J. Direct Freeform Fabrication of Seeded Hydrogels in Arbitrary Geometries. Tissue Eng. 2006, 12 (5), 1325-1335. https://doi.org/10.1089/ten.2006.12.1325.

(296) Qi, H.; Ghodousi, M.; Du, Y.; Grun, C.; Bae, H.; Yin, P.; Khademhosseini, A. DNA Directed Self-Assembly of Shape-Controlled Hydrogels. https://doi.org/l 0.1038/ncomms3275.

(297) Todhunter, M. E.; Jee, N. Y.; Hughes, A. J.; Coyle, M. C.; Cerchiari, A.; Farlow, J.; Garbe, J. C.; LaBarge, M. A.; Desai, T. A.; Gartner, Z. J. Programmed Synthesis of Three-Dimensional Tissues. Nat. Methods 201 5, 12 (I0), 975-98I. https://doi.org/ I0.1038/nmeth.3553.

(298) Engler, A. J.; Sen, S.; Sweeney, H. L.; Discher, D. E. Matrix Elasticity Directs Stem Cell $\begin{array}{lllll}\text { Lineage Specification. } \quad \text { Cell 2006, } & \text { 677-689. }\end{array}$ https://doi.org//0.1016/j.cell.2006.06.044.

(299) Thomas, W. E.; Discher, D. E.; Prasad Shastri, V. Mechanical Regulation of Cells by Materials and Tissues. MRS Bull. 20 I 0, 35 (8), 578-583. https://doi.org/I0.1557/mrs2010.525.

(300) Engler, A. J.; Sen, S.; Sweeney, H. L.; Discher, D. E. Matrix Elasticity Directs Stem Cell $\begin{array}{lllll}\text { Lineage } \quad \text { Specification. } & \text { 20ll } & \text { 2006, } & \end{array}$ https://doi.org/10.1016/j.cell.2006.06.044.

(30I) Martino, M. M.; Briquez, P. S.; Ranga, A.; Lutolf, M. P.; Hubbell, J. A. Heparin-Binding Domain of Fibrin(Ogen) Binds Growth Factors and Promotes Tissue Repair When Incorporated within a Synthetic Matrix. Proc. Natl. Acad. Sci. U. S. A. 2013, IIO (I2), 4563-4568. https://doi.org//0.1073/pnas.1221602110.

(302) Pakulska, M. M.; Miersch, S.; Shoichet, M. S. Designer Protein Delivery: From Natural to 
Engineered Affinity-Controlled Release Systems. Science (80-. ). 20 I6, 35 I (6279), aac4750aac4750. https://doi.org// 0.1 I 26/science.aac4750.

(303) Lutolf, M. P.; Tirelli, N.; Cerritelli, S.; Cavalli, L.; Hubbell, J. A. Systematic Modulation of Michael-Type Reactivity of Thiols through the Use of Charged Amino Acids. Bioconjugate Chem. 200I, I2, 105I-1056. https://doi.org/I0.102I/BC0I55I9E.

(304) Lutolf, M. P.; Raeber, G. P.; Zisch, A. H.; Tirelli, N.; Hubbell, J. A. Cell-Responsive Synthetic Hydrogels. Adv. Mater. 2003, 15 (II), 888-892. https://doi.org/I0.1002/adma.20030462I.

(305) Lutolf, M. P.; Hubbell, J. A. Synthesis and Physicochemical Characterization of End-Linked Poly(Ethylene Glycol)-Co-Peptide Hydrogels Formed by Michael-Type Addition. Biomacromolecules 2003, 4 (3), 7I3-722. https://doi.org/I 0.102 I/BM025744E.

(306) Hubbell, J. A. Matrix-Bound Growth Factors in Tissue Repair. Swiss Med. Wkly. 2006, 136 (25-26), 387-39I. https://doi.org/smw-I I 402 [pii] In2006/25/smw-I I 402.

(307) Drury, J. L.; Mooney, D. J. Hydrogels for Tissue Engineering: Scaffold Design Variables and Applications. Biomaterials 2003, 24 (24), 4337-435I. https://doi.org/l0.1016/S01429612(03)00340-5.

(308) Veiseh, O.; Doloff, J. C.; Ma, M.; Vegas, A. J.; Tam, H. H.; Bader, A. R.; Li, J.; Langan, E.; Wyckoff, J.; Loo, W. S.; et al. Size- and Shape-Dependent Foreign Body Immune Response to Materials Implanted in Rodents and Non-Human Primates. Nat. Mater. 20I5, 14 (6), 643-65I. https://doi.org//0.1038/nmat4290.

(309) Vegas, A. J.; Veiseh, O.; Doloff, J. C.; Ma, M.; Tam, H. H.; Bratlie, K.; Li, J.; Bader, A. R.; Langan, E.; Olejnik, K.; et al. Combinatorial Hydrogel Library Enables Identification of Materials That Mitigate the Foreign Body Response in Primates. Nat. Biotechnol. 2016, 34 (3), 345-352. https://doi.org// 0.1038/nbt.3462.

(310) Moscatelli, D.; Rifkin, D. B. Membrane and Matrix Localization of Proteinases: A Common Theme in Tumor Cell Invasion and Angiogenesis. Biochim. Biophys. Acta 1988, 948 (I), 6785.

(3II) Gross, J. L.; Moscatelli, D.; Jaffe, E. A.; Rifkin, D. B. Plasminogen Activator and Collagenase Production by Cultured Capillary Endothelial Cells. J. Cell Biol. 1982, 95 (3), 974-98I.

(312) Presta, M.; Moscatelli, D.; Joseph-Silverstein, J.; Rifkin, D. B. Purification from a Human Hepatoma Cell Line of a Basic Fibroblast Growth Factor-like Molecule That Stimulates Capillary Endothelial Cell Plasminogen Activator Production, DNA Synthesis, and Migration. Mol. Cell. Biol. 1986, 6 (I I), 4060-4066. https://doi.org/I0.I I 28/MCB.6.I I.4060.

(313) Montesano, R.; Orci, L.; Belin, D.; Montour, J. L.; Wilson, J. D.; Nishizuka, Y. TumorPromoting Phorbol Esters Induce Angiogenesis in Vitro. Cell 1985, 42 (2), 469-477. https://doi.org/I0.1016/0092-8674(85)90104-7.

(314) Montesano, R.; Pepper, M. S.; Vassalli, J.-D.; Orci, L. Phorbol Ester Induces Cultured Endothelial Cells to Invade a Fibrin Matrix in the Presence of Fibrinolytic Inhibitors. J. Cell. Physiol. 1987, I 32 (3), 509-516. https://doi.org//0.1002/jcp. 104/3203/3.

(315) Herronl, G. S.; Bands, M. J.; Clark, E. J.; Gavrilovic, J.; Werb, Z. Secretion of Metalloproteinases by Stimulated Capillary Endothelial Cells. J. Biol. Chem. 1986, 26 I (6), 28I4-28I8.

(316) Kalebic, T.; Garbisa, S.; Glaser, B.; Liotta, L. Basement Membrane Collagen: Degradation by Migrating Endothelial Cells. Science (80-. ). 1983, 22 I (4607).

(317) Seagar, M. J.; Granier, C.; Couraud, F. Interactions of the Neurotoxin Apamin with a Ca2+Activated K+ Channel in Primary Neuronal Cultures. J. Biol. Chem. 1984, 259, I49|-1495.

(318) Yamada, R.-H.; Wakabayashi, Y.; Iwashima, A.; Hasegawa, T. Inhibition of Aspartate Aminotransferase by Hydrazinosuccinate. Biochim. Biophys. Acta - Gen. Subj. 1984, 80 I (I), I5I-I54. https://doi.org/I0.1016/0304-4165(84)90224-I.

(319) Hamilton, J. A.; Lingelbach, S. R.; Partridge, N. C.; Martin, T. J. Stimulation of Plasminogen Activator in Osteoblast-like Cells by Bone-Resorbing Hormones. Biochem. Biophys. Res. Commun. 1984, I 22 (I), 230-236. https://doi.org/I0.1016/0006-29IX(84)90464-9.

(320) Krystosek, A.; Seeds, N. W. Plasminogen Activator Secretion by Granule Neurons in Cultures of Developing Cerebellum. Proc. Natl. Acad. Sci. U. S. A. I98I, 78 (I2), 78I0-78I4.

(32I) Pittman, R. N. Release of Plasminogen Activator and a Calcium-Dependent Metalloprotease from Cultured Sympathetic and Sensory Neurons. Dev. Biol. 1985, IIO (I), 9I-10I. https://doi.org/l0.1016/0012-1606(85)90067-3.

(322) Monard, D. Cell-Derived Proteases and Protease Inhibitors as Regulators of Neurite 
Outgrowth. Trends Neurosci. 1988, II (I2), 54I-544. https://doi.org//0.1016/0I662236(88) $90182-8$.

(323) McGrogan, M.; Kennedy, J.; Ping Li, M.; Hsu, C.; Scott, R. W.; Simonsen, C. C.; Baker, J. B. Molecular Cloning and Expression of Two Forms of Human Protease Nexin I. Nat. Biotechnol. 1988, 6 (2), I72-177. https://doi.org//0.1038/nbt0288-I72.

(324) Belcastro, A. N.; Arthur, G. D.; Albisser, T. A.; Raj, D. A. Heart, Liver, and Skeletal Muscle Myeloperoxidase Activity during Exercise. J. Appl. Physiol. 1996, 80 (4), I33 I-I 335.

(325) Fielding, R. A.; Manfredi, T. J.; Ding, W.; Fiatarone, M. A.; Evans, W. J.; Cannon, J. G. Acute Phase Response in Exercise. III. Neutrophil and IL-I Beta Accumulation in Skeletal Muscle. Am. J. Physiol. 1993, 265 (I Pt 2), RI66-72.

(326) Lowe, D. A.; Warren, G. L.; Ingalls, C. P.; Boorstein, D. B.; Armstrong, R. B. Muscle Function and Protein Metabolism after Initiation of Eccentric Contraction-Induced Injury. J. Appl. Physiol. 1995, 79 (4), I260-1270.

(327) Tidball, J. G. Inflammatory Processes in Muscle Injury and Repair.

(328) Henson, P. M.; Johnston, R. B. Perspectives Tissue Injury in Inflammation Oxidants, Proteinases, and Cationic Proteins. J. Clin. Invest. 1987, 79, 669-674.

(329) Britigan, B. E.; Hassett, D. J.; Rosen, G. M.; Hamill, D. R.; Cohen, M. S. Neutrophil Degranulation Inhibits Potential Hydroxyl-Radical Formation. Relative Impact of Myeloperoxidase and Lactoferrin Release on Hydroxyl-Radical Production by IronSupplemented Neutrophils Assessed by Spin-Trapping Techniques. Biochem. J. 1989, 264 (2), 447-455.

(330) Reeves, E. P.; Lu, H.; Jacobs, H. L.; Messina, C. G. M.; Bolsover, S.; Gabella, G.; Potma, E. O.; Warley, A.; Roes, J.; Segal, A. W. Killing Activity of Neutrophils Is Mediated through Activation of Proteases by K+ Flux. Nature 2002, 416 (6878), 29l-297. https://doi.org//0.1038/41629/a.

(33I) Okada, Y. Proteinases and Matrix Degradation. In Kelley \& Firestein's Textbook of Rheumatology; Elsevier: Philadelphia, 2017; pp 106-125.

(332) Novotná, J.; Herget, J. Possible Role of Matrix Metalloproteinases in Reconstruction of Peripheral Pulmonary Arteries Induced by Hypoxia. Physiol. Res 2002, 5I, 323-334.

(333) Bauer, P. I.; Machovich, R.; Büki, K. G.; Csonka, E.; Koch, S. A.; Horváth, I. Interaction of Plasmin with Endothelial Cells. Biochem. J. 1984, 2 I8 (I).

(334) Zhao, B.-Q.; Tejima, E.; Lo, E. H. Neurovascular Proteases in Brain Injury, Hemorrhage and Remodeling After Stroke. Stroke 2007, 38 (2).

(335) Muto, T.; Kokubu, T.; Mifune, Y.; Inui, A.; Harada, Y.; Yoshifumi, F.; Takase, F.; Kuroda, R.; Kurosaka, M. Temporary Inductions of Matrix Metalloprotease-3 (MMP-3) Expression and Cell Apoptosis Are Associated with Tendon Degeneration or Rupture after Corticosteroid Injection. J. Orthop. Res. 20 I 4, 32 (10), I 297-1304. https://doi.org/I0.1002/jor.2268I.

(336) Corbel, M.; Boichot, E.; Lagente, V. Role of Gelatinases MMP-2 and MMP-9 in Tissue Remodeling Following Acute Lung Injury. Brazilian J. Med. Biol. Res. 2000, 33 (7), 749-754. https://doi.org/I0.1590/S0100-879X2000000700004.

(337) Acharya, P. S.; Zukas, A.; Chandan, V.; Katzenstein, A.-L. A.; Puré, E. Fibroblast Activation Protein: A Serine Protease Expressed at the Remodeling Interface in Idiopathic Pulmonary $\begin{array}{lllll}\text { Fibrosis. Hum. 2006, } 37 \text { (3), 352-360. } & \text { Pathol. }\end{array}$ https://doi.org//0.1016/j.humpath.2005.II.020.

(338) Chapman, H. A.; Munger, J. S.; Shi, G.-P. The Role of Thiol Proteases in Tissue Injury and Remodeling. Am. J. Respir. Crit. Care Med. 1994, 150 (6_pt_2), SI55-SI59. https://doi.org/I 0.1 I64/ajrccm/I50.6_Pt_2.SI55.

(339) Drake, F. H.; Dodds, R. A.; James, I. E.; Connor, J. R.; Debouck, C.; Richardson, S.; LeeRykaczewski, E.; Coleman, L.; Rieman, D.; Barthlow, R.; et al. Cathepsin K, but Not Cathepsins B, L, or S, Is Abundantly Expressed in Human Osteoclasts. J. Biol. Chem. 1996, 27 (21), I25II-125I6. https://doi.org/I0.1074/JBC.27I.21.125II.

(340) Salminen-Mankonen, H.; Morko, J.; Vuorio, E. Role of Cathepsin K in Normal Joints and in the Development of Arthritis. Curr. Drug Targets 2007, 8 (2), 3/5-323. https://doi.org// 0.2174// 38945007779940188.

(34I) Mason, S. D.; Joyce, J. A. Proteolytic Networks in Cancer. Trends Cell Biol. 20 I I, 2 I (4), 228-237. https://doi.org/10.1016/j.tcb.2010.12.002.

(342) Heussen, C.; Dowdle, E. B. Electrophoretic Analysis of Plasminogen Activators in 
Polyacrylamide Gels Containing Sodium Dodecyl Sulfate and Copolymerized Substrates. Anal. Biochem. I 980, 102 (I), 196-202. https://doi.org/I0.1016/0003-2697(80)90338-3.

(343) Van Zutphen, L. F. M.; den Bleman, M. G. C. W. Rat Esterases: An Update of Linkage Group V. J. Hered. I 984, 75 (4), 313-3 I3. https://doi.org/ I0.1093/oxfordjournals.jhered.a 09942.

(344) Foltmann, B. Detection of Proteases. I 985, 360, 353-360.

(345) Saitoh, E.; Yamamoto, S.; Okamoto, E.; Hayakawa, Y.; Hoshino, T.; Sato, R.; Isemura, S.; Ohtsubo, S.; Taniguchi, M. Identifi Cation of Cysteine Proteases and Screening of Cysteine Protease Inhibitors in Biological Samples by a Two-Dimensional Gel System of Zymography and Reverse Zymography. Anal. Chem. Insights 2007, 2, $51-59$.

(346) Thimon, V.; Belghazi, M.; Labas, V.; Dacheux, J.-L.; Gatti, J.-L. One-and Two-Dimensional SDS-PAGE Zymography with Quenched Fluorogenic Substrates Provides Identification of Biological Fluid Proteases by Direct Mass Spectrometry. 2007. https://doi.org/10.1016/j.ab.2007.12.026.

(347) Thimon, V.; Métayer, S.; Belghazi, M.; Dacheux, F.; Dacheux, J.-L.; Gatti, J.-L. Shedding of the Germinal Angiotensin I-Converting Enzyme (GACE) Involves a Serine Protease and Is Activated by Epididymal Fluid I. Biol. Reprod. 2005, 73, 88I-890. https://doi.org/10.1095/biolreprod.105.042929.

(348) Wilkesman, J.; Kurz, L. Advances in Zymography Techniques and Patents Regarding Protease Analysis. Recent Pat Biotechnol 2012, 6 (2), I06-I 14. https://doi.org/BIOT-EPUB20I20528-3 [pii].

(349) Hibbs, M. S.; Hasty, K. a; Seyer, J. M.; Kang, a H.; Mainardi, C. L. Biochemical and Immunological Characterization of the Secreted Forms of Human Neutrophil Gelatinase. J. Biol. Chem. 1985, 260 (4), 2493-2500.

(350) Masure, S.; Billiau, A.; Van Damme, J.; Opdenakker, G. Human Hepatoma Cells Produce an $85 \mathrm{KDa}$ Gelatinase Regulated by Phorbol I2-Myristate I3-Acetate. BBA - Mol. Cell Res. I990, 1054 (3), 317-325. https://doi.org/10.1016/0167-4889(90)90103-K.

(35I) Lê, J.; Dauchot, P.; Perrot, J. L.; Cambazard, F.; Frey, J.; Chamson, A. Quantitative Zymography of Matrix Metalloproteinases by Measuring Hydroxyproline: Application to Gelatinases A and B. Electrophoresis 1999, $20 \quad$ (14), 2824-2829. https://doi.org//0.1002/(SICl) I522-2683(I999I00 I)20:|4<2824::AID-

ELPS2824>3.0.CO;2-H.

(352) Liabakk, N. B.; Talbot, I.; Smith, R. A.; Wilkinson, K.; Balkwill, F. Matrix Metalloprotease 2 (MMP-2) and Matrix Metalloprotease 9 (MMP-9) Type IV Collagenases in Colorectal Cancer. Cancer Res. 1996, 56 (I), 190-196.

(353) Vandooren, J.; Geurts, N.; Martens, E.; Van den Steen, P. E.; Opdenakker, G. Zymography Methods for Visualizing Hydrolytic Enzymes. Nat. Methods 2013, 10 (3), $211-220$. https://doi.org/10.1038/nmeth.237I.

(354) Cayouette, M.; Hansen, C. J.; McClure, A.; Sun, M.; Gramatikova, S.; Dycaico, M.; Barton, N. R.; Stege, J. T.; Aboushadi, N. M. Proteases, Nucleic Acids Encoding Them and Methods for Making and Using Them. US7642079 B2, October 10, 2003.

(355) Hoyhtya, M.; Fridman, R.; Komarek, D.; Porter-Jordan, K.; Stetler-Stevenson, W. G.; Liotta, L. A.; Liang, C. M. Immunohistochemical Localization of Matrix Metalloproteinase 2 and Its Specific Inhibitor TIMP-2 in Neoplastic Tissues with Monoclonal Antibodies. Int. J. Cancer 1994, 56 (4), 500-505.

(356) Weissleder, R.; Tung, C. H.; Mahmood, U.; Bogdanov, a. In Vivo Imaging of Tumors with Protease-Activated near-Infrared Fluorescent Probes. Nat. Biotechnol. I999, I 7 (4), 375378. https://doi.org/10.1038/7933.

(357) Bremer, C.; Tung, C. H.; Weissleder, R. In Vivo Molecular Target Assessment of Matrix Metalloproteinase Inhibition. Nat. Med. 200I, 7 (6), 743-748. https://doi.org/10.1038/89126.

(358) Crawford, B. D.; Pilgrim, D. B. Ontogeny and Regulation of Matrix Metalloproteinase Activity in the Zebrafish Embryo by in Vitro and in Vivo Zymography. Dev. Biol. 2005, 286 (2), 405-4I4. https://doi.org/I 0.1016/j.ydbio.2005.06.035.

(359) Galis, Z. S.; Sukhova, G. K.; Libby, P. Microscopic Localization of Active Proteases by in Situ Zymography: Detection of Matrix Metalloproteinase Activity in Vascular Tissue. FASEB J. 1995, 9 (10), 974-980.

(360) Wyatt, R. A.; Keow, J. Y.; Harris, N. D.; Haché, C. A.; Li, D. H.; Crawford, B. D. The 
Zebrafish Embryo: A Powerful Model System for Investigating Matrix Remodeling. Zebrafish 2009, 6 (4), 347-354. https://doi.org/I0.1089/zeb.2009.0609.

(36I) Keow, J. Y.; Herrmann, K. M.; Crawford, B. D. Differential in Vivo Zymography: A Method for Observing Matrix Metalloproteinase Activity in the Zebrafish Embryo. Matrix Biol. 20 I I, 30 (3), 169-177. https://doi.org/10.1016/j.matbio.2011.01.003.

(362) Nakamura, H.; Ueno, H.; Yamashita, K.; Shimada, T.; Yamamoto, E.; Noguchi, M.; Fujimoto, N.; Sato, H.; Seiki, M.; Okada, Y. Enhanced Production and Activation of Progelatinase A Mediated by Membrane-Type I Matrix Metalloproteinase in Human Papillary Thyroid Carcinomas. Cancer Res. I999, 59 (2), 467-473.

(363) Woessner, J. F. Matrix Metalloproteinases and Their Inhibitors in Connective Tissue Remodeling. FASEB J. I99 I, 5 (8), 2I45-2I54.

(364) Kupai, K.; Szucs, G.; Cseh, S.; Hajdu, I.; Csonka, C.; Csont, T.; Ferdinandy, P. Matrix Metalloproteinase Activity Assays: Importance of Zymography. J. Pharmacol. Toxicol. Methods 20 I 0, 6 I (2), 205-209. https://doi.org/I0.1016/j.vascn.2010.02.0I I.

(365) Hryhorovych, M. V.; Hanusevych, I. I.; Sydoryk, Y. P.; Valentynovych, K. M. Method for Estimating Efficiency of Arterial Hypertension Therapy, 2006.

(366) Kim, C.-H.; Lee, D.-M.; Chung, T.-W.; Ko, J.-H. Method of Diagnosing the Chances of Pregnancy and the Diagnostic Kit for the Same. US7060502 B2, 2003.

(367) Moses, M. A.; Freeman, M. R.; Wiederschain, D. Non-Invasive Enzyme Screen for Cancer. US68II 995 BI, December 22, 1999.

(368) Liotta, L. A.; Stetler-Stevenson, W.; Krutzsch, H. Metalloproteinase Peptides: Role in Diagnosis and Therapy. US5270447 A, 1989.

(369) Zucker, S. Diagnostic Tests Measuring Gelatinase/Inhibitor Complexes for Detection of Aggressive and Metastatic Cancer. US5324634 A, 1992.

(370) Dickson, R. B.; Shi, Y. E. Matrix-Degrading Metalloproteinase. US5482848 A, 1994.

(37I) Moses, M. A.; Freeman, M. R.; Wiederschain, D. Enzyme Screen for Breast Cancer. US6037I38 A, 1997.

(372) Koyama, I.; Yasumura, T.; Nemoto, K.; Mae, T.; Saiga, K.; Takagi, H.; Isoda, A.; Tanabe, T. Method for Examining Chronic Rejection Reactions Following Organ Transplantation and Method for Determining Urine Components. US62 I09I2 BI, 1997.

(373) Brünner, N.; Rømer, J.; Ellis, V.; Pyke, C.; Grøndahl-Hansen, J.; Pedersen, H.; Hansen, H. H.; Danø, K. Suppression of Inhibitors. US6224865 BI, 1994.

(374) Greene, J. M.; Rosen, C. A. Human Tissue Inhibitor of Metalloproteinase-4. US654476I B2, 2001.

(375) Seiki, M.; Sato, H.; Shinagawa, A. Novel Metalloprotease and Dna Coding for the Same. EP0685557 AI, November 30, 1994.

(376) Verheijen, J. H. Modified Proenzymes as Substrates for Proteolytic Enzymes. EP 069/409 AI, 2017.

(377) Stetler-Stevenson, W. G.; Liotta, L. A Method for Quantitatively Measuring Collagenase. WOI99I0II7I4 AI, I99I.

(378) Moses, M.; Freeman, M.; Wiederschain, D. Non-Invasive Enzyme Screen for Tissue Remodeling Associated Conditions. US200700I5227 AI, 2006.

(379) Folkman, J.; Moses, M. A. Method of Treating Lymphangioleiomyomatosis (Lam), 2006. https://doi.org/WO2006I2496I A2.

(380) Tesfaigzi, Y.; Belinsky, S. A. Metalloproteinase Gene Polymorphism in Copd. WO20050I7II3 A2, 2004.

(38I) Wormstone, I. M.; Dawes, L.; Eldred, J. A.; Edwards, D.; Hodgkinson, L. Treatment of Fibrotic Eye Disorders Using an Mmp2 Inhibitor. US20I I 0236395 AI, 2009.

(382) Centeno, M.; Enrique, D.; Del, E.-M.; Es, V. Non-Invasive Enzyme Screen for Tissue Remodelling-Associated Conditions. EP I 832876 A2, 2012.

(383) Lee, M.; Ikejiri, M.; Chang, M.; Fridman, R.; Mobashery, S. Inhibitors of Matrix Metallaproteinases, 2005.

(384) Lovaas, J. D.; Zhu, L.; Chiao, C. Y.; Byles, V.; Faller, D. V; Dai, Y. SIRTI Enhances Matrix Metalloproteinase-2 Expression and Tumor Cell Invasion in Prostate Cancer Cells. https://doi.org/10.1002/pros.22592.

(385) Nemori, R.; Yamamoto, M.; Nakamura, K.; Okada, Y. Thin Membrane for Measuring Protease Activity. US7067272, 2001. 
(386) Centeno, M.; Enrique, D.; Del, E.-M.; Es, V. Method for Early Diagnosis of Proliferative Diabetic Retinopathy. EP I 865 07I AI, 2012.

(387) Jenkin, G.; Trounson, A. O.; Wallace, E. M.; Moodley, Y.; Manuelpillai, U.; llancheran, S. Treatment of Chronic Lung Disease. WO2008I44820 AI, 2008.

(388) Pirilä, E.; Suojanen, J.; Sorsa, T.; Salo, T.; Koivunen, E. Peptide Gacfsiahecga for Targeting Mtl-Mmp. WO200900097I, 2017.

(389) Dubin, G.; Potempa, J. A Protease from Staphylococcus Aureus, Particularly Spia or Spib, Peptides It Recognises and Their Use. WO2008I53429, 2007.

(390) Grillo, I.; Penfold, J.; Tucker, I.; Cousin, F. Spontaneous Formation of Nanovesicles in Mixtures of Nonionic and Dialkyl Chain Cationic Surfactants Studied by Surface Tension and SANS †. Langmuir 2009, 25 (7), 3932-3943. https://doi.org/10.1021/la802435h.

(39I) Micsonai, A.; Wien, F.; Kernya, L.; Lee, Y.; Goto, Y.; Réfrégiers, M.; Kardos, J. Accurate Secondary Structure Prediction and Fold Recognition for Circular Dichroism Spectroscopy. Proc. Natl. Acad. Sci. 20I5, II/2 (24), 3095-3I03. https://doi.org/I0.1073/pnas. I50085 I II 2.

(392) Liu, W.; Dreher, M. R.; Chow, D. C.; Zalutsky, M. R.; Chilkoti, A. Tracking the in Vivo Fate of Recombinant Polypeptides by Isotopic Labeling. J. Control. Release 2006, I 4 (2), I84192. https://doi.org/I0.1016/j.jconrel.2006.06.00I.

(393) Konttinen, Y. T.; Ainola, M.; Vallcala, H.; Ma, J.; Ida, H.; Mandelin, J.; Kinne, R. W.; Santavirta, S.; Sorsa, T.; López-Otín, C.; et al. Analysis of 16 Different Matrix Metalloproteinases (MMP-I to MMP-20) in the Synovial Membrane: Different Profiles in Trauma and Rheumatoid Arthritis. Ann. Rheum. Dis. 1999, 58 (II), 69l-697. https://doi.org/10.1 I36/ard.58.11.691.

(394) Saarialho-Kere, U.; Kerkelä, E.; Jeskanen, L.; Ranki, A.; Vaalamo, M.; Hasan, T.; Pierce, R.; Starcher, B.; Raudasoja, R.; Oikarinen, A. Accumulation of Matrilysin (MMP-7) and Macrophage Metalloelastase (MMP-12) in Actinic Damage. J. Invest. Dermatol. 1999, I/3 (4), 664-672. https://doi.org/I0.1046/J.1523-I747.1999.0073I.X.

(395) Taddese, S.; Weiss, A. S.; Neubert, R. H. H.; Schmelzer, C. E. H. Mapping of Macrophage Elastase Cleavage Sites in Insoluble Human Skin Elastin. Matrix Biol. 2008, 27 (5), 420-428. https://doi.org/I0.1016/j.matbio.2008.02.00I.

(396) Van Doren, S. R. Matrix Metalloproteinase Interactions with Collagen and Elastin. Matrix Biol. 20 I 5, 44-46, 224-23I. https://doi.org/I0.10I6/j.matbio.2015.01.005.

(397) Turk, B. E.; Huang, L. L.; Piro, E. T.; Cantley, L. C. Determination of Protease Cleavage Site Motifs Using Mixture-Based Oriented Peptide Libraries. Nat. Biotechnol. Publ. online OI July 200 I; | doil0.1038/90273 200 I, 19 (7), 66I. https://doi.org/I0.1038/90273.

(398) Fields, G. B. A Model For Interstitial Collagen Catabolism by Mammalian Collagenases. J. theor. Biol I99I, 153, 585-602.

(399) Nagase, H.; Fields, G. B. Human Matrix Metalloproteinase Specificity Studies Using Collagen Sequence-Based Synthetic Peptides. Biopolymers 1996, 40 (4), 399-416. https://doi.org/I0.1002/(SICI) I097-0282(1996)40:4<399::AID-BIP5>3.0.CO;2-R.

(400) Fosang, A. J.; Last, K.; Neame, P. J.; Murphy, G.; Knäuper, V.; Tschesche, H.; Hughes, C. E.; Caterson, B.; Hardingham, T. E. Neutrophil Collagenase (MMP-8) Cleaves at the Aggrecanase Site E373-A374 in the Interglobular Domain of Cartilage Aggrecan. Biochem. J. 1994, 304 (2).

(40I) Nagase, H.; Enghild, J. J.; Suzuki, K.; Salvesen, G. Stepwise Activation Mechanisms of the Precursor of Matrix Metalloproteinase 3 (Stromelysin) by Proteinases and (4Aminophenyl)Mercuric Acetate. Biochemistry 1990, 29 (24), 5783-5789. https://doi.org/10.1021/bi00476a020.

(402) Fosang, A. J.; Neamell, P. J.; Last, K.; Hardinghamll, T. E.; Murphy, G.; Hamilton, J. A. The Interglobular Domain of Cartilage Aggrecan Is Cleaved by PUMP, Gelatinases, and Cathepsin B. J. Biol. Chem. 1992, 267 (27), 19470-19474.

(403) Martín-Alonso, M.; García-Redondo, A. B.; Guo, D.; Camafeita, E.; Martínez, F.; Alfranca, A.; Méndez-Barbero, N.; Pollán, Á.; Sánchez-Camacho, C.; Denhardt, D. T.; et al. Deficiency of MMPI7/MT4-MMP Proteolytic Activity Predisposes to Aortic Aneurysm in Mice. Mol. Med. 20 I 5. https://doi.org/I0.I I6I/CIRCRESAHA.I I7.305I08.

(404) Papke, C. L.; Yamashiro, Y.; Yanagisawa, H. MMPI7/MT4-MMP and Thoracic Aortic Aneurysms: OPNing New Potential for Effective Treatment. Circ. Res. 20 I 5, I I 7 (2), I09- 
I 12. https://doi.org/I0.1 I6I/CIRCRESAHA.II7.30685I.

(405) Zhang, X.; Chen, C. T.; Bhargava, M.; Torzilli, P. A. A Comparative Study of Fibronectin Cleavage by MMP-I, -3, -13, and -14 . Cartilage 2012, 3 (3), 267-277. https://doi.org//0.1 I77/19476035।|435273.

(406) Wysocki, A. B.; Staiano-Coico, L.; Grinnell, F. Wound Fluid from Chronic Leg Ulcers Contains Elevated Levels of Metalloproteinases MMP-2 and MMP-9. J. Invest. Dermatol. 1993, I0I (I), 64-68. https://doi.org/I0.III I/I523-I747.EPI2359590.

(407) Murray, M. Y.; Birkland, T. P.; Howe, J. D.; Rowan, A. D.; Fidock, M.; Parks, W. C.; Gavrilovic, J. Macrophage Migration and Invasion Is Regulated by MMPIO Expression. PLoS One 20 I 3, 8 (5), e63555. https://doi.org/l0.137I/journal.pone.0063555.

(408) Jenkins, M. H.; Alrowaished, S. S.; Goody, M. F.; Crawford, B. D.; Henry, C. A. Laminin and Matrix Metalloproteinase II Regulate Fibronectin Levels in the Zebrafish Myotendinous Junction. Skelet. Muscle 20 I 6, 6 (I), I8. https://doi.org/I0.I 186/s I3395-016-0089-3.

(409) Tatti, O.; Gucciardo, E.; Pekkonen, P.; Holopainen, T.; Louhimo, R.; Repo, P.; Maliniemi, P.; Lohi, J.; Rantanen, V.; Hautaniemi, S.; et al. MMPI6 Mediates a Proteolytic Switch to Promote Cell-Cell Adhesion, Collagen Alignment, and Lymphatic Invasion in Melanoma. Cancer Res. 2015, 75 (10), 2083-2094. https://doi.org/I0.I I 58/0008-5472.CAN-I4-I 923.

(4I0) Roberts, S.; Dzuricky, M.; Chilkoti, A. Elastin-like Polypeptides as Models of Intrinsically Disordered Proteins. FEBS Lett. 2015, 589 (I9PartA), 2477-2486. https://doi.org// 0.1016/j.febslet.2015.08.029.

(4II) Gao, Z.; Eisenberg, A. A Model of Micellization for Block Copolymers in Solutions. Macromolecules 1993, 26 (26), 7353-7360. https://doi.org/I0.1021/ma00078a035.

(4I2) Tian, H.-Y.; Yan, J.-J.; Wang, D.; Gu, C.; You, Y.-Z.; Chen, X.-S. Synthesis of ThermoResponsive Polymers With Both Tunable UCST and LCST. Macromol. Rapid Commun. 20 I I, 32 (8), 660-664. https://doi.org/10.1002/marc.2010007I3.

(4I3) Maeda, Y.; Mochiduki, H.; Ikeda, I. Hydration Changes during Thermosensitive Association of a Block Copolymer Consisting of LCST and UCST Blocks. Macromol. Rapid Commun. 2004, 25 (14), I330-1334. https://doi.org/I0.1002/marc.200400062.

(4I4) Arotçaréna, M.; Heise, B.; Ishaya, S.; Laschewsky, A. Switching the Inside and the Outside of Aggregates of Water-Soluble Block Copolymers with Double Thermoresponsivity. J. Am. Chem. Soc. 2002, I 24 (I4), 3787-3793. https://doi.org/I0.102 I/ja0 I2 I67d.

(4I5) Ning, J.; Li, G.; Haraguchi, K. Synthesis of Highly Stretchable, Mechanically Tough, Zwitterionic Sulfobetaine Nanocomposite Gels with Controlled Thermosensitivities. Macromolecules 2013, 46 (I 3), 53 I7-5328. https://doi.org/10.1021/ma4009059.

(416) Xu, Z.; Liu, W. Poly( N-Acryloyl Glycinamide): A Fascinating Polymer That Exhibits a Range of Properties from UCST to High-Strength Hydrogels. Chem. Commun. 2018, 54 (75), 10540-10553. https://doi.org/10.1039/C8CC046 |4J.

(417) Fujihara, A.; Shimada, N.; Maruyama, A.; Ishihara, K.; Nakai, K.; Yusa, S. Preparation of Upper Critical Solution Temperature (UCST) Responsive Diblock Copolymers Bearing Pendant Ureido Groups and Their Micelle Formation Behavior in Water. Soft Matter 20 I 5, II (26), 5204-52I3. https://doi.org/10.1039/C5SM00499C.

(4I8) Yoshimitsu, H.; Kanazawa, A.; Kanaoka, S.; Aoshima, S. Well-Defined Polymeric lonic Liquids with an Upper Critical Solution Temperature in Water. Macromolecules 20 I 2, 45 (23), 9427-9434. https://doi.org/10.1021/ma301746u.

(419) Yokota, D.; Kanazawa, A.; Aoshima, S. Precise Synthesis of UCST-Type Amphiphilic Diblock Copolymers with Pendant Imidazolium Ionic Liquid Segments and Their Thermosensitive Physical Gelation at Extremely Low Concentrations in Water. Polym. Chem. 201 8. https://doi.org/10.1039/C8PY0II39G.

(420) Kwon, G. S.; Okano, T. Soluble Self-Assembled Block Copolymers for Drug Delivery. Pharm. Res. 1999, 16 (5), 597-600.

(42I) Torchilin, V. P. Targeted Polymeric Micelles for Delivery of Poorly Soluble Drugs. Cell. Mol. Life Sci. 2004, 6 I (19-20), 2549-2559. https://doi.org/I0.1007/s00018-004-4I53-5.

(422) Hunter, R. J. Influence of More Complex Adsorbates on Zeta Potential. In Zeta potential in colloid science : principles and applications; School of Chemistry, University of Sydney: Sydney, Austarlia, 198I; PP 305-344. https://doi.org/https://doi.org//0.1016/B978-0-12-36/96I7.500I2-2.

(423) Woodle, M. C.; Collins, L. R.; Sponsler, E.; Kossovsky, N.; Papahadjopoulos, D.; Martin, F. 
J. Sterically Stabilized Liposomes. Reduction in Electrophoretic Mobility but Not Electrostatic Surface Potential. Biophys. J. 1992, 6I (4), 902-910. https://doi.org//0.1016/S0006-3495(92)81897-0.

(424) Magarkar, A.; Dhawan, V.; Kallinteri, P.; Viitala, T.; Elmowafy, M.; Róg, T.; Bunker, A. Cholesterol Level Affects Surface Charge of Lipid Membranes in Saline Solution; 2014; Vol. 4. https://doi.org/l0.1038/srep05005.

(425) Alanazi, F. K.; Haq, N.; Radwan, A. A.; Alsarra, I. A.; Shakeel, F. Formulation and Evaluation of Cholesterol-Rich Nanoemulsion (LDE) for Drug Delivery Potential of CholesterylMaleoyl-5-Fluorouracil. Pharm. Dev. Technol. 2015, 20 (3), 266-270. https://doi.org/I0.3109/I0837450.2013.86055I.

(426) Liu, D.-Z.; Chen, W.-Y.; Tasi, L.-M.; Yang, S.-P. Microcalorimetric and Shear Studies on the Effects of Cholesterol on the Physical Stability of Lipid Vesicles. Colloids Surfaces A Physicochem. Eng. Asp. 2000, 172 (I-3), 57-67. https://doi.org//0.1016/S09277757(00)00560-4.

(427) Babak, V. G.; Baros, F.; Boulanouar, O.; Boury, F.; Fromm, M.; Kildeeva, N. R.; Ubrich, N.; Maincent, P. Impact of Bulk and Surface Properties of Some Biocompatible Hydrophobic Polymers on the Stability of Methylene Chloride-in-Water Mini-Emulsions Used to Prepare Nanoparticles by Emulsification-Solvent Evaporation. Colloids Surfaces B Biointerfaces 2007, 59 (2), 194-207. https://doi.org//0.1016/J.COLSURFB.2007.05.010.

(428) Chernysheva, Y. V.; Babak, V. G.; Kildeeva, N. R.; Boury, F.; Benoit, J. P.; Ubrich, N.; Maincent, P. Effect of the Type of Hydrophobic Polymers on the Size of Nanoparticles Obtained by Emulsification-Solvent Evaporation. Mendeleev Commun. 2003, 13 (2), 65-67. https://doi.org/I0.1070/MC2003v0I3n02ABEH00I690.

(429) Rapaka, R. S.; Okamoto, K.; Urry, D. W. NON-ELASTOMERIC POLYPEPTIDE MODELS OF ELASTIN. Int. J. Pept. Protein Res. 1978, I I (2), 109-127. https://doi.org//0.I I I /j. I39930II.1978.tb02830.x.

(430) Brodie, N. I.; Popov, K. I.; Petrotchenko, E. V; Dokholyan, N. V; Borchers, C. H. Solving Protein Structures Using Short-Distance Cross-Linking Constraints as a Guide for Discrete Molecular Dynamics Simulations. Sci. Adv. 2017, 3 (July), el 700479-87.

(43I) Micsonai, A.; Wien, F.; Kun, J.; Vadászi, H.; Réfrégiers, M.; Kardos, J. Protein Fold Recognition by Circular Dichroism Spectroscopy. Biophys. J. 2018, II4 (3), 174a. https://doi.org/10.1016/j.bpj.2017.11.970.

(432) Ward, M. A.; Georgiou, T. K.; Ward, M. A.; Georgiou, T. K. Thermoresponsive Polymers for Biomedical Applications. Polymers (Basel). 20II, 3 (3), 1215-I242. https://doi.org// 0.3390/polym303/2I5.

(433) Banskota, S.; Yousefpour, P.; Kirmani, N.; Li, X.; Chilkoti, A. Long Circulating Genetically Encoded Intrinsically Disordered Zwitterionic Polypeptides for Drug Delivery. Biomaterials 2019, 192, 475-485. https://doi.org//0.1016/J.BIOMATERIALS.2018.11.012.

(434) Campo, V. L.; Kawano, D. F.; Silva, D. B. da; Carvalho, I. Carrageenans: Biological Properties, Chemical Modifications and Structural Analysis - A Review. Carbohydr. Polym. 2009, 77 (2), 167-180. https://doi.org/10.1016/J.CARBPOL.2009.01.020.

(435) Akiyoshi, K.; Deguchi, S.; Moriguchi, N.; Yamaguchi, S.; Sunamoto, J. Self-Aggregates of Hydrophobized Polysaccharides in Water. Formation and Characteristics of Nanoparticles. Macromolecules 1993, 26 (I2), 3062-3068. https://doi.org/I0.102I/ma00064a0I I.

(436) Ercole, F.; Whittaker, M. R.; Quinn, J. F.; Davis, T. P. Cholesterol Modified Self-Assemblies and Their Application to Nanomedicine. Biomacromolecules 2015, 16 (7), 1886-1914. https://doi.org/I0.1021/acs.biomac.5b00550.

(437) Fitriyani, S.; Liu, C.-Y.; Yuniarti, Y.; Liu, J.-H. Chiral Effect on the Self-Assembly of Chiral Molecules Synthesized from Cholesterol. J. Taiwan Inst. Chem. Eng. 2018, 9I, 48I-488. https://doi.org//0.1016/J.JTICE.2018.05.019.

(438) Ougizawa, T.; Inoue, T. UCST and LCST Behavior in Polymer Blends and Its Thermodynamic Interpretation. Polym. J. 1986, 18 (7), 52I-527. https://doi.org/I0.1295/polymj.18.52I.

(439) Israelachvili, J. N. Intermolecular and Surface Forces, Third Edition.; EISevier: Santa Barbara, 2011.

(440) Teramura, Y.; Iwata, H. Cell Surface Modification with Polymers for Biomedical Studies. Soft Matter 20 I 0, 6 (6), I08I. https://doi.org/10.1039/b9/362 I e. 
(44I) Gong, P.; Zheng, W.; Huang, Z.; Zhang, W.; Xiao, D.; Jiang, X. A Strategy for the Construction of Controlled, Three-Dimensional, Multilayered, Tissue-Like Structures. Adv. Funct. Mater. 2013, 23 (I), 42-46. https://doi.org/I0.1002/adfm.20I 201275.

(442) Chandra, R. A.; Douglas, E. S.; Mathies, R. A.; Bertozzi, C. R.; Francis, M. B. Programmable Cell Adhesion Encoded by DNA Hybridization. Angew. Chemie Int. Ed. 2006, 45 (6), 89690I. https://doi.org/I0.1002/anie.20050242I.

(443) Tayalia, P.; Mendonca, C. R.; Baldacchini, T.; Mooney, D. J.; Mazur, E. 3D Cell-Migration Studies Using Two-Photon Engineered Polymer Scaffolds. Adv. Mater. 2008, 20 (23), 4494 4498. https://doi.org/10.1002/adma.200801319.

(444) Seunarine, K.; Gadegaard, N.; Tormen, M.; Meredith, D. O.; Riehle, M. O.; Wilkinson, C. D. W. 3D Polymer Scaffolds for Tissue Engineering. Nanomedicine (Lond). 2006, I (3), 28I296. https://doi.org//0.2217//7435889.1.3.28I.

(445) Chan, G.; Mooney, D. J. New Materials for Tissue Engineering: Towards Greater Control over the Biological Response. Trends Biotechnol. 2008, 26 (7), 382-392. https://doi.org/I0.1016/j.tibtech.2008.03.0I I.

(446) Chen, A. M.; Scott, M. D. Immunocamouflage: Prevention of Transfusion-Induced Graftversus-Host Disease via Polymer Grafting of Donor Cells. J. Biomed. Mater. Res. 2003, 67A (2), 626-636. https://doi.org/10.1002/jbm.a.I0I46.

(447) Nishiguchi, A.; Matsusaki, M.; Akashi, M. Structural and Viscoelastic Properties of Layer-byLayer Extracellular Matrix (ECM) Nanofilms and Their Interactions with Living Cells. ACS Biomater. Sci. Eng. 2015, I (9), 8I6-824. https://doi.org/l0.102I/acsbiomaterials.5b00I88.

(448) Asano, Y.; Shimoda, H.; Matsusaki, M.; Akashi, M. Transplantation of Artificial Human Lymphatic Vascular Tissues Fabricated Using a Cell-Accumulation Technique and Their Engraftment in Mouse Tissue with Vascular Remodelling. J. Tissue Eng. Regen. Med. 20I8, 12 (3), el50I-el5I0. https://doi.org/I0.1002/term.2570.

(449) Simnick, A. J.; Valencia, C. A.; Liu, R.; Chilkoti, A. Morphing Low-Affinity Ligands into HighAvidity Nanoparticles by Thermally Triggered Self-Assembly of a Genetically Encoded Polymer. ACS Nano 201 0, 4 (4), 2217-2227. https://doi.org/I0.1021/nn90I732h.

(450) Wieprecht, T.; Dathe, M.; Beyermann, M.; Krause, E.; Maloy, W. L.; MacDonald, D. L.; Bienert, M. Peptide Hydrophobicity Controls the Activity and Selectivity of Magainin 2 Amide in Interaction with Membranes. Biochemistry 1997, 36 (20), 6124-6132. https://doi.org/l0.1021/bi9619987.

(45I) Brahms, S.; Brahms, J.; Spach, G.; Brack, A. Identification of Beta,Beta-Turns and Unordered Conformations in Polypeptide Chains by Vacuum Ultraviolet Circular Dichroism. Proc. Natl. Acad. Sci. U. S. A. 1977, 74 (8), 3208-3212.

(452) Hennessey, J. P.; Johnson, W. C. Information Content in the Circular Dichroism of Proteins. Biochemistry I 98 I, 20 (5), 1085-1094. https://doi.org/l 0.102 I/bi00508a007.

(453) Kazunari Akiyoshi, *; Atsushi Ueminami; Satoshi Kurumada, and; Nomura, Y. SelfAssociation of Cholesteryl-Bearing Poly(I-Lysine) in Water and Control of Its Secondary Structure by Host-Guest Interaction with Cyclodextrin. 2000. https://doi.org/10.1021/MA991949C.

(454) Zhu, Q.; Chen, X.; Xu, X.; Zhang, Y.; Zhang, C.; Mo, R. Tumor-Specific Self-Degradable Nanogels as Potential Carriers for Systemic Delivery of Anticancer Proteins. Adv. Funct. Mater. 20 I 8, 28 (I7), I70737I. https://doi.org/I0.1002/adfm.20170737I.

(455) Khmelinskaia, A.; Mücksch, J.; Petrov, E. P.; Franquelim, H. G.; Schwille, P. Control of Membrane Binding and Diffusion of Cholesteryl-Modified DNA Origami Nanostructures by DNA Spacers. Langmuir 2018, 34 (49), |492|-|493|. https://doi.org/10.102I/acs.langmuir.8b01850.

(456) Heal, W. P.; Jovanovic, B.; Bessin, S.; Wright, M. H.; Magee, A. I.; Tate, E. W. Bioorthogonal Chemical Tagging of Protein Cholesterylation in Living Cells. Chem. Commun. 20 II, 47 (14), 408I. https://doi.org/I0.1039/c0cc047I0d.

(457) Theesfeld, C. L.; Pourmand, D.; Davis, T.; Garza, R. M.; Hampton, R. Y. The Sterol-Sensing Domain (SSD) Directly Mediates Signal-Regulated Endoplasmic Reticulum-Associated Degradation (ERAD) of 3-Hydroxy-3-Methylglutaryl (HMG)-CoA Reductase Isozyme $\begin{array}{lllll}\text { Hmg2. J. Biol. Chem. 20II, } 286 \quad \text { (30), 26298-26307. } & \end{array}$ https://doi.org/I0.1074/jbc.MIII.244798.

(458) Hoop, C. L.; Sivanandam, V. N.; Kodali, R.; Srnec, M. N.; van der Wel, P. C. A. Structural 
Characterization of the Caveolin Scaffolding Domain in Association with Cholesterol-Rich Membranes. Biochemistry 20 I 2, 5 I (I), 90-99. https://doi.org/10.102 I/bi201356v.

(459) Hassan, H. H.; Denis, M.; Krimbou, L.; Marcil, M.; Genest, J. Cellular Cholesterol Homeostasis in Vascular Endothelial Cells. Can. J. Cardiol. 2006, 22 Suppl B (Suppl B), 35B40B.

(460) Faggiotto, A.; Ross, R.; Harker, L. Studies of Hypercholesterolemia in the Nonhuman Primate. I. Changes That Lead to Fatty Streak Formation. Arteriosclerosis 4 (4), 323-340. 

APPENDIX 



\section{$7 \quad$ Appendix}

\subsection{Supporting Information}

Table 18: Datapoints of BeStSel algorythm fit to CD data.

\begin{tabular}{|c|c|c|c|c|c|c|c|c|c|c|c|c|c|c|}
\hline \multirow{2}{*}{$\begin{array}{l}\text { Sample } \\
\text { Temp. }\left({ }^{\circ} \mathrm{C}\right)\end{array}$} & \multicolumn{14}{|c|}{ VKV } \\
\hline & \multicolumn{2}{|l|}{5} & \multicolumn{2}{|l|}{10} & \multicolumn{2}{|l|}{15} & \multicolumn{2}{|l|}{20} & \multicolumn{2}{|l|}{25} & \multicolumn{2}{|l|}{30} & \multicolumn{2}{|l|}{35} \\
\hline $\begin{array}{l}\text { Waveln. } \\
\text { (nm) }\end{array}$ & $\begin{array}{l}\text { Exp } \\
\text {. }\end{array}$ & Fit & $\begin{array}{l}\operatorname{Exp} \\
. \\
\end{array}$ & Fit & $\begin{array}{l}\operatorname{Exp} \\
. \\
\end{array}$ & Fit & $\begin{array}{l}\text { Exp } \\
.\end{array}$ & Fit & $\begin{array}{l}\text { Exp } \\
. \\
\end{array}$ & Fit & $\begin{array}{l}\text { Exp } \\
. \\
\end{array}$ & Fit & $\begin{array}{l}\operatorname{Exp} \\
\cdot \\
\end{array}$ & Fit \\
\hline & - & - & - & - & - & - & - & - & - & - & - & - & - & - \\
\hline 190,00 & 3,56 & 3,19 & 3,39 & 3,01 & 3,12 & 2,77 & 2,77 & 2,51 & 2,57 & 2,33 & 2,35 & 2,11 & 2,20 & 1,93 \\
\hline & - & - & - & - & - & - & - & - & - & - & - & - & - & - \\
\hline 191,00 & 3,98 & 3,80 & 3,73 & 3,57 & 3,39 & 3,28 & 3,08 & 2,96 & 2,87 & 2,76 & 2,54 & 2,48 & 2,26 & 2,14 \\
\hline & - & - & - & - & - & - & - & - & - & - & - & - & - & - \\
\hline 192,00 & 4,39 & 4,39 & 4,10 & 4,11 & 3,75 & 3,78 & 3,37 & 3,40 & 3,17 & 3,18 & 2,84 & 2,85 & 2,33 & 2,36 \\
\hline & - & - & - & - & - & - & - & - & - & - & - & - & - & - \\
\hline 193,00 & 4,78 & 4,91 & $4,4 I$ & 4,61 & 4,12 & 4,25 & 3,73 & 3,82 & 3,47 & 3,58 & 3,09 & 3,21 & 2,44 & 2,57 \\
\hline & - & - & - & - & - & - & - & - & - & - & - & - & - & - \\
\hline 194,00 & 5,09 & 5,31 & 4,77 & 4,98 & 4,40 & 4,61 & 3,99 & 4,14 & 3,73 & 3,89 & 3,39 & 3,51 & 2,53 & 2,72 \\
\hline & - & - & - & - & - & - & - & - & - & - & - & - & - & - \\
\hline 195,00 & 5,31 & 5,48 & 5,05 & 5,14 & 4,61 & 4,77 & 4,16 & 4,28 & 3,95 & 4,03 & 3,56 & 3,65 & 2,62 & 2,73 \\
\hline & - & - & - & - & - & - & - & - & - & - & - & - & - & - \\
\hline 196,00 & 5,45 & 5,47 & 5,13 & 5,15 & 4,78 & 4,79 & 4,32 & 4,30 & 4,07 & 4,05 & 3,70 & 3,68 & 2,66 & 2,66 \\
\hline & - & - & - & - & - & - & - & - & - & - & - & - & - & - \\
\hline 197,00 & 5,52 & 5,39 & 5,18 & 5,09 & 4,88 & 4,76 & 4,33 & 4,28 & 4,12 & 4,03 & 3,74 & 3,67 & 2,68 & 2,60 \\
\hline & - & - & - & - & - & - & - & - & - & - & - & - & - & - \\
\hline 198,00 & 5,40 & 5,22 & 5,12 & 4,95 & 4,83 & 4,64 & 4,32 & 4,19 & 4,09 & 3,95 & $3,7 \mid$ & 3,60 & 2,65 & 2,48 \\
\hline & - & - & - & - & - & - & - & - & - & - & - & - & - & - \\
\hline 199,00 & 5,18 & 5,04 & 4,97 & 4,81 & 4,68 & 4,52 & 4,29 & 4,10 & 3,97 & 3,87 & 3,68 & 3,55 & 2,56 & 2,44 \\
\hline & - & - & - & - & - & - & - & - & - & - & - & - & - & - \\
\hline 200,00 & 4,93 & 4,87 & 4,78 & 4,67 & 4,44 & 4,39 & 4,03 & 3,99 & 3,79 & 3,78 & 3,49 & 3,47 & 2,43 & 2,38 \\
\hline & - & - & - & - & - & - & - & - & - & - & - & - & - & - \\
\hline 201,00 & 4,65 & 4,46 & 4,44 & 4,29 & 4,13 & 4,03 & 3,76 & 3,67 & 3,57 & 3,48 & 3,26 & 3,18 & 2,26 & 2,14 \\
\hline & - & - & - & - & - & - & - & - & - & - & - & - & - & - \\
\hline 202,00 & 4,19 & 4,11 & 4,01 & 3,97 & 3,72 & 3,73 & 3,46 & 3,41 & 3,30 & 3,24 & 3,05 & 2,98 & 2,06 & 2,01 \\
\hline & - & - & - & - & - & - & - & - & - & - & - & - & - & - \\
\hline 203,00 & 3,76 & 3,76 & 3,62 & 3,64 & 3,43 & 3,42 & 3,12 & 3,15 & 3,00 & 3,01 & 2,7 I & 2,76 & I,87 & 1,88 \\
\hline & - & - & - & - & - & - & - & - & - & - & - & - & - & - \\
\hline 204,00 & 3,36 & 3,37 & 3,27 & 3,26 & 3,05 & 3,08 & 2,84 & 2,84 & 2,69 & 2,72 & 2,47 & 2,50 & 1,68 & I,7I \\
\hline & - & - & - & - & - & - & - & - & - & - & - & - & - & - \\
\hline 205,00 & 2,97 & 3,01 & 2,91 & 2,91 & 2,74 & 2,75 & 2,53 & 2,54 & 2,42 & 2,44 & 2,22 & 2,25 & I,50 & 1,55 \\
\hline & - & - & - & - & - & - & - & - & - & - & - & - & - & - \\
\hline 206,00 & 2,64 & 2,68 & 2,54 & 2,59 & 2,44 & 2,44 & 2,21 & 2,26 & 2,16 & 2,18 & 2,00 & 2,01 & 1,33 & 1,39 \\
\hline & - & - & - & - & - & - & - & - & - & - & - & - & - & - \\
\hline 207,00 & 2,31 & 2,44 & 2,25 & 2,36 & 2,15 & 2,25 & 1,99 & 2,08 & 1,94 & 2,00 & 1,78 & 1,85 & 1,20 & 1,30 \\
\hline & - & - & - & - & - & - & - & - & - & - & - & - & - & - \\
\hline 208,00 & 2,05 & 2,21 & 1,98 & 2,14 & $\mathrm{I}, 94$ & 2,05 & I,79 & 1,89 & 1,76 & 1,83 & 1,62 & $\mathrm{I}, 70$ & 1,12 & 1,22 \\
\hline & - & - & - & - & - & - & - & - & - & - & - & - & - & - \\
\hline 209,00 & 1,86 & 2,01 & 1,81 & 1,96 & $\mathrm{I}, 77$ & 1,90 & 1,63 & I,77 & 1,62 & 1,73 & 1,54 & 1,61 & $\mathrm{I}, 07$ & 1,19 \\
\hline & - & - & - & - & - & - & - & - & - & - & - & - & - & - \\
\hline 210,00 & $\mathrm{I}, 70$ & 1,83 & $\mathrm{I}, 67$ & 1,80 & 1,61 & $\mathrm{I}, 77$ & 1,53 & 1,67 & 1,52 & 1,66 & $\mathrm{I}, 43$ & 1,57 & 1,06 & 1,24 \\
\hline & - & - & - & - & - & - & - & - & - & - & - & - & - & - \\
\hline 211,00 & 1,59 & 1,66 & I,57 & 1,65 & I,55 & $\mathrm{I}, 63$ & 1,50 & 1,55 & 1,46 & 1,55 & 1,39 & $\mathrm{I}, 48$ & $\mathrm{I}, 07$ & 1,19 \\
\hline & - & - & - & - & - & - & - & - & - & - & - & - & - & - \\
\hline 212,00 & $|, 5|$ & I,53 & $|, 5|$ & 1,52 & $\mathrm{I}, 48$ & $|, 5|$ & $|, 4|$ & 1,45 & 1,42 & $\mathrm{I}, 46$ & 1,38 & $|, 4|$ & 1,09 & 1,17 \\
\hline & - & - & - & - & - & - & - & - & - & - & - & - & - & - \\
\hline 213,00 & 1,46 & $\mathrm{I}, 42$ & $\mathrm{I}, 45$ & 1,42 & $\mathrm{I}, 44$ & 1,42 & 1,39 & 1,37 & 1,42 & 1,40 & 1,35 & 1,36 & 1,13 & 1,16 \\
\hline & - & - & - & - & - & - & - & - & - & - & - & - & - & - \\
\hline 214,00 & 1,42 & 1,39 & $\mathrm{I}, 42$ & 1,40 & $\mathrm{I}, 42$ & 1,40 & 1,37 & 1,37 & $|, 4|$ & 1,40 & 1,38 & 1,37 & 1,18 & 1,22 \\
\hline & - & - & - & - & - & - & - & - & - & - & - & - & - & - \\
\hline 215,00 & 1,39 & $\mathrm{I}, 35$ & $\mathrm{I}, 42$ & 1,37 & $\mathrm{I}, 42$ & 1,38 & 1,37 & 1,35 & 1,42 & 1,40 & 1,38 & 1,37 & 1,24 & 1,25 \\
\hline & - & - & - & - & - & - & - & - & - & - & - & - & - & - \\
\hline 216,00 & 1,37 & 1,32 & 1,39 & $\mathrm{I}, 34$ & $\mathrm{I}, 40$ & 1,36 & 1,39 & 1,34 & $\mathrm{I}, 43$ & 1,39 & 1,42 & 1,37 & $|, 3|$ & 1,28 \\
\hline & - & - & - & - & - & - & - & - & - & - & - & - & - & - \\
\hline 217,00 & 1,34 & 1,32 & $\mathrm{I}, 38$ & 1,34 & $\mathrm{I}, 40$ & 1,37 & 1,39 & 1,35 & $\mathrm{I}, 44$ & 1,40 & $|, 4|$ & 1,39 & 1,38 & 1,33 \\
\hline & - & - & - & - & - & - & - & - & - & - & - & - & - & - \\
\hline 218,00 & 1,35 & $\mathrm{I}, 30$ & 1,38 & $\mathrm{I}, 33$ & $\mathrm{I}, 42$ & 1,36 & 1,40 & 1,34 & 1,45 & 1,40 & $\mathrm{I}, 43$ & 1,39 & $\mathrm{I}, 44$ & 1,36 \\
\hline
\end{tabular}




\begin{tabular}{|c|c|c|c|c|c|c|c|c|c|c|c|c|c|c|}
\hline & & & & - & & & & - & & & & & & - \\
\hline 219,00 & 1,32 & $\begin{array}{l}1,25 \\
-\end{array}$ & $\begin{array}{l}1,37 \\
-\end{array}$ & $\begin{array}{l}1,29 \\
-\end{array}$ & 1,39 & $\begin{array}{l}1,32 \\
-\end{array}$ & $\begin{array}{l}1,39 \\
-\end{array}$ & $\begin{array}{l}1,32 \\
-\end{array}$ & 1,46 & $\begin{array}{l}1,38 \\
-\end{array}$ & $\mathrm{I}, 44$ & $\begin{array}{l}1,37 \\
-\end{array}$ & $\begin{array}{l}1,49 \\
-\quad\end{array}$ & $\begin{array}{l}1,37 \\
-\end{array}$ \\
\hline 220,00 & 1,31 & $\mathrm{I}, 27$ & 1,36 & 1,30 & 1,40 & I,34 & 1,41 & 1,33 & I,46 & 1,40 & 1,46 & 1,39 & 1,53 & $\mid, 41$ \\
\hline & - & - & - & - & & - & - & - & - & - & - & - & & - \\
\hline 221,00 & 1,30 & I,24 & 1,34 & 1,28 & 1,39 & 1,31 & 1,37 & 1,31 & I,44 & I,37 & I,45 & 1,36 & 1,54 & I,42 \\
\hline & - & - & - & - & - & & - & - & - & - & & - & & - \\
\hline 222,00 & 1,25 & 1,22 & 1,29 & I,27 & 1,34 & $\mid, 31$ & 1,36 & 1,30 & I,42 & 1,37 & $|, 4|$ & 1,36 & 1,55 & 1,44 \\
\hline 223,00 & 1,23 & I,23 & 1,29 & I,27 & 1,32 & $\mid, 31$ & 1,32 & 1,31 & 1,39 & I,38 & 1,40 & 1,36 & 1,55 & 1,48 \\
\hline 22400 & $i_{20}$ & 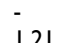 & & - & & & - & - & - & - & & 5 & & $-i 50$ \\
\hline 224,00 & $\begin{array}{l}1,20 \\
-\end{array}$ & $\begin{array}{l}\mathrm{I}, 2 \mathrm{I} \\
-\end{array}$ & $\begin{array}{l}1,23 \\
-\end{array}$ & $\begin{array}{l}1,26 \\
-\end{array}$ & $\begin{array}{l}1,29 \\
-\end{array}$ & $\begin{array}{l}1,30 \\
-\end{array}$ & $\begin{array}{l}1,29 \\
-\end{array}$ & $\begin{array}{l}1,30 \\
-\end{array}$ & $\begin{array}{l}1,36 \\
-\end{array}$ & $\begin{array}{l}1,37 \\
-\end{array}$ & $\begin{array}{l}1,34 \\
-\end{array}$ & $\begin{array}{l}1,36 \\
.\end{array}$ & $\begin{array}{l}1,53 \\
-\end{array}$ & $\begin{array}{l}1,50 \\
-\end{array}$ \\
\hline 225,00 & 1,15 & 1,19 & 1,19 & 1,24 & 1,27 & 1,28 & 1,25 & 1,29 & $\mid, 31$ & 1,36 & 1,32 & 1,35 & 1,49 & 1,53 \\
\hline 226,00 & I,II & $\mathrm{I}, 18$ & 1,15 & 1,23 & 1,19 & 1,27 & 1,19 & 1,28 & 1,25 & I,35 & 1,26 & I,34 & 1,44 & I,54 \\
\hline 227,00 & 1,05 & 1,15 & 1,09 & 1,19 & 1,13 & 1,23 & 1,12 & 1,24 & 1,19 & 1,31 & 1,19 & 1,30 & 1,38 & 1,51 \\
\hline & - & - & - & - & - & & - & - & - & - & - & - & & - \\
\hline 228,00 & 0,98 & $\mathrm{I}, 10$ & $\mathrm{I}, 03$ & $\mathrm{I}, 14$ & I,07 & 1,18 & I,08 & 1,19 & 1,13 & 1,25 & 1,12 & 1,25 & 1,32 & 1,47 \\
\hline 229,00 & 0,93 & 1,00 & 0,97 & $\mathrm{I}, 04$ & $|, 0|$ & 1,08 & $\mathrm{I}, 0 \mathrm{I}$ & 1,09 & $\mathrm{I}, 07$ & 1,15 & 1,07 & 1,15 & 1,25 & 1,36 \\
\hline & & & - & - & - & & - & & - & - & - & - & - & - \\
\hline 230,00 & $\begin{array}{l}0,88 \\
-\end{array}$ & $\begin{array}{l}0,91 \\
-\end{array}$ & $\begin{array}{l}0,91 \\
-\end{array}$ & $\begin{array}{l}0,94 \\
-\end{array}$ & $\begin{array}{l}0,93 \\
-\end{array}$ & 0,98 & $\begin{array}{l}0,96 \\
-\end{array}$ & $\begin{array}{l}1,00 \\
-\end{array}$ & $\begin{array}{l}\mathrm{I}, 0 \mathrm{I} \\
-\end{array}$ & $\begin{array}{l}1,06 \\
-\end{array}$ & $\begin{array}{l}1,02 \\
-\end{array}$ & $\begin{array}{l}\mathrm{I}, 06 \\
.\end{array}$ & $\begin{array}{l}1,18 \\
.\end{array}$ & $\begin{array}{l}\mathrm{I}, 27 \\
.\end{array}$ \\
\hline $23 \mathrm{I}, 00$ & 0,82 & 0,82 & 0,85 & 0,86 & 0,89 & 0,89 & 0,90 & 0,91 & 0,94 & 0,97 & 0,93 & 0,97 & I,II & 1,18 \\
\hline 232,00 & $\overline{0,75}$ & $\overline{0,71}$ & $\overline{0,79}$ & $\overline{0,75}$ & $\overline{0,80}$ & $\overline{0}, 78$ & $\overline{0,83}$ & $\overline{0,80}$ & $\overline{0,87}$ & 0,85 & $\overline{0}, 86$ & $\overline{0,86}$ & 1,03 & $\bar{i}, 05$ \\
\hline & - & - & - & - & - & - & - & - & - & - & - & - & - & - \\
\hline 233,00 & 0,70 & 0,60 & 0,73 & 0,63 & 0,75 & 0,67 & 0,76 & 0,69 & 0,80 & 0,73 & 0,81 & 0,74 & 0,95 & 0,91 \\
\hline 234,00 & 0,64 & 0,49 & 0,65 & 0,52 & 0,67 & 0,55 & 0,69 & 0,57 & 0,73 & 0,61 & 0,72 & 0,61 & 0,87 & 0,76 \\
\hline & - & - & - & - & - & 0 & - & - & - & - & - & - & - & - \\
\hline 235,00 & $\begin{array}{l}0,5 / \\
-\end{array}$ & $\begin{array}{l}0,38 \\
-\end{array}$ & $\begin{array}{l}0,61 \\
-\end{array}$ & $\begin{array}{l}0,41 \\
-\end{array}$ & $\begin{array}{l}0,60 \\
-\end{array}$ & 0,43 & 0,62 & $\begin{array}{l}0,45 \\
-\end{array}$ & $\begin{array}{l}0,66 \\
-\end{array}$ & 0,48 & $\begin{array}{l}0,65 \\
-\end{array}$ & $\begin{array}{l}0,49 \\
-\end{array}$ & $\begin{array}{l}0,19 \\
-\end{array}$ & $\begin{array}{l}0,61 \\
-\end{array}$ \\
\hline 236,00 & 0,52 & 0,26 & 0,55 & 0,29 & 0,57 & 0,31 & 0,57 & 0,33 & 0,60 & 0,35 & 0,61 & $\begin{array}{l}0,36 \\
-\end{array}$ & 0,72 & 0,46 \\
\hline 237,00 & 0,47 & 0,22 & 0,48 & 0,24 & 0,50 & 0,26 & 0,52 & 0,27 & 0,54 & 0,29 & 0,54 & 0,30 & 0,65 & 0,38 \\
\hline 238,00 & 0,42 & 0,20 & 0,42 & 0,22 & 0,45 & 0,24 & 0,45 & 0,26 & 0,49 & 0,28 & 0,48 & 0,29 & 0,58 & 0,37 \\
\hline & - & - & - & - & - & - & - & - & - & 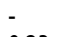 & - & - & & - \\
\hline 239,00 & 0,37 & 0,15 & 0,39 & 0,17 & 0,40 & 0,19 & 0,41 & 0,21 & 0,44 & 0,23 & 0,44 & 0,24 & 0,52 & 0,31 \\
\hline 240,00 & 0,34 & 0,11 & 0,35 & 0,13 & 0,35 & 0,15 & 0,37 & 0,17 & $\overline{0,39}$ & 0,18 & $\overline{0,38}$ & 0,19 & $\overline{0}, 46$ & 0,25 \\
\hline & - & - & & - & $\therefore$ & 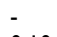 & 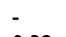 & - & - & - & - & - & - & - \\
\hline 241,00 & 0,29 & 0,07 & 0,30 & 0,08 & 0,30 & 0,10 & 0,32 & 0,12 & 0,34 & 0,13 & 0,34 & 0,14 & 0,40 & 0,18 \\
\hline & - & - & - & - & - & - & - & - & - & - & - & - & - & - \\
\hline 242,00 & 0,26 & 0,02 & 0,28 & 0,03 & 0,27 & 0,04 & 0,28 & 0,06 & 0,30 & 0,07 & 0,29 & 0,08 & 0,35 & 0,11 \\
\hline & - & - & - & - & - & - & - & - & - & - & - & - & & - \\
\hline 243,00 & 0,23 & 0,03 & 0,24 & 0,04 & 0,24 & 0,05 & 0,24 & 0,06 & 0,26 & 0,07 & 0,26 & 0,08 & 0,30 & 0,10 \\
\hline 244,00 & $\overline{0,21}$ & $\overline{0,02}$ & $\overline{0,21}$ & $\overline{0,03}$ & $\overline{0,21}$ & 0,04 & $\overline{0,21}$ & $\overline{0,05}$ & $\overline{0,23}$ & $\overline{0,06}$ & $\overline{0}, 23$ & $\overline{0,07}$ & $\overline{0}, 26$ & $\overline{0,08}$ \\
\hline & & & & (0) & & & & 000 & & & & - & & \\
\hline 245,00 & $\begin{array}{l}0,16 \\
-\end{array}$ & 0,01 & $\begin{array}{l}0,18 \\
-\end{array}$ & 0,02 & $\begin{array}{l}0,16 \\
-\end{array}$ & $\begin{array}{l}0,02 \\
-\end{array}$ & 0,17 & 0,03 & 0,21 & $\begin{array}{l}0,04 \\
-\end{array}$ & $\begin{array}{l}0,18 \\
-\end{array}$ & $\begin{array}{l}0,04 \\
-\end{array}$ & $\begin{array}{l}0,22 \\
-\end{array}$ & $\begin{array}{l}0,05 \\
-\end{array}$ \\
\hline 246,00 & $\begin{array}{l}0,15 \\
-\end{array}$ & 0,01 & $\begin{array}{l}0,16 \\
-\end{array}$ & 0,00 & 0,15 & 0,01 & $\begin{array}{l}0,16 \\
-\end{array}$ & $\begin{array}{l}0,01 \\
-\end{array}$ & $\begin{array}{l}0,18 \\
-\end{array}$ & $\begin{array}{l}0,02 \\
-\end{array}$ & $\begin{array}{l}0,16 \\
-\end{array}$ & $\begin{array}{l}0,02 \\
-\end{array}$ & 0,19 & $\begin{array}{l}0,03 \\
-\end{array}$ \\
\hline 247,00 & 0,14 & 0,01 & 0,14 & 0,00 & 0,14 & 0,00 & 0,14 & 0,01 & 0,16 & 0,01 & 0,15 & 0,02 & 0,16 & 0,03 \\
\hline 248,00 & 0,11 & 0,04 & 0,13 & 0,03 & 0,11 & 0,03 & 0,12 & 0,02 & 0,15 & 0,02 & 0,12 & 0,01 & 0,15 & 0,00 \\
\hline 249,00 & 0,13 & 0,07 & 0,14 & 0,07 & 0,13 & 0,06 & 0,12 & 0,05 & 0,14 & 0,05 & 0,13 & 0,04 & 0,13 & 0,03 \\
\hline 250,00 & 0,11 & 0,08 & $\overline{0}, 11$ & 0,08 & 0,10 & 0,07 & 0,11 & 0,07 & 0,13 & 0,06 & 0,10 & 0,06 & $\overline{0}, 12$ & 0,05 \\
\hline Sample & CTA & & & & & & & & & & & & & \\
\hline Temp. $\left({ }^{\circ} \mathrm{C}\right.$ & 5 & & 10 & & 15 & & 20 & & 25 & & 30 & & 35 & \\
\hline $\begin{array}{l}\text { Waveln. } \\
(\mathrm{nm})\end{array}$ & $\begin{array}{l}\text { Exp } \\
.\end{array}$ & Fit & Exp & Fit & Exp & Fit & Exp & Fit & $\begin{array}{l}\text { Exp } \\
.\end{array}$ & Fit & Exp & Fit & Exp & Fit \\
\hline & & & & & & & & & & & & & & \\
\hline 190,00 & $\begin{array}{l}4,76 \\
-\end{array}$ & $\begin{array}{l}3,83 \\
-\end{array}$ & 4,46 & 3,62 & 4,26 & 3,43 & 3,75 & 3,14 & 2,78 & 2,44 & 2,44 & $\begin{array}{l}2,15 \\
-\quad\end{array}$ & 2,20 & $\begin{array}{l}1,93 \\
-\end{array}$ \\
\hline 191,00 & 4,95 & 4,48 & 4,62 & 4,21 & 4,32 & 3,96 & 3,83 & 3,58 & 2,90 & 2,77 & 2,55 & 2,42 & 2,26 & 2,14 \\
\hline & & 5.10 & 482 & $-\overline{476}$ & 4.42 & & & & $\overline{3,06}$ & $\overline{3}, 08$ & & $\overline{2}, 68$ & & \\
\hline 192,00 & $\begin{array}{l}5,17 \\
-\end{array}$ & $\begin{array}{l}5,10 \\
-\end{array}$ & $\begin{array}{l}4,82 \\
-\end{array}$ & $\begin{array}{l}4,76 \\
-\end{array}$ & $\begin{array}{l}4,42 \\
-\end{array}$ & $\begin{array}{l}\text { 4,44 } \\
-\end{array}$ & $\begin{array}{l}3,95 \\
-\end{array}$ & $\begin{array}{l}3,96 \\
-\end{array}$ & $\begin{array}{l}3,06 \\
-\end{array}$ & $\begin{array}{l}3,08 \\
-\end{array}$ & $\begin{array}{l}\text { 2,68 } \\
-\end{array}$ & $\begin{array}{l}2,68 \\
-\end{array}$ & $\begin{array}{l}2,33 \\
-\end{array}$ & $\begin{array}{l}2,36 \\
-\end{array}$ \\
\hline 193,00 & 5,38 & 5,62 & 4,99 & 5,22 & 4,55 & 4,84 & 4,05 & 4,28 & 3,20 & 3,36 & 2,80 & 2,93 & 2,44 & 2,57 \\
\hline 194,00 & $\overline{5,56}$ & $\overline{5,96}$ & $\overline{5,15}$ & $\overline{5,52}$ & $\overline{4,76}$ & $\overline{5,09}$ & $\overline{4,15}$ & $\overline{4,46}$ & $\overline{3,34}$ & $\overline{3,56}$ & $\overline{2} .90$ & $\overline{3.11}$ & $\overline{2}, 53$ & $\overline{2}, 72$ \\
\hline
\end{tabular}




\begin{tabular}{|c|c|c|c|c|c|c|c|c|c|c|c|c|c|c|}
\hline & & & & & & & & & & & & & & \\
\hline 195,00 & $\begin{array}{l}5,67 \\
-\end{array}$ & 6,01 & $\begin{array}{l}5,24 \\
-\end{array}$ & $\begin{array}{l}5,55 \\
-\end{array}$ & 4,83 & $\begin{array}{l}5,09 \\
-\end{array}$ & $\begin{array}{l}4,23 \\
-\end{array}$ & $\begin{array}{l}4,42 \\
-\end{array}$ & 3,46 & $\begin{array}{l}3,57 \\
-\end{array}$ & 2,98 & 3,12 & $\begin{array}{l}2,62 \\
-\end{array}$ & 2,73 \\
\hline 196,00 & 5,72 & 5,86 & 5,29 & 5,39 & 4,88 & 4,94 & 4,27 & 4,27 & 3,50 & 3,49 & 3,05 & 3,05 & 2,66 & 2,66 \\
\hline 197,00 & 5,70 & 5,64 & 5,27 & 5,19 & 4,86 & 4,75 & 4,24 & 4,11 & 3,49 & 3,40 & 3,06 & 2,98 & 2,68 & 2,60 \\
\hline & & & & & & & & & & & & & & \\
\hline 198,00 & $\begin{array}{l}5,60 \\
-\quad\end{array}$ & $\begin{array}{l}5,35 \\
-\quad\end{array}$ & $\begin{array}{l}5,18 \\
-\end{array}$ & $\begin{array}{l}4,93 \\
-\end{array}$ & $\begin{array}{l}4,76 \\
-\end{array}$ & $\begin{array}{l}4,53 \\
-\quad\end{array}$ & $\begin{array}{l}4,16 \\
-\end{array}$ & $\begin{array}{l}3,95 \\
-\end{array}$ & 3,45 & $\begin{array}{l}3,28 \\
-\end{array}$ & $\begin{array}{l}3,04 \\
-\end{array}$ & $\begin{array}{l}2,86 \\
-\end{array}$ & $\begin{array}{l}2,65 \\
-\end{array}$ & $\begin{array}{l}2,48 \\
-\end{array}$ \\
\hline 199,00 & 5,41 & 5,12 & 4,99 & 4,74 & 4,62 & 4,37 & 4,03 & 3,85 & 3,34 & 3,21 & 2,95 & 2,81 & 2,56 & 2,44 \\
\hline & & - & 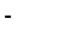 & - & - & - & - & - & & - & - & - & - & - \\
\hline 200,00 & 5,12 & 4,97 & 4,72 & 4,60 & 4,39 & 4,25 & 3,82 & 3,75 & 3,19 & 3,14 & 2,79 & 2,74 & 2,43 & 2,38 \\
\hline 201,00 & 4,76 & 4,51 & 4,40 & 4,18 & 4,05 & 3,86 & 3,53 & 3,41 & 3,00 & 2,86 & 2,60 & 2,47 & 2,26 & 2,14 \\
\hline & - & - & - & - & -7 & - & - & & & & - & - & - & \\
\hline 202,00 & 4,35 & 4,13 & 4,03 & 3,84 & 3,70 & 3,56 & 3,25 & 3,17 & 2,75 & 2,67 & 2,38 & 2,31 & 2,06 & 2,01 \\
\hline 203,00 & $\begin{array}{l}3,93 \\
-\end{array}$ & $\begin{array}{l}3,83 \\
-\end{array}$ & $\begin{array}{l}3,65 \\
-\end{array}$ & $\begin{array}{l}3,57 \\
-\end{array}$ & 3,36 & 3,30 & $\begin{array}{l}2,96 \\
-\end{array}$ & 2,96 & 2,49 & $\begin{array}{l}2,47 \\
-\end{array}$ & $\begin{array}{l}2,15 \\
-\end{array}$ & 2,15 & $\begin{array}{l}1,87 \\
-\end{array}$ & $\begin{array}{l}1,88 \\
-\end{array}$ \\
\hline 204,00 & 3,51 & 3,41 & 3,27 & 3,19 & 2,99 & 2,95 & 2,69 & 2,66 & 2,21 & 2,24 & 1,92 & 1,95 & I,68 & I,7I \\
\hline 205,00 & 3,13 & 3,05 & 2,92 & 2,86 & 2,68 & 2,64 & 2,43 & 2,39 & 1,97 & 2,01 & $\bar{i}, 71$ & i,75 & 1,50 & $\bar{i}, 55$ \\
\hline 206,00 & $\overline{2,77}$ & $\overline{2,75}$ & $\overline{2}, 59$ & $\overline{2}, 57$ & $\overline{2,40}$ & $\overline{2,38}$ & $\overline{2,17}$ & $\overline{2,14}$ & $\overline{i, 73}$ & $\overline{i, 80}$ & $\overline{1,52}$ & $\bar{i}_{1,57}$ & $\overline{i, 33}$ & $\overline{i, 39}$ \\
\hline 207,00 & 2,46 & 2,47 & 2,31 & 2,34 & 2,16 & 2,19 & 1,95 & 2,01 & I,55 & 1,66 & 1,36 & I,47 & 1,20 & $\overline{i, 30}$ \\
\hline 208,00 & 2,20 & 2,28 & 2,08 & 2,17 & I,94 & 2,03 & ।,75 & ।,87 & I,40 & 1,54 & I,25 & 1,36 & 1,12 & 1,22 \\
\hline 209,00 & 1,99 & 2,10 & 1,90 & 2,02 & I,77 & $\mid, 91$ & 1,61 & I,77 & $\mid, 31$ & 1,47 & 1,17 & $\mid, 31$ & ।,07 & 1,19 \\
\hline & - & - & - & - & - & - & - & - & . & - & - & - & - & - \\
\hline 210,00 & 1,83 & 1,93 & I,77 & 1,88 & 1,67 & 1,80 & 1,53 & 1,69 & 1,25 & I,44 & 1,14 & 1,33 & 1,06 & 1,24 \\
\hline ح0 & $i_{72}$ & 78 & $i 60$ & - 77 & 5 & 5 & iso & - & 123 & -73 & - & - & - & - \\
\hline 211,00 & $\begin{array}{l}1, / 2 \\
-\end{array}$ & $\begin{array}{l}1, / 8 \\
-\end{array}$ & $\begin{array}{l}1,69 \\
-\end{array}$ & - 1,15 & $\begin{array}{l}1,60 \\
-\end{array}$ & $\begin{array}{l}1,68 \\
-\end{array}$ & $\begin{array}{l}1,48 \\
-\end{array}$ & $\begin{array}{l}1,59 \\
-\end{array}$ & $\begin{array}{l}1,23 \\
-\end{array}$ & - 1,36 & $\begin{array}{l}1,14 \\
-\end{array}$ & $\begin{array}{l}1,27 \\
-\end{array}$ & - & $\begin{array}{l}1,19 \\
-\end{array}$ \\
\hline 212,00 & I,64 & 1,65 & 1,63 & 1,63 & I,54 & I,58 & 1,46 & 1,50 & 1,23 & 1,30 & 1,16 & 1,23 & 1,09 & 1,17 \\
\hline & - & - & - & - & - & - & - & - & - & - & - & - & - & - \\
\hline 213,00 & 1,60 & I,55 & I,59 & I,54 & I,56 & $|, 5|$ & I,47 & I,44 & 1,26 & 1,27 & 1,19 & $|, 2|$ & 1,13 & 1,16 \\
\hline & - & - & - & - & - & - & - & - & - & - & - & - & - & - \\
\hline 214,00 & I,57 & I,54 & I,58 & I,54 & I,55 & $|, 5|$ & I,48 & I,46 & 1,29 & I,30 & I,23 & 1,25 & 1,18 & 1,22 \\
\hline 215,00 & 1,56 & 1,52 & I,57 & I,53 & 1,54 & $|, 5|$ & I,50 & 1,46 & I,34 & $|, 3|$ & 1,28 & 1,28 & I,24 & 1,25 \\
\hline 216,00 & 1,56 & 1,49 & i,58 & $\overline{|, 5|}$ & I,56 & 1,50 & 1,53 & i,46 & 1,39 & 1,33 & i,34 & 1,30 & $|, 3|$ & 1,28 \\
\hline 217,00 & 1,56 & 1,49 & 1,58 & I,52 & I,58 & I,52 & ।,55 & i,49 & 1,43 & 1,36 & 1,40 & I,34 & $\overline{1,38}$ & 1,33 \\
\hline 218,00 & I,56 & 1,48 & 1,59 & I,51 & 1,61 & 1,52 & 1,58 & I,50 & $\mathrm{I}, 46$ & 1,38 & I,45 & I,37 & I,44 & 1,36 \\
\hline 219,00 & $\bar{i}, 55$ & $\bar{l}, 44$ & $\overline{1}, 59$ & $\bar{l}, 48$ & 1,62 & $\overline{1}, 50$ & $\bar{i}, 59$ & $\bar{i}, 48$ & 1,49 & $\overline{1,38}$ & $\overline{1}, 49$ & $\bar{i}, 37$ & $\bar{i}, 49$ & $\bar{i}, 37$ \\
\hline 220,00 & 1,54 & $\overline{1,46}$ & $\overline{1,58}$ & $\overline{\mid, 51}$ & 1,62 & $\overline{1,53}$ & $\overline{1,61}$ & $\overline{\mid, 51}$ & 1.51 & $\overline{1,42}$ & $\overline{1.52}$ & $\overline{|, 4|}$ & $\overline{1,53}$ & $\overline{|, 4|}$ \\
\hline & - & - & - & - & - & - & - & - & - & - & - & - & - & - \\
\hline 221,00 & I,52 & 1,44 & I,57 & 1,49 & 1,63 & I,52 & 1,60 & 1,50 & 1,52 & $|, 4|$ & 1,53 & $|, 4|$ & I,54 & I,42 \\
\hline & - & - & - & - & & - & - & - & & - & - & - & - & - \\
\hline 222,00 & I,49 & 1,43 & I,54 & I,48 & 1,59 & I,52 & I,59 & $|, 5|$ & I,52 & I,43 & 1,53 & I,43 & I,55 & I,44 \\
\hline & $\bar{i}_{46}$ & - & - & - 49 & - & 53 & 56 & -53 & $i_{50}$ & i & it5? & - & 55 & - \\
\hline 223,00 & $\begin{array}{l}1,46 \\
-\end{array}$ & $\begin{array}{l}1,43 \\
-\end{array}$ & $\begin{array}{l}1,51 \\
-\end{array}$ & $\begin{array}{l}1,49 \\
-\end{array}$ & $\begin{array}{l}1,58 \\
-\end{array}$ & $\begin{array}{l}1,53 \\
-\end{array}$ & $\begin{array}{l}1,56 \\
-\end{array}$ & $\begin{array}{l}1,53 \\
-\end{array}$ & $\begin{array}{l}1,50 \\
-\end{array}$ & $\begin{array}{l}1,46 \\
-\end{array}$ & $\begin{array}{l}1,52 \\
-\end{array}$ & $\begin{array}{l}1,47 \\
-\end{array}$ & $\begin{array}{l}1,55 \\
-\end{array}$ & $\begin{array}{l}1,48 \\
-\end{array}$ \\
\hline 224,00 & I,42 & $|, 4|$ & I,48 & I,47 & I,53 & I,52 & I,53 & I,53 & I,47 & I,47 & 1,50 & I,48 & I,53 & I,50 \\
\hline & - & - & - & - & - & - & - & - & - & - & - & - & - & - \\
\hline 225,00 & 1,37 & 1,38 & I,44 & I,45 & 1,49 & $|, 5|$ & I,49 & I,52 & I,43 & I,48 & 1,46 & I,50 & I,49 & I,53 \\
\hline 226,00 & 1,33 & $\overline{1}, 38$ & $\overline{1,38}$ & $\bar{i}, 44$ & $\overline{1}, 42$ & $\overline{1}, 50$ & $\bar{i}, 43$ & $\overline{1}, 52$ & $\overline{1}, 38$ & $\overline{1}, 48$ & $\overline{1,41}$ & $\overline{i, 51}$ & $\bar{i}, 44$ & $\overline{1,54}$ \\
\hline & - & - & - & - & & - & - & - & - & - & - & - & - & - \\
\hline 227,00 & 1,27 & 1,33 & I,32 & I,40 & 1,37 & I,46 & I,37 & I,48 & 1,33 & I,45 & I,35 & I,48 & I,38 & $|, 5|$ \\
\hline 228,00 & 1,22 & 1,28 & 1,26 & 1,34 & 1,30 & 1,40 & $\mid, 31$ & 1,43 & 1,27 & 1,40 & 1,29 & I,43 & 1,32 & 1,47 \\
\hline 229,00 & 1,14 & I, 14 & 1,19 & 1,20 & 1,22 & I,27 & 1,25 & $|, 3|$ & 1,20 & 1,29 & 1,23 & 1,32 & 1,25 & 1,36 \\
\hline 230,00 & 1,07 & 1,02 & 1,12 & I,08 & 1,17 & 1,16 & 1,17 & $|, 2|$ & 1,12 & 1,19 & 1,16 & I,22 & I,18 & 1,27 \\
\hline & & 091 & - & & & - & - & & & - & & & - & - \\
\hline $23 \mathrm{I}, 00$ & I,00 & 0,91 & I,05 & 0,98 & $\mathrm{I}, \mathrm{II}$ & 1,05 & 1,10 & 1,10 & I,05 & 1,10 & 1,08 & 1,13 & I,II & 1,18 \\
\hline 232,00 & 0,93 & 0,79 & 0,98 & 0,85 & 1,02 & 0,92 & 1,03 & 0,98 & 0,98 & 0,97 & 1,00 & 1,01 & 1,03 & 1,05 \\
\hline 233,00 & $\overline{0,86}$ & 0,65 & $\overline{0,91}$ & $\overline{0}, 72$ & 0,95 & 0,78 & $\overline{0}, 95$ & 0,84 & 0,90 & $\overline{0,84}$ & 0,92 & 0,87 & $\overline{0}, 95$ & $\overline{0,91}$ \\
\hline & - & - & - & - & - & & - & - & & - & - & & - & \\
\hline 234,00 & 0,80 & 0,53 & 0,84 & 0,58 & 0,88 & 0,64 & 0,88 & 0,69 & 0,82 & 0,70 & 0,83 & 0,73 & 0,87 & 0,76 \\
\hline
\end{tabular}




\begin{tabular}{|c|c|c|c|c|c|c|c|c|c|c|c|c|c|c|}
\hline & & & & & & & & & & & & & & \\
\hline 235,00 & 0,74 & 0,41 & 0,77 & 0,46 & 0,80 & 0,51 & 0,81 & 0,56 & 0,74 & $\begin{array}{l}0,56 \\
-\end{array}$ & 0,76 & 0,59 & $\begin{array}{l}0,79 \\
-\end{array}$ & $\begin{array}{l}0,61 \\
-\end{array}$ \\
\hline 236,00 & 0,68 & 0,27 & 0,71 & 0,32 & 0,74 & 0,36 & 0,74 & 0,41 & 0,67 & 0,41 & 0,69 & 0,43 & 0,72 & 0,46 \\
\hline 237,00 & 0,62 & 0,22 & 0,65 & 0,26 & 0,68 & 0,30 & 0,68 & 0,34 & 0,60 & $\overline{0}, 34$ & 0,62 & 0,36 & 0,65 & 0,38 \\
\hline 238,00 & 0,57 & 0,17 & 0,60 & 0,22 & 0,61 & 0,26 & 0,62 & 0,31 & 0,53 & 0,33 & 0,55 & 0,35 & 0,58 & 0,37 \\
\hline 239,00 & 0,51 & $\overline{0,12}$ & $\overline{0,55}$ & $\overline{0,16}$ & $\overline{0,56}$ & 0,19 & $\overline{0}, 56$ & $\overline{0}, 24$ & 0,47 & $\overline{0,27}$ & $\overline{0,49}$ & $\overline{0,29}$ & $\overline{0}, 52$ & $\overline{0,31}$ \\
\hline & & - & - & - & & & - & & - & - & - & - & & - \\
\hline 240,00 & 0,47 & 0,09 & 0,49 & 0,12 & 0,50 & 0,15 & 0,51 & 0,19 & 0,42 & 0,21 & 0,43 & 0,23 & 0,46 & 0,25 \\
\hline 241,00 & $\overline{0,43}$ & $\overline{0,04}$ & $\overline{0,45}$ & $\overline{0,07}$ & $\overline{0,44}$ & $\overline{0,10}$ & $\overline{0,47}$ & $\overline{0,13}$ & $\overline{0,36}$ & $\overline{0,15}$ & $\overline{0,38}$ & $\overline{0,17}$ & $\overline{0}, 40$ & $\overline{0,18}$ \\
\hline 271,00 & & 0,07 & - & - & - & & - & & & 0 & & & & - \\
\hline 242,00 & 0,39 & 0,02 & 0,41 & 0,01 & 0,42 & 0,03 & 0,42 & 0,06 & 0,32 & 0,09 & 0,33 & 0,10 & 0,35 & 0,11 \\
\hline 243,00 & 0,35 & 0,00 & 0,37 & 0,02 & 0,37 & 0,04 & 0,38 & 0,07 & 0,27 & 0,08 & 0,28 & 0,09 & 0,30 & 0,10 \\
\hline 244,00 & 0,33 & 0,00 & 0,34 & 0,02 & 0,34 & 0,04 & 0,35 & 0,06 & 0,24 & 0,07 & $\begin{array}{l}0,24 \\
-\end{array}$ & 0,08 & $\begin{array}{l}0,26 \\
-\end{array}$ & $\begin{array}{l}0,08 \\
-\end{array}$ \\
\hline 245,00 & 0,30 & 0,01 & 0,32 & 0,01 & 0,30 & 0,02 & 0,32 & 0,04 & 0,21 & 0,04 & 0,20 & 0,05 & 0,22 & 0,05 \\
\hline 246,00 & 0,28 & 0,02 & 0,29 & 0,01 & 0,29 & 0,00 & 0,29 & 0,02 & 0,19 & $\overline{0}, 02$ & 0,18 & 0,02 & $\overline{0}, 19$ & 0,03 \\
\hline 247,00 & 0,27 & 0,02 & 0,27 & 0,01 & 0,28 & 0,00 & 0,27 & 0,02 & 0,16 & 0,02 & 0,16 & 0,03 & 0,16 & 0,03 \\
\hline 248,00 & 0,26 & 0,06 & 0,26 & 0,05 & 0,24 & 0,04 & 0,26 & 0,02 & 0,14 & 0,01 & 0,14 & 0,00 & 0,15 & 0,00 \\
\hline 249,00 & $\begin{array}{l}0,24 \\
-\end{array}$ & 0,09 & 0,26 & 0,09 & 0,26 & 0,08 & 0,24 & 0,06 & 0,13 & 0,05 & 0,12 & 0,04 & 0,13 & 0,03 \\
\hline 250,00 & 0,23 & 0,10 & 0,25 & 0,09 & 0,24 & 0,09 & 0,23 & 0,08 & 0,12 & 0,06 & 0,11 & 0,06 & 0,12 & 0,05 \\
\hline Temp. $\left({ }^{\circ} \mathrm{C}\right)$ & \multicolumn{14}{|c|}{ CTAI } \\
\hline Temp. $\left({ }^{\circ} \mathrm{C}\right)$ & 5 & & 10 & & 15 & & 20 & & 25 & & 30 & & 35 & \\
\hline $\begin{array}{l}\text { Waveln. } \\
(\mathrm{nm})\end{array}$ & Exp & Fit & $\begin{array}{l}\text { Exp } \\
.\end{array}$ & Fit & $\begin{array}{l}\text { Exp } \\
.\end{array}$ & Fit & $\begin{array}{l}\text { Exp } \\
.\end{array}$ & Fit & $\begin{array}{l}\text { Exp } \\
.\end{array}$ & Fit & $\begin{array}{l}\text { Exp } \\
.\end{array}$ & Fit & Exp & Fit \\
\hline 190,00 & $\overline{2,91}$ & 2,61 & $\overline{2,66}$ & $\overline{2,42}$ & $\overline{2,39}$ & 2,12 & $\overline{2,13}$ & 1,95 & 1,36 & 1,26 & $\overline{i, 17}$ & 1,05 & $\bar{i}, 04$ & $\overline{0}, 92$ \\
\hline & & & & & & & & & & - & & & & - \\
\hline 191,00 & 3,20 & 3,06 & 2,96 & 2,84 & 2,49 & 2,45 & 2,42 & 2,28 & 1,49 & $\mathrm{I}, 44$ & 1,23 & 1,18 & 1,06 & 1,02 \\
\hline 192,00 & $\overline{3,54}$ & $\overline{3,52}$ & $\overline{3,27}$ & $\overline{3,24}$ & $\overline{2,86}$ & $\overline{2,81}$ & $\overline{2,63}$ & $\overline{2,60}$ & $\overline{1}, 68$ & $\overline{i, 66}$ & $\overline{1,33}$ & $\overline{1,37}$ & $\overline{1,17}$ & $\overline{1,18}$ \\
\hline & - & - & - & - & - & - & - & $\rightarrow \infty$ & - & - & - & & & - \\
\hline 193,00 & 3,77 & 3,95 & 3,54 & 3,62 & 3,02 & 3,15 & 2,80 & 2,92 & 1,95 & 1,89 & 1,53 & I,58 & 1,37 & 1,37 \\
\hline & - & - & - & - & - & - & - & - & - & - & - & - & & - \\
\hline 194,00 & 4,10 & 4,29 & 3,65 & 3,92 & 3,26 & 3,44 & 3,02 & 3,18 & 2,00 & 2,12 & 1,76 & I,79 & 1,38 & 1,56 \\
\hline 195,00 & 4,26 & 4,44 & 3,99 & 4,03 & 3,44 & 3,56 & 3,23 & 3,28 & 2,03 & 2,21 & I,74 & 1,87 & 1,55 & 1,63 \\
\hline 196,00 & $\overline{4,51}$ & $\overline{4,45}$ & $\overline{3,99}$ & $\overline{4,03}$ & $\overline{3,54}$ & 3,57 & $\overline{3,19}$ & 3,28 & $\overline{2,21}$ & $\overline{2,22}$ & $\overline{i, 87}$ & 1,89 & $\overline{1,69}$ & $\overline{1,63}$ \\
\hline & - & - & - & - & - & - & - & - & - & - & - & - & - & - \\
\hline 197,00 & 4,51 & 4,41 & 3,94 & 3,98 & 3,67 & 3,54 & 3,39 & 3,26 & 2,26 & 2,24 & 1,92 & 1,90 & 1,65 & $\mathrm{I}, 64$ \\
\hline 198,00 & 4,41 & 4,29 & 4,14 & 3,88 & 3,57 & 3,43 & 3,25 & 3,15 & 2,31 & 2,15 & 1,97 & 1,80 & 1,64 & 1,54 \\
\hline 19900 & $-\overline{439}$ & $-\overline{4.18}$ & $-\overline{3.98}$ & $-\overline{3.78}$ & $-\overline{3.47}$ & 3,34 & $\overline{3.22}$ & $-\overline{309}$ & $\bar{i}_{222}$ & $\overline{2}_{212}$ & 188 & -777 & -65 & $\overline{1.52}$ \\
\hline 200,00 & 4,08 & $-\overline{4.06}$ & $\overline{3}, 64$ & $\overline{3,67}$ & $\overline{3,30}$ & 3,24 & $\bar{s}_{3,11}$ & 3.02 & $\bar{z}_{2,17}$ & $\overline{2.11}$ & $\overline{1.87}$ & 1,75 & $\overline{1}, 60$ & $i, 52$ \\
\hline & & - & & - & & & & & & - & & & & - \\
\hline 201,00 & 3,79 & 3,71 & 3,48 & 3,34 & 3,02 & 2,94 & 2,79 & 2,74 & 2,01 & 1,90 & I,58 & I,57 & I,47 & 1,35 \\
\hline 202,00 & 3,47 & 3,43 & 3,09 & 3,10 & 2,76 & 2,72 & 2,61 & 2,55 & 1,85 & 1,80 & I,46 & I,48 & 1,30 & 1,29 \\
\hline & & - & - & - & - & & - & & & - & - & & & - \\
\hline 203,00 & 3,16 & 3,15 & 2,82 & 2,85 & 2,50 & 2,51 & 2,39 & 2,37 & I,64 & 1,69 & I,44 & 1,40 & 1,22 & 1,22 \\
\hline 204,00 & $\overline{2,83}$ & $\overline{2,82}$ & $\overline{2,59}$ & $\overline{2,56}$ & $\overline{2,23}$ & $\overline{2,26}$ & $\overline{2,16}$ & $\overline{2,13}$ & $\overline{1,57}$ & $\overline{1,53}$ & $\overline{i, 26}$ & $\overline{i, 28}$ & $\overline{1,13}$ & $\overline{1,12}$ \\
\hline & & - & - & - & - & & - & - & & - & - & 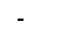 & & - \\
\hline 205,00 & 2,50 & 2,51 & 2,31 & 2,28 & 2,01 & 2,01 & 1,80 & 1,90 & 1,32 & 1,36 & I,II & 1,14 & 0,92 & 1,00 \\
\hline 206,00 & 2,17 & $\overline{2,21}$ & $\overline{1}, 95$ & 2,02 & $\overline{1,73}$ & $\overline{1}, 78$ & $\bar{i}, 6 \mid$ & 1,69 & $\overline{1}, 12$ & $i, 21$ & $\overline{0}, 98$ & $\overline{1}, 02$ & $\overline{0,84}$ & $\overline{0,90}$ \\
\hline & & - & - & - & 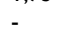 & & - & - & & - & - & & & - \\
\hline 207,00 & 1,92 & 2,01 & $|, 7|$ & I,84 & I,53 & 1,63 & 1,47 & I,55 & 0,98 & 1,09 & 0,80 & 0,91 & 0,73 & 0,81 \\
\hline & & - & - & - & & & & & مח & - & - & & & - \\
\hline 208,00 & 1,68 & $|, 8|$ & I,54 & 1,67 & 1,38 & I,48 & 1,33 & 1,42 & 0,92 & 1,00 & 0,75 & 0,84 & 0,61 & 0,76 \\
\hline 209,00 & $\begin{array}{l}, 51 \\
-\end{array}$ & $\begin{array}{l}, 67 \\
-\end{array}$ & $\begin{array}{l}1,43 \\
-\end{array}$ & $\begin{array}{l}\bar{i}, 56 \\
-\end{array}$ & 1,27 & 1,40 & $\begin{array}{l}1,22 \\
-\end{array}$ & 1,35 & 0,86 & $\begin{array}{l}0,96 \\
-\end{array}$ & $\begin{array}{l}0,70 \\
-\end{array}$ & 0,82 & 0,67 & $\begin{array}{l}0,76 \\
-\end{array}$ \\
\hline 210,00 & 1,40 & 1,54 & 1,32 & 1,48 & 1,25 & 1,36 & 1,18 & I,34 & 0,82 & 1,00 & 0,68 & 0,87 & 0,66 & 0,83 \\
\hline
\end{tabular}




\begin{tabular}{|c|c|c|c|c|c|c|c|c|c|c|c|c|c|c|}
\hline & & & & & & & & - & & & & & & - \\
\hline 211,00 & $\begin{array}{l}1,29 \\
-\end{array}$ & $\begin{array}{l}1,42 \\
-\end{array}$ & $\begin{array}{l}1,29 \\
-\end{array}$ & $\begin{array}{l}1,37 \\
-\end{array}$ & $\begin{array}{l}1,17 \\
-\end{array}$ & 1,28 & 1,14 & $\begin{array}{l}1,27 \\
-\end{array}$ & 0,85 & 0,96 & 0,72 & 0,85 & 0,69 & $\begin{array}{l}0,82 \\
-\end{array}$ \\
\hline $2 \mid 2,00$ & 1,25 & 1,32 & I,24 & 1,28 & 1,13 & 1,22 & 1,18 & 1,22 & 0,84 & 0,94 & 0,74 & 0,84 & 0,74 & 0,83 \\
\hline 213,00 & 1,25 & 1,24 & 1,24 & 1,22 & 1,14 & 1,17 & 1,14 & 1,19 & 0,91 & 0,93 & $\overline{0,81}$ & $\overline{0,85}$ & 0,79 & $\overline{0}, 85$ \\
\hline 21400 & 1,25 & 1,24 & 1,16 & 1,22 & 1,18 & 1,19 & 1.21 & 1,23 & 0.92 & 0,99 & 0,87 & 0.92 & 0,87 & $\overline{0.93}$ \\
\hline & - & - & - & - & - & - & & - & & - & - & & - & - \\
\hline 215,00 & 1,24 & 1,22 & 1,18 & 1,22 & 1,23 & 1,20 & 1,26 & 1,25 & 1,01 & 1,02 & 0,93 & 0,97 & 0,92 & 0,98 \\
\hline & $-i 23$ & i & i & in & - & - & 130 & - & - & - & - & - & - & - ind \\
\hline 216,00 & $\begin{array}{l}1,23 \\
-\end{array}$ & 1,21 & 1,24 & $\begin{array}{l}1,22 \\
-\end{array}$ & 1,20 & $\begin{array}{l}1,21 \\
-\end{array}$ & 1,30 & 1,27 & 1,08 & 1,06 & 1,00 & $\mathrm{I}, 0 \mathrm{I}$ & I,05 & 1,04 \\
\hline 217,00 & 1,25 & 1,22 & 1,30 & I,24 & 1,29 & 1,23 & 1,32 & 1,30 & 1,12 & 1,09 & 1,11 & 1,06 & 1,13 & 1,09 \\
\hline & - & - & - & - & - & & & - & & - & - & - & & - \\
\hline 218,00 & 1,26 & 1,22 & $\mid, 31$ & 1,24 & 1,28 & 1,24 & I,39 & I,33 & 1,20 & 1,12 & 1,19 & 1,10 & 1,23 & 1,14 \\
\hline 219,00 & 1,29 & 1,19 & 1,35 & 1,23 & 1,35 & $\overline{1,23}$ & $\overline{1}, 45$ & i,33 & 1,22 & 1,13 & 1,25 & 1,12 & $\overline{1,28}$ & 1,17 \\
\hline & 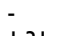 & - & & - & - & & & - & & & - & - & & - \\
\hline 220,00 & 1,31 & 1,22 & I,34 & 1,26 & 1,32 & 1,26 & I,47 & 1,38 & 1,26 & 1,18 & 1,28 & 1,18 & 1,36 & 1,23 \\
\hline 221,00 & 1,29 & 1,20 & 1,34 & 1,25 & 1,35 & 1,25 & $\mathrm{I}, 48$ & 1,38 & 1,32 & 1,19 & 1,31 & 1,19 & 1,40 & 1,25 \\
\hline 222,00 & $\overline{1.24}$ & $\overline{1,20}$ & $\bar{i}, 32$ & $\overline{1.26}$ & $\overline{1}, 35$ & $\overline{1.26}$ & $\overline{1.49}$ & $\overline{1,39}$ & $\overline{1.32}$ & $\overline{1.22}$ & $\overline{1,34}$ & $\overline{1.23}$ & $\overline{1,38}$ & $\overline{1.29}$ \\
\hline 223,00 & 1,25 & $|, 2|$ & 1,32 & I,28 & 1,34 & 1,28 & 1,50 & 1,43 & I,35 & 1,26 & 1,36 & 1,28 & I,43 & $\overline{1,35}$ \\
\hline 224,00 & 1,22 & 1,21 & 1,29 & 1,29 & 1,30 & 1,29 & 1,45 & 1,45 & 1,32 & 1,30 & 1,36 & 1,32 & I,43 & 1,40 \\
\hline 225,00 & 1,18 & 1,21 & 1,25 & 1,29 & 1,30 & 1,31 & 1,42 & 1,47 & 1,30 & 1,35 & $\overline{1,34}$ & 1,38 & 1,39 & I,45 \\
\hline & - & - & - & - & - & - & - & - & - & - & - & - & - & - \\
\hline 226,00 & 1,13 & $|, 2|$ & 1,22 & 1,30 & $\mid, 21$ & 1,32 & 1,37 & I,48 & 1,29 & 1,38 & 1,30 & $|, 4|$ & I,38 & 1,49 \\
\hline 227,00 & $\overline{1,09}$ & $\overline{1,18}$ & $\overline{1,19}$ & $\overline{1,27}$ & $\overline{1,21}$ & $\overline{1,29}$ & 1,33 & $\overline{1,45}$ & $\overline{1,27}$ & $\overline{1,37}$ & $\overline{1,29}$ & $\overline{|, 4|}$ & $\overline{1,38}$ & $\overline{1}, 48$ \\
\hline & - & - & - & - & - & - & & - & - & - & - & - & - & - \\
\hline 228,00 & 1,03 & 1,14 & 1,12 & 1,23 & 1,14 & 1,25 & I,27 & $\mid, 41$ & $\mid, 21$ & 1,34 & 1,24 & 1,39 & 1,30 & 1,46 \\
\hline & - & - & - & - & - & - & - & - & - & - & - & - & - & - \\
\hline 229,00 & 0,99 & $\mathrm{I}, 05$ & 1,06 & 1,13 & $\mathrm{I}, 08$ & 1,16 & 1,22 & $|, 3|$ & 1,14 & 1,27 & 1,20 & $|, 3|$ & 1,24 & 1,38 \\
\hline & - & - & - & - & - & - & - & - & - & - & - & - & & - \\
\hline 230,00 & 0,91 & 0,96 & 1,00 & 1,05 & 1,00 & I,07 & 1,16 & 1,22 & $\mathrm{I}, \mathrm{II}$ & 1,19 & 1,12 & $\mathrm{I}, 24$ & 1,18 & 1,30 \\
\hline $23 I, 00$ & $\overline{0}, 85$ & $\overline{0,88}$ & $\overline{0,91}$ & $\overline{0,97}$ & $\overline{0,94}$ & $\overline{1}, 00$ & $\bar{i}, 08$ & $\overline{1,13}$ & $\overline{1}, 02$ & $\overline{1,12}$ & $\overline{1}, 08$ & $\overline{1,16}$ & $\bar{i}, 10$ & $\overline{1,22}$ \\
\hline 232,00 & $\overline{0}, 78$ & 0,77 & 0,85 & $\overline{0}, 85$ & $\overline{0}, 87$ & 0,88 & 0,99 & 1,00 & 0,96 & 1,00 & $\overline{0}, 99$ & 1,04 & I,04 & 1,09 \\
\hline 233,00 & 0,71 & 0,66 & 0,78 & 0,74 & 0,80 & 0,76 & 0,89 & 0,87 & 0,89 & 0,88 & 0,91 & 0,91 & 0,98 & $\overline{0}, 95$ \\
\hline 234,00 & 0,66 & 0,55 & 0,71 & 0,61 & 0,72 & 0,63 & 0,82 & 0,72 & 0,81 & 0,73 & 0,84 & 0,76 & 0,91 & 0,80 \\
\hline 235,00 & $\overline{0,58}$ & $\overline{0}, 43$ & $\overline{0}, 63$ & $\overline{0,49}$ & $\overline{0,66}$ & $\overline{0,51}$ & $\overline{0,74}$ & $\overline{0,58}$ & 0,74 & 0,59 & $\overline{0,77}$ & $\overline{0,61}$ & $\overline{0,79}$ & $\overline{0}, 64$ \\
\hline 236,00 & $\overline{0}, 53$ & 0,31 & 0,59 & 0,36 & $\overline{0,59}$ & 0,37 & 0,68 & $\overline{0,43}$ & 0,69 & 0,43 & $\overline{0,74}$ & $\overline{0,45}$ & 0,76 & $\overline{0,48}$ \\
\hline & - & - & & - & - & $\therefore$ & & - & - & - & - & - & & - \\
\hline 237,00 & $\begin{array}{l}0,46 \\
-\end{array}$ & $\begin{array}{l}0,25 \\
-\end{array}$ & 0,53 & $\begin{array}{l}0,29 \\
-\end{array}$ & $\begin{array}{l}0,53 \\
-\end{array}$ & 0,31 & $\begin{array}{l}0,62 \\
-\end{array}$ & $\begin{array}{l}0,35 \\
-\end{array}$ & 0,63 & 0,36 & 0,67 & 0,38 & $\begin{array}{l}0,70 \\
-\end{array}$ & 0,40 \\
\hline 238,00 & 0,44 & 0,25 & 0,49 & 0,29 & 0,49 & 0,30 & 0,53 & 0,34 & 0,57 & 0,36 & 0,59 & 0,37 & 0,62 & 0,39 \\
\hline & - & - & & & - & & & - & & & - & - & - & - \\
\hline 239,00 & 0,38 & 0,20 & 0,42 & 0,23 & 0,42 & 0,25 & 0,50 & 0,28 & 0,51 & 0,30 & 0,55 & 0,31 & 0,54 & 0,33 \\
\hline & - & - & 00 & - & - & & - & - & - & & - & & & דיבי \\
\hline 240,00 & $\begin{array}{l}0,32 \\
-\end{array}$ & $\begin{array}{l}0,16 \\
-\end{array}$ & $\begin{array}{l}0,36 \\
-\end{array}$ & $\begin{array}{l}0,19 \\
-\end{array}$ & $\begin{array}{l}0,37 \\
-\end{array}$ & $\begin{array}{l}0,20 \\
-\end{array}$ & $\begin{array}{l}0,43 \\
-\end{array}$ & $\begin{array}{l}0,23 \\
-\end{array}$ & $\begin{array}{l}0,45 \\
-\end{array}$ & $\begin{array}{l}0,24 \\
-\end{array}$ & $\begin{array}{l}0,48 \\
-\end{array}$ & $\begin{array}{l}0,26 \\
-\end{array}$ & $\begin{array}{l}0,50 \\
-\end{array}$ & $\begin{array}{l}0,27 \\
-\end{array}$ \\
\hline $24 I, 00$ & 0,26 & 0,11 & 0,31 & 0,13 & 0,35 & 0,14 & 0,39 & 0,17 & 0,39 & 0,18 & 0,41 & 0,19 & 0,42 & 0,20 \\
\hline 242,00 & 0,24 & 0,05 & 0,29 & 0,07 & 0,28 & 0,08 & 0,30 & 0,09 & 0,31 & 0,10 & 0,37 & 0,11 & 0,35 & 0,12 \\
\hline & & - & & - & - & & - & - & & - & - & & & - \\
\hline 243,00 & 0,19 & 0,05 & 0,22 & 0,07 & 0,24 & 0,08 & 0,26 & 0,09 & 0,28 & 0,10 & 0,29 & 0,11 & 0,31 & 0,11 \\
\hline 244,00 & 0,18 & 0,04 & 0,19 & 0,06 & 0,21 & 0,06 & 0,25 & 0,07 & 0,23 & 0,08 & 0,26 & 0,09 & 0,26 & 0,09 \\
\hline 245,00 & 0,16 & 0,03 & 0,16 & 0,04 & 0,17 & 0,04 & 0,19 & $\overline{0,05}$ & 0,22 & 0,05 & $\overline{0}, 23$ & 0,06 & 0,23 & 0,06 \\
\hline 246,00 & 0,14 & 0,01 & 0,16 & 0,01 & 0,17 & 0,02 & 0,20 & 0,02 & 0,20 & 0,03 & 0,21 & 0,03 & 0,21 & 0,03 \\
\hline & $\overline{0}^{-}$ & 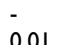 & $\overline{0}_{13}$ & 1 & $\overline{0}_{13}$ & & $\overline{0}_{017}$ & $\overline{8} 03$ & $\overline{0}_{016}$ & $\overline{8} 84$ & & $\overline{0} 04$ & & $\overline{0,04}$ \\
\hline $24 /, 00$ & - & 0,01 & -10 & 0,01 & - & 0,02 & -17 & 0,05 & .10 & $\begin{array}{l}0,04 \\
-\end{array}$ & $\begin{array}{l}0,17 \\
-\end{array}$ & -04 & .17 & - \\
\hline 248,00 & 0,08 & 0,02 & 0,08 & 0,02 & 0,13 & 0,01 & 0,12 & 0,00 & 0,15 & 0,01 & 0,15 & 0,02 & 0,15 & 0,02 \\
\hline 249,00 & 0,10 & 0,06 & 0,10 & 0,05 & 0,13 & 0,04 & 0,15 & 0,04 & 0,13 & 0,02 & 0,15 & 0,02 & 0,15 & 0,02 \\
\hline 250,00 & $\overline{0}, 09$ & 0,07 & $\overline{0}, 09$ & 0,06 & $\overline{0,11}$ & 0,06 & $\overline{0}, 10$ & 0,06 & $\overline{0,08}$ & 0,04 & $\overline{0}, 11$ & 0,04 & $\overline{0}, 11$ & 0,04 \\
\hline
\end{tabular}




\begin{tabular}{|c|c|c|c|c|c|c|c|c|c|c|c|c|c|c|}
\hline \multirow{3}{*}{$\begin{array}{l}\text { Temp. }\left({ }^{\circ} \mathrm{C}\right) \\
\text { Waveln. } \\
(\mathrm{nm})\end{array}$} & \multicolumn{14}{|c|}{ CTA5 } \\
\hline & \multicolumn{2}{|l|}{5} & \multicolumn{2}{|l|}{10} & \multicolumn{2}{|l|}{15} & \multicolumn{2}{|l|}{20} & \multicolumn{2}{|l|}{25} & \multicolumn{2}{|l|}{30} & \multicolumn{2}{|l|}{35} \\
\hline & Exp & Fit & Exp & Fit & $\begin{array}{l}\text { Exp } \\
.\end{array}$ & Fit & Exp & Fit & $\begin{array}{l}\text { Exp } \\
\end{array}$ & Fit & $\begin{array}{l}\text { Exp } \\
\text {. }\end{array}$ & Fit & Exp & Fit \\
\hline 190,00 & $\bar{i}, 82$ & 1,62 & 3,13 & $\overline{2,77}$ & 3,08 & 2,71 & $\overline{2,82}$ & 2,45 & 2,19 & 1,93 & $\overline{1,99}$ & 1,76 & $\overline{1,82}$ & 1,62 \\
\hline 191,00 & 1,83 & $\mathrm{I}, 74$ & 3,31 & 3,15 & 3,22 & 3,08 & 2,91 & 2,77 & 2,25 & 2,13 & 2,02 & 1,92 & 1,83 & I,74 \\
\hline 192,00 & 1,88 & I,88 & 3,48 & 3,51 & 3,40 & 3,42 & 3,03 & 3,06 & 2,34 & 2,34 & 2,09 & 2,09 & I,88 & I,88 \\
\hline 193,00 & 1,92 & 2,02 & 3,65 & 3,84 & 3,55 & 3,72 & 3,16 & 3,33 & 2,42 & 2,54 & 2,16 & 2,27 & 1,92 & 2,02 \\
\hline 194,00 & 1,97 & 2,14 & 3,84 & 4,06 & 3,69 & 3,92 & 3,27 & 3,52 & 2,51 & 2,71 & 2,24 & 2,42 & 1,97 & 2,14 \\
\hline 195,00 & 2,01 & 2,12 & 3,94 & $\begin{array}{l}- \\
4,09\end{array}$ & $\begin{array}{l}- \\
3,78\end{array}$ & $\begin{array}{l}- \\
3,92\end{array}$ & 3,38 & $\begin{array}{l}3,52 \\
-\end{array}$ & $\begin{array}{l}- \\
2,59\end{array}$ & 2,73 & 2,30 & $\begin{array}{l}- \\
2,42\end{array}$ & 2,01 & 2,12 \\
\hline 196,00 & $\begin{array}{l}2,05 \\
-\end{array}$ & $\begin{array}{l}2,05 \\
-\end{array}$ & $\begin{array}{l}4,01 \\
-\end{array}$ & $\begin{array}{l}4,02 \\
-\end{array}$ & $\begin{array}{l}3,82 \\
-\end{array}$ & $\begin{array}{l}3,83 \\
-\end{array}$ & $\begin{array}{l}3,45 \\
-\end{array}$ & $\begin{array}{l}3,43 \\
-\end{array}$ & $\begin{array}{l}2,63 \\
-\end{array}$ & $\begin{array}{l}2,67 \\
-\end{array}$ & $\begin{array}{l}2,35 \\
-\end{array}$ & $\begin{array}{l}2,36 \\
-\end{array}$ & $\begin{array}{l}2,05 \\
-\end{array}$ & $\begin{array}{l}2,05 \\
-\end{array}$ \\
\hline 197,00 & $\begin{array}{l}2,04 \\
-\end{array}$ & $\begin{array}{l}2,00 \\
-\end{array}$ & $\begin{array}{l}4,04 \\
-\end{array}$ & $\begin{array}{l}3,92 \\
-\end{array}$ & $\begin{array}{l}3,83 \\
-\end{array}$ & $\begin{array}{l}3,73 \\
-\end{array}$ & $\begin{array}{l}3,46 \\
-\end{array}$ & $\begin{array}{l}3,34 \\
-\end{array}$ & $\begin{array}{l}2,68 \\
-\end{array}$ & $\begin{array}{l}2,62 \\
-\end{array}$ & $\begin{array}{l}2,34 \\
-\end{array}$ & $\begin{array}{l}2,30 \\
-\end{array}$ & $\begin{array}{l}2,04 \\
-\end{array}$ & 2,00 \\
\hline 198,00 & $\begin{array}{l}2,02 \\
-\end{array}$ & $\begin{array}{l}\mathrm{I}, 87 \\
-\end{array}$ & $\begin{array}{l}3,97 \\
-\end{array}$ & $\begin{array}{l}3,78 \\
-\end{array}$ & $\begin{array}{l}3,79 \\
-\end{array}$ & $\begin{array}{l}3,60 \\
-\end{array}$ & $\begin{array}{l}3,40 \\
-\end{array}$ & $\begin{array}{l}3,21 \\
-\end{array}$ & $\begin{array}{l}2,67 \\
-\end{array}$ & $\begin{array}{l}2,49 \\
-\end{array}$ & $\begin{array}{l}2,31 \\
-\end{array}$ & $\begin{array}{l}2,16 \\
-\end{array}$ & $\begin{array}{l}2,02 \\
-\end{array}$ & $\begin{array}{l}1,87 \\
-\end{array}$ \\
\hline 199,00 & $\begin{array}{l}1,96 \\
-\end{array}$ & $\begin{array}{l}\mathrm{I}, 84 \\
-\end{array}$ & $\begin{array}{l}3,82 \\
-\end{array}$ & $\begin{array}{l}3,68 \\
-\end{array}$ & $\begin{array}{l}3,67 \\
-\end{array}$ & $\begin{array}{l}3,52 \\
-\end{array}$ & $\begin{array}{l}3,29 \\
-\end{array}$ & $\begin{array}{l}3,15 \\
-\end{array}$ & $\begin{array}{l}2,58 \\
-\end{array}$ & $\begin{array}{l}2,43 \\
-\end{array}$ & $\begin{array}{l}2,24 \\
-\end{array}$ & $\begin{array}{l}2,11 \\
-\end{array}$ & $\begin{array}{l}1,96 \\
-\end{array}$ & $\begin{array}{l}1,84 \\
-\end{array}$ \\
\hline 200,00 & $\begin{array}{l}1,86 \\
-\end{array}$ & $\begin{array}{l}1,80 \\
-\end{array}$ & $\begin{array}{l}3,63 \\
-\end{array}$ & $\begin{array}{l}3,58 \\
-\end{array}$ & $\begin{array}{l}3,49 \\
-\end{array}$ & $\begin{array}{l}3,43 \\
-\end{array}$ & $\begin{array}{l}3,11 \\
-\end{array}$ & $\begin{array}{l}3,06 \\
-\end{array}$ & $\begin{array}{l}2,43 \\
-\end{array}$ & $\begin{array}{l}2,36 \\
-\end{array}$ & $\begin{array}{l}2,11 \\
-\end{array}$ & $\begin{array}{l}2,05 \\
-\end{array}$ & $\begin{array}{l}1,86 \\
-\end{array}$ & $\begin{array}{l}1,80 \\
-\end{array}$ \\
\hline 201,00 & $\begin{array}{l}1,74 \\
-\end{array}$ & $\begin{array}{l}1,60 \\
-\end{array}$ & $\begin{array}{l}3,38 \\
-\end{array}$ & $\begin{array}{l}3,26 \\
-\end{array}$ & $\begin{array}{l}3,26 \\
-\end{array}$ & $\begin{array}{l}3,12 \\
-\end{array}$ & $\begin{array}{l}2,89 \\
-\end{array}$ & $\begin{array}{l}2,78 \\
-\end{array}$ & $\begin{array}{l}2,23 \\
-\end{array}$ & $\begin{array}{l}2,11 \\
-\end{array}$ & $\begin{array}{l}1,95 \\
-\end{array}$ & $\begin{array}{l}1,82 \\
-\end{array}$ & $\begin{array}{l}1,74 \\
-\end{array}$ & $\begin{array}{l}1,60 \\
-\end{array}$ \\
\hline 202,00 & $\begin{array}{l}1,58 \\
-\end{array}$ & $|, 5|$ & 3,07 & $\begin{array}{l}3,02 \\
-\end{array}$ & $\begin{array}{l}2,98 \\
-\end{array}$ & 2,90 & $\begin{array}{l}2,64 \\
-\end{array}$ & $\begin{array}{l}2,59 \\
-\end{array}$ & 2,03 & $\begin{array}{l}1,97 \\
-\end{array}$ & $\begin{array}{l}\text { I,77 } \\
-\end{array}$ & $\begin{array}{l}1,70 \\
-\end{array}$ & $\begin{array}{l}1,58 \\
-\end{array}$ & $\begin{array}{l}1,51 \\
-\end{array}$ \\
\hline 203,00 & 1,43 & I,43 & 2,78 & 2,78 & 2,69 & 2,68 & 2,39 & 2,40 & 1,82 & $\mathrm{I}, 83$ & 1,60 & 1,59 & I,43 & 1,43 \\
\hline 204,00 & $\begin{array}{l}1,27 \\
-\end{array}$ & $\begin{array}{l}1,31 \\
-\end{array}$ & $\begin{array}{l}2,49 \\
-\end{array}$ & $\begin{array}{l}2,50 \\
-\end{array}$ & $\begin{array}{l}2,40 \\
-\end{array}$ & $\begin{array}{l}2,42 \\
-\end{array}$ & $\begin{array}{l}2,14 \\
-\end{array}$ & $\begin{array}{l}2,17 \\
-\end{array}$ & $\begin{array}{l}1,63 \\
-\end{array}$ & $\begin{array}{l}1,66 \\
-\end{array}$ & $\begin{array}{l}1,41 \\
-\end{array}$ & $\begin{array}{l}\mathrm{I}, 44 \\
-\end{array}$ & $\begin{array}{l}1,27 \\
-\end{array}$ & 1,31 \\
\hline 205,00 & $\begin{array}{l}1,13 \\
-\end{array}$ & $\begin{array}{l}1,18 \\
-\end{array}$ & $\begin{array}{l}2,22 \\
-\end{array}$ & $\begin{array}{l}2,24 \\
-\end{array}$ & $\begin{array}{l}2,13 \\
-\end{array}$ & 2,17 & $\begin{array}{l}1,91 \\
-\end{array}$ & $\begin{array}{l}1,95 \\
-\end{array}$ & $\begin{array}{l}\mathrm{I}, 44 \\
-\end{array}$ & $\begin{array}{l}1,48 \\
-\end{array}$ & $\begin{array}{l}1,24 \\
-\end{array}$ & $\begin{array}{l}1,29 \\
-\end{array}$ & $\begin{array}{l}1,13 \\
-\end{array}$ & $\begin{array}{l}1,18 \\
-\end{array}$ \\
\hline 206,00 & $\begin{array}{l}1,00 \\
-\end{array}$ & $\begin{array}{l}1,06 \\
-\end{array}$ & $\begin{array}{l}1,95 \\
-\end{array}$ & $\begin{array}{l}1,99 \\
-\end{array}$ & $\begin{array}{l}1,87 \\
-\end{array}$ & $\begin{array}{l}1,93 \\
-\end{array}$ & 1,70 & 1,74 & 1,27 & 1,32 & 1,09 & 1,16 & 1,00 & 1,06 \\
\hline 207,00 & $\begin{array}{l}0,90 \\
-\end{array}$ & $\begin{array}{l}0,99 \\
-\end{array}$ & $\begin{array}{l}1,73 \\
-\end{array}$ & $\begin{array}{l}\mathrm{I}, 83 \\
-\end{array}$ & $\begin{array}{l}1,67 \\
-\end{array}$ & $\begin{array}{l}1,78 \\
-\end{array}$ & $\begin{array}{l}1,53 \\
-\end{array}$ & $\begin{array}{l}1,62 \\
-\end{array}$ & $\begin{array}{l}1,12 \\
-\end{array}$ & $\begin{array}{l}1,23 \\
-\end{array}$ & $\begin{array}{l}0,97 \\
-\end{array}$ & $\begin{array}{l}1,08 \\
-\end{array}$ & $\begin{array}{l}0,90 \\
-\end{array}$ & $\begin{array}{l}0,99 \\
-\end{array}$ \\
\hline 208,00 & $\begin{array}{l}0,82 \\
-\end{array}$ & $\begin{array}{l}0,92 \\
-\end{array}$ & $\begin{array}{l}\mathrm{I}, 54 \\
-\end{array}$ & $\begin{array}{l}1,66 \\
-\end{array}$ & $\begin{array}{l}1,49 \\
-\end{array}$ & $\begin{array}{l}1,64 \\
-\end{array}$ & $\begin{array}{l}1,37 \\
-\end{array}$ & $\begin{array}{l}1,49 \\
-\end{array}$ & $\begin{array}{l}1,00 \\
-\end{array}$ & $\begin{array}{l}1,13 \\
-\end{array}$ & $\begin{array}{l}0,89 \\
-\end{array}$ & $\begin{array}{l}1,00 \\
-\end{array}$ & $\begin{array}{l}0,82 \\
-\end{array}$ & $\begin{array}{l}0,92 \\
-\end{array}$ \\
\hline 209,00 & $\begin{array}{l}0,78 \\
-\end{array}$ & $\begin{array}{l}0,91 \\
-\end{array}$ & $\begin{array}{l}1,39 \\
-\end{array}$ & $\begin{array}{l}1,56 \\
-\end{array}$ & $\begin{array}{l}1,37 \\
-\end{array}$ & $\begin{array}{l}1,54 \\
-\end{array}$ & $\begin{array}{l}1,26 \\
-\end{array}$ & $\begin{array}{l}1,42 \\
-\end{array}$ & $\begin{array}{l}0,94 \\
-\end{array}$ & $\begin{array}{l}1,09 \\
-\end{array}$ & $\begin{array}{l}0,85 \\
-\end{array}$ & $\begin{array}{l}0,98 \\
-\end{array}$ & $\begin{array}{l}0,78 \\
-\end{array}$ & $\begin{array}{l}0,91 \\
-\end{array}$ \\
\hline 210,00 & $\begin{array}{l}0,78 \\
-\end{array}$ & $\begin{array}{l}0,98 \\
-\end{array}$ & $\begin{array}{l}1,30 \\
-\end{array}$ & $\begin{array}{l}\mathrm{I}, 46 \\
-\end{array}$ & $\begin{array}{l}1,30 \\
-\end{array}$ & $\begin{array}{l}\mathrm{I}, 48 \\
-\end{array}$ & $\begin{array}{l}1,20 \\
-\end{array}$ & $\begin{array}{l}1,40 \\
-\end{array}$ & $\begin{array}{l}0,92 \\
-\end{array}$ & $\begin{array}{l}1,11 \\
-\end{array}$ & $\begin{array}{l}0,84 \\
-\end{array}$ & $\begin{array}{l}1,03 \\
-\end{array}$ & $\begin{array}{l}0,78 \\
-\end{array}$ & $\begin{array}{l}0,98 \\
-\end{array}$ \\
\hline 211,00 & $\begin{array}{l}0,81 \\
-\end{array}$ & $\begin{array}{l}0,96 \\
-\end{array}$ & $\begin{array}{l}1,24 \\
-\end{array}$ & $\begin{array}{l}1,36 \\
-\end{array}$ & $\begin{array}{l}\mathrm{I}, 25 \\
-\end{array}$ & $\begin{array}{l}1,38 \\
-\end{array}$ & $\begin{array}{l}1,17 \\
-\end{array}$ & $\begin{array}{l}1,32 \\
-\end{array}$ & $\begin{array}{l}0,92 \\
-\end{array}$ & $\begin{array}{l}1,06 \\
-\end{array}$ & $\begin{array}{l}0,86 \\
-\end{array}$ & $\begin{array}{l}1,00 \\
-\end{array}$ & $\begin{array}{l}0,81 \\
-\end{array}$ & $\begin{array}{l}0,96 \\
-\end{array}$ \\
\hline 212,00 & $\begin{array}{l}0,86 \\
-\end{array}$ & $\begin{array}{l}0,96 \\
-\end{array}$ & $\begin{array}{l}1,20 \\
-\end{array}$ & $\begin{array}{l}1,27 \\
-\end{array}$ & $\begin{array}{l}1,24 \\
-\end{array}$ & $\begin{array}{l}1,30 \\
-\end{array}$ & $\begin{array}{l}1,18 \\
-\end{array}$ & $\begin{array}{l}1,26 \\
-\end{array}$ & $\begin{array}{l}0,94 \\
-\end{array}$ & $\begin{array}{l}\mathrm{I}, 04 \\
-\end{array}$ & $\begin{array}{l}0,89 \\
-\end{array}$ & $\begin{array}{l}0,99 \\
-\end{array}$ & $\begin{array}{l}0,86 \\
-\end{array}$ & $\begin{array}{l}0,96 \\
-\end{array}$ \\
\hline 213,00 & 0,93 & 0,97 & 1,19 & $\begin{array}{l}1,20 \\
-\end{array}$ & $\begin{array}{l}1,24 \\
-\end{array}$ & 1,25 & $\begin{array}{l}1,21 \\
-\end{array}$ & $\begin{array}{l}1,22 \\
-\end{array}$ & 0,98 & $\begin{array}{l}1,02 \\
-\end{array}$ & $\begin{array}{l}0,94 \\
-\end{array}$ & $\begin{array}{l}0,99 \\
-\end{array}$ & 0,93 & 0,97 \\
\hline 214,00 & 0,99 & $\mathrm{I}, 04$ & 1,19 & 1,21 & 1,26 & 1,26 & 1,24 & 1,25 & 1,03 & $\mathrm{I}, 07$ & 1,00 & 1,05 & 0,99 & 1,04 \\
\hline 215,00 & $\begin{array}{l}1,06 \\
-\end{array}$ & $\begin{array}{l}1,08 \\
-\end{array}$ & $\begin{array}{l}1,21 \\
-\end{array}$ & $\begin{array}{l}1,21 \\
-\end{array}$ & $\begin{array}{l}1,29 \\
-\end{array}$ & $\begin{array}{l}1,26 \\
-\end{array}$ & $\begin{array}{l}1,29 \\
-\end{array}$ & $\begin{array}{l}1,27 \\
-\end{array}$ & $\begin{array}{l}1,09 \\
-\end{array}$ & $\begin{array}{l}1,10 \\
-\end{array}$ & $\begin{array}{l}1,07 \\
-\end{array}$ & $\begin{array}{l}1,09 \\
-\end{array}$ & $\begin{array}{l}1,06 \\
-\end{array}$ & $\begin{array}{l}1,08 \\
-\end{array}$ \\
\hline 216,00 & 1,14 & 1,12 & 1,24 & $\mid, 21$ & 1,32 & 1,27 & 1,34 & 1,29 & 1,15 & 1,12 & 1,14 & 1,12 & 1,14 & 1,12 \\
\hline 217,00 & $\begin{array}{l}1,21 \\
-\end{array}$ & 1,17 & 1,28 & $\begin{array}{l}1,22 \\
-\end{array}$ & $\begin{array}{l}1,35 \\
-\end{array}$ & 1,30 & $\begin{array}{l}1,39 \\
-\end{array}$ & $\begin{array}{l}1,33 \\
-\end{array}$ & 1,21 & $\begin{array}{l}1,16 \\
-\end{array}$ & $\begin{array}{l}1,21 \\
-\end{array}$ & 1,16 & 1,21 & $\begin{array}{l}1,17 \\
-\end{array}$ \\
\hline 218,00 & 1,28 & $\mid, 21$ & 1,30 & 1,23 & 1,37 & $|, 3|$ & $\mathrm{I}, 44$ & 1,35 & 1,26 & 1,18 & 1,27 & 1,20 & 1,28 & $|, 2|$ \\
\hline 219,00 & $\bar{i}, 35$ & $\overline{1,23}$ & $\overline{1,32}$ & $\overline{l, 2 \mid}$ & $\overline{1,40}$ & $\overline{1,29}$ & $\overline{1,48}$ & $\overline{1,34}$ & $\overline{1,30}$ & $\overline{1,18}$ & $\overline{1,32}$ & $\overline{1,20}$ & $\overline{1,35}$ & $\overline{1,23}$ \\
\hline & - & - & - & - & - & - & - & - & - & - & - & - & - & - \\
\hline 220,00 & 1,40 & 1,28 & 1,33 & 1,23 & $\mid, 41$ & 1,33 & I,49 & 1,39 & 1,33 & 1,22 & 1,36 & 1,25 & 1,40 & 1,28 \\
\hline 221,00 & $\begin{array}{l}\overline{1}, 43 \\
-\end{array}$ & $\begin{array}{l}\overline{1}, 29 \\
-\end{array}$ & $\begin{array}{l}1,32 \\
-\end{array}$ & $\begin{array}{l}\overline{1}, 22 \\
\overline{-}\end{array}$ & $\begin{array}{l}\overline{1}, 42 \\
-\end{array}$ & $\begin{array}{l}1,32 \\
-\end{array}$ & $\begin{array}{l}1,50 \\
-\end{array}$ & $\begin{array}{l}\overline{1}, 39 \\
-\end{array}$ & $\begin{array}{l}\mathrm{I}, 34 \\
-\end{array}$ & $\overline{1,22}$ & $\begin{array}{l}\bar{i}, 39 \\
-\end{array}$ & $\begin{array}{l}1,26 \\
-\end{array}$ & 1,43 & $\begin{array}{l}\overline{1}, 29 \\
-\end{array}$ \\
\hline 222,00 & 1,45 & 1,32 & 1,30 & 1,23 & 1,41 & 1,33 & 1,50 & $\mid, 41$ & 1,35 & $\begin{array}{l}1,24 \\
-\end{array}$ & 1,40 & 1,28 & 1,45 & 1,32 \\
\hline 223,00 & $\begin{array}{l}1,45 \\
-\end{array}$ & I,37 & $\begin{array}{l}1,29 \\
-\end{array}$ & 1,26 & 1,40 & 1,36 & $\begin{array}{l}1,49 \\
-\end{array}$ & 1,45 & $\begin{array}{l}1,35 \\
-\end{array}$ & 1,28 & $\begin{array}{l}1,39 \\
-\end{array}$ & $\begin{array}{l}1,32 \\
-\end{array}$ & 1,45 & 1,37 \\
\hline 224,00 & 1,44 & $\mathrm{I}, 40$ & 1,26 & 1,26 & 1,37 & 1,37 & $\mathrm{I}, 47$ & $\mathrm{I}, 46$ & 1,33 & 1,30 & 1,38 & $\mathrm{I}, 34$ & $\mathrm{I}, 44$ & 1,40 \\
\hline 225,00 & $\overline{i, 41}$ & $\mathrm{I}, 44$ & 1,23 & $\overline{1,27}$ & 1,34 & 1,37 & 1,43 & 1,48 & 1,31 & $\overline{1,33}$ & $\overline{1,36}$ & 1,38 & $\mid, 41$ & $\bar{i}, 44$ \\
\hline 226,00 & 1,38 & 1,47 & 1,19 & 1,27 & 1,30 & 1,38 & 1,39 & 1,49 & 1,27 & 1,35 & 1,31 & $\mathrm{I}, 40$ & 1,38 & i,47 \\
\hline
\end{tabular}




\begin{tabular}{|c|c|c|c|c|c|c|c|c|c|c|c|c|c|c|}
\hline & - & - & - & - & - & - & - & - & - & - & - & - & - & - \\
\hline \multirow[t]{2}{*}{227,00} & 1,33 & $\mathrm{I}, 45$ & 1,14 & 1,24 & $\mathrm{I}, 24$ & 1,35 & 1,33 & 1,46 & 1,22 & 1,33 & 1,26 & I,38 & 1,33 & $\mathrm{I}, 45$ \\
\hline & - & - & - & - & - & - & - & - & - & - & - & - & - & - \\
\hline \multirow[t]{2}{*}{228,00} & 1,27 & 1,42 & 1,09 & 1,20 & 1,18 & 1,30 & 1,28 & $|, 4|$ & 1,17 & 1,30 & $|, 2|$ & I,35 & 1,27 & 1,42 \\
\hline & - & - & - & - & - & - & - & - & - & - & - & - & - & - \\
\hline \multirow[t]{2}{*}{229,00} & $|, 2|$ & 1,32 & 1,03 & I,II & 1,12 & 1,20 & $|, 2|$ & 1,30 & 1,11 & $|, 2|$ & 1,15 & I, 25 & $|, 2|$ & I,32 \\
\hline & - & - & - & - & - & - & - & - & - & - & - & - & - & - \\
\hline \multirow[t]{2}{*}{230,00} & 1,15 & 1,24 & 0,97 & 1,02 & 1,05 & $\mathrm{I}, \mathrm{II}$ & 1,14 & $\mid, 21$ & 1,04 & 1,13 & 1,08 & 1,17 & 1,15 & 1,24 \\
\hline & - & - & - & - & - & - & - & - & - & - & - & - & - & - \\
\hline \multirow[t]{2}{*}{231,00} & I,07 & 1,16 & 0,91 & 0,94 & 0,98 & 1,02 & I,07 & 1,12 & 0,98 & 1,05 & $|, 0|$ & 1,09 & I,07 & 1,16 \\
\hline & - & - & - & - & - & - & - & - & - & - & - & - & - & - \\
\hline \multirow[t]{2}{*}{232,00} & 1,00 & $\mathrm{I}, 04$ & 0,84 & 0,84 & 0,91 & 0,91 & 0,99 & 0,99 & 0,91 & 0,94 & 0,93 & 0,98 & 1,00 & I,04 \\
\hline & - & - & - & - & - & - & - & - & - & - & - & - & - & - \\
\hline \multirow[t]{2}{*}{233,00} & 0,92 & 0,91 & 0,77 & 0,72 & 0,84 & 0,78 & 0,91 & 0,86 & 0,84 & 0,82 & 0,86 & 0,85 & 0,92 & 0,91 \\
\hline & - & - & - & - & - & - & - & - & - & - & - & - & - & - \\
\hline \multirow[t]{2}{*}{234,00} & 0,85 & 0,76 & 0,70 & 0,60 & 0,76 & 0,65 & 0,84 & 0,72 & 0,77 & 0,68 & 0,79 & 0,71 & 0,85 & 0,76 \\
\hline & - & - & - & - & - & - & - & - & - & - & - & - & - & - \\
\hline \multirow[t]{2}{*}{235,00} & 0,77 & 0,61 & 0,64 & 0,48 & 0,69 & 0,52 & 0,76 & 0,58 & 0,70 & 0,55 & 0,72 & 0,57 & 0,77 & 0,61 \\
\hline & - & - & - & - & - & - & - & - & - & - & - & - & - & - \\
\hline \multirow[t]{2}{*}{236,00} & 0,70 & 0,45 & 0,58 & 0,35 & 0,62 & 0,38 & 0,69 & 0,43 & 0,63 & 0,40 & 0,66 & 0,42 & 0,70 & 0,45 \\
\hline & - & - & - & - & - & - & - & - & - & - & - & - & - & - \\
\hline \multirow[t]{2}{*}{237,00} & 0,64 & 0,38 & 0,52 & 0,29 & 0,56 & 0,32 & 0,63 & 0,35 & 0,57 & 0,33 & 0,59 & 0,35 & 0,64 & 0,38 \\
\hline & - & - & - & - & - & - & - & - & - & - & - & - & - & - \\
\hline \multirow[t]{2}{*}{238,00} & 0,57 & 0,37 & 0,47 & 0,28 & 0,50 & 0,30 & 0,56 & 0,34 & 0,50 & 0,32 & 0,52 & 0,34 & 0,57 & 0,37 \\
\hline & - & - & - & - & - & - & - & - & - & - & - & - & - & - \\
\hline \multirow[t]{2}{*}{239,00} & 0,51 & 0,31 & 0,42 & 0,22 & 0,44 & 0,24 & 0,50 & 0,28 & 0,45 & 0,27 & 0,46 & 0,28 & 0,51 & 0,31 \\
\hline & - & - & - & - & - & - & - & - & - & - & - & - & - & - \\
\hline \multirow[t]{2}{*}{240,00} & 0,45 & 0,25 & 0,36 & 0,18 & 0,39 & 0,19 & 0,44 & 0,22 & 0,39 & 0,22 & 0,40 & 0,23 & 0,45 & 0,25 \\
\hline & - & - & - & - & - & - & - & - & - & - & - & - & - & - \\
\hline \multirow[t]{2}{*}{241,00} & 0,39 & 0,19 & 0,32 & 0,12 & 0,35 & 0,14 & 0,39 & 0,16 & 0,34 & 0,16 & 0,35 & 0,17 & 0,39 & 0,19 \\
\hline & - & - & - & - & - & - & - & - & - & - & - & - & - & - \\
\hline \multirow[t]{2}{*}{242,00} & 0,33 & 0,11 & 0,28 & 0,06 & 0,31 & 0,07 & 0,35 & 0,09 & 0,29 & 0,09 & 0,31 & 0,10 & 0,33 & 0,11 \\
\hline & - & - & - & - & - & - & - & - & - & - & - & - & - & - \\
\hline \multirow[t]{2}{*}{243,00} & 0,28 & 0,10 & 0,24 & 0,06 & 0,26 & 0,07 & 0,30 & 0,09 & 0,25 & 0,09 & 0,26 & 0,09 & 0,28 & 0,10 \\
\hline & - & - & - & - & - & - & - & - & - & - & - & - & - & - \\
\hline \multirow[t]{2}{*}{244,00} & 0,25 & 0,08 & 0,21 & 0,06 & 0,24 & 0,06 & 0,27 & 0,07 & 0,21 & 0,07 & 0,23 & 0,07 & 0,25 & 0,08 \\
\hline & - & - & - & - & - & - & - & - & - & - & - & - & - & - \\
\hline \multirow[t]{2}{*}{245,00} & 0,21 & 0,05 & 0,18 & 0,03 & 0,20 & 0,04 & 0,23 & 0,04 & 0,18 & 0,04 & 0,19 & 0,04 & 0,21 & 0,05 \\
\hline & - & - & - & - & - & - & - & - & - & - & - & - & - & - \\
\hline 246,00 & 0,18 & 0,03 & 0,15 & 0,01 & 0,17 & 0,02 & 0,20 & 0,02 & 0,15 & 0,02 & 0,16 & 0,02 & 0,18 & 0,03 \\
\hline & - & - & - & - & - & - & - & - & - & - & - & - & - & - \\
\hline 247,00 & 0,15 & 0,04 & 0,13 & 0,01 & 0,15 & 0,02 & 0,18 & 0,02 & 0,13 & 0,03 & 0,14 & 0,03 & 0,15 & 0,04 \\
\hline & - & - & - & & - & & - & & - & & - & - & - & - \\
\hline 248,00 & $\begin{array}{l}0,14 \\
-\end{array}$ & 0,01 & $\begin{array}{l}0,12 \\
-\end{array}$ & 0,02 & $\begin{array}{l}0,13 \\
-\end{array}$ & 0,01 & $\begin{array}{l}0,16 \\
-\end{array}$ & 0,01 & $\begin{array}{l}0,11 \\
-\end{array}$ & 0,00 & $\begin{array}{l}0,12 \\
-\end{array}$ & 0,01 & $\begin{array}{l}0,14 \\
-\end{array}$ & 0,01 \\
\hline 249,00 & $\begin{array}{l}0,12 \\
-\end{array}$ & 0,03 & $\begin{array}{l}0,11 \\
-\end{array}$ & 0,05 & $\begin{array}{l}0,12 \\
-\end{array}$ & 0,05 & $\begin{array}{l}0,15 \\
-\end{array}$ & 0,05 & 0,09 & 0,03 & $\begin{array}{l}0,10 \\
-\end{array}$ & 0,03 & $\begin{array}{l}0,12 \\
-\end{array}$ & 0,03 \\
\hline 250,00 & 0,11 & 0,05 & 0,11 & 0,07 & 0,11 & 0,07 & 0,13 & 0,06 & 0,08 & 0,05 & 0,09 & 0,05 & 0,11 & 0,05 \\
\hline
\end{tabular}




\subsubsection{ABBREVIATIONS}

AA: amino acid

A: absorbance

BMP: bone morphogenic protein

CA: contact angle

CD: circular dichroism

CT: computed tomography

CTA: Cholesteryl triethylenglykol azide

DLS: Dynamic light scattering

DSC: differential scanning calorimetry

ECM: extracellular matrix

ELbcR: elastin-like block co-recombinamer

ELP: elastin-like protein

ELR: elastin-like recombinamers

$E L R^{C T A x}$ : ELR modified with $x$ CTA groups

FGF: fibroblast growth factor

FN: Fibronectin

FP: fluorescent protein

FRET: Förster resonance energy transfer

HASMCs: human aortic smooth muscle cells

hMSCs: human mesenchymal stem cells 
HPLC: high-performance liquid cromatography

HUVECs: human umbilical vein endothelial cells

IGZ: in-gel zymography

ITC: inverse transition cycle

ITT: inverse temperature transition

IWZ: in-well zymography

LCST: lower critical solution temperature

MALDI-TOF: matrix-assisted laser desorption/ionization-time-of-flight

MCST: multi-slice computed tomography

MMP: matrix metalloproteinase

MQ: milliQ ultra-pure water

Mw: molecular weight

NMR: nuclear magnetic resonance

PA: plasminogen activator

PBS: phosphate buffered saline

$p K_{a}$ : dissociation constant of acids

$p K_{b}$ : dissociation constant of bases

PTH: parathyroid hormone

ROI: region of interest

SEM: scanning electron microscopy

SDS-PAGE: sodium dodecyl sulfate-polyacrylamide gel electrophoresis

SELR: silk-elastin-like recombinamers 
TEM: transmission electron microscopy

TGF-b: transforming growth factor beta

TIMP: tissue inhibitors of metalloproteases

TNF $\alpha$ : tumor necrosis factor $\alpha$

tPA: tissue plasminogen activator

Try: Trypsin

$T_{t}$ : transition temperature

uPA: urokinase plasminogen aktivator

$\varepsilon$ : extinction coefficient 


\subsubsection{TABLE OF STANDARD AMINO ACID ABBREVIATIONS}

\begin{tabular}{|c|c|c|}
\hline Amino acid & 3-letter code & I-letter code \\
\hline Alanine & Ala & A \\
\hline Arginine & Arg & R \\
\hline Asparagine & Asn & N \\
\hline Aspartic acid & Asp & D \\
\hline Cysteine & Cys & C \\
\hline Glutamic acid & Glu & E \\
\hline Glutamine & Gln & Q \\
\hline Glycine & Gly & G \\
\hline Histidine & His & H \\
\hline Isoleucine & lle & I \\
\hline Leucine & Leu & L \\
\hline Lysine & Lys & K \\
\hline Methionine & Met & M \\
\hline Phenylalanine & Phe & F \\
\hline Proline & Pro & P \\
\hline Serine & Ser & S \\
\hline Threonine & Thr & T \\
\hline Tryptophan & Trp & W \\
\hline Tyrosine & Tyr & Y \\
\hline Valine & Val & \\
\hline & & V \\
\hline
\end{tabular}




\section{List of Tables}

Table I: Zymography used for clinical diagnostics and related zymogenic substrates. 64

Table 2: Reagents employed and corresponding suppliers. 73

Table 3: Restriction enzymes used in this work and corresponding suppliers. 75

Table 4: Other reagents used for this work. 79

Table 5:Bacterial strains used for this work 79

Table 6: Composition and molecular weight of the ELbcRs and ELRs employed. 81

Table 7: Relation of linear DNA migration with the bromophenol blue (BFB). 83

Table 8: Optimum percentage of Acrylamide/Bisacrylamide according to protein size. 90

Table 9: Composition of the resolving and stacking gel in a gel I5\%T 91

Table 10: Amino acid sequence of the different building blocks employed in this work.

Table I I: Theoretical and experimental molecularweight of ELRs and the corresponding amino acid sequence, obtained by amino acid quantification. $1 / 6$

Table I2: Results of characterization of ELR modification with methacrylate groups (MA) by NMR and MALDI-TOF. Spectra are shown below.

Table 13: Linearity of ELR-Calibration curve at different wavelengths of absorbance. I 28

Table I4: Overview of NMR-signals and the related conversion of functional groups. I 39

Table 15: Comparison of viscosities obtained from flow measurements at a shear rate of $60 \mathrm{~s}^{-1}$ (Exp.) using parameters derived from the Bingham and Herschel-Bulkley models. 153

Table 16: Overview of NMR signals and the related conversion of functional groups.P I serves as internal reference, representing - $\mathrm{CH} 3$ and $-\mathrm{CH}$ - protons of amino acid residues $(G, E, L, K, M, P, S, V)$; $P 2$ represents $H 2 C-O(C=0) O$ - of the $B C N$ linker; $P 3$ represents $\mathrm{C}=\mathrm{C}-\mathrm{H}$ proton of the cholesteryl residue; $\mathrm{P} 4$ is an isolated signal from the ETERNEON fluorophore (structure not known).Complete spectra are provided as Supplementary Information. 175

Table 17: Degree of modification, calculated from the mass analysis. 177

Table 18: Datapoints of BeStSel algorythm fit to CD data. III 


\section{List of Figures}

Figure I: a) Structural changes of VPGVG oligopeptide below and above their LCST. b)

Water in clathrate-type structured state. c) Type I/ 8 -turn in the VPGVG

pentapeptides $^{1 / 9}$.

Figure 2: Dependence of Tt on the guest residue in poly penta-peptide of the structure poly[fv (VPGVG), $f x$ (VPGXG)]. fv and $f x$ represent the mole fractions of the respective co-monomers $(f v+f x=I)^{127}$.

Figure 3: Tt as a function of the number of pentapeptides for three different types of ELRs at $25 \mu \mathrm{M}$ in PBS. Reproduced from Meyer et. al. ${ }^{128}$.

Figure 4: Effect of Hofmeister anions on the transition temperature of ELRs.

Figure 5: Condensed summary of recombinant gene oligomerization in a vector with 2 restriction enzymes. Adapted from ${ }^{142}$.

Figure 6: Illustration of the recognition sequences of Ear I and Sap I type IIS endonucleases.

Figure 7: Ligation-based DNA assembly using restriction endonucleases. a) DNA assembly using conventional type II endonucleases requires a type II recognition site at the junction between the two starting pieces of DNA. The junction remains in the product, precluding the construction of arbitrary DNA sequences. b) DNA assembly using type IIS endonucleases, which allow the generation of overhangs of any arbitrary sequence, and thus sequence-independent construction. Reproduced from ${ }^{130}$. 28

Figure 8: The diversity of ELR structures and their sequential origin. 38

Figure 9: Schematic illustration of the poly core model for cholesteryl stabilized particles. Reproduced from ${ }^{230}$. 42 Figure 10: Synonyms of peptidases and the differences in endo- and exopeptidases. The names in the box are commonly used terms for proteolytic enzymes. The differences in endo- and exopeptidases are, that endopeptidases preferentially act away from protein termini and exopeptidases act close to the $\mathrm{C}$ - or $\mathrm{N}$-terminus (as indicated by the triangular shades) ${ }^{235}$. 46

Figure I I: Cascade of peptidase pro-form activations by peptidase mediated cleavage ${ }^{24 !}$. 48 
Figure 12: Peptidases expressed by cell types and their relation to tumor cells.

Reproduced from ${ }^{338}$. 60

Figure 13: Scheme of the pDrive cloning vector with mapped restriction sites. 77

Figure 14: Scheme of p 7expression vector based on Navagen's pET-25b(+) vector._78

Figure 15: DNA sequence of the 204 base pairs (white region) and the corresponding amino acid sequence.

Figure 16: SDS-PAGE of ELRs to determine molecular weights. $M=$ marker, $I=E L R$ -

Control, $2=E L R-E l a, 3=E L R-F N, 4=E L R-E l a+F N$

Figure 17: Mass spectra obtained by MALDI-TOF. The left column presents the pure ELRs and the right column shows mass after modification with methacrylic anhydride.

Figure I8: NMR spectra of modified and unmodified ELRs used in this study.

Methacrylate signals are isolated singuletts at 5.25 and 5.60 ppm.

Figure 19: Design of recombinant protein for protease detection and mechanism of zymographic detection. The first step is the genetic design of the ELR consisting of nonstaining, stainable and functional, and degradable region. The next step is the introduction of cross-linking features on free- lysins, which allow for cross-linking to the substrate and disable Coomassie BB detection of modified lysins. The ELR-substrate complex is than incubated with proteolytic enzymes and cleaved parts are washed off and the remaining gel is stained with Coomassie $B B$, and the efficiency of cleavage towards the presented group is monitored. 121

Figure 20: ELR-Zymogramms: On the left developed gels after development and on the right, densitometry data obtained from the degradation of ELR-Ela+FN with different concentrations of trypsin (GIBCO) ranging from $0.3 \mathrm{nM}$ to $3 \mu \mathrm{M}$. 123

Figure 21: Comparison of ELR zymograms with two different types of trypsin and their densitometry profiles (right) (Tryl corresponds to Corning® and Tryll to GIBCO® Trypsin). 124

Figure 22: ELR zymogramms of the degradation of ELR-Control and ELR-Ela+FN with different concentrations of MMP 2 and 9. 125

Figure 23: Schematic description of the hypothesis for the novel in-well zymography (IWZ) method. 
Figure 24: Optimization of parameters for the screening method. A: Optimization of Acrylamide concentration. B: Optimization of gel volume of $0.1 \%$ ELR-Ela+FN $8 \%$ acrylamide gels. C: Optimization of thewavelength of absorbance with different gel volumes. D: Absorbance image collected from wells of different ELR-Ela+FN concentrations, increasing from left to right, first well contains no ELR. E: plot of ELR concentration over absorbance at 4 different absorbance wavelength.

Figure 25: Comparison of ELR-Control and ELR-Ela+FN 40h of incubation after staining and destaining. 129

Figure 26:: Screening of MMPs I-I I with four different ELRs collected over time. _ 130

Figure 27: Screening of MMPs I 2-20 with four different ELRs collected over time._ 132

Figure 28: 'H- NMR Spectra of CTAO. 140

Figure 29: ' $H$ - NMR Spectra of CTAI. 140

Figure 30: 'H- NMR Spectra of CTA5.

Figure 3 I: Results of MALDI-TOF for VKV,CTAO, CTA I and CTA5.

Figure 32: Reaction of (VKV) with BCN succinimide results in (CTAO), and after copper-free addition of cholesteryl-TEG-azide CTAI or CTA5 are obtained respectively.

Figure 33: Determination of CMC by surface tension measurements revealing a different behavior for CTA5 which is most prominent at low temperatrues. A) at $5^{\circ} \mathrm{C}, \mathrm{B}$ ) at $\left.15^{\circ} \mathrm{C}, \mathrm{C}\right)$ at $35^{\circ} \mathrm{C}$ and $\left.\mathrm{D}\right)$ the resulting $\mathrm{CMCs}$. Error bars represent $S D$.

Figure 34: Intensity distributions of ELRs at different temperatures. 146

Figure 35: Dynamic light scattering measurements for CTAx at a concentration of 15 $\mu \mathrm{M}$ and different temperatures. The addition of cholesteryl groups leads to less thermosensitive particles which are more negatively charged. A) hydrodynamic radii, B) Zeta potential. Error bars represent SD.

Figure 36: $C D$ raw data before BeStSel fitting. 148

Figure 37: Cloud point determination of modified ELRs. Left heating, right cooling _ 149 Figure 38: Results from circular dichroism, deconvoluted using the BeStSel algorithm, showing the relative distribution of distorted helix $(\bullet)$, relaxed $(\mathbf{\Delta})$ or right-twisted $(\boldsymbol{\nabla})$ anti-parallel beta-sheets, parallel beta sheets ( ) or turns (०). For VKV and CTAO and $\Delta$ appear at temperatures between $20-25^{\circ} \mathrm{C}$ which is in correlation with 
observed LCST transitions, surprisingly the same is as well observed in CTA5 at temperatrues below $10^{\circ} \mathrm{C}$.

Figure 39: The accumulated percentage of secondary structures by CD defines the total order of proteins in solution. The missing percentage corresponds to random, or structural components unrecognized by the used algorithm. 152

Figure 40: Stress over shear rate raw data with Herschel Bulkley Fit (thin line). 154

Figure 4I: Stress over shear rate raw data with Bingham Fit (thin line). 155

Figure 42: Rheological characterization of samples under gelling conditions $(0.75 \mathrm{mM})$.

A) Oscillatory measurement, the evolution of G' with temperature. B) Flow measurement, values displayed for a shear rate of $60 \mathrm{~s}^{-1}$ (complete dataset available as supporting information). 155

Figure 43: Contact-angle measurements for solvent-cast CTA samples at different temperatures. Representative images of drops correspond to contact angles for the corresponding dashed lines.

Figure 44: Phasediagram for CTA5,derived from CD data, Absorbance and rheology.

Changes in the secondary structure are in correlation with observed solubility in water. For absorbance CTAO curve was plotted due to the absence of cloudpoint in CTA5 even though secondary structural changes of CTAO and CTA5 above $20^{\circ} \mathrm{C}$ are in accordance.

Figure 45: TEM images of CTA samples (I $25 \mu \mathrm{M})$ incubated at $4^{\circ} \mathrm{C}$ for $24 \mathrm{~h}, 3,7$ or 28 days. 160

Figure 46: SEM images of CTA samples $(0.25 \mathrm{mM})$ incubated at $4^{\circ} \mathrm{C}$ for $24 \mathrm{~h}, 72 \mathrm{~h}, 7$ days or 28 days. Scale bar: $5 \mu \mathrm{m}$. 161

Figure 47: Top: SEM images of CTA samples (I.25 mM)d at $4^{\circ} \mathrm{C}$ for $24 \mathrm{~h}, 72 \mathrm{~h}, 7$ days or 28 days. Scale bar: $10 \mu \mathrm{m}$. Bottom: Pore-size analysis of an area of $3000 \mu \mathrm{m}^{2}$.

Figure 48: TEM images of CTA samples $(/ 25 \mu M)$ incubated at $37^{\circ} \mathrm{C}$ for $24 \mathrm{~h}, 3,7$ or 28 days. 164

Figure 49: SEM images of CTA samples $(0.25 \mathrm{mM})$ incubated at $37^{\circ} \mathrm{C}$ for $24 \mathrm{~h}, 72 \mathrm{~h}$, 7 days or 28 days. Scale bar: $5 \mu \mathrm{m}$. 165 
Figure 50: Top: SEM images of CTA samples $(1.25 \mathrm{mM})$ incubated at $37^{\circ} \mathrm{C}$ for $24 \mathrm{~h}$, 72 h, 7 days or 28 days, Scale bar: $10 \mu \mathrm{m}$. Bottom: Pore-size analysis of an area of $3000 \mu m^{2}$.

Figure 5 I: Signals of Eterneon and Cholesterol in NMR spectras of CTAx*. Signals were normalized to PI (for complete Spectra refer to Figure 28 to Figure 30). 174

Figure 52: MALDI-TOF Spectra of modified ELRs. 176

Figure 53: Volume Intensities of cholesteryl ELRs in PBS at different temperatures.

Graphs show an overlay of three individual measurements. Black arrowsmark thesize shiftof distribution.

Figure 54: Correlation function of CTAO, I, and 5 at 4 and $37^{\circ} \mathrm{C}$. Most prominent is the left shift of CTA I and 5 at $37^{\circ} \mathrm{C}$ indicating the presence of smaller aggregates/particles (CTA3 was removed for better visibility).

Figure 55: Cloudpoint determination of ELRs. The cholesteryl-modified ELRs show markedly reduced to no absorbance above the LCST of CTAO.

Figure 56: Metabolic activity of cells incubated with ELRs and ELR-CTA at 375 and 750 nM. A) HUVEC cells; and B) HASMC. P values refer to cells cultured on TCPS (* $P<0.05$;** $P<0.01$; *** $P<0.001$ ).

Figure 57: Flow Cytometry forward vs side scatter and gated single HASMC cell population (A) used for quantification of fluorescence.

Figure 58: Flow Cytometry forward vs side scatter and gated single HUVEC cell population (A) used for quantification of fluorescence.

Figure 59: Forward scatter intensity (FS INT) vs. fluorescence (FL3 INT) of HASMC cells treated with CTA samples.

Figure 60: Forward scatter intensity (FS INT) vs. fluorescence (FL3 INT) of HUVEC cells treated with CTA samples, obtained by flow cytometry. A) untreated HUVEC cells; B) HUVEC cells treated with CTAO, C) HUVEC cells treated with CTA I, D) HUVEC cells treated with CTA3, E) HUVEC cells treated with CTA5, F) Fluorescence fraction of HUVEC and HASMC cells. See the supporting information for HASMC dot plots. $P$ values refer to cells treated with CTAO $(* P<0.05 ; * * P<0.01)$ 184

Figure 6 I: Confocal images of HUVEC $(A)$ and HASMCs (B) after incubation with CTAx samples. From left to right: texas red (displayed color was changed to magenta for 
better visibility of small particles), phase, and merge. Top to bottom: CTA0, CTA I, CTA3 and CTA5. The scale bars represent $7.5 \mu \mathrm{m}$.

Figure 62: Z-slicing of HUVEC cell with CTA5. Slices are from top to bottom starting from the top left $(z 04)$ to the bottom right image (z 19). ELR fluorescence in the top image covers most of the cell surface, whereas in the lower slices the ELR is more concentrated at the perimeter of the cell, thus indicating that the ELR is not incorporated into the cells. The scale bars represent $7.5 \mu \mathrm{m}$, slicing depth is $0.4 \mu \mathrm{m}$.

Figure 64: $C D$ spectra of modified ELRs at $37^{\circ} \mathrm{C}$. Upon the addition of the $B C N$ linker, a negative shoulder at $220 \mathrm{~nm}$ is slightly increased. This change is reversed by the addition of CTA I-5, accompanied by a reduction of the negative peak at $197 \mathrm{~nm} .188$ Figure 65: Life cell imaging of HASMC cells incubated with $375 \mathrm{nM}$ CTAO over a period of I8h, circle and arrow highlight movement and fusion of ELR agglomerates into bigger agglomerates. 190 Figure 66: Life cell imaging of HASMC cells incubated with $375 \mathrm{nM} \mathrm{CTAI} \mathrm{over} \mathrm{a} \mathrm{period}$ of $18 \mathrm{~h}$. 190

Figure 67: Life cell imaging of HASMC cells incubated with 375 nM CTA3 over a period of $18 h$. 191

Figure 68: Life cell imaging of HASMC cells incubated with 375 nM CTA5 over a period of $18 \mathrm{~h}$. 191

Figure 69: Life cell imaging of HUVEC cells incubated with 375 nM CTAO over a period of $18 \mathrm{~h}$. 192

Figure 70: Life cell imaging of HUVEC cells incubated with 375 nM CTAI over a period of $18 \mathrm{~h}$. 192

Figure 7I: Life cell imaging of HUVEC cells incubated with 375 nM CTA3 over a period of $18 \mathrm{~h}$. 193

Figure 72:Life cell imaging of HUVEC cells incubated with 375 nM CTA5 over a period of $18 \mathrm{~h}$.

Figure 73: Schematic interaction of cholesteryl ELR with the cell membrane. Upon incubation the cholesteryl-ELR adsorbs to the membrane. Over time the ELR either agglomerates on the cell membrane or are further distributed on the membrane. Top right: ELR-CTAO* incubated with HASMC, ELR-CTAO* sticks to the membrane and 
agglomerated due to ELR-ELR contacts. Bottom right: ELR-CTA5* incubation, cells maintain mobility and ELR-CTA5* is distributed in small dots throughout the membrane. The left images indicate t0 after incubation, the right images $t=6 \mathrm{~h}$. 


\section{LIST OF ARTICLES AND PATENTS ORIGINATED FROM THE WORK OF THIS PhD THESIS}

J.C. Rodriguez-Cabello, A. Ibáñez Fonseca, M. Alonso Rodrigo, L. Poocza, F. Cipriani, I. González De Torre, Encyclopedia of Polymer Science and Technology: Elastin-Like Polymers: Properties, Synthesis, and Applications, 2017, Wiley Publishing

J.C. Rodríguez-Cabello, I. González De Torre, F. Cipriani, L. Poocza, Elastinlike materials for tissue regeneration and repair in Peptides and Proteins as Biomaterials for Tissue Regeneration and Repair, Dec 2017, Woodhead Publishing.

L. Poocza, M. Alonso Rodrigo, J.C. Rodríguez-Cabello, Recombinant Biopolymer for Proteases Detection, Patent PCT/EP2019/068674 (Submitted: 04/18).

L. Poocza, F. Cipriani, M. Alonso Rodrigo, J.C. Rodriguez-Cabello, Hydrophobic cholesteryl moieties trigger substrate cell-membrane interaction of elastin-mimetic protein coatings in vitro, ACS OMEGA, 2019, $4,6,10818-27$.

S. Acosta, L. Poocza, L. Quintanilla Sierra J.C. Rodriguez-Cabello, Charge Distribution as a molecular modulator of the nanostructuration in intrinsically disordered proteins, small submitted November 2019. 
L. Poocza, S. Acosta, M. Alonso Rodrigo, J.C. Rodriguez-Cabello, Introduction of thermoreversible UCST gelation by hydrophobically hijacking LCST related secondary structure motifs in a model Elastin-like recombinamer, submitted November 2019.

L. Poocza, M. Alonso Rodrigo, J.C. Rodriguez-Cabello A fast, sensitive and cost-effective method for protease detection using non-fluorescent substrate, in preparation.

F. Cipriani, L. Poocza, I. González de Torre, M. Alonso Rodrigo, José Carlos Rodríguez-Cabello, Selective Enzymatic Responsive Smart-ELRs with Allosteric Control of RNase A Activity, in preparation.

\section{Other contributions}

Oral presentations

Kampleiter, L. Poocza, C. Richard, G. Hildebrand, K. Liefeith, J. C. Rodríguez-Cabello, C. González, A. Markus, C. Dullin, F. Alves, O. Hoffmann, Pre-clinical screening of novel biodegradable biomaterials for bone tissue engineering, 24th Scientific Congress of Austrian Pharmaceutical Society, Vienna, Austria, Sep. 2015. 
L. Poocza, F. Cipriani, J.C. Rodíguez-Cabello, Elastin-like Recombiners (ELRs): From bioinspired Motifs to Biomedical Application, Ringberg Conference, Schloß Ringberg, Germany, May 2016.

L. Poocza, P. de Almeida, F. Cipriani, I.G. de Torre, P. Kouwer, AE Rowan, JC Rodíguez-Cabello, Cross-linking of elastin-like recombinamers (ELRs) for biomedical application, 10th Young Researchers' Retreat University of Osaka (YRR), Kyoto, Japan, Jul. 2016.

L. Poocza, M. Alonso, J. C. Rodríguez-Cabello, Hydrophobic modification of ELRs for enhanced cell membrane interaction, Advanced Materials for Biomedical Application, Ghent, Belgium, Sep. 2017.

L. Poocza, M. Alonso, J.C. Rodríguez-Cabello, Hydrophobic cholesteryl moieties trigger substrate cell-membrane interaction of elastin-mimetic protein coatings in vitro, European Elastin Meeting, Nijmegen, Netherlands, Jun. 2018.

L. Poocza, F. Cipriani, M. Alonso, J.C. Rodríguez-Cabello, Hydrophobic cholesteryl moieties trigger substrate cell-membrane interaction of elastinmimetic protein coatings in vitro, AND,

L. Poocza, F. Cipriani, M. Alonso, J.C. Rodríguez-Cabello, Specific Detection of Proteases using novel-protein substrates for Zymographic Methods, 5th TERMIS World Congress, Kyoto, Japan Sep. 2018.

\section{Poster presentations}

L. Poocza, P. de Almeida, F. Cipriani, P. Kouwer, A.E. Rowan, J.C. RodíguezCabello, Strain-Stiffening Behaviour in PIC-ELR Hybrid Systems: Their Potential as Stimuli Responsive Scaffolds, Ringberg Conference, Schloß Ringberg, Germany, May 2016. 
L.Poocza, P. de Almeida, F. Cipriani, I.G. de Torre, PHJ Kouwer, AE Rowan, JC Rodíguez-Cabello, Cross-linking of elastin-like recombinamers (ELRs) for biomedical application, 10th Young Researchers' Retreat University of Osaka (YRR), Osaka/Kyoto, Japan, Jul. 2016.

L. Poocza, P. de Almeida, P. Kouwer, J.C. Rodíguez-Cabello Stress-Stiffening in PIC-ELR Hybrid Systems Trigger Myofibroblast Differentiation in vitro, Coatings and Sensors Business Case Workshop at Noviosense, Nijmegen, Netherlands, Apr. 2017.

L Poocza, P de Almeida, F Cipriani, P Kouwer, JC Rodríguez-Cabello, Functional Hybrids of elastin-like recombinamers and polyisocyanates, 6th China-Europe Symposium on Biomaterials in Regenerative Medicine (CESB), Porto, Portugal, May 2017.

L. Poocza, P. de Almeida, P. Kouwer, A.E. Rowan, J.C. Rodriguez-Cabello, Introduction of strain-stiffening features into elastin-like recombinamers by isocyanate hybridization, European Chapter Meeting of the Tissue Engineering and Regenerative Medicine International Society (TERMIS), Davos, Switerland, Jun. 2017.

L. Poocza, P. de Almeida, F. Cipriani, P. H. J. Kouwer, J. C. RodriguezCabello, Elastin-like Recombinamers and Polyisocyanates: A Functional Hybrid System for Tissue Engineering, 28th Annual Conference of the European Society for Biomaterials (ESB), Athens, Greece, Sep. 2017.

L. Poocza, M. Alonso, JC Rodríguez-Cabello, Hydrophobic cholesteryl moieties trigger substrate cell-membrane interactions of elastin-mimetic protein coatings in vitro, Material for Life 2nd Karman Conference, Bergisch Gladbach, Germany, Apr. 2018. 


\section{Courses and certifications}

- Time and Project Management. Bpmsat (Spain).

- Statistical Validation and Experimental Design. Biostatech (Spain).

- Leadership and coaching techniques. University of Valladolid (Spain).

- Research ethics and integrity. Organized by BIOGEL project.

- Mechanical properties of the biomaterials. Radboud University. Nijmegen (the Netherlands).

- Biomimetic hydrogels. Organized by BIOGEL project.

- Skills you really need when you apply for a job. Organized by BIOGEL project.

- The Route to Academia: How to fail successfully. Organized by BIOGEL project.

- Hydrogel Imaging. Austrian Institute of Technology (AIT). (Wien) Austria.

- In vitro, ex vivo, and in vivo models. LifeTec Group. (Eindhoven) the Netherlands.

- Synthesis of Biomaterials. University of Thessaloniki. Thessaloniki (Greece).

- Critical thinking for public discourse. University of Amsterdam (The Netherlands). 
7Marie Curie Fellowship for Early Stage Research Training

Attendance of the listed progress meetings with scientific communication:

- Network Meeting at TPNBT, 14th December, 2015. Valladolid (Spain).

- Network Meeting at Radboud University, 22th June, 2016. Nijmegen (the Netherlands).

- Network Meeting at University of Valladolid, 12th December, 2016. Valladolid (Spain).

- Network Meeting organized by the Centre for Research \& Technology Hellas (CERTH), I4th June, 2017. Poros (Greece).

- Network Meeting at Austrian Institute of Technology (AIT), 30th January, 2018. (Wien) Austria.

- Network Meeting at DWI-Leibniz Institute for Interactive Materials, 25th July, 2018. (Aachen) Germany.

- Network Meeting at DWI-Leibniz Institute for Interactive Materials, 14th December, 2018. Aachen (Germany).

Teaching

Supervision of the scientific training and mentorship of the bachelors thesis with the title "DESAROLLO DE UN MÉTODO ANALIITICO A PARTIR DE BIOPOLIMEROS" of the student Cristina Merino Garotte at the University of Valladolid (Spain). 